\title{
Limits of Liberal Multiculturalism
}

Philosophical Studies from the University of Helsinki 38 
Filosofisia tutkimuksia Helsingin yliopistosta

Filosofiska Studier från Helsingfors universitet

Philosophical Studies from the University of Helsinki

Publishers:

Theoretical Philosophy

Philosophy (in Swedish)

Social and Moral Philosophy

P.O. Box 24 (Unioninkatu 40A)

00014 University of Helsinki

Finland

Editors:

Panu Raatikainen

Tuija Takala

Bernt Österman 


\section{Limits of Liberal Multiculturalism}

Academic dissertation to be publicly discussed, with the permission of the Faculty of Social Sciences of the University of Helsinki, for public examination in Auditorium XII of the Main Building (Fabianinkatu 33) on 3rd June 2013, at 10 am. 
ISBN 978-952-10-8780-6 (paperback)

ISBN 978-952-10-8781-3 (PDF)

ISSN 1458-8331 (series)

Juvenes Print

Tampere 2013 


\begin{abstract}
Limits of Liberal Multiculturalism is a work in normative political philosophy. In particular, it is a work on liberal approaches to cultural diversity. The work assesses some of the benefits and limitations of liberal multiculturalism (broadly conceived) and develops a more individuated, yet culturally sensitive, approach to cultural diversity.

The two main parts of the work discuss the normative justifications and rationales for differentiated rights within liberalism (Part I) and the more practical problems of applying these rights in practice (Part II).

The first three chapters (Part I) analyse the so-called autonomy-, toleration- and equality-based approaches to cultural diversity as presented by Will Kymlicka, Chandran Kukathas and Brian Barry. This part argues that the autonomy-, toleration- and equality-based approaches provide frameworks within which the liberal responses to cultural diversity should reside, but fail to give any definitive guidance into how the liberal state should react to cultural diversity in particular circumstances. These approaches leave a substantive scope of variation to the cultural policies of the liberal state, including the possibility, albeit not a requirement, to grant differentiated rights.

The three latter chapters (Part II) develop a more individuated, yet culturally sensitive, approach to cultural diversity by concentrating on the further issues of allocating differentiated rights. The first chapter (Ch. 4) highlights the difficulties of defining one's membership in a cultural group and argues that, in order to track their targets, the individually exercised differentiated rights should be allocated in accordance with need or selfidentification. Chapter 5 develops the individual-centred approach further by concentrating on the issues of the right of exit, and the liberal state's responses to those who have decided to leave the contours of their group without rejecting their identity as a member. The final chapter (Ch. 6) focuses on the legal-theoretical debate on allowing cultural defence in criminal courts and gives an
\end{abstract}


application of the individuated approach in the criminal justice system.

The main claims of the work are that the liberal multiculturalists have been successful in clarifying the grounds upon which the liberal responses to cultural diversity should reside and in showing that the culturally differentiated rights (variously construed) are not necessarily incompatible with liberalism. The liberal multicultural theories do not, however, give any definitive guidance on how the liberal state should respond to cultural diversity, nor do they always take sufficiently into account the variations within (and without) cultural groups. The work rejects the common assumption of differentiated rights as specifically group-differentiated rights, and argues for a more individuated approach that, nevertheless, takes people's cultural commitments and their group identities seriously. 


\section{Short Contents}

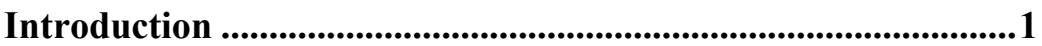

Background: Liberalism, multiculturalism, and liberal multiculturalism.............................................................................

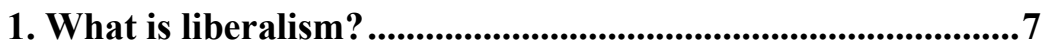

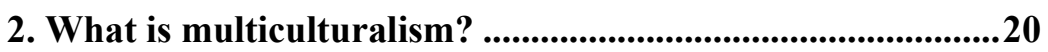

3. Liberal multiculturalism and its limits .................................47

PART I Justifying Minority Rights: the grand theories and their constraints ..............................................................................63

Ch 1 Kymlicka's liberal multiculturalism ...............................67

1. Equality for minority members.................................................69

2. Minority rights and the limitations of Kymlicka's

framework .............................................................................................8 87

3. Conclusion on Kymlicka's liberal multiculturalism.............112

Ch 2 Autonomy vs. toleration.................................................115

1. Limits of autonomy liberalism.............................................118

2. Diversity liberalism and the critique of autonomy .............133

3. Minority rights, diversity and the state ................................148

4. Conclusion on autonomy vs. toleration...................................169

Ch 3 Liberal egalitarianism and equality of opportunity ......171

1. Multiculturalism and equality of opportunity ......................174

2. Opportunities, opportunity sets, and equality of opportunity to $X$................................................................................185

3. The proper object of opportunity............................................204

4. Conclusion on liberal egalitarianism and equality of opportunity .....................................................................................222

PART II Liberal multiculturalism and minority rights in practice .......................................................................................227 
Ch 4 Liberal multiculturalism, group membership, and allocation of differentiated rights .........................................231

1. Analysing group membership..............................................234

2. Group membership and allocation........................................247

3. Conclusion on liberal multiculturalism, group membership, and allocation of differentiated rights ...............266

Ch 5 Exit, identity, and membership .........................................267

1. Cultural groups and the right of exit -approach..................269

2. Exit and membership ...............................................................287

3. Conclusion on exit, identity, and membership.......................305

Ch 6 Liberal Individualism and cultural defence....................307

1. What is cultural defence?.......................................................309

2. Normative issues ............................................................................320

3. Cultural defence and culturally motivated actions...............332

4. Conclusion on liberal individualism and cultural defence. 357

Conclusion: Liberal multiculturalism and its limits.................361

1. The grand theories and their constraints: theoretical

frameworks vs. policy guidance....................................................363

2. Minority rights in practice: group-differentiated rights

vs. individuated allocation...............................................................365

3. Towards more individuated approach to cultural

diversity ............................................................................................369

Bibliography..........................................................................................373 


\section{Long Contents}

Acknowledgements .................................................................

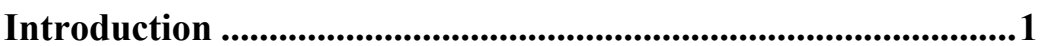

Background: Liberalism, multiculturalism, and liberal

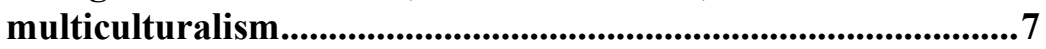

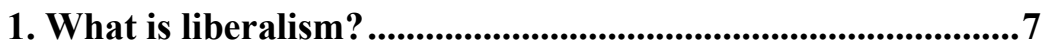

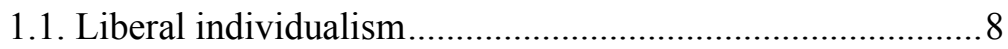

1.2. Individual liberty, autonomy and equality ..........................10

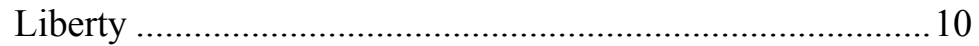

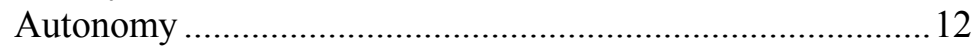

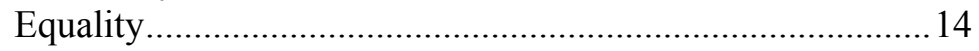

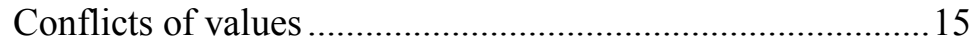

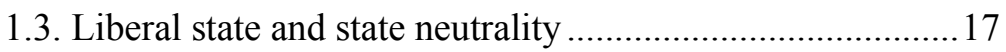

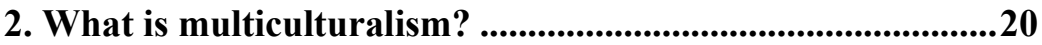

2.1. Three conceptions of multiculturalism ...............................20

Descriptive multiculturalism .................................................20

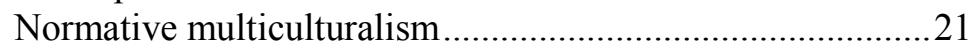

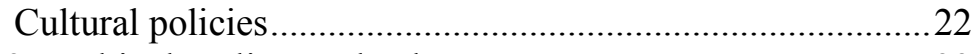

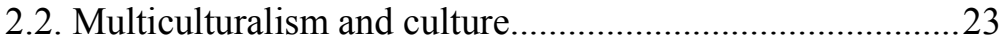

From homogeneous cultural contents to fluid cultural

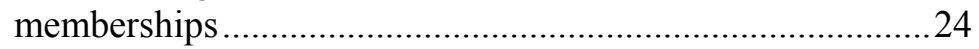

Instrumental/non-instrumental, individualist/non-

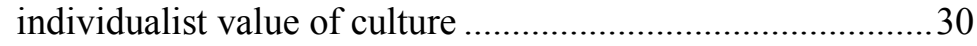

2.3. Multiculturalism and cultural policies .................................35

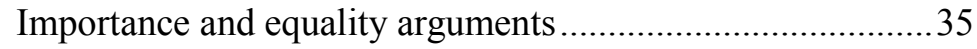

Cultural policies and the exposition of minority rights .........38

3. Liberal multiculturalism and its limits ..................................47

3.1. Liberalism, liberal multiculturalism, and cultural policies .48

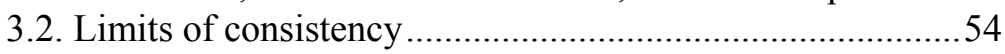

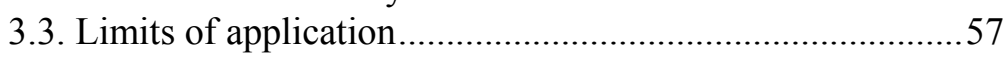


PART I Justifying Minority Rights: the grand theories and

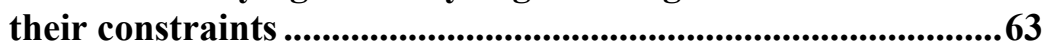

Ch 1 Kymlicka's liberal multiculturalism ..................................67

1. Equality for minority members......................................69

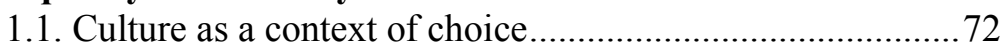

The prerequisite for choice -argument ...................................72

The importance -argument ....................................................... 74

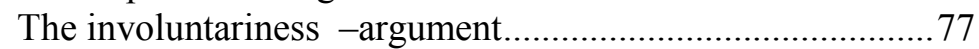

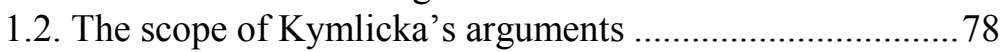

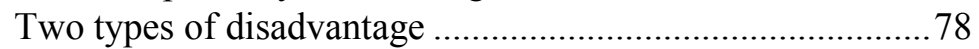

Reasons for the liberal state to be concerned about these

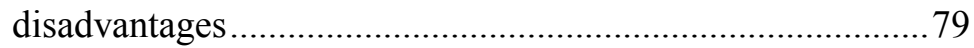

The importance -argument and specific cultural practices....83

2. Minority rights and the limitations of Kymlicka's

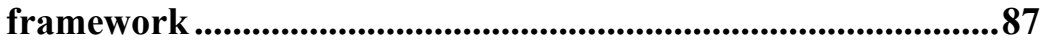

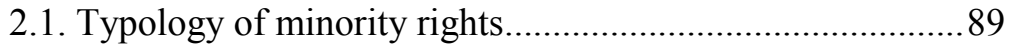

2.2. The rationale for concern vs. the rationale for minority

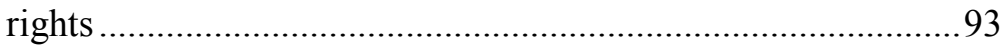

Minority rights as promoting certain conceptions and contents of culture..................................................................94

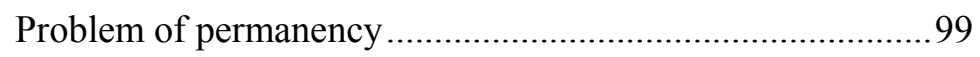

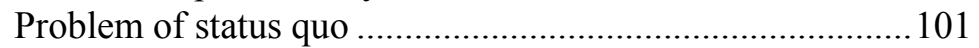

2.3. Minority rights and cultural membership ..........................104

Terminological issues: contents, structures and

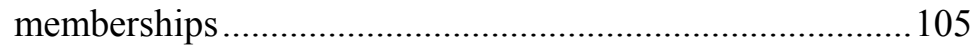

Two senses of protecting membership.................................. 108

3. Conclusion on Kymlicka's liberal multiculturalism.............112

Ch 2 Autonomy vs. toleration ......................................................115

1. Limits of autonomy liberalism...................................................118

1.1. External protections and internal restrictions ....................119

Dealing with the distinction.............................................120

Protecting vs. promoting individual autonomy.....................123

1.2. Liberal rights and liberal imposition..................................128

The self-governing status of illiberal groups .......................130

Practical reasons for non-interference ................................. 132

2. Diversity liberalism and the critique of autonomy ...............133 
2.1. Chandran Kukathas's account of a free society................135

2.2. Freedom of association, exit and autonomy ......................138

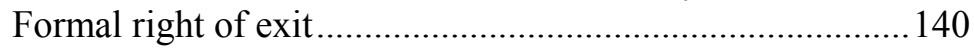

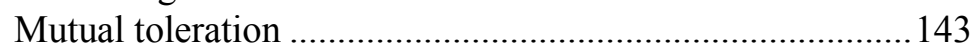

3. Minority rights, diversity and the state ............................148

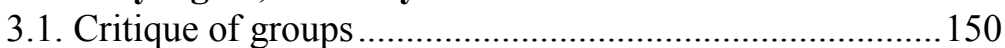

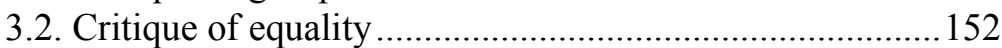

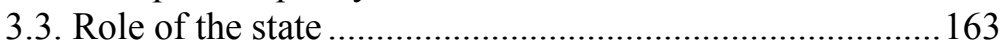

4. Conclusion on autonomy vs. toleration...............................169

Ch 3 Liberal egalitarianism and equality of opportunity ......171

1. Multiculturalism and equality of opportunity ......................174

1.1. The Rawlsian framework of fair equality of opportunity. 176

1.2. Fair equality of opportunity in multiculturalism............... 178

Proportional underrepresentation.......................................180

Differentiated impact of a rule.............................................180

2. Opportunities, opportunity sets, and equality of

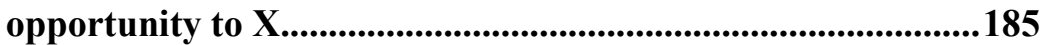

2.1. Brian Barry on equal opportunities....................................186

Objective and subjective conceptions of opportunity..........189

Subjective opportunities and opportunity sets .....................190

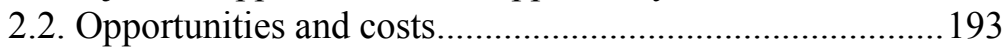

The excessive costs -argument and strategies for its

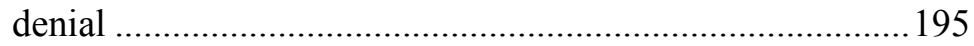

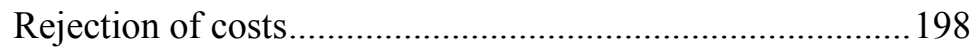

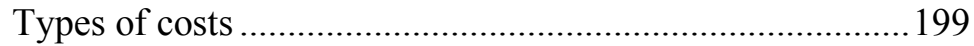

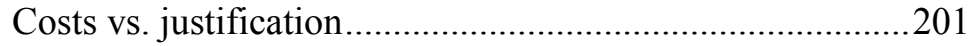

3. The proper object of opportunity ...........................................204

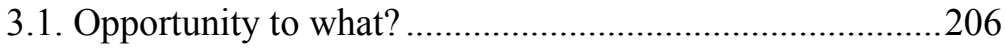

General categories vs. particular cases .................................208

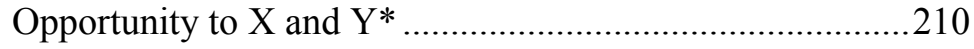

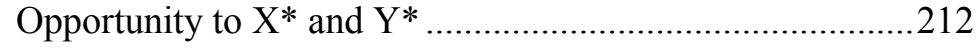

3.2. Joint opportunities and cultural exemptions .....................2.216

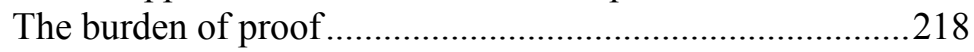

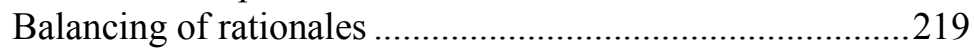

4. Conclusion on liberal egalitarianism and equality of

opportunity .............................................................................................222 
PART II Liberal multiculturalism and minority rights in practice

Ch 4 Liberal multiculturalism, group membership, and allocation of differentiated rights .........................................231

1. Analysing group membership.........................................234

1.1. Raz and Margalit on group membership ........................234

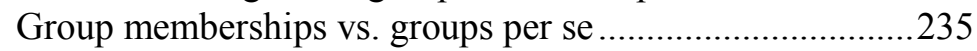

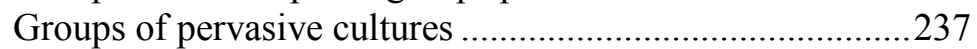

1.2. Membership-based accounts of cultural accommodation. 238

Advantages of membership-based accounts .......................239

Cultural policies and cultural contents ................................240

1.3. Recognition based accounts of group membership ..........242

Value laden and instrumental conceptions of recognition...243

Internal and external recognition ..........................................245

2. Group membership and allocation..........................................247

2.1. Politically relevant groups and group memberships .........247

Appiah on the structure of social identities .........................248

Discrepancy in group membership .....................................250

2.2. Groups deciding their own members? ...............................253

Weaker and stronger formulations of mutual recognition ...255

2.3. Cultural policies and membership-based allocation .........258

Reasons for recognizing one a member ...............................259

Reasons and contents of cultural policies ............................260

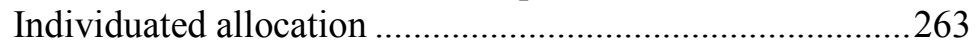

3. Conclusion on liberal multiculturalism, group

membership, and allocation of differentiated rights ...............266

Ch 5 Exit, identity, and membership .........................................267

1. Cultural groups and the right of exit -approach..................269

1.1. Conceptualizing cultural groups ......................................2270

Broad undemocratic groups ................................................271

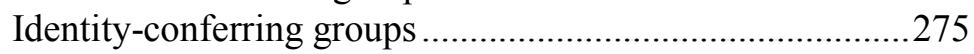

1.2. Identity-conferring groups and group membership ..........277

Self-identification and group-membership .........................278

Recognition-based account of membership .........................280

The rationale for state recognition........................................283

2. Exit and membership ...............................................................287

viii 


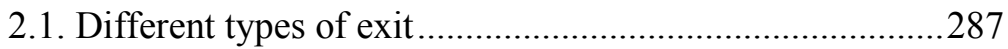

Membership and belonging ...............................................28

Exit as leaving group influence vs. exit as renouncing

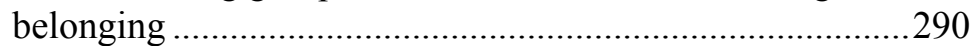

2.2. Reducing the costs of exit by state recognition ................292

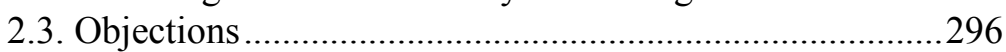

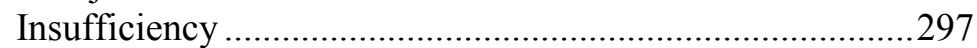

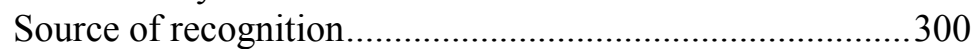

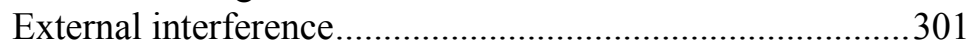

3. Conclusion on exit, identity, and membership .....................305

Ch 6 Liberal Individualism and cultural defence....................307

1. What is cultural defence?.....................................................309

1.1. Example case: Jacob Zuma's rape trial 2005-2006 ..........311

1.2. Cultural evidence in conjunction with other types of

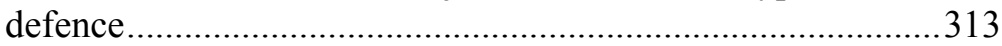

Mistake of fact -defences.......................................................

Insanity and diminished capacity.........................................316

1.3. Cultural defence as a formal defence..................................317

2. Normative issues .......................................................................320

2.1. Arguments for and against cultural defence .....................321

Cultural diversity and respect for different cultures ............321

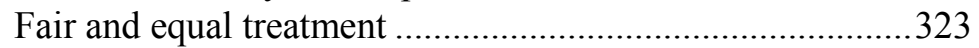

Victim's perspective and legitimation of oppressive

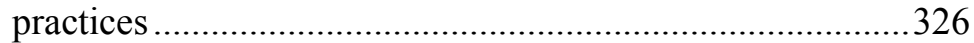

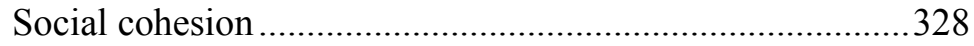

2.2. Cultural defence and cultural offences .............................329

3. Cultural defence and culturally motivated actions..............332

3.1. How can an action be motivated by culture?.....................333

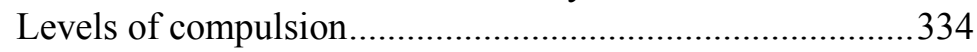

Substantive and instrumental motivations ............................337

Adherence, conformity, preservation, protection and

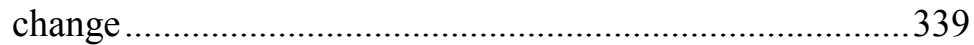

3.2. Establishing motivations in criminal courts.......................343

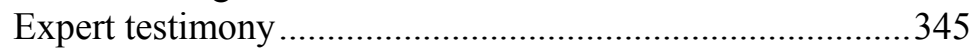

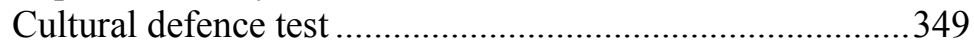

4. Conclusion on liberal individualism and cultural defence. 357 
Conclusion: Liberal multiculturalism and its limits. .361

1. The grand theories and their constraints: theoretical frameworks vs. policy guidance.

2. Minority rights in practice: group-differentiated rights

vs. individuated allocation.

3. Towards more individuated approach to cultural diversity .369

Bibliography .373 


\section{Acknowledgements}

This work could not have been completed without the support and input of several friends, colleagues and institutions.

Thank you to my supervisor, Heta Gylling (University of Helsinki) for her continuous support: for providing this work an institutional home and for believing in me even at times when I found the task of completing this thesis daunting and next to impossible.

My most sincere thanks also to Dagmar Borchers (Bremen University) and Tom Campbell (CAPPE, ANU) for welcoming me to their institutions and for giving me invaluable feedback and guidance during my stays in Bremen and Canberra.

Thank you also to the two pre-examiners of this thesis, Juha Räikkä and Leila Toiviainen, for the tremendous work of reading and providing such thorough and useful comments on this work.

Thanks to Toby Archer who kindly agreed to read through this work and helped to improve the English of this thesis.

I have learned tremendously from several colleagues, friends and associates in Helsinki, Bremen and ANU, as well as from people I have met on several shorter research visits and conferences around the world. It would be impossible to thank everyone individually, so I wish to thank you collectively for being part of the inspiration, hard work and processing that has made this work possible.

My special thanks to those friends and colleagues who I have had the pleasure to work with on different stages of this process, who have had the patience to read and comment unfinished manuscripts, and who have guided and supported me during this journey: Peter Balint, Kerstin Budde, John Dryzek, Marilyn Friedman, Robert Goodin, Sirkku Hellsten, Zara Järvinen, Kristian Klockars, Eszter Kollar, Iivi Anna Masso, Larry May, Pilvi Toppinen, Teemu Toppinen, Raimo Tuomela, Vilma Venesmaa.

The seeds of this work were, of course, laid much earlier, and I also like to thank my teachers and mentors at Cardiff University where I, as an undergraduate, first realized how much fun philosophy could be: Robin Attfield, Andrew Belsey, Andrew Edgar, Alex Miller, Chris Norris, Peter Sedgwick, Alessandra 
Tanessini, Barry Wilkins, and the wonderful group of philosophy students I was hanging around with - thank you!

To my mother and father, Liisa and Martti Vitikainen, for giving me the best possible grounds to pursue whatever I decided to pursue in life.

To Johanna Karhumäki, for both professional and personal support: for being there, always.

To Katja Häkli, for the present.

Two of the chapters in this work are based on articles that were previously published elsewhere. Chapter 4 is a revised version of "Liberal Multiculturalism, Group Membership, and Distribution of Cultural Policies", Ethnicities 9(1), pp. 53-74. Chapter 5 is based on "Exit, Identity, and Membership", in: Borchers and Vitikainen (eds.): On Exit: Interdisciplinary perspectives on the right of exit in liberal multicultural societies. Berlin and Boston: De Gruyter, pp. 78-101. I thank the publishers for their permission to reuse.

This work was conducted at the Department of Political and Economic Studies/ Social and Moral Philosophy, University of Helsinki, with longer research periods also at the Centre for Applied Philosophy and Public Ethics, Australian National University and Institute of Philosophy, Bremen University. I gratefully acknowledge the financial support of the following institutions: Academy of Finland, Bremen University, EU Australia Network of Degrees in Ethics, Human Rights and Institutions, Finnish Cultural Foundation, University of Helsinki.

Annamari Vitikainen

Helsinki, April 2013 


\section{Introduction}

Cultural diversity - the existence of several cultural and religious groups within one society - is an inalienable element of western liberal democracies. The fact of cultural diversity, however, is not entirely unproblematic, as different groups, and their members, may also hold different norms, values and world views that are sometimes incompatible with the general norms of society. The incompatibility of different norms, as well as particular cultural or religious practices, raises questions about how the state should respond to cultural diversity, and how - and if - these differences should be accommodated.

From the perspective of liberal political theory and philosophy, the questions of cultural accommodation are various. Why should the liberal state be concerned about people's cultural differences, or culturally induced disadvantages? How should the liberal state respond to these differences? Upon what grounds should the state base its cultural policies? Can these policies, including a variety of minority or culturally differentiated rights, even be justified within the liberal framework? And if they can, to whom should they be granted?

In this work, I address some, although by no means all of these normative questions relating to cultural diversity. The title of this work, Limits of Liberal Multiculturalism, refers to my aim to expose some of the theoretical as well as practical limitations of some of the major liberal approaches to cultural diversity, ${ }^{1}$ although this work should not be read as simply a critique of liberal multiculturalism. On the contrary, one of the main claims of this work is that the debates on multiculturalism, and especially on liberal multiculturalism, have been extremely important in clarifying the grounds upon which the liberal responses to cultural diversity must reside, and in explicating the reasons for the liberal state to be concerned about cultural disadvantages. They have also been extremely important in showing that culturally differentiated

\footnotetext{
1 These approaches include the autonomy-based, diversity-based and equality-based approaches to cultural diversity, to be discussed in Part I (Ch. 1,2 and 3).
} 
rights (variously construed) are not, as has often been thought, incompatible with liberalism, but that there is scope for the liberal state to aim at rectifying cultural disadvantages by culturally differentiated rights.

Having said that, I also argue that the theoretical debates on liberal multiculturalism have not been able to give any conclusive guidance to how the liberal state should respond to cultural diversity, but that the complexity of issues relevant for any particular cases render the liberal multicultural theories somewhat silent with respect to the appropriate means of responding to cultural diversity. This, of course, is not a very novel idea, as the gap between political theories and political practice is well known as well as widely discussed. The approach developed in this work, however, provides some new means for narrowing this gap. It points out some of the issues often ignored within liberal multicultural theory that are, nevertheless, essential for the concrete application of these theories in practice.

First and foremost, this work is a defence of a more individuated approach to cultural diversity and, especially, a more individuated approach to the allocation of culturally differentiated rights. As an individuated approach it is, however, still an approach that takes people's cultural belonging and their group identity seriously, although it denies the common view of differentiated rights as specifically group-differentiated rights. During the course of this work, I look at issues of cultural membership, cultural identity and cultural motivation, ${ }^{2}$ and argue that a more individuated approach, consistent both with the basic tenets of liberalism as well as multiculturalism, is needed in order for the liberal multicultural theory to be applicable in practice, as well as in order for the multicultural policies to perform the tasks they are set to perform.

This study is divided into two main sections (Part I and Part II), and a background section on liberalism, multiculturalism, and liberal multiculturalism. The main substance of this work lies in

${ }^{2}$ The issues relating to cultural membership, identity and motivation are discussed in chapters 4, 5 and 6 respectively. 
Parts I and II, although it is clear that the arguments developed in these parts are situated as well as based on the theoretical frameworks outlined previously.

In the Background, I outline the framework within which this work operates, including an exposition of those basic values and principles that, I believe, any liberal theory of multiculturalism must be committed to. The two first sections of this background, What is liberalism? and What is multiculturalism?, also bring forth several conceptual clarifications, both with respect to the key values of liberalism as well as to the key concepts of multiculturalism. The main arguments, as well as the motivation of this work, are outlined in the final section, Liberal multiculturalism and its limits, in which I also situate my work within the theoretical debates on multiculturalism.

The first main part of this book, Part I: Justifying minority rights: the grand theories and their constraints, concentrates mainly on the questions of consistency and on the difficulties that the general frameworking of debates within liberal political theory has brought for the so-called grand theories of multiculturalism to be applicable in practice. The first chapter, Kymlicka's liberal multiculturalism, concentrates on the equality based arguments for multiculturalism, as put forth especially by Will Kymlicka, and looks at the scope within which these arguments can be used to give rationale for the liberal state being concerned about and to try to rectify, people's cultural disadvantages. Whereas this chapter builds a strong case for the liberal state to take cultural disadvantages seriously, it also cautions against too straight forward an application of minority rights as the appropriate means for rectifying these disadvantages. Chapter two, Autonomy vs. toleration, looks at the now famous debate between autonomy- and diversity liberalism and assesses the extent to which the liberal commitment to the value of individual autonomy must operate as one of the side constraints for the justifiability of allowing cultural groups to conduct their internal affairs. This chapter argues that even those rejecting the role of the liberal state in protecting or promoting individual autonomy must be committed to some minimal 
protection of the conditions for individual autonomy, although they do not need to commit themselves to the role of the liberal state in promoting individual autonomy. Chapter three, Liberal egalitarianism and equality of opportunity, turns to a more specific discussion on equality of opportunity and the so-called liberal egalitarian critique of the rule and exemption approach. By looking at different conceptualisations of equality of opportunity as well as different normative issues incorporated in cultural exemptions, this chapter argues for a default position for the liberal state to try to rectify those disadvantages that result from the incompatibility of particular cultural practices and general rules and norms of society. This default position, however, constitutes nothing as strong as a requirement for the liberal state to grant cultural exemptions in specific cases, although it does explicate the rationale through which these exemptions may be justified.

The second part, Part II: Liberal multiculturalism and minority rights in practice, builds up a more individuated, yet culturally sensitive approach to allocating differentiated rights and assesses some of the implications of this approach to the cultural policies of the liberal state. Chapter four, Liberal multiculturalism, group membership, and allocation of differentiated rights, looks at the theoretical difficulties and discrepancies of defining group membership and argues for a more individuated, yet culturally sensitive, approach for allocating differentiated rights in practice. This chapter argues that, in order to track their targets, individually exercised differentiated rights should not be allocated on the basis of group membership, but rather on the basis of individual needs and self-identifications. Chapter five, Exit, identity, and membership, assesses some of the implications of this individuated approach to the debates on the right of exit, including one's understanding of exit and the role of the liberal state in guaranteeing right of exit to everyone. By focusing on the identity forming functions of belonging, this chapter suggests that the liberal state should continue recognizing people as members of cultural or religious groups even after they have exited the contours of their group without renouncing their identity as a member of that 
group. Chapter six, Liberal individualism and cultural defence, transfers the more theoretical discussions of the previous chapters into the context of criminal courts, considering the usage of cultural defence in those courts. By looking at the ways in which actions (in these cases, crimes) can be motivated by culture, this chapter points towards a more sophisticated, individual centred approach for assessing people's cultural motivations, in order for the criminal courts to treat all members of minority cultural groups fairly and equally. Together these chapters question the common assumptions of differentiated rights as specifically group-differentiated rights and argue for a liberal, individuated approach to cultural diversity that, nevertheless, takes people's cultural commitments and their group identities seriously. 


\section{Background}

\section{Liberalism, multiculturalism, and liberal multiculturalism}

Liberal multicultural theories (broadly conceived) stand in a very specific relation to both liberalism as well as multicultural policies. From the 1990's onwards, many of the debates on multiculturalism have been conducted within the framework of liberalism and the questions of cultural accommodation have been approached from the perspective of the liberal state. The key questions of liberal multiculturalists have involved questions about the justifiability of minority rights within liberalism, although many have also argued for specific kinds of policies for the liberal state to respond to people's cultural differences.

In this background section, I shed some light on the framework within which this work is situated, by looking at some of the commonalities, as well as differences, between different theories of liberal multiculturalism. I begin (section 1) by looking at those basic values and principles that, I believe, any liberal theory of multiculturalism must be based on, before turning into the key questions and controversies of multiculturalism and cultural accommodation (section 2). In the final section (Liberal multiculturalism and its limits), I return to the basic framework of debates between liberalism, liberal multiculturalism and multicultural policies and, by way of doing so, also outline the basic motivation and arguments of this work.

\section{What is liberalism?}

Liberalism, as a school of thought, constitutes no unified viewpoint or theory, but rather a cluster of different types of theories as well as competing viewpoints placed under the rubric of the liberal tradition. $^{3}$ As my focus, in this work, is on liberal political theory

${ }^{3}$ The liberal tradition, of course, may not be any easier to define than liberalism itself, although the historical roots of liberalism can be traced 
and, more specifically, on liberal multiculturalism, I wish to focus on those commitments that, I believe, any contemporary liberal theory of multiculturalism should be committed to. Any political theory, after all, needs to be committed to something in order to be called a liberal theory. In this section, I thus aim to identify those basic values and principles central to any contemporary liberal theory of multiculturalism, although I also show some legitimate variation in how these values and principles can be understood.

\subsection{Liberal individualism}

Although the notion of liberal individualism and, especially, the notion of the individuated self has attracted vast amounts of criticism, ${ }^{4}$ there is no denying that, at the very heart of liberal political theory lies some commitment to the individual and the moral primacy of the individual. According to liberalism, what matters, in the end, is the individual: how her life goes, her wellbeing. There may, of course, be substantive disagreements on how to judge, or whether it is even possible to judge, individual wellbeing or what this well-being entails, but these disagreements do not take away the central idea, incorporated within any liberal political theory, that it is the individual that ultimately counts. For liberal political theory, it is the individual that is of utmost importance, and this should also be reflected in the political organisation of society.

It should be emphasized, however, that the ethical individualism of liberal political theory is, precisely, ethical individualism, and does not need to entail any particular metaphysical or ontological commitments about the nature of society or about the nature of the self. Liberal political theory does not need to (although it surely

back to thinkers such as Locke, Kant and Mill. For historical overview, see e.g. Gray 1986.

4 See esp. communitarian critiques of liberal individualism in: MacIntyre 1981; Sandel 1982; Taylor 1989, Walzer 1983; for debate and overview, Gutmann 1986; Buchanan 1989; Mulhall and Swift 1992, Kymlicka 2002, ch. 6 . 
can) be committed to an atomistic view of society. ${ }^{5}$ It does not need to view society simply as an aggregation of its parts (individual members), but is compatible with the view according to which societies, and smaller groups within societies, are viewed as incorporating something more than their individual members (for example, shared values, social bonds, common interests, that cannot be accounted for with reference to individuals alone). Consequently, liberal political theory is compatible with the view according to which the interests of society, and of the smaller groups within society, may not be reducible to the interests of their individual members, but can, at times, even conflict with the interests of their individual members. All that the ethical individualism of liberal political theory is necessarily committed to is that in assessing the organisation of society, or the needs, interests or value of society (or smaller groups within society), the moral primacy of the individual should prevail. The interests of cultural or religious groups, for example, should be assessed in the light of how these interests affect individuals, and the value of religious or cultural groups (liberalism can, indeed, attach value to these groups) must be derived from the value that these groups have for individuals. Whereas liberal political theory does, in the ethical or normative sense, put the individual first, it does not need to be committed to the view according to which other things - groups, cultures, religions - could not also matter. Quite clearly, they do but only because they matter to the individuals and to their wellbeing.

The ethical individualism of liberal political theory does not, also, need to entail the view of an individual as an unencumbered

\footnotetext{
${ }^{5}$ The atomistic views of society are often connected to classical thinkers such as Hobbes, Locke, and Mill, although certain types of social atomism can also be found in the work of more recent liberal and/or libertarian thinkers, such as Hayek, Rand and Nozick. For Taylor's classical attack on liberal atomism, see: Taylor 1985, ch. 7; for debate, see e.g. Kymlicka 1989, ch. 5; 2002, ch. 6; Smith 2002, ch. 6; Den Uyl and Rasmussen 2006.
} 
and unembedded self. ${ }^{6}$ Liberal political theory needs not, and - as I argue during the course of this work - should not ignore the social embeddedness of individuals and the often tremendous influence that an individual's belonging to a particular group may have for their identity and well-being. It needs not ignore the social ties of individuals, nor does it need to insist that the very core of the individual - the true individual self - could somehow be abstracted from its social ties or surroundings. What it does, however, need to be committed to is that the value of these ties and social surroundings needs to be assessed from the standpoint of an individual: from how they make individual lives go. As will become clear during the course of this work, there may be several interpretations to the idea of the individual standpoint, but these differences do not take away the basic liberal commitment to the moral primacy of the individual. For liberal political theory, including liberal multiculturalism, it is, first and foremost, the individual that matters, and the social, political and/or economic organisation of society should also take this into account.

\subsection{Individual liberty, autonomy and equality}

\section{Liberty}

Liberalism, unsurprisingly, is an ideology that attaches value to liberty, and to individual liberty more specifically. According to liberalism, people should, as a default, be allowed to live their lives in whatever manner they wish to, and any interventions into this liberty need justification. What liberals do not necessarily agree upon, however, is what this liberty means, when it can be infringed upon, or how, in any interpretation of the term, it is to be secured. ${ }^{7}$

\footnotetext{
${ }^{6}$ The terms being coined by Michael Sandel (1982). For liberal responses, see e.g. Rawls 1986; 1996; Kymlicka 1989, ch. 4.

${ }^{7}$ The classical distinction, given by Isaiah Berlin (1969), between negative liberty (incorporating freedom from interference) and positive liberty (incorporating also the ability to act) is, in recent political philosophy, often supplemented with a third, republican, conception of freedom (incorporating freedom from domination, or susceptibility to interference) Pettit 1997; 2001; Skinner 2002. Whereas the distinctions between these
} 
The contemporary liberal political theorists do, nevertheless, tend to agree that people may have very different views on what they find valuable and what they consider to be good life and that, to a large extent, ${ }^{8}$ people should be free to pursue their different conceptions of the good. In order to guarantee this freedom to everyone (liberalism is, in this sense, universalist), the liberal political theorists often come to promote some set of basic rights (such as freedom of conscience, freedom of religion, freedom of expression etc. $)^{9}$ as well as a specific role for the state in guaranteeing these basic rights to everyone. ${ }^{10}$ Although liberal political theorists may disagree on the conception of liberty, on the institutional mechanisms needed for securing this liberty, as well as on the justifiable interferences in individual liberty, what they do agree upon is that, as a default, people should be free to live their lives in accordance with their own conceptions of the good, and that any (state) interference on this liberty needs justification.

three conceptions of liberty do play a part in discussions on liberal multiculturalism (most notably, in debates on the right of exit - discussed in Ch. 2 and 5), most of the controversies within liberal multiculturalism do not need to hang on these differences. Whereas the three main theorists discussed in this work, Kymlicka, Kukathas and Barry (Ch. 1, 2 and 3) would, most likely, subscribe to slightly different conceptions of individual liberty, their main differences do not (at least directly) stem from their different conceptions of freedom, but rather from their emphases and treatment of other liberal values, such as autonomy and equality.

${ }^{8}$ One of the classical formulations of the limits to individual freedom can be found in Mill's famous harm principle. According to Mill, "The sole end for which mankind are warranted, individually or collectively, in interfering with the liberty of action of any of their number is selfprotection. That the only purpose for which power can rightfully be exercised over any member of a civilised community against his will is to prevent harm to others. His own good, whether physical or moral, is not a sufficient warrant." Mill 1986 [1859], ch. 1, para 9.

${ }^{9}$ There is, no doubt, substantive disagreement on what exactly these basic rights are, and liberal theorists have also been notoriously reluctant to formulate any conclusive lists of such rights.

${ }^{10}$ I will discuss the role of the liberal state in more detail in section 1.3. 
Limits of Liberal Multiculturalism

\begin{abstract}
Autonomy
In the footsteps of Humboldt and Mill, many liberal theorists have included individual autonomy as one of the basic values of liberalism, and the protection of individual autonomy as one of the tasks of the liberal state. Individual autonomy, broadly construed, involves the idea of a person living her life from within, of being (in part) the author of her own life. ${ }^{11}$ For many, this entails the idea of the individual deciding for herself what is valuable in life, and for living her life in accordance with that decision. ${ }^{12}$

This idea of individual autonomy, and the role of the liberal state in protecting autonomy, has, however, become contested, not least among liberal theorists of multiculturalism. ${ }^{13}$ Not everyone, after all, would seem to attach such value to individual autonomy, and the freedom to live one's life in accordance with one's own conception of the good would seem to include also the freedom to reject the value of individual autonomy and one's ability to decide for oneself what is valuable in life. The liberal state, aiming to protect or even promote individual autonomy, would thus seem to be infringing on the freedom of those wanting to reject the value of
\end{abstract}

\footnotetext{
${ }^{11}$ As Joseph Raz puts it: "The ruling idea behind the ideal of personal autonomy is that people should make their own lives. The autonomous person is a (part) author of his own life. The ideal of personal autonomy is the vision of people controlling, to some degree, their own destiny, fashioning it through successive decisions throughout their lives." (Raz 1986, 369.) On a more recent formulation: "Autonomy is an ideal of people deciding for themselves what is a valuable life, and living their lives in accordance with that decision." (Colburn 2010, 19.) For alternative conceptions, including hierarchy of motives -theories, see Frankfurt 1971; Dworkin, G. 1988; for relational conceptions of autonomy, see: MacKenzie and Stoljar 2000.

12 For different views on what this "decision" may involve, ranging from well-informed, critical self-reflection to hypothetical affirmation, see e.g. Meyers 1989; Friedman 1986; 2003, ch.1; Dworkin, G. 1988; Christman 1987; 1991.

${ }^{13}$ One such rejection, that of Chandran Kukathas's, will be discussed in more detail in Ch. 2.
} 
individual autonomy and wanting to conform to other ideals than the ideal of autonomous life.

In the face of this controversy, a few remarks on the role of individual autonomy in liberal political theory may already be in order.

Firstly, with respect to the critique mentioned above, there is no reason to presume that a person who rejects the value of individual autonomy could not still be considered as living an autonomous life. The leading of an autonomous life does not require the person to value individual autonomy, although it does require the person to decide (in some relevant sense of the term) what is valuable, and to be able to live her life accordingly. Secondly, there is no reason to think why a life of, say, total submission could not still be a life lead from within, as long as the decision (again, in some relevant sense of the term) to value submission and to adhere to a life of submission, is the person's own. ${ }^{14}$ These two considerations do not, of course, say anything yet about those cases in which people have not decided (in some relevant sense of the term) to adhere to a life of submission as a decision of their own, but they do point towards the idea that the above mentioned critique may only work against some, more substantive conceptions of autonomy.

Moreover - and most importantly - the disagreements on individual autonomy within liberal political theory may not be so much disagreements on the status of individual autonomy as a liberal value, but disagreements on the role that the liberal state should take with respect to individual autonomy. Although it certainly remains contested whether the liberal state should be in the business of promoting individual autonomy, in this work (esp. Ch. 2), I show that even those suspicious of the role of the liberal state in promoting individual autonomy may need to subscribe to a view that certain minimal conditions for individual autonomy must

\footnotetext{
${ }^{14}$ The proponents of some more substantive conceptions of autonomy may reject this, arguing that, in order to be autonomous, the agent's decisions need also be of the right kind. On substantive theories and debate on content neutrality, see Benson 1994.
} 
be protected, although they do not necessarily need to subscribe to a view where the aim of the state policies should be the promotion of individual autonomy and autonomous life.

\section{Equality}

Apart from the questions of individual freedom and autonomy, within recent decades, much of liberal political theory has concentrated on the issues of social justice, and the just organisation of liberal institutions. ${ }^{15}$ For many contemporary liberals, social justice - and the incorporated notion of equality ${ }^{16}$ - operates at the very centre of liberal political theory. In its most minimal interpretation, liberal equality entails equal moral standing of, and concern for, each individual, although, to an increasing extent, it has also come to be seen as incorporating the ideal of equal distribution of resources or basic goods in society. ${ }^{17}$ It also incorporates the ideal of the liberal state treating all of its members with equal concern and respect, although there is, no doubt, substantive disagreement on what this equal concern and respect amounts to, and to whom it should be extended. ${ }^{18}$

\footnotetext{
${ }^{15}$ John Rawls's A Theory of Justice (1971) may be described as one of the turning points of political philosophy, and it is also a work in relation to which much of contemporary analytical work on issues of social justice is conducted.

${ }^{16}$ For debate on the relation between justice and equality, see e.g. Cohen 2008; Arneson 2008.

${ }^{17}$ It should be noted that, for example, Rawls's theory may not be viewed as strictly egalitarian, as his famous difference principle aims rather at justifying inequalities than providing for an equal distribution of social and economic goods. Nevertheless, taking Rawls's first principle as well as the second part of his second principle (fair equality of opportunity), and taking the strong presumption in favour of equality present in the difference principle, it is clear that, for Rawls, equality operates as one of the fundamental liberal values and is also incorporated in his two principles of justice.

${ }_{18}$ Most notably, approaches, broadly labelled under the term "politics of recognition", question the traditional liberal approaches of granting individuals certain basic rights as being sufficient for treating them with
} 
Liberal egalitarians do, of course, differ on a variety of issues, including the currency (equality of what?), scope (equality among whom?) and the justificatory basis for equality (equality, why?). They do, also, differ on their views on the kinds of equality relevant for an egalitarian theory of justice, as well as on the institutional frameworks required for the pursuing of equality. ${ }^{19}$ Whereas the views of liberal political theorists do vary, to a substantive degree, on a variety of issues relating to equality, they do, nevertheless, share a commitment to at least some (minimal) notion of equality. For any liberal political theory, including liberal multiculturalism, the fundamental commitment to the equal moral worth of individuals is untradeable, and the requirement for the liberal state to treat (at least) all its members with equal concern seems nonnegotiable. What it means for the liberal state to treat all its members with equal concern, and what the role of the liberal state should be in a liberal society are, however, highly contested issues, of which I will say more in the following subsection (1.3.).

\section{Conflicts of values}

Whereas I believe that any liberal political theory, including liberal multiculturalism, must be committed to the basic liberal values of individual liberty, autonomy and equality, there may, nevertheless, be substantive disagreements on how these values are interpreted, and how these interpretations bear upon the wider normative questions about the organisation of liberal institutions or liberal society. The disagreements among liberal political theorists are not only restricted to disagreements about the specific interpretations or

equal respect and concern. (e.g. Taylor 1994; Young 1990; 2000; Fraser and Honneth 2003) Many theorists of global justice, on the other hand, have questioned the traditional presumptions of the scope of the liberal principles of justice, claiming that the egalitarian principles of justice (variously construed) should also apply across the globe and not merely within some predetermined societies (normally, nation states). (e.g. Pogge 1989; 2002; Beitz 1979; 2005; Moellendorf 2002; Tan 2004; Caney 2005)

19 For an excellent overview on contemporary debates on equality, see: Holtug and Lippert-Rasmussen 2007. 
applications of any particular liberal value, but include disagreements about the ordering or negotiation of these values. The basic liberal values of individual freedom, autonomy and equality may, at times, pull in different directions and liberals do, to a substantive degree, differ over their views on how to negotiate these conflicts. ${ }^{20}$ For example, certain interpretations of individual liberty (say, in the economic sphere) clearly violate certain notions of equality, and the trade-offs between different values, within liberal political theory, are more of a norm than an exception. Nor are these basic values necessarily the only considerations that cause disagreement, but other considerations (for example, social stability or security) may also play an important part - often, as legitimating certain restrictions on individual freedom, autonomy or equality. As will be noted time and again in the course of this work, the world is a very complex place, and those considerations relevant in one set of circumstances may be very different from the considerations relevant in another. When applied to concrete political practice, the basic liberal values, or the resorting to some basic liberal principles, may simply not be enough, as the issues, encountered in the real world, are very different from the issues encountered at the level of political theory. This is not to say that the theoretical discussions be they on liberalism, multiculturalism or liberal multiculturalism would not be of any importance in debates on concrete political practices. It is merely to say that political theories (be they liberal or non-liberal) may leave considerable scope for variation in legitimate political practices and that the search for theoretical normative guidance may not produce the kinds of results wanted, as the issues of the real world may not fit neatly to the theoretical frameworks of political theorists. ${ }^{21}$

\footnotetext{
${ }^{20}$ For an on-going debate on the (in)compatibility of equality and liberty, see e.g. Dworkin 2002; Narveson and Sterba 2010; articles in May, Sistare and Schonsheck 1997.

${ }^{21}$ These remarks about the difficulties of applying political theories or theoretical principles into concrete political practice are, of course, not new, and it would be foolish to claim that the political theorists (including liberal political theorists) would not be aware of such difficulties
} 
To make things clear, I do not advocate a view according to which political (liberal or non-liberal) theory could not give any normative guidance to concrete political practice. I do believe that the concrete political responses (be they multicultural policies or other ways of responding to cultural diversity), should take the basic liberal commitments to the moral primacy of the individual and to the basic liberal values of individual liberty, autonomy and equality seriously. These basic commitments provide the framework within which, not only liberal theory, but also the liberal state and society, should operate, as well as considerations that, in concrete political practice, cannot be ignored. Whereas it may be an open question, how to negotiate between these competing values, and what kinds of considerations may justify limitations on individual freedom, autonomy and equality, these values, nevertheless, must occupy a central place in the negotiations, along with the other relevant considerations (that may well vary depending on the context and the issue at hand).

\subsection{Liberal state and state neutrality}

The basic liberal commitments to the moral primacy of the individual and to (at least some notions of) individual freedom, autonomy and equality, may not, as already indicated, say much about how the liberal state should respond to cultural diversity or to other issues in society. Nor do they (directly) say much about how the liberal society should be organized, how its institutions should operate, or what the role of the state should be in society. Indeed,

themselves. I do, however, believe this point to be worth restating as many liberal multiculturalists do, in fact, aim at building frameworks that would give normative guidance - sometimes, very specific normative guidance to concrete political practices. Whereas I do, in the course of this work, argue that liberal multiculturalists largely fail in this task, this is not to say that their efforts would have been completely in vain. Rather, as I discuss later in this background (3.1.), the primary target of liberal multiculturalists may not have been so much in the directing of actual cultural policies, but rather in the modification, or (perhaps more accurately) clarification of the liberal theory itself. 


\section{Limits of Liberal Multiculturalism}

liberal political theorists disagree, to a considerable extent, on the basic structure of society, partially due to their disagreements on the nature and the status of the basic liberal values. Having said that, liberals do tend to agree on two things. Firstly, they agree that people differ, that there may be more than one acceptable way of living, and more than one acceptable way of thinking about what is valuable in life. Provided that liberals are also committed to protecting individual liberty and people's freedom to pursue their own conceptions of the good, they also agree that the basic structure of society should be organized in ways that allows, to a great degree, people to live their lives in accordance to their own conceptions of the good. For many (although not all) ${ }^{22}$ liberals, this has led to a view according to which the liberal state should stay neutral with respect to people's conceptions of the good.

The notion of state neutrality is itself a very complex one, and has been debated extensively among liberal political theorists (and their critics). ${ }^{23}$ Whereas I do not even attempt to build a coherent picture of all the debates and issues involved, a few remarks relevant for my purposes should be made. Firstly, as I discuss in more detail in the upcoming chapters, many have come to question the idea of whether the state could ever be neutral with respect to people's different conceptions of the good. The state institutions national languages, public holidays, school curriculums - are always reflective of some particular set of values and ways of life and, by upholding these institutions, the liberal state necessarily supports certain conceptions of the good at the expense of others. ${ }^{24}$ This, it may be argued, puts the whole idea of state neutrality into

\footnotetext{
${ }^{22}$ The perfectionist liberals, such as Joseph Raz, reject the ideal of state neutrality, claiming that "it is the goal of all political action to enable individuals to pursue valid conceptions of the good and to discourage evil or empty ones" (Raz 1986, 133).

${ }^{23}$ For some defences of state neutrality see: Dworkin 1978; Ackerman 1980; Rawls 1996; Gaus 2003; For debate, see e.g. Wall and Klosko 2003.

${ }^{24}$ This is, roughly, the beginning of Will Kymlicka's equality based argument for multiculturalism, discussed in $\mathrm{Ch} .1$.
} 
doubt as, for a functional society, the state cannot but support some conceptions of the good over others. ${ }^{25}$

Secondly, the liberal proponents of state neutrality may disagree on what exactly the requirement of state neutrality amounts to. Even if the state institutions and public policies reflected, say, Western Christian values and ways of life, this does not necessarily constitute a violation of state neutrality. The key distinction here is the distinction between neutrality of justification and neutrality of effect, and the liberal institutions and state policies, although not neutral in effect, may still be neutral in their justification. As will be discussed later on in this work (esp. Ch. 3), there is substantive disagreement on whether policies that are, apparently, neutral in their justification can, nevertheless, be considered as discriminatory, should their effects be systematically disadvantageous to particular groups of people. The underlying liberal standpoint is perhaps better described in terms of the state being required to treat all its citizens equally (rather than in terms of state neutrality), although, as already indicated, there may be substantive disagreements on what this equal treatment amounts to. Nevertheless, I believe that for any contemporary liberal political theory, including liberal multiculturalism, some commitment to the role of the state, not as an explicit advocate or promoter of any particular conception of the good, should be maintained. ${ }^{26}$ The liberal commitments to individual freedom, autonomy and equality do somewhat restrict the role of the liberal state and the operations of liberal institutions. The liberal state, rather than aiming to uphold

\footnotetext{
${ }^{25}$ As will be seen, liberals differ on their responses to this observation. According to some (e.g. Kymlicka), the state should give similar kind of support (for example, in the form of minority rights) to those ways of life that are not, currently, supported by the state institutions. According to others (e.g. Kukathas and Barry), there may not be a case for such alternative support, as the bias of liberal institutions is simply unavoidable, and the giving of alternative support may either create biases of different kind (Kukathas), or be theoretically unsound (Barry).

${ }^{26}$ This view, I believe, is also consistent with pluralist perfectionist views, such as Raz's.
} 
a society in which only some particular ways of life can be pursued, should rather aim at upholding a framework that enables people to pursue their different conceptions of the good, and the state policies, although not always neutral in effect (nor justification), should aim at treating individuals with equal concern and respect.

\section{What is multiculturalism?}

Having outlined some of the very basic commitments that, I believe, any liberal political theory must be based on, I now turn to look at some of the key debates and distinctions on issues on multiculturalism. I begin (2.1.) by looking at the various ways in which the term multiculturalism has been used in political theory, and - by doing so - also clarify some of the terminology used in this work. I then (2.2.) look at different conceptualisations of culture as well as the value of culture, and outline the specifically liberal commitments to an individualist and, primarily, instrumental value of culture. Finally (2.3.), I look at some of the approaches that the liberal state may adopt in responding to cultural diversity, and further specify the scope of the arguments that will be advanced in the following chapters.

\subsection{Three conceptions of multiculturalism}

\section{Descriptive multiculturalism}

The term "multiculturalism" has, in political theory as well as in public discussions, been used in a variety of slightly different, partially overlapping, and certainly confusing, ways. As a descriptive term, multiculturalism refers to a state of affairs present in contemporary societies: that of the existence of different cultures and cultural groups within one society. As a descriptive term, multiculturalism incorporates no claims about the desirability or the value of this state of affairs, nor does it include any normative claims about how this state of affairs should be responded to. Descriptive multiculturalism, or - as I call it - cultural diversity, ${ }^{27}$

${ }^{27}$ In order to distinguish descriptive multiculturalism from what shall later be called "normative multiculturalism", several alternative expressions 
Background

is simply an acknowledgement of the existence of different cultures and cultural groups in society, not an ideological or political stand or an attempt to respond to this diversity.

\section{Normative multiculturalism}

The state of cultural diversity may prompt several normative questions about how this diversity should be responded to. Multiculturalism, as a normative term, incorporates certain value judgements about the state of cultural diversity, but it also incorporates a vast variety of views and different theories about the appropriate responses to this diversity. Following Joseph Raz, normative multiculturalism is saying yes to the state of cultural diversity. ${ }^{28}$ That is, it is affirming cultural diversity as an acceptable state of affairs that, at the very least, should not be deliberately attempted to get rid of.

Multicultural theorists do, of course, disagree on what this "saying yes" to cultural diversity amounts to. Some cherish the value of cultural diversity, and view cultural diversity in itself as worthy of protection. ${ }^{29}$ For others, it is not cultural diversity itself that should be protected, but people's ability to live their lives in accordance with their culture, should they so wish. ${ }^{30}$ For others still, the affirmation of cultural diversity comes in a very minimal form, as an acknowledgement of cultural diversity as an acceptable state of affairs, but does not lead to claims of cherishing or protecting this diversity, or even people's abilities to live their lives in

have been suggested, including "circumstances of multiculturalism" (Kelly 2002), "fact of pluralism" (Raz 1994; 1998), "multicultural" (Loobuyck 2005) and "cultural pluralism" (also used as a normative term, cf. Kymlicka 2001). The term adopted here ("cultural diversity") stands as one commonly used suggestion that, I believe, represents well the kind of diversity at stake, including diversity within as well as between different cultures and cultural groups.

${ }^{28}$ Raz 1994, 158.

${ }^{29}$ E.g. Parekh 2000; see also: Taylor 1994; Galston 1995.

${ }^{30}$ See esp. Kymlicka 1989; 1995. 
accordance with their culture. ${ }^{31}$ For these theorists, one's cultural background creates no legitimate claims against the state or society, although it certainly operates as the locus of discussions, broadly labelled under the term "normative multiculturalism".

In this work, I use the term normative multiculturalism as an umbrella term, incorporating a variety of theories that (1) affirm cultural diversity as an acceptable state of affairs, and (2) concentrate on the normative issues arising from the coexistence of different cultures and cultural groups within society. ${ }^{32}$

\section{Cultural policies}

Thirdly, multiculturalism is also often used to describe those policies that aim at accommodating different cultural groups and their members within western liberal societies. ${ }^{33}$ The vast variety of cultural policies (ranging from the rights of self-determination to

\footnotetext{
${ }^{31}$ E.g. Barry 2001; Kukathas 2003.

${ }^{32}$ It should be noted that, in this usage of the term, normative multicultural theories also incorporate many theories that have not been commonly labelled as multicultural. For example, Brian Barry's polemic attack on some classical forms of multiculturalism and Susan Okin's feminist critique are, according to this interpretation, multicultural theories themselves. Whereas I acknowledge that there are differences between those "classical multiculturalists" that concentrate primarily on the ways of rectifying disadvantages faced by cultural minorities and their justification (such as Kymlicka and Taylor), and those "unwilling multiculturalists" who point out the dangers of doing so too swiftly or uncritically (such as Barry, Kukathas and Okin), I also believe these theories fall on a continuum. This makes it sensible to talk of normative multiculturalism as an umbrella term, incorporating a vast variety of theories and differing viewpoints that, nevertheless, concentrate on those issues that arise from the coexistence and co-living of different cultural groups and their members within the same society.

${ }_{33}$ For the most part, the debates on multiculturalism have been conducted in the context of western liberal democracies, and this work is no exception to this focus. For some attempts to expand from the predominantly western perspective, see: Kymlicka and Opalski 2001; Berman, Eyoh and Kymlicka 2004; for discussions on multiculturalism in global contexts, see e.g. Kymlicka 2007a; Parekh 2008.
} 
the cultural sensitizing of official documents or educational curriculums) are one of the subject matters of normative multiculturalism, and many multicultural theorists also advocate some systems of minority rights, or policies based on the acknowledgement of cultural diversity, and the acceptability of this diversity, within liberal society. Although it may thus be difficult to fully differentiate normative multiculturalism from the actual cultural policies (a more thorough account of which will be given in 3.2.), I believe this distinction to be worth making as the debates on multiculturalism often tend to confuse the actual multicultural policies with their justification. Whereas one of the primary aims of normative multiculturalism and multicultural theories is to find those general principles upon which the state's responses to cultural diversity should be based, these general principles, as I argue in more detail in the upcoming chapters, do not necessarily give any definitive guidance on what kinds of policies the state should adopt in any particular circumstances. Whereas the bases and principles of different normative theories of multiculturalism may be, and also have been, used to argue for a variety of multicultural policies (including culturally differentiated or minority rights), I will show that the scope of these arguments is far more restricted than many normative multiculturalists would hope for. They provide only general frameworks within which the liberal state's responses to cultural diversity should reside, rather than give clear guidance into whether the liberal state should, or should not, adopt any particular multicultural policies in practice.

\subsection{Multiculturalism and culture}

The differentiation between descriptive multiculturalism (cultural diversity), normative multiculturalism (theoretical bases for responding to this diversity) and cultural policies (state responses) may not, as yet, say much about the actual subject matter of multiculturalism, that of culture and the accommodation of people's cultural differences. To recall, multicultural theorists affirm the state of cultural diversity as an acceptable state of affairs within society, and they also look for ways and bases upon which the co- 
living of different cultural groups and their members should be organized. The terms culture, cultural group and cultural membership, however, are far from self-explanatory, and multicultural theorists do, to a substantive extent, differ on their views on what they conceive culture, or any of the related terms, to mean. Not surprisingly, these different views of culture as well as the value of culture also have an effect on the broader normative questions of cultural accommodation, and it is thus important to see how culture, and the value of culture, can be understood.

From homogeneous cultural contents to fluid cultural memberships For contemporary multicultural theorists, culture is often conceived as a broad framework of norms, values, beliefs and practices that structures and regulates the lives of those within that culture. ${ }^{34}$ As a broad framework of norms, values, beliefs and practices, culture can be seen as having a profound effect on its members: on their senses of themselves, on their ways of living and on their views of the world. What the theorists of culture and multiculturalism disagree upon, is the extent to which one's culture or one's religion $^{35}$ can be seen as structuring and regulating the lives or

\footnotetext{
${ }^{34}$ For example, Bhikhu Parekh describes culture as "a historically created system of meaning and significance or, what comes to the same thing, a system of beliefs and practices in terms of which a group of human beings understand, regulate and structure their individual and collective lives. " (Parekh 2000, 143) On a distinction (as well as possible inter-linkages) between so-called high culture and culture as a system of norms, see Wallerstein 1990. For an excellent analysis on different conceptions of culture (including semiotic, normative and societal conceptions), see: Festenstein 2005.

${ }^{35}$ In this work, I treat religion as one of the instances of culture, having largely the same structure as culture. For the most part, the arguments put forth are thus extended to both cultural as well as religious differences and many of the examples used are precisely examples from religion. Despite this broad application, I also acknowledge that at times (especially with respect to the rationale of the liberal state to accommodate particular minority practices) it may make a difference whether the issue at hand is conceived as cultural or religious. In these cases, I will make explicit
} 
identities of individuals, and how the cultural policies should take these effects into account.

Based on the views of the classical anthropologists, who saw cultures as coherent, holistic packages,$^{36}$ the ideals of cultural homogeneity and the pervasiveness or comprehensiveness of culture has been surprisingly difficult to surpass. ${ }^{37}$ Cultures can be seen as pervasive, either in the sense in which they are the only, or at least the primary, regulators of people's lives (singular culture $\mathrm{SC}$ ), but they can also be viewed as pervasive in the sense in which they regulate a broad array of people's lives, ranging from their choices of occupation to their personal affairs, such as marriage and family (broad culture - BC). Distinguished from the two previous senses of pervasiveness ( $\mathrm{SC} \& \mathrm{BC}$ ), cultures can also be seen as pervasive in the sense in which they are seen as determining people's behaviour, or some aspects of their behaviour, by providing very strict rules on some, or all, aspects of people's lives (determining culture - DC).

Cultural homogeneity, although much criticised, can also be seen as incorporating at least three different elements: those of the homogeneity in cultural content (that is, homogeneity in the interpretations of what the cultural norms, values, beliefs and practices contain - Hcontent), homogeneity in scope (that is, homogeneity in the views of which norms, values, beliefs and practices are conceived as cultural - Hscope), and homogeneity in membership (that is, homogeneity in the views of who are

reference as to whether I am talking of culture or religion, as well as why this distinction, in any particular case, is important.

${ }^{36}$ For classical anthropological views on culture, see e.g. Tylor 1973 [1871]; for later, interpretive accounts, see: Geertz 1973.

${ }^{37}$ Numerous critiques of contemporary multicultural theories have, indeed, focused on the ways in which multicultural theories, either explicitly or implicitly, view cultures as homogeneous, comprehensive wholes thus also essentializing cultures or certain elements of culture. On charges of essentialism within multiculturalism (including cultural essentialism in terms of pervasiveness and homogeneity), see: Mason 2007; Phillips 2010, ch. 5 . 
conceived to be members of a particular culture - Hmembership). In its most rigid formulation, culture is seen as the sole regulatory framework of a person's life (SC) that determines everything that that person does $(\mathrm{BC}+\mathrm{DC})$, allowing no contestation in the interpretations of those norms and practices that are conceived as cultural (Hcontent; Hscope), nor in the views of whether one does, or does not, come under the rigid regulatory framework this culture (Hmembership).

In brief, no multicultural theorist, or - to be fair - even the classical anthropologists, would accept this rigid formulation of culture, although the different elements of pervasiveness and homogeneity do, to various extents, feature also in the discussions of the multicultural theorists. Cultures have been seen to "encompass many, varied, and important aspects of life, a culture that defines or marks a variety of forms or styles of life, types of activity, occupation, pursuit and relationship" ${ }^{\text {"38 }}$. Whereas the exact scope of cultural regulation ${ }^{39}$ as well as the extent to which culture operates as the only system of regulation ${ }^{40}$ can be variously

\footnotetext{
${ }^{38}$ Raz and Margalit, 1994.

${ }^{39}$ As Amy Gutmann has succinctly put it: "Culture [...] is comprehensive, but no single characteristic - such as a common language, dress, holidays, or territorial concentration - is absolutely necessary for an actual culture to be considered as such. Theorists of culture assume a rough approximation rather than a perfect match of the actual to the ideal type: a culture constitutes and constrains the identities (and therefore lives) of its members by providing them with common language, history, institutions of socialization, range of occupations, lifestyles, distinctive literary and artistic traditions, architectural styles, music, dress, ceremonies and holidays, and customs that are shared by an intergenerational community that occupies a distinct territory. Actual cultures encompass the lives of their members in many of these ways but not necessarily all." Gutmann 2003, 40 .

${ }^{40}$ For example, Jeremy Waldron has argued for a view according to which cultures can no longer be viewed as the sole regulatory frameworks of people's lives, but, in circumstances of cultural diversity, people draw from and navigate between many cultures. (Waldron 1992.) For different emphases on cultural interaction and change, see: Benhabib 2002; Scheffler 2007; Levy 2009.
} 
interpreted (including variations between different cultures and cultural groups), some have come to argue that the broadness of cultural regulation, conjoined with a view of the value of culture (to be discussed shortly), has also prompted a case for accommodating (at least some) cultural groups, and their distinctive cultural structures, within the framework of the larger liberal society. ${ }^{41}$

Not all debates within multiculturalism, however, focus on the questions of how to accommodate these broad systems or frameworks of norms, values etc. as a whole. Rather, they concentrate on the questions of how to respond to some particular cultural norms or practices (such as customs of marriage or relationship, religious or cultural obligations, customary or religious rituals etc.), and how to ensure that these responses do not unduly prioritize certain interpretations of culture, or discriminate against certain members of cultural groups. The underlying difficulty being that multicultural theorists, along with other contemporary theorists of culture, tend to deny the other aspects of the rigid formulation (SC \& DC), viewing cultures as relatively broad (although not comprehensive) frameworks within which people operate, rather than as systems that would determine what the members of a particular culture think or how they behave. ${ }^{42}$ Consequently, multicultural theorists also deny the idea that cultures would be homogeneous, as different people may - and they also do - have very different interpretations of what they conceive their cultural norms, values, beliefs or practices to contain. The acknowledgement of the heterogeneity of cultural norms, values,

\footnotetext{
${ }^{41}$ This is roughly the view of Kymlicka to whom cultures are primarily viewed in terms of "societal cultures" (to be discussed in more detail in Ch. 1) For alternative BC views of culture, see e.g. Shachar 2001 ("nomoi communities"); Walzer 1983 ("communities of character"); Raz and Margalit 1994.

42 For discussion on how the idea of culture as determining people's behaviour and the connected conceptions of (non)agency have operated in discussions on multiculturalism, see Phillips 2007, ch. 4. I will discuss questions relating to cultural motivation, including cultural compulsion, in Ch. 6.
} 
beliefs and practices has proved especially problematic with respect to the various cultural policies that, as I argue in more detail in chapters 1, 4 and 5, tend to prioritize certain cultural contents over others. Moreover, the notions of cultural heterogeneity - both in the sense of heterogeneity of scope and heterogeneity of membership create even further difficulties for normative multiculturalists, as it may no longer be clear whether some particular norms or practices should even be considered as cultural, or to whom these practices should be attached to.

Instead of viewing cultures in terms of particular cultural contents, some multicultural theorists have attempted to reformulate the term culture in ways that would not be so prone to the accusations of cultural homogeneity, or to the underlying notions of cultural determination or cultural singularity. ${ }^{43}$ Most notably, Will Kymlicka has attempted to distinguish between cultural contents (or the character of a cultural community), and culture as a context of choice (or membership in a cultural community), claiming that it is only the latter (cultural context or membership) that should be the proper concern of liberal theorists, as well as the liberal state. ${ }^{44}$ The context of choice view would seem to take better into account cultural heterogeneity (Hcontent \& Hscope), and the viewing of culture in terms of cultural membership rather than in terms of some particular cultural character would seem to better accommodate the generally accepted ideas of cultural fluidity, change and heterogeneity of cultural values, norms, beliefs and practices.

Whereas I will return to Kymlicka's characterisations of culture, and the difficulties incorporated in these characterisations in more detail in chapters 1 and 2, what can already be seen is the importance of explicating clearly, what precisely one is referring to when one debates the various issues of cultural accommodation. Although it may make sense to talk of culture, and cultural

\footnotetext{
${ }^{43}$ See also Scott 2003 , who points out to the tendency of the theorists to define culture in ways that fit their normative theories.

${ }^{44}$ Esp. Kymlicka 1989; 1995.
} 
accommodation, as a short hand for a wide variety of issues within normative multiculturalism, one cannot talk of specific issues (such as the state's response to particular cultural practices, specific cultural groups, types of cultural disadvantages etc.) without explicating what the term culture, in these contexts, is set to refer to. As will be seen during the course of this work, the normative conclusions of multicultural theorists depend, to an extent, also on their interpretations of culture and on the extent to which they view cultures as singular, broad, determining or homogeneous (although none of them would subscribe to the rigid formulation given above). It also makes a difference whether one views culture in terms of a set of norms, values, beliefs and practices, or in terms of cultural membership and belonging that may, or may not, incorporate certain levels of adherence to those norms and practices conceived as cultural.

In this work, I use the terms culture and cultural accommodation as umbrella terms, incorporating a wide variety of views both with respect to the nature of culture as well as with respect to the ways in which different cultures and/or different cultural groups should be accommodated. The key distinctions, to which I try my best to refer to and which I will explicate in more detail in context, however, are as follows. Firstly, I use the term cultural context to refer to that broad (although not necessarily comprehensive) framework within which people conduct their lives. This cultural context can be seen to incorporate things such as values and beliefs, norms as well as practices, although these values, norms, beliefs or practices (cultural contents) are not necessarily specific, but fluid and contestable. Secondly, I talk of specific cultural practices when referring to particular cases (such as religious dress codes, rituals of marriage, initiation ceremonies) although this reference incorporates no claims about these practices, or specific interpretations of these practices, as being fixed. On the contrary, there can be substantive disagreements on what the practices of any particular cultural group contain (Hcontent) as well as whether these practices can be conceived as cultural (Hscope). 
Thirdly, when talking of cultural groups, I refer to those people who can, in yet undefined terms, be seen to come under the regulatory framework of some cultural context. Fourthly, I talk of cultural membership in terms of those people who, in yet undefined terms, can be seen to be members of a cultural group. As will be discussed especially in Ch. 4 and 5, the relations between the two first categories (cultural context and specific cultural practices) and the two latter (cultural groups and cultural membership) are very complex, and the possible discrepancies both within as well as between these categories will also have a profound effect on the questions of cultural accommodation and, especially, on the questions of allocating culturally differentiated rights in practice. Whereas I do, thus, join the common canon of viewing cultural contents as heterogeneous, fluid and contested, I also point to some of the difficulties that the complexity of cultural membership (and the related notions of cultural belonging and cultural identity) bring to the normative debates on multiculturalism. Whereas I do point to some of the additional problems that the acknowledgement of the heterogeneity of cultural memberships creates, I also point to some of the ways in which a more thorough analysis of membership may help reformulate the liberal multicultural positions, and how the recognition of cultural heterogeneity, in all levels (Hcontent, Hscope, Hmembership), may be used for the identification of the proper objects of cultural accommodation, as well as for a better application of cultural policies in practice.

Instrumental/non-instrumental, individualist/non-individualist value of culture

As already indicated, there may be as many ways of understanding culture as there are theorists of multiculturalism. The theorists' views on the singularity, broadness, determination as well as homogeneity of cultures differ, as do their emphases on either the contents (values, norms, beliefs and practices) or memberships (groups and their members) as the proper objects of cultural accommodation. Regardless of these variations, one of the questions that any multicultural theorist needs to answer is why 
culture (in any sense of the term) matters: why and in what senses is culture valuable.

The different views on the value of culture (variously construed) can be understood by looking at two axes according to which one's views on the value of culture are seen to differ: those of instrumental/non-instrumental, and individualist/non-individualist. ${ }^{45}$ According to the individualists, cultures are valuable only and in so far as they contribute to the well-being of their individual members. Cultures do not possess any moral standing of their own, but the value of culture (variously construed) is reducible, without a remainder, to the value that it has for contributing to the lives of individuals. According to the non-individualists or collectivists, on the contrary, the value of culture cannot be accounted for purely with reference to individuals, but the collective nature of culture also has an effect on the value of culture, seen as irreducible to the value it has for individuals. ${ }^{46}$

Whereas the collectivists are surely right in pointing to the collective nature of culture - cultures are surely group phenomena, and certain cultural goods, such as languages, cannot be enjoyed without at least some other individuals too enjoying such goods - it does not, however, necessarily follow that the value of culture could not be accounted for by reference to the role that it plays in the lives of individuals. ${ }^{47}$ Further, even if the collectivists are right in arguing that the value of culture cannot be reduced to its value in relation to individuals, the implications of this for liberal political theory are far from clear. As will be seen during the course of this work, the collective nature of culture does produce some difficulties for liberal multicultural theory in so far as those aspects of culture,

\footnotetext{
${ }^{45}$ For similar analyses on the value of culture, see Festenstein 2005, 3843; Johnson 2000; Mason 2000, ch. 2.

${ }^{46}$ As Charles Taylor has argued, cultures should be conceived of as irreducibly social goods. For Taylor, cultures are both produced as well as consumed collectively, and due to the collective nature of culture, the value of culture cannot be reduced to the value it has for the individual members of that culture. Taylor 1994; 1995.

${ }^{47}$ Griffin 1986; Moore and Crisp 1996.
} 
contributing to the well-being of individuals, are produced collectively, although it does not need to affect the basic liberal commitment to the moral primacy of the individual. Even if the value of culture could not be (fully) accounted for in terms of individuals, for liberal multiculturalists, this would be of secondary importance. After all, what ultimately matters, according to liberals, is the individual, and it is thus from the standpoint of the individual that the value of culture, and the possible accommodative measures, should be assessed.

The second axis, that of the instrumental and non-instrumental conceptions of the value of culture, is not in a straight forward relationship to the individualist/non-individualist-distinction, although there is some tendency for the individualists to view the value of culture in instrumentalist terms, whereas the collectivists tend to be more open also to some non-instrumentalist conceptions. ${ }^{48}$ In order to elaborate on this distinction, it may be worth bringing in yet another category of value, that of intrinsic value. According to Joseph Raz, there are three ways in which things - such as cultures or cultural memberships - could be conceived of as intrinsically valuable. For Raz, things can be intrinsically valuable, firstly, because they are valuable in themselves, irrespective of what else exists. Secondly, things can be intrinsically valuable because they are constituent of that which is intrinsically valuable in the first sense (and, according to Raz, them being constitutive parts of the valuable thing in itself brings value that is not something already inherent in the thing in itself). And thirdly, things can be intrinsically valuable in virtue of them being ultimate goods or values - that is, justificatory and explanatory of the value of the things valuable in themselves (in which the value of

\footnotetext{
${ }^{48}$ For example, Will Kymlicka's conception may, at first sight, be read as an individualist-instrumental conception, emphasizing the value of culture only and in so far as it provides for the well-being of individuals. On the contrary, Charles Taylor's conception of culture as a locus of good falls more properly under the axes of collectivist-non-instrumentality. (Esp. Taylor 1995, 136-139.)
} 
the ultimate good or value does not need to refer to anything else in order for its value to be explained). ${ }^{49}$

If we apply Raz's second notion of intrinsic value to the questions of culture and cultural accommodation, something interesting emerges. In Kymlicka's view, for instance, cultures (that is, cultural memberships) are conceived of as preconditions for individual freedom and autonomy and, being such, necessary conditions for individuals' well-being. Being necessary conditions for individual freedom, autonomy and well-being, cultures or cultural memberships can also be considered as constitutive elements of this well-being, as nothing else can logically provide for the well-being thus constituted. ${ }^{50}$ Being constitutive elements of that which is intrinsically valuable (individual freedom, autonomy and well-being), Kymlicka's account can thus be interpreted as individualist-non-instrumentalist. If cultures or cultural memberships can be conceived of as constitutive elements for individual freedom, autonomy and well-being, then cultures or cultural memberships are not valued in virtue of them being instrumentally valuable but for being necessary, constitutive parts of that which is intrinsically valuable. If no other condition than culture or cultural membership can provide for the flourishing of individual freedom and autonomy, then - following Raz's second notion of intrinsic value - cultures or cultural memberships must also be conceived as intrinsically and, at least in this sense, noninstrumentally valuable.

Whereas I will return to the questions of the value of culture, including the questions of what, precisely, can be viewed as valuable in cultures later on in this work, a few preliminary remarks on the possible consequences of one's conception of the value of culture for liberal political theory are in order.

As already indicated, for liberals, what matters first and foremost is how individual lives go. Keeping this in mind, what liberals are interested in, and what should also play upon their

${ }^{49}$ Raz 1986, 200.

${ }^{50}$ See also: Festenstein 2005, 41. 
views on cultural accommodation, are the ways in which culture, or some aspects of culture, provide for the well-being of individuals. This, it would at first seem, connects the liberal standpoint strongly with the individualist-instrumentalist conception of the value of culture. This, however, would be an oversimplification, as the questions about the value of culture are, at least to an extent, independent of, and prior to, the questions relating to cultural accommodation. Whereas liberals are, first and foremost, interested in how individual lives go, there is no reason why liberals could not also be committed to (some) individualist-non-instrumental conception of the value of culture - that is, for example, to the view of cultures as constitutive elements of individual well-being. Should cultures, as in the case of Kymlicka, be viewed as constitutive elements of individual well-being, they would also, necessarily, be viewed as valuable from the perspective of the individual, contributing (in the constitutive sense) to their well-being. For theorists such as Kymlicka, the questions about whether cultures (or cultural memberships) provide for the well-being of individuals have already been answered, and the views on the accommodation of different cultures (or cultural memberships) are set to reflect this view. $^{51}$ The viewing of cultures (variously construed) as constitutive elements of individual well-being, however, does not necessarily lead to the view according to which all cultures, or all elements of culture, should also be seen as constitutive in the same sense, and the liberal multicultural theory may, in fact, be better off taking a more cautious approach to the value of culture, assessing on a case to case basis whether, and to what extent, cultures (variously construed) provide for the well-being of individuals and for different individuals differently.

\footnotetext{
${ }^{51}$ It should be noted that Kymlicka, as well as other multicultural theorists, also build arguments for why cultures can be conceived of as constitutive for individual well-being, although these arguments, I should add, are analytically separate from the arguments for cultural accommodation.
} 
Background

\subsection{Multiculturalism and cultural policies}

So far, I have laid out some background and clarified some terminology with respect to the notions of liberalism, multiculturalism, culture and value of culture. None of this, however, has said anything directly about the kinds of responses, or the kinds of policies, that the liberal theorists of multiculturalism may promote, or the grounds upon which these policies are argued for. As I indicated in section 2.1., it may at times be difficult to distinguish normative multiculturalism from the actual cultural policies, and this section, no doubt, also faces this difficulty. The actual cultural policies (of which I will give a more thorough analysis shortly) cannot, however, be discussed without the framework within which they are argued for, and it is thus important to first outline some of the major arguments that have been given for the liberal state to engage in cultural accommodation (whatever the actual means for this accommodation may be). As I try to indicate, and as I will argue in more detail in the subsequent chapters, these arguments do not, however, lead directly to any particular cultural policies, although they do provide some reasons for why the liberal state should take cultural considerations into account and why the policy approaches, so fiercely debated among liberal multicultural theorists, have been developed.

\section{Importance and equality arguments}

The two most prominent groups of arguments with respect to the need of the liberal state to accommodate different cultures and/or cultural groups may be described as arguments from equality and arguments from importance. ${ }^{52}$ According to the equality argument,

\footnotetext{
52 The arguments from importance are also sometimes referred to as arguments from difference, playing certain heed to those theories that have come to be known as "politics of identity" or "politics of difference" (see e.g. Connolly 1991; Young 1990; 2000; for overview, see: Kenny 2004). As my intention is not to participate in these discussions (although some elements of these discussions will be used during the course of this book), and as I also attempt to steer clear from making too close connection between the arguments for cultural accommodation and the actual policies
} 
members of minority cultural groups are in a disadvantaged position to that of the majority, and the aim of cultural accommodation is to rectify this inequality. At the most general level, the members of minority cultures are disadvantaged in terms of having no automatic access to their own cultural structure, having to live their lives in a society organized in accordance with the rules and norms of the culture of the majority. On another level, the members of minority cultures can also be seen as disadvantaged in cases where their specific cultural norms and practices collide with the norms and practices of the majority, denying them either equal access to public goods (such as education or employment), or denying them the freedom to participate in their particular cultural practices or to engage in particular cultural rituals. ${ }^{53}$ In order to rectify these disadvantages, it is often argued that the state should adopt certain systems of minority rights, aiming to lift the members of minority groups to the same line with the majority.

The arguments from equality do not, however, work without some support for why the cultural inequalities, faced by minority members, should be proper concerns of the liberal state. This support, as will be seen in more detail in the course of this work, comes from two sources. First, it has been argued that cultural inequalities are proper concerns of the liberal state due to the nonchosen nature of culture and cultural membership. One's belonging to a particular cultural group is normally not a choice of one's own, but can rather be viewed in parallel to other non-chosen circumstances, the disadvantages (or benefits) of which one should not be held responsible for. ${ }^{54}$ Second, and often in combination with the luck-egalitarian position above, cultures (variously construed)

of doing so, I stick to the expression of "arguments from importance". One particular form of these arguments, as well as the extent to which this argument needs to be utilized also by the proponents of the equality arguments, is discussed in Ch. 1 .

${ }_{53}$ The different kinds of equality arguments are assessed in more detail in Ch. 1 and 3 .

54 This, so-called luck-egalitarian argument, and the scope of this argument within discussions on multiculturalism, is assessed in Ch. 1. 
can also be seen as such important elements of their members' lives that it would not be reasonable, as a default, to expect people to abandon these elements. Rather, the liberal state should look for ways in which people could adhere to, or identify with, their own cultures without this resulting in the kinds of disadvantages mentioned above. In order for the equality argument to work, some notion of the value of culture thus needs to be subscribed to (at the very least, the proponents of the equality argument need to acknowledge that people may have reasonable interests in adhering to or identifying with their cultures), although the reasons for the liberal state to aim at accommodating people's cultural differences are not based on the value of culture as such, but on the disadvantages that the members of minority cultures face.

The argument from importance, on the contrary, takes the value of culture as the pivotal point, claiming that people's cultural differences should be accommodated, not because they put members of minority cultures in a disadvantaged position to that of the majority (although, in many cases, this may also be true), but because they are important, perhaps even inalienable, elements of their members' lives. Although the arguments from equality and arguments from importance are often run together, it is important to note that the scope of these arguments is very different, as they incorporate very different views on the proper aims of cultural accommodation as well as on the proper objects of this accommodation. Whereas for the proponents of the equality argument, the proper aim of cultural accommodation is the rectifying of those disadvantages that members of minority cultures (by virtue of their culture) face, for the proponents of the importance argument, the aim of cultural accommodation is to enable people to continue adhering to their cultures or those aspects of their culture they are deeply associated with. ${ }^{55}$ This difference

\footnotetext{
${ }^{55}$ Not surprisingly, the importance argument is often supported by claims about the majority's tendencies to swamp other cultures, and the aim of cultural accommodation is to counter this constant threat of annihilation and to preserve the viability of minority cultures. (See e.g. Taylor 1994;
} 
also bears upon the views on what precisely the state should aim to accommodate, and can also affect the views on the appropriate means of accommodation. Whereas the proponents of the equality argument tend to concentrate on those aspects of culture (e.g. specific cultural practices, norms, memberships) the disadvantage of which can be clearly measured (e.g. lack of opportunities, underrepresentation, discrimination), the promoters of the importance argument often extend their views further, viewing also those aspects of culture as worthy of attention that do not necessarily create a disadvantage, or a clearly measurable disadvantage, for their members (e.g. cultural identities, symbols, values and beliefs). ${ }^{56}$ As will become clear during the course of this work, neither of these arguments (or their combination), however, extends as far as dictating the appropriate means upon which people's cultural differences should be accommodated, but leaves substantive scope for variation in those policies that the liberal state may adopt.

\section{Cultural policies and the exposition of minority rights}

Multicultural policies may be distinguished from other policies responding to the state of cultural diversity by looking at either the aim or the content of these policies. Regarding the general aim of multicultural policies, multiculturalism can be placed somewhere between the assimilationist and segregationist approaches to managing cultural diversity. The assimilationist approaches, widely

\footnotetext{
Margalit \& Halbertal 1994; Reaume 2000.) It should, however, be noted that the importance -argument presented here does not entirely coincide with the view according to which cultures should be preserved, as it is possible to argue for cultural preservation even in cases where culture (or some aspects of culture) were not considered as essential for its members' well-being. For example, certain accounts of the value of cultural diversity (as opposed to the value of culture) may fall within this category.

56 The lack of recognition of people's cultural identities, symbols, values or beliefs can also be viewed in terms of cultural disadvantages, and I will utilize this observation especially in chapters 4 and 5 .
} 
argued for until the early nineties ${ }^{57}$ aim at constructing a single, unified culture within the state, either by assimilating minority cultures into the ways of the majority, or by the so-called "meltingpot" approach, merging cultures into one. ${ }^{58}$ The segregationist approaches, such as that of apartheid South-Africa, aim at keeping different cultures and cultural groups separated with minimum contact and interaction. Different to these two approaches stands multiculturalism, aiming not to eliminate or segregate cultural diversity, but to create conditions in which different cultural groups and their members can live together, harmoniously within the same society.

It may be argued that, at the level of the general aims of multicultural policies, it is very difficult to maintain the distinction made earlier between normative multiculturalism and actual multicultural policies. Any policies, promoted by normative multiculturalists, would be multicultural policies, as the aim of these policies incorporates the very basic commitments of normative multiculturalism - those of the acknowledgement of the existence and acceptability of cultural diversity within society, and the need to find common rules for the peaceful co-living of different cultural groups and their members within society. Whereas this may be true with respect to the general rationale behind those policies promoted by the normative multiculturalists, I use the term multicultural policies in a slightly different and more specific manner, incorporating only those policies that are, in some relevant sense, culturally differentiated. That is, they are sensitive and reflective of people's cultural differences, taking these differences as legitimate reasons for altering the status quo or, in some cases,

\footnotetext{
${ }_{58}^{57}$ E.g. Glazer 1997

${ }^{58}$ The assimilationist approaches may thus be seen as having much in common with some forms of nationalism that emphasize the importance of national unity and unified national identity. Not all forms of nationalism, however, are assimilationist with respect to managing cultural diversity, as the existence, or even promotion, of cultural diversity can be seen as compatible with the preservation of united national identity. See e.g. Miller 1995; 2000; Kymlicka and Banting 2006.
} 
taking these differences as legitimating differentiated treatment of different people by virtue of their culture. ${ }^{59}$ These kinds of policies, in the literature on multiculturalism, have been referred to in a variety of ways - as cultural- or multicultural policies, minority-, differentiated-, group-differentiated-, cultural-, collective-, corporate-, group-, or membership rights - although none of these terms is totally subsuming of or identical to the others.

The minority- or differentiated rights ${ }^{60}$ incorporate a vast variety of rights, distinguished from one another both with respect to the structure as well as the content of such rights. As a preliminary

\footnotetext{
${ }^{59}$ A distinction between cultural policies and multicultural policies may help to explain this usage of the terms. In my usages, cultural policies refer to any of those policies that the normative theorists of multiculturalism have come to advocate in response to managing cultural diversity within society. The state's response of benign neglect, promoted by Chandran Kukathas, or the difference-blind approach of Brian Barry thus fall (in their application) within the realm of cultural policies, simply by virtue of being policies, advocated as appropriate responses to the state of cultural diversity. The affirmation of a general rule or the rejection of a minority right, in this usage of the term, are conceived as cultural policies just as much as are the alteration of the rule, or the granting of an exemption. The term multicultural policies, however, is reserved only to the latter kinds of policies, as in these cases, the taking into account of people's cultural differences has resulted into an active alteration of the status quo and, in the last example, into a granting of a differentiated right (e.g. exemption).

${ }^{60}$ In this work, I use the terms minority rights and differentiated rights interchangeably, although the scope of these rights is not, strictly speaking, identical. Whereas minority rights (perhaps the most commonly used term for multicultural policies in the above sense) are rights accorded to minority cultural groups or their members (and not others), differentiated rights could also be conceived as incorporating any rights the according of which was not universal (or based on citizenship), such as rights accorded to majority cultural groups or their members, rights of children, LGBT -rights etc. Within discussions on multiculturalism, however, differentiated rights can be seen as referring precisely to those rights that involve minority cultural groups and their members, and I will thus use these terms interchangeably. The group-aspect of these rights will be questioned in Part II.
} 
distinction, minority rights can be divided into membership rights and group rights proper depending on whom the right in question is accorded to and by whom it is exercised. ${ }^{61}$ The membership rights, such as the exemptions of turban wearing Sikhs from motor cycle helmet laws (UK) or dress codes of the Royal Canadian Mounted Police, are rights that are accorded to as well as exercised by individuals (members of a particular group), irrespective of the actions of the other right-holders or of the group as a whole. Group rights proper, on the other hand, are rights accorded to and exercised by the group as a collective, although the benefits of such rights may still be viewed in terms of the benefits the exercising of such right has for the individuals. ${ }^{62}$ Various forms of rights of selfgovernment for ethnic, cultural or national minorities, for example, are rights that are accorded to the group as a whole, and it is also the group as a collective (rather than its individual members) that is seen as exercising such right. Not all minority rights do, of course, fit neatly to the division between membership rights and group rights proper, ${ }^{63}$ although this distinction is important, as the

${ }^{61}$ For some classical distinctions within literature on multiculturalism, see Kymlicka 1995, ch. 2 and 3; Parekh 2000: 213-219; Barry 2001, ch. 4.

${ }^{62}$ It should be noted that there is substantive disagreement on whether the benefits of group rights proper can be accounted for with respect to the benefits for the individuals. One illuminating discussion on the kinds of interests that group rights proper are set to serve is given by Peter Jones, who makes a differentiation between so-called collective rights and corporate rights. Whereas the collective rights are dependent on the exercising of such rights by a group of individuals jointly, the interests they are set to serve can nevertheless be traced back to the serving of the interests of particular individuals. Corporate rights, on the contrary, can be seen as serving the interests of the group itself, independent of the interests of its individual members. (Jones, 1999) For a similar distinction between derivative and sui generis rights, see Parekh 2000, 213-219.

${ }^{63}$ For example, certain types of positive advantages, such as quotas or other forms of positive discrimination, may be viewed as group rights in the sense in which they are accorded to the group as a whole, but membership rights in the sense in which they are taken advantage of by individuals. These rights differ from individually exercised membership rights in so far as taking advantage of such a right may be inherently 
normative issues incorporated in any particular type of right depend heavily on the questions of who is seen to be the proper exerciser and/or beneficiary of such right.

The normative issues relevant for the assessment of any particular minority right are not, of course, defined simply by the structure of such rights as either membership or group rights, but involve variety of other considerations. For example, the nature of the group in question (e.g. cultural, religious, national, indigenous) may have an effect on whether the group (or its members) are entitled to differentiated treatment by the state. Different kinds of rights may also be seen as aiming to rectify different kinds of disadvantages (e.g. equality of opportunity, autonomy, recognition/self-respect), and the minority rights also vary with respect to the specific issue they are referring to (e.g. language, land, religion, representation). In the assessment of any particular minority right, it must also be kept in mind, what kinds of relations within society the right in question has an effect upon, some rights affecting mainly the relations between the state and the minority groups, others having a profound effect on the relations between the group and its own members. ${ }^{64}$ In order to highlight the heterogeneity of normative issues relevant for different kinds of minority rights, Jacob Levy gives an illuminating categorisation of minority or cultural rights, with each category incorporating slightly different normative considerations relevant for the assessments of such rights in practice:

dependent on the actions of other right holders, as the reference point of the right is the group as a whole rather than its individual members. For further discussion, see Barry 2001, ch. 4.1.

${ }^{64}$ Aylet Schachar has categorised the relations, relevant for any discussions on multiculturalism and minority rights into six types, those of (1) individual vs. individual, (2) individual vs. state, (3) identity group vs. identity group, (4) identity group vs. state, (5) non-member vs. identity group, and (6) individual group member vs. identity group. Shachar, 2001, 27. 
Figure 1: Jacob T. Levy's classification of cultural rights

\begin{tabular}{|l|l|}
\hline CATEGORY & EXAMPLES \\
\hline $\begin{array}{l}\text { Exemptions from laws which } \\
\text { penalize or burden cultural } \\
\text { practices }\end{array}$ & $\begin{array}{l}\text { Sikhs / motorcycle helmet laws, } \\
\text { Indians / peyote, hunting laws }\end{array}$ \\
\hline $\begin{array}{l}\text { Assistance to do those things the } \\
\text { majority can do unassisted }\end{array}$ & $\begin{array}{l}\text { Multilingual ballots, affirmative } \\
\text { action, funding ethnic associations }\end{array}$ \\
\hline $\begin{array}{l}\text { Self-government for ethnic, } \\
\text { cultural or 'national" minorities }\end{array}$ & $\begin{array}{l}\text { Secession (Slovenia), federal unit } \\
\text { (Catalonia), other polity (Puerto } \\
\text { Rico) }\end{array}$ \\
\hline $\begin{array}{l}\text { External rules restricting non- } \\
\text { members' liberty to protect } \\
\text { members' culture }\end{array}$ & $\begin{array}{l}\text { Quebec / restrictions on English } \\
\text { language, Indians / restrictions on } \\
\text { local whites voting }\end{array}$ \\
\hline $\begin{array}{l}\text { Internal rules for members' } \\
\text { conduct enforced by ostracism, } \\
\text { ex-communication }\end{array}$ & $\begin{array}{l}\text { Mennonite shunning, disowning } \\
\text { children who marry outside the } \\
\text { group }\end{array}$ \\
\hline $\begin{array}{l}\text { Recognition/enforcement of } \\
\text { traditional legal code by the } \\
\text { dominant legal system }\end{array}$ & $\begin{array}{l}\text { Aboriginal land rights, traditional or } \\
\text { group-specific family law }\end{array}$ \\
\hline $\begin{array}{l}\text { Representation of minorities in } \\
\text { government bodies, guaranteed } \\
\text { or facilitated }\end{array}$ & $\begin{array}{l}\text { Maori voting roll for Parliament, } \\
\text { U.S. black-majority Congressional } \\
\text { districts }\end{array}$ \\
\hline $\begin{array}{l}\text { Symbolic claims to acknowledge } \\
\text { the worth, status, or existence of } \\
\text { various groups }\end{array}$ & $\begin{array}{l}\text { Disputes over name of polity, } \\
\text { national holidays, teaching of history }\end{array}$ \\
\hline
\end{tabular}

Jacob Levy (1997): “Classifying Cultural Rights”, p. 25.

Regardless of whether Levy's classification is exhaustive, or whether some other classification could better be used to explain the variety of normative issues relevant for different types of minority rights ${ }^{65}$, Levy's categorisation brings nicely forth the

${ }^{65}$ For other classifications, some of which will be returned to later on in this work, see: Kymlicka 1995, ch. 2 and 3; Barry 2001, ch. 4; Jones 1999; Miller 2002a; see also: articles in Sistare, May and Francis 2001. 
heterogeneity of minority rights and their normative justification. For example, whereas the rights of self-government, external and internal rules as well as the recognition / enforcement of legal codes are often portrayed as rights that protect the cultural autonomy of the group in question, the exemptions, assistance, representation as well as symbolic claims may better be described as rights that aim to promote the civic equality and inclusion of minority members within society. ${ }^{66}$ The rights of self-government, external and internal rules can also be seen as affecting slightly different relations within society: the rights of self-government addressing (mainly) the state vs. group or group vs. group -relations, the external rules addressing the issues of group vs. non-members or members vs. non-members, and the internal rules involving the difficult questions of the relation between the group and its own members. Nor are the considerations relevant for an assessment of any particular right within any particular category necessarily the same, but may involve very different normative considerations, only assessable at the level of the particular right in question, and in the context within which this right is argued for.

For example, the exemption rights, characterized by Levy as "individually exercised negative liberties granted to members of a religious or cultural group whose practices are such that a generally and ostensibly neutral law would be a distinctive burden on them", ${ }^{67}$ incorporate various examples. As already mentioned, the turban wearing Sikhs in the UK have been exempted from motor cycle helmet laws, as have the Canadian Sikhs from certain aspects of the dress code of the Royal Canadian Mounted Police. The religious use of peyote by the American Indians has been exempted from the laws on narcotics and hallucinogens, and the Jews and Muslims may be exempted from humane slaughter laws in order to acquire meat that has been killed in accordance with their religious

\footnotetext{
${ }^{66}$ All of these rights (some more than others), may also be described in terms of promoting the self-esteem of minority groups or their members. See also: May, Moodod and Squires 2004, 4.

${ }^{67}$ Levy 1997, 25.
} 
requirements. In the United States, the old order Amish have (successfully) pursued a right not to send their children to school after a certain age, and in several places, the right to wear (or not to wear) a veil by Muslim females has caused extensive discussions, resulting both in the rigorous upholding of the rules (as in the French case of laïcité), as well as in exemptions from, for example, supermarket working uniforms (Norway).

Although there is clearly something similar in all of these cases (in order for them to be discussed under the heading of exemptions), the normative considerations, in each case, are slightly different. Although the right of the Amish not to send their children to school after a certain age can, in a certain sense, be viewed as an individually exercised negative liberty, it is substantially different from the other examples, as the one most affected by the exemption (child) is a different person from those to whom this right is granted (parents). In this sense, the right of the Amish pays some, albeit not very much, resemblance to the exemptions from humane slaughter laws or even the claims of the Sikhs or Roma to carry ceremonial daggers or knifes in public, as in these cases, those most affected (or potentially affected) by the exemption are others than the right holder herself. An altogether different case, however, is represented by the French case of laïcité and the contested right of Muslim girls to wear a veil in public schools. In Levy's formulation, the claims of the Muslim girls cannot be viewed as claims for exemption, because the principle of laïcité, far from being generally and ostensibly neutral, is directed precisely against the wearing of such religious symbols in the first place. At the level of what the law or the requirement is for, the exemptions on humane slaughter laws and the exemptions from laws on narcotics and hallucinogens pay some resemblance to the case of the French laïcité, as the aim of the law is, in these cases, to prevent precisely the practice (or some element of that practice) that one is seeking an exemption from. Moreover, it is clear that the "distinctive burden" referred to by Levy can be of several forms, as the burdens created by the requirements of a work place or educational institution are burdens relating to the basic (public) opportunities of individuals (such as 
education and employment), whereas the burdens created, for example, by humane slaughter laws or by motor cycle helmet regulations are burdens relating mainly to the pursuit of people's interests in private (such as the eating of religiously slaughtered meat or riding a motor bike). ${ }^{68}$

Whereas it is thus clear that any categorization, however specified, will incorporate a vast variety of cases, the assessment of which can only be done in context, it is, nevertheless, important to look for some commonalities, as well as general principles, through which these cases can be assessed. Although I do not claim that liberal political theory could provide any definitive guidance into how the liberal state should respond to cultural diversity in any particular case - in fact, that is one of the main claims of this work - I do, however, believe that political theorists and philosophers can provide some general frameworks within which the assessment of these cases can begin.

In this work, the distinctions between the individually exercised membership rights and collectively exercised group rights, as well as the distinctions between the kinds of relations that any particular right comes to regulate, play an important part, as these two axes, I believe, are particularly important for assessing the kinds of normative considerations that different kinds of differentiated rights incorporate. At the same time, the concentration on these two axes makes my discussions on cultural accommodation manageable

${ }^{68}$ Rather than taking exemptions as a singular category, one can thus distinguish at least between: (1) those exemptions that affect solely or mainly the person to whom the exemption is granted and those that's main effect is on others, (2) those exemptions that are sought from a law that is incidentally in conflict with the cultural practice in question and those that's aim is the prevention of the practice or some aspect of the practice, and (3) those exemptions that aim at giving people equal opportunities to participate in public life (such as employment and education) and those that influence people's private conduct. Levy's own categorization concentrates on the rationale of the law that the exemption is sought from, differentiating between laws that are aimed at the protection of children, rules that seek to protect outsiders or the environment, and moralistic or paternalistic rules that regulate the behaviour of adults. (Levy 1997, 28) 
without being reduced to an overtly simplified discussion on minority rights as a whole. Whereas I will defend the view according to which minority rights (variously construed) are compatible with liberalism, I will also show how the basic liberal commitments to the moral primacy of the individual, individual liberty, autonomy and equality create certain constraints both for the justifiability as well as for the applicability of these rights in practice. The exposition of these constraints, however, cannot be done without understanding the context within which the debates on liberal multiculturalism have been conducted, and the final section of this background chapter aims to shed some light on these contexts, as well as on the kinds of limitations of liberal multiculturalism that this book is primarily concerned with.

\section{Liberal multiculturalism and its limits}

The basic liberal commitments to the moral primacy of the individual, individual liberty, autonomy and equality, create certain constraints to any liberal theory of multiculturalism. These constraints may be interpreted in a variety of ways, depending on the kinds of policies (minority rights) that one is talking about, on one's understanding of culture and the value of culture, as well as on one's interpretations of the basic commitments of liberalism. Clearly, there are several liberal theories of multiculturalism (or liberal multiculturalism, broadly construed), and to give an uncontested answer to the question of what is liberal multiculturalism would, no doubt, be as difficult as giving an uncontested answer to the question of what is liberalism. Liberal multicultural theories have, however, been formed in certain contexts - both theoretical as well as political - and to understand some of the key debates and some of the difficulties in these debates one must keep these contexts in mind.

In this section, I start with some of the historical background of these discussions and also identify the framework(s) within which these discussions have taken place. In the first section (3.1.), I outline a threefold structure of debates on liberal multiculturalism, and point towards some of the difficulties of negotiating between 
these three levels of discussion. I then turn (sections 3.2. and 3.3.) to look at the kinds of limitations of liberal multiculturalism that I wish to point out to my reader, and that will also form the main substance of the remaining chapters of this work. These sections will also give a preliminary account of my own approach, that is, a more individuated yet culturally sensitive approach to cultural diversity, the details of which will need to be filled in the chapters to follow.

\subsection{Liberalism, liberal multiculturalism, and cultural policies}

In the early stages of debates, the theoretical discussions on multiculturalism were strongly connected to the liberalismcommunitarianism debate. ${ }^{69}$ Drawing from the communitarian critique of the antecedently fixed, disembedded and disembodied self, the early discussants on multiculturalism reflected extensively upon the questions on the social embeddedness and communality of individuals, and the implications that one's views on the (ir)reducibility of cultural groups to their individual members had on the justifiability of group or collective rights. As a default, most of the discussions of the 70's and 80's focused on the questions of collective rights (with minority groups as potential right-holders), with the more individual oriented thinkers normally rejecting such rights, and the more collective or communitarian thinkers arguing for the need of such rights in the face of the acknowledgement of the communality and cultural embeddedness of individuals. ${ }^{70}$

Whereas the questions about the nature of cultural groups, the social or cultural embeddedness of individuals and the justifiability of collectively exercised group rights still play important roles in the debates on normative multiculturalism, from the late eighties

\footnotetext{
${ }^{69}$ For an excellent overview of the liberalism-communitarianism -debate, see: Mulhall and Swift 1992. For a similar contextualisation of the early debates on multiculturalism within the framework of liberalismcommunitarianism debate, see: Kymlicka 2007b.

${ }^{70}$ For communitarian oriented accounts, see e.g. Van Dyke 1975; 1977, Johnston 1989; McDonald 1991; Addis 1992; for more individual centred accounts, e.g. Narveson 1991; Hartney 1991.
} 
onwards, there has been a notable shift in (as well as an upsurge of) debates on multiculturalism. No longer do the theorists of normative multiculturalism view cultural policies simply in terms of collective rights (group rights proper), nor does one's stand on the liberal-communitarian axis necessarily define one's stand on multicultural policies (variously construed). Rather, there have been several notable attempts to create a specifically liberal approach to multiculturalism, and many of the discussions on multiculturalism are nowadays constructed within the framework of liberalism (present work included). ${ }^{71}$

In his ground breaking work Liberalism, Community and Culture (1989), Will Kymlicka set the task of answering the question of whether the cultural claims of minority groups or their members could be reconciled with liberalism. As will be discussed in more detail especially in Ch. 1 and 2, Kymlicka's arguments were not always clear and addressed several different issues (the exposition of which was often wanting), but the general aim of Kymlicka's work was, nevertheless, obvious. That is, the reconciliation of cultural claims and multicultural policies (minority rights) with liberalism. As is well known, Kymlicka's answers to the question of the compatibility of cultural claims and liberalism were rather robust. According to Kymlicka, culture (or cultural membership) was, within the traditional liberal frameworks such as Rawls's and Dworkin's, one of the primary goods that the liberal state ought to protect, and the minority rights (variously construed) were not only compatible with liberalism, but in fact required by the liberal principles of justice. ${ }^{72}$

\footnotetext{
${ }^{71}$ Perhaps the most prominent, self-confessedly liberal approaches to multiculturalism that will also be discussed in this work include those of Will Kymlicka (esp. 1989; 1995; 2001), Chandran Kukathas (esp. 2003) and Brian Barry (esp. 2001). For alternative liberal approaches, see: Raz 1994; 1998; Tamir 1993; Spinner-Halev 1994, 2000, Carens 2000. Many feminist approaches to multiculturalism can also be seen as located broadly within the liberal framework, e.g. Okin 1999; 2005; Benhabib 2002; 2004; Shachar 2001; Song 2007; Phillips 2007; 2010.

${ }^{72}$ Kymlicka 1989, esp. ch. 8 and 9.
} 
The influence of Kymlicka's work ${ }^{73}$ for later discussions on multiculturalism cannot be overestimated. Not only have people used Kymlicka's framework to argue for a variety of minority rights in different contexts, but the alternative liberal theories of multiculturalism have also posited themselves in relation, and in opposition, to Kymlicka's. Furthermore, and perhaps more problematically, the initial questions of Kymlicka - those of the reconciliation of cultural claims and multicultural policies with liberalism - were widely adopted. Much of the subsequent theoretical discussion on multiculturalism has operated precisely at the level of trying to justify (or reject) the taking into account of cultural claims at the level of liberal policies and the possibly, although by no means necessarily, resulting differentiated rights. Many liberal multiculturalists, again in the footsteps of Kymlicka, also wish their normative theories to be applicable in practise, giving guidance to the ways in which the liberal state should respond to cultural diversity. The following figure illustrates this threefold structure of debate on liberal multiculturalism, including the basic questions of Liberalism (Theory 1), questions of Liberal Multiculturalism (Theory 2 / Application 1), actual state responses (Application 2), and their relations to one another:

Figure 2: Three-fold structure of debates on liberal multiculturalism ${ }^{74}$

\footnotetext{
${ }_{73}^{73}$ Esp. Kymlicka 1989; 1995.

${ }^{74}$ It may be contested whether the two parts of "Theory" in the structure (Liberalism and Liberal Multiculturalism) are, in fact, distinct or whether liberal multiculturalism should rather be seen as an extension of liberalism (for an argument against the distinctiveness of liberal multicultural theory, see Barry 2001; Colburn 2010). Whereas I believe that liberal multiculturalism does, and rightly so, fall within the broader framework of liberalism, for explanatory purposes, these two levels of discussion are kept separated.
} 


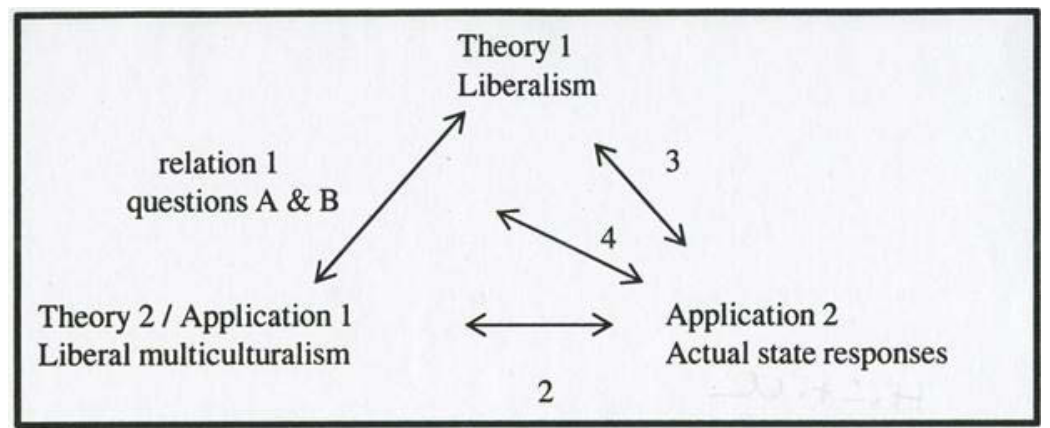

Not surprisingly, given Kymlicka's initial framing of the debate, most theoretical discussions on liberal multiculturalism have been operating precisely within and between the frameworks of Theory 1 (liberalism) and Theory 2 / Application 1 (liberal multiculturalism). The key questions, located in this area (relation 1), however, may be very different questions to those of the actual responses of the liberal state (application 2) and the relations within which these responses should stand to liberal multicultural theories (relation 2), the basic tenets of liberalism (relation 3), or the initial questions themselves (relation 4). As already indicated, the two questions that Kymlicka set out to answer were questions about the role of cultural claims (A) and differentiated rights (B) within liberalism. These two questions, however, are very different and the answer to one need not determine the answer to the other. The first question, properly understood, is a question about the rationale that the liberal state may have for including culture (variously construed) among those considerations that need to be taken into account in state policies. As I will argue, liberal multiculturalists have been successful in showing that there are, indeed, good reasons for the liberal state to take cultural considerations into account, and that the cultural disadvantages, faced by minority members, should also be proper concerns of the liberal state.

The second question of the justifiability of culturally differentiated rights within liberalism is, however, a very different question to that of the rationale for the liberal state to take cultural 
considerations into account. Surely, in order to argue for the compatibility of culturally differentiated rights and liberalism, one also needs to give an affirmative answer to the question of whether cultural considerations should be taken into account by the liberal state, but an affirmative answer to this question (A) need not entail affirmative answer to the latter (B). It is perfectly possible for one to agree that the liberal state should take cultural considerations into account in public policies, yet reject the claim that culturally differentiated rights (or some of them) would be consistent with the basic principles of liberalism. In this work, I argue that liberal multiculturalists have been successful in showing that culturally differentiated rights are not, inherently, in conflict with the basic liberal commitments to individual freedom, autonomy and equality, although I also argue that this compatibility of culturally differentiated rights with liberalism leads not to the view, promoted by Kymlicka, that such rights would also be required by the liberal principles of justice.

Why this is so, should already be apparent from the initial framing of the debates and from the fact that neither of the initial questions (A or B) are addressing the question of how the liberal state should respond to cultural diversity, but rather questions located within the theoretical framework of liberalism itself. When thinking about the actual state responses, several other considerations need to be borne in mind. Even if there were no inherent inconsistency with, for example, collectively exercised group rights for certain levels of self-determination (for example, an aboriginal group's right for territorial autonomy, or the right of a religious group to enforce its own family jurisdiction) with liberalism, this does not, as yet, lead to the view according to which the liberal state should also respond to cultural claims by granting such rights. As has been noted especially by many feminists, these rights may potentially be used against individuals, and the adequate response of the liberal state may well depend on whether these rights are also conjoined with other measures, protecting the basic 
Background

rights of individuals. ${ }^{75}$ Nor is it always the case that differentiated rights (variously construed) would be the only, let alone the best, responses to cultural diversity, especially in cases where the disadvantage that the particular right is aiming to rectify can also be rectified by other means. ${ }^{76}$

Moreover, as will be argued in the forthcoming chapters, the questions about the actual granting of differentiated rights (whether individually exercised membership rights or group rights proper) involve not only questions about the rationale and justifiability of such rights, but also questions about the allocation of such rights. That is, questions about who, and on what grounds, should be eligible for such rights (individually exercised membership rights), or who, and on what grounds, should fall within the scope of the right in question (collectively exercised group rights proper). These questions about the allocation of differentiated rights have, to a large extent, been ignored by the liberal theorists of multiculturalism, and one of the main contributions of this work is to bring these issues into a better focus. As will be argued, especially in Part II of this book, the common assumptions about the differentiated rights as being specifically group-differentiated rights may not stand up to closer scrutiny, as there may not be any uncontested way of defining where the borders of the group stand, or who should be considered as a member of any particular group.

\footnotetext{
${ }^{75}$ One of the minimal safe-guards, that of the right of exit, and its possible inadequacies will be discussed in chapters 2 and 5 .

${ }^{76}$ In Ch. 3 I discuss the so-called rule and exemption -approach that has often been argued for in cases where the cultural or religious practices of a minority collide with the general rules and norms of a majority, thus creating disadvantage to those engaging in such practices. Whereas I will defend the rationale behind the rule and exemption -approach, my intention is not to say that this approach should, as a default, be used to rectify such disadvantages. Nor do I, however, suggest that an alternative approach, such as the changing of the general rule, should always be adopted, but that within the liberal multicultural framework, there is a substantive amount of scope for the liberal state to respond to such cases in a variety of ways (incl. differentiated rights), and that the reasons for- as well as against- any particular policy need to be assessed in context.
} 
In the issues of allocation, it will be argued, the basic liberal commitments to the moral primacy of the individual and to individual freedom and autonomy should be brought back to the forefront, creating a more individuated, yet culturally sensitive approach to allocating differentiated rights in practice.

\subsection{Limits of consistency}

The predominantly individuated, yet culturally sensitive, approach developed in this book builds upon two distinct, although partially related, arguments about the kinds of constraints that contemporary debates on liberal multiculturalism are seen to suffer. Especially Part I (Ch. 1, 2 and 3) concentrates on the kinds of difficulties that the so-called grand theories of multiculturalism are faced with due to them prioritising a particular liberal value, and due to them attempting to create comprehensive liberal multicultural theories based on their chosen value. These theories, as will be seen, are not only attempts to answer the initial questions about the compatibility of cultural claims or differentiated rights with liberalism, but also attempts to give normative guidance to the kinds of responses that the liberal state, faced with issues of cultural diversity, should adopt.

In broad outlines, the liberal approaches to multiculturalism can be divided into autonomy-based, toleration-based and equalitybased approaches to accommodating people's cultural differences within a liberal society. ${ }^{77}$ The distinctions between these three categories are not, however, always clear cut, and the arguments from autonomy, toleration (derived from freedom of association) and equality have also been used in conjunction with one another,

77 The most prominent autonomy-based account is that of Will Kymlicka's, although Kymlicka's account can also be seen as an equalitybased approach to cultural diversity (a rather different equality-based approach by Brian Barry will be discussed in Ch. 3). The toleration-based accounts of Chandran Kukathas and William Galston will be discussed in Ch. 2. 
depending on the normative issues at hand. ${ }^{78}$ The usage of different kinds of arguments for (or against) multicultural policies should not, of course, come as a surprise, as the normative issues relevant with respect to any particular policy may differ, and the rationale for the liberal state to take cultural considerations into account should not be based on the prioritisation of any one particular liberal value, but on a combination of these. ${ }^{79}$ Not all grand theorists of multiculturalism recognize this, and one of the aims of Part I is to show some of the theoretical difficulties that an overt emphasis on a particular liberal value brings to the undoubtedly complex and diverse discussions on multiculturalism.

The difficulties, encountered by the grand theorists of multiculturalism, stem partially from the already mentioned

\footnotetext{
${ }^{78}$ For example, Will Kymlicka uses both arguments from autonomy and arguments from equality in building his case, both for the rationale for the liberal state to be concerned about cultural disadvantages as well as for differentiated rights. (These arguments will be discussed in Ch. 1 and 2) Perhaps more surprisingly, Chandran Kukathas's toleration based argument also incorporates elements from the autonomy approach, or so I try to argue in Ch. 2.

${ }^{79}$ As already indicated (1.2.) different liberal values may pull in different directions, and some balancing act between the key values of individual freedom, autonomy and equality must be made. This, however, does not necessarily mean that any of these values could, in all cases, trump the others, but, depending on the issue at hand, the balancing act may well turn out differently. Regardless of whether one comes to prioritise one or another liberal value at the centre of any particular cases (for example, whether one comes to prioritize individual autonomy over toleration in one's assessment of particular rights of illiberal groups, or whether one's main focus is on questions of equality in discussions on cultural exemptions), this needs not entail that the centrality and primacy of that particular value would extend to all cases of cultural accommodation. Nor does one's emphasis on, say, freedom of association make the claims based on individual autonomy or equality fully redundant, as these are considerations that any liberal theory needs to take seriously. Whereas it may be an open question how to negotiate between the (possibly) conflicting values of individual freedom, autonomy and equality in particular cases, these values, nevertheless, must occupy a central place in the negotiations, and cannot be fully ignored.
} 
structure of debates, including the different levels of debate outlined above (3.1., Figure 2.) As already suggested, most of the discussions on liberal multiculturalism have been conducted within the theoretical framework of liberalism, aiming to address two questions that, although interlinked, are nevertheless analytically separate: that of the rationale for the liberal state to take cultural considerations into account (A), and that of the compatibility of differentiated rights with the basic tenets of liberalism (B). Besides these questions, however, liberal multiculturalists have also tried to tie their theories into concrete political practice, aiming to give guidance to the ways in which liberal states should respond to cultural diversity (C). Unfortunately, as will be seen during the course of this work, there has been a tendency to conflate these three questions, and to presume an inherent linkage between the answers to the questions of rationale (A), compatibility (B), and actual policies (C). The linkages between these three questions, however, are far from straight forward and, as I will show, the scope of the arguments, given by the grand theorists of liberal multiculturalism, do not extend to the final questions about the actual policies that the liberal state should adopt. Whereas I argue that the autonomy-based, toleration-based and equality-based approaches have provided slightly different frameworks from which to address the questions of rationale (A) and compatibility (B), I also show that the grand theories remain, and also should remain, relatively silent about the final questions concerning the adoption (or rejection) of differentiated rights in practice. Whereas I argue (at times in opposition to the theorists themselves) that the autonomy, toleration and equality based approaches all give good reasons to answer in the affirmative to questions A and B, I also argue that they fail to give any definitive guidance on how the liberal state should respond to cultural diversity in practice (C). Rather, the grand theories of multiculturalism leave substantive scope for variation in the legitimate state responses to cultural diversity, including the possibility (although not a requirement) for a variety of differentiated rights to be applied. 
Background

\subsection{Limits of application}

Provided that the grand theories of liberal multiculturalism leave open the possibility (albeit not a requirement) to apply culturally differentiated rights in practice, but fail to give any definitive guidance into this application, the question remains: according to which principles should culturally differentiated rights (variously construed) be applied? Following Joseph Carens and his emphasis on taking into account the concrete circumstances and specificities of different cases in constructing the principles of multicultural accommodation, I too believe that many of the questions relating to the concrete application of minority rights (or any minority right in particular) can only be solved in specific contexts. ${ }^{80}$ This, I believe, should already be clear from the plurality of differentiated rights and the heterogeneity of the normative considerations relevant for each type of right (see also 2.3. above). Rather than concentrating on specific types of rights - be they defined by the content of such rights (e.g. language, land, religion), the holders of such rights (individuals, groups), the form of such rights (e.g. exemptions, assistance, self-determination), or by the specific circumstances of a specific political community - in this work, my focus is on one of the often ignored aspects of application, that of the allocation of different kinds of culturally differentiated rights in practice. This question of allocation, it should be emphasized, is a very specific sub-category of the questions of application, addressing issues of scope rather than issues commonly conceived as relevant to the initial granting of such rights in practice.

\footnotetext{
${ }^{80}$ See: Carens 2000; 2004. It should be noted that the contextual approach, adopted by Carens may not be anything particularly new to political philosophy (for discussions, see e.g. Kukathas 2004), and the grand theorists of multiculturalism discussed in Part I all utilize several concrete examples in constructing and assessing their theories. Carens's work is, however, a particularly systematic attempt to narrow the gap between abstract political theory and concrete political practice and, as such, deserves proper acknowledgement.
} 
The difference between these two questions of application (questions of scope and questions of granting such rights) may be outlined as follows: on the one hand, it may be asked, in which circumstances, and according to which principles, should the liberal state grant differentiated rights (or any particular differentiated right) to cultural groups or their members. Whereas the liberal principles of individual freedom, autonomy and equality do not, as such, overrule minority rights as legitimate ways for the liberal state to respond to cultural diversity, in certain circumstances there may be good reasons not to implement such rights in practice. For example, the answer to the question of whether to grant an exemption to a particular group or group members in order to alleviate the burdens that their specific cultural or religious practices are seen to cause may depend on several factors, such as the centrality of the practice itself, the legitimacy and the purpose of the rule from which the exemption is sought from, the area of conduct that the rule is governing, etc. - all considerations that can only be properly assessed in context. ${ }^{81}$ On the other hand, however, it may also be asked, to whom, and according to which principles, should the right in question be granted (individually exercised membership rights), or who should come under the influence of such rights (collectively exercised group rights proper). These questions of allocation are not, as such, questions about whether a particular right should, or should not, be implemented, but questions about the relevant scope of these rights.

An objection could be raised that this question of allocation makes no sense unless combined with some principles that guide the actual granting of differentiated rights in the first place (that is, the principles defining those instances in which the liberal state should adopt some particular culturally differentiated rights to be implemented). To an extent, this is true, as the appropriate ways of allocating differentiated rights may well depend on those circumstances in which these rights are granted, and the principles

${ }^{81}$ Some of these issues, relevant for the rule and exemption approach, will be discussed in Ch. 3 . 
for granting such rights may well depend on the proper scope of such rights. Whereas I will also discuss some of the issues relating to the relation between the justifiability of granting a particular minority right and its application, for the most part, my intention is simply to look for those guidelines that, from the liberal standpoint, should guide the actual allocation, or the scope of differentiated rights in practice. Whereas the constructing of such guidelines may well end up being partial, rather general, and certainly need to be more specified in specific contexts, I also believe that there is a pressing need to construct such guidelines in order for liberal multicultural theory to be more applicable in practice. This need is especially acute as many western liberal democracies have, in effect, adopted some systems of minority rights (regardless of whether they should or should not have done so), and the effects of such rights are very real, affecting the lives of both those coming under the direct influence of such rights (the right bearers) as well as others.

The main argument, put forward especially in Part II of this book (Ch. 4, 5 and 6) is that, in questions of allocation, the basic liberal commitment to the primacy of the individual should be put back to the forefront. As already mentioned, culturally differentiated rights have, traditionally, been considered as groupdifferentiated rights, either in the sense in which the right is granted to a particular cultural or religious group as a collective, or in the sense in which the right is granted to an individual by virtue of her membership in this group. The allocation of differentiated rights along group boundaries or on the basis of group memberships, however, is far more problematic than would at first seem. As will be discussed especially in Ch. 4, there is no uncontested way of defining where the borders of any particular group should lie, or who should be considered as a member. In the face of this indeterminacy, I argue, the liberal state should adopt a more individuated approach to allocating culturally differentiated rights, not on the basis of one's group membership, but on the basis of individual needs and individual self-identifications. 
The questions of what the individual needs or individual selfidentifications precisely refer to, and how they are to be assessed, are of course difficult questions, and cannot be answered without some reference to the actual rationales of the differentiated rights and the justificatory framework within which these rights are argued for. The liberal frameworks discussed in Part I thus provide important starting points for a specifically liberal approach to allocating differentiated rights, by showing how culture (variously construed) can create certain kinds of disadvantages, ${ }^{82}$ and how differentiated rights (variously construed) can operate as rectifying these disadvantages. These rationales, combined with the specific contents of differentiated rights ${ }^{83}$ should, however, be in line with those to whom the right in question is allocated, and, more often than not, those falling within the proper scope of any particular right transcend the commonly ascribed group boundaries and group memberships. As will be argued during the course of this work, the discrepancies both in one's views on the contents of culture as well as in one's views of cultural membership, cast some serious doubt on whether culturally differentiated rights, granted on the basis of group membership, really manage to adequately track those whose disadvantages the rights are aiming to rectify. A more individuated approach, on the contrary, would seem to have the benefit of better tracking the proper beneficiaries of such rights, denying the inherent linkage between the kind of disadvantage that the right in question is aiming to rectify and one's commonly ascribed membership in a particular cultural or religious group.

The specifics of this individuated, yet culturally sensitive approach to allocating different types of differentiated rights need

\footnotetext{
${ }^{82}$ These disadvantages may be of several kinds. For example, people may be disadvantaged by the lack of access to a familiar cultural context, by the incompatibility of particular cultural practices and general rules of society, but they may also be disadvantaged by the lack of recognition, or affirmation of their cultural identities. The questions of state recognition, as related to group memberships, will be discussed in more detail in Ch. 5 . ${ }^{83}$ The necessity of differentiated rights as promoting certain cultural contents will be discussed especially in Ch. 1, 4 and 5 .
} 
to, of course, be discussed in more detail, and Part II of this book is dedicated to doing this. Whereas this part by no means gives a comprehensive account of the ways in which the individuated approach alters the traditional ways of allocating differentiated rights in a variety of circumstances, it does, nevertheless, point out to some important implications that a more individuated approach to cultural diversity would have at the level of actual multicultural policies. This focus on the issues of allocation and the implications of the individuated approach to actual multicultural policies, I believe, is not only important in order for the variety of differentiated rights to better track their targets, but also for liberal multicultural theory. Whereas the liberal multiculturalists have been extremely concerned with the questions of justifying different types of differentiated rights, and have attempted (even if unsuccessfully) to guide the kinds of policies that the liberal states should adopt, they have seemed to largely ignore the fact that the final justification of any particular policy depends also on the scope of this policy - that is, on the questions of who, precisely, comes under the policy in question. As will be argued in this work, a distinctively liberal approach to cultural diversity needs to take this question of scope seriously, not only in order to be a good liberal theory, but also in order to be better applicable in practice. 


\section{PART I \\ Justifying Minority Rights: the grand theories and their constraints}

Broadly construed, liberal multicultural theories can be divided into autonomy-based, toleration-based and equality-based approaches to cultural diversity. The autonomy-based approaches emphasize individual autonomy as one of the key values of liberalism, and also argue for the need of the liberal state to protect and/or promote individual autonomy through state policies and public institutions. Autonomy-based arguments have been used in support of both collectively as well as individually exercised differentiated rights, but they have also been used to indicate certain limitations to these rights: the right of a cultural or religious group to conduct its internal affairs, for example, cannot be used to suppress individual autonomy, but is conditional upon a framework within which individuals are both free as well as capable of leading autonomous lives, including being free and capable of rejecting the rules and norms imposed on them by their own cultural or religious groups.

The toleration-based approaches tend to reject the centrality of individual autonomy within liberalism and the role of the liberal state in protecting and/or promoting individual autonomy. The toleration-based approaches highlight the freedom of individuals to associate (and to disassociate) in whatever ways they wish, including ways that suppress individual autonomy, and argue for a requirement of the different cultural or religious groups to tolerate that is, to not interfere with - the affairs of another. The tolerationbased arguments can be used both in support of as well as against a variety of differentiated rights, although most prominently, the toleration-based approaches have been associated with the rigid rejection of both the liberal state's role in promoting individual autonomy as well as its role in accommodating minority cultural groups with the help of differentiated rights. 


\section{Part I Justifying Minority Rights}

The equality-based approaches, unsurprisingly, start from the presupposition that the liberal state should treat all of its members with equal concern and respect. The equal treatment of different people may, however, sometimes mean differentiated treatment, and the equality based arguments have been used to argue for a need to grant cultural groups and their members differentiated rights on the basis of considerations of equality. The equality-based arguments may, however, also be used in opposition to differentiated rights, for example in cases where a differentiated right is seen to disadvantage certain members of groups (for example, when a group's right to govern its internal affairs is used to discriminate against some of its own members), or in cases where the differentiated right would undermine the rationale for a universal rule (for example, in cases where an exemption is sought from rules that, for good reasons, are upheld for everyone).

Clearly, the autonomy-based, toleration-based and equalitybased arguments can be used to different effects and, as will become clear later on, the distinctions between these three approaches are far from clear cut. On the contrary, most theorists of multiculturalism utilize autonomy, toleration and equality arguments conjointly, and one's emphasis on one type of argument rather than another may well depend on the specific issue at hand. The autonomy-, toleration- and equality-based approaches do, however, provide slightly different grounds upon which to begin assessing the difficult issues of liberal multiculturalism, including the rationale for the liberal state to take cultural considerations into account (A), the compatibility of differentiated rights with liberalism (B), and the state policies of cultural accommodation (C).

In this part, I look at the so-called grand theories of multiculturalism (broadly labelled under the autonomy, toleration and equality -approaches) ${ }^{84}$ and assess the ways in which these

\footnotetext{
${ }^{84}$ The so-called grand theories include those of Will Kymlicka (Ch. 1 \& 2), Chandran Kukathas (Ch. 2) and Brian Barry (Ch. 3). I call these theories "grand theories", as each of the authors aim at building fairly comprehensive accounts of how to justify (or not justify) culturally
} 
grand theories are capable (or incapable) of answering the questions of rationale (A), compatibility (B) and state policies (C). In the course of doing so, I build a strong case, based on the basic liberal commitments to individual freedom, autonomy and equality, for the liberal state to be concerned about people's cultural disadvantages and to aim at rectifying these disadvantages, possibly - albeit not necessarily - with the help of different kinds of minority rights.

The kinds of cultural disadvantages, faced by minority groups and their members are of various kinds, and one of the purposes of this part is to shed some light on the kinds of cultural disadvantages that can be conceived of as proper concerns of the liberal state. This part also assesses the scope of the arguments put forth both in defence, as well as in opposition to, differentiated rights, showing how the arguments for rationale (A) have often been conflated with the arguments for state policies (C). For the benefit of the second part of this work (Part II: Liberal multiculturalism and minority rights in practice) this part identifies some of the internal inconsistencies in the works of the so-called grand theorists, that are partially due to their overt emphasis on a particular liberal value (be it autonomy, freedom of association or equality), partially due to the conflating of the three questions of rationale (A), compatibility (B) and state policies (C). Whereas I argue (sometimes contrary to the theorists themselves) that the grand theories of liberal multiculturalism do provide strong cases for the liberal state to be concerned about and to try to rectify people's cultural disadvantages, I also show that they remain relatively silent about those specific policies that the liberal state should adopt, leaving considerable scope in the legitimate variation of the ways in which

differentiated rights within liberalism and how the liberal state should respond to cultural diversity. Each of these positions have also prompted extensive discussions in their own right (some of which will also be commented upon in due course). To an extent, this part can also be read as a historical overview of the debates on liberal multiculturalism, starting from the classical debates on "minority rights" (as a bulk), proceeding to the more recent, specified and critical approaches to accommodating people's cultural differences in liberal societies. 
Part I Justifying Minority Rights

the liberal state can respond to cultural diversity in practice. Contrary to providing conclusive guidance to the liberal state in issues on cultural diversity, I argue that the grand theories of multiculturalism should rather be viewed as providing frameworks within which different cases - no doubt to be assessed in context can be discussed.

As the discussions on liberal multiculturalism cannot ignore the tremendous influence of Will Kymlicka's ground breaking work, I, too, begin by assessing some of the benefits and weaknesses of Kymlicka's account. In the first chapter, Kymlicka's liberal multiculturalism, I focus especially on Kymlicka's luck-egalitarian defence of minority rights before (in Ch. 2) turning to his autonomy based commitments and to the so-called diversity-liberal critique of autonomy liberalism. In chapter 3, Liberal egalitarianism and equality of opportunity, I return to the egalitarian standpoint (now specified in the context of individually exercised membership rights) to complement my argument for the different kinds of rationales that the grand theories of liberal multiculturalism provide for the liberal state to be concerned about and to try to rectify cultural disadvantages, without, however, providing conclusive guidance on the kinds of policies that the liberal state should adopt. 


\section{Chapter 1}

\section{Kymlicka's liberal multiculturalism}

Kymlicka's argument for minority rights ${ }^{85}$ within the liberal framework incorporates several elements. Firstly, Kymlicka is committed to the view according to which the liberal state should stay neutral with respect to people's conceptions of the good. That is, the liberal state should not base its policies on an assessment of the value of people's ways of living, but allow, as far as possible, people to decide for themselves what they see valuable in life and to pursue whatever conceptions of the good they may have. Secondly, Kymlicka is committed to the value of individual autonomy, and the role of the state in catering for autonomy. According to Kymlicka, people can, and they also do, sometimes revise or even reject their current conceptions of the good, and the liberal state should provide for conditions in which people are able to do so. Thirdly, Kymlicka holds that the liberal state should be committed to treating people equally, and that this requires the state to rectify those inequalities that people are not themselves responsible for. That is, the liberal state should rectify those inequalities that result, not from the choices that people make, but from their unchosen circumstances.

\footnotetext{
${ }^{85}$ The term "minority rights", in Kymlicka's work, is used as a short hand for a variety of culturally or religiously based group-differentiated rights. Minority or group-differentiated rights incorporate both the individually exercised freedoms of group members (membership rights), as well as rights exercised by a collective (group rights proper). They may also include measures that work for the benefit of a minority, but that are not, as such, exercised by the group or its members (e.g. symbolic recognition). What is distinctive about minority rights, in Kymlicka's framework, is that they are, in some relevant sense, group-differentiated: they go beyond the common rights of citizenship by treating people differently due to their different cultural or religious backgrounds. See e.g. Kymlicka 1989, 138140; 1995, ch. 2; 2001, 42; for further distinctions, see Background 2.3.
} 


\section{Part I Justifying Minority Rights}

Kymlicka's commitments to 1) neutrality of the state, 2) value of individual autonomy and 3) luck-egalitarianism, however, say nothing, as yet, about cultural groups or the need of the liberal state to respond to cultural diversity by granting minority rights to these groups or their members. Thus, Kymlicka complements his account with two further commitments. Fourthly, Kymlicka views cultures as contexts of choice. That is, he views cultures as frameworks within which people can access a variety of options provided by culture and make meaningful choices among them. Fifthly, Kymlicka sees one's cultural membership as unchosen. That is, he sees one's cultural membership as the kind of circumstance that, should this membership create disadvantage, the liberal state should aim to rectify this disadvantage. With these five commitments in place, Kymlicka constructs his liberal argument for minority rights.

As Kymlicka's argument incorporates several moves between these five elements, it is worth looking in more detail, how his argument is constructed and what kinds of (extra) background commitments Kymlicka builds into his account. As Kymlicka's argument is predominantly a liberal egalitarian argument for minority rights, my starting point is in Kymlicka's concerns on equality and the ways in which his other commitments build into his egalitarian framework. (I will return to Kymlicka's views on individual autonomy in more detail in ch 2) In this chapter, I argue that the egalitarian framework, promoted by Kymlicka, is both capable of explaining the kinds of inequalities faced by minority members as well as of giving reasons for why the liberal state should be concerned about and try to rectify these inequalities. It is not, however, capable of providing any conclusive case for the need of minority rights, but is rather suggestive of extreme caution with respect to the application of different types of minority rights in practice. This, I argue, has to do with the nature of minority rights as always promoting certain conceptions and contents of culture, as well as with certain problems of these rights to perform the tasks they are set to perform.

This chapter proceeds as follows. In the first part, Equality for minority members, I outline Kymlicka's luck-egalitarian position 
and identify three distinct arguments that Kymlicka uses for positing the base line of equality at the point in which people can live their lives in their own cultural contexts (1.1.). I then (1.2.) assess the scope of these arguments with respect to the kinds of disadvantages identifiable within Kymlicka's framework, and with respect to the rationales for the liberal state to be concerned about these disadvantages. In the second part, Minority rights and the limitations of Kymllicka's framework, I turn to some of the difficulties of applying the luck-egalitarian framework at the level of state policies. In section 2.1. I give a brief typology of minority rights before turning into two main difficulties inherent in Kymlicka's account. Section 2.2. focuses on the problematic relationship between minority rights and cultural contents, section 2.3. on the ways in which minority rights can (or cannot) be seen as protecting people's memberships. Both of these difficulties, I argue, suggest a far more cautious approach to the application of minority rights in practice without nullifying the rationales that the liberal state has for being concerned about and aiming to rectify people's cultural disadvantages.

\section{Equality for minority members}

Kymlicka's equality based argument for the liberal state to grant differentiated rights to minority groups or their members takes approximately the following form. As the liberal state (indeed any state) is necessarily organized in accordance with particular cultural norms and practices ${ }^{86}$ this puts members of other cultures in a disadvantaged position to that of the majority. Whereas the members of the dominant culture - the majority - have an automatic access to their own culture and are able to live in accordance with their own cultural norms and practices, the members of the minority are not. To the contrary, the minority members are faced with a stark choice of either abandoning their

${ }^{86}$ For example, official languages, public holidays, national symbols, education curriculums are always reflective of certain culture(s), normally the culture of the majority. e.g. Kymlicka 1995, 108; 2001, 80. 
Part I Justifying Minority Rights

own cultural framework or spending vast amounts of resources to maintain it - something that the majority is getting for free. According to Kymlicka, this disadvantage is the kind of disadvantage that the liberal state should be concerned about, thus creating a case for minority rights within the liberal framework.

Kymlicka's argument for the state to be concerned about and to try to rectify the disadvantage faced by the minority members is strongly based on a Dworkinian model of equality of resources. ${ }^{87}$ According to Dworkin, people should be held responsible for their choices, but they should not suffer (or gain) from their unchosen circumstances, including their inborn disabilities, low talents, or misfortunes caused by bad brute luck. In order to eliminate the inequalities that people could not be held responsible for, Dworkin developed a model according to which to distribute resources that people could then use to their own liking. The Dworkinian model (based on hypothetical auction and the envy test) incorporated two elements. Firstly, the equal distribution of the initial resources of individuals (which they are (bearing the consequences) free to use as well or as badly as they see fit), and secondly, the continuous compensation of those who, to no fault of their own, cannot make the best (or as good as others) of the initial resources given. ${ }^{88}$

Whereas Kymlicka's account is a pronouncedly 'resourcist' account of equality, based on the Dworkinian conception of equality of resources, there are certain modifications that Kymlicka introduces to the Dworkinian model. According to Kymlicka, it is not that the members of minority cultures would be disadvantaged due to them having fewer initial resources (although this might also be the case), or because they are not able to make as good a use of their resources (although this might, too, be the case), ${ }^{89}$ but they are

\footnotetext{
${ }^{87}$ Dworkin 1981 b.

${ }^{88}$ Dworkin 1981b; for alternative views on the currency of egalitarian justice, see: Dworkin 1981a; Arneson 1989; Cohen 1989; Sen 1980; Nussbaum 1988; for critiques of the luck-egalitarian position, see e.g. Anderson 1999; Wolff 1998; Scheffler 2003.

${ }^{89}$ Kymlicka does point towards the idea that the members of minority cultures cannot necessarily pursue their chosen ways of life as
} 
disadvantaged due to them lacking the familiar cultural context in which these resources could be utilized. Whereas people should, pace Kymlicka and Dworkin, be held responsible for and pay the price of their own choices, they should not be held responsible for lacking the actual context in which these choices (to be responsible for) could be made. For Kymlicka, unlike Dworkin, it is not only the equality of resources that matters, but also the context within which these resources can be utilized. ${ }^{90}$

Although Kymlicka's further claim (not of inequality of initial resources in the Dworkinian sense, but of inequality of being able to utilize one's resources in one's own cultural context) would seem to go beyond the Dworkinian conception of equality of resources, ${ }^{91}$ Kymlicka, nevertheless, attempts to back this further claim up within the framework of the Dworkinian model. According to Kymlicka, the existence of just one prominent cultural framework (that of the majority) creates a situation in which the members of minority cultures will have to use vast amounts of their resources for the maintenance of their own cultural framework. Even if they were able to do this (that is, preserve their own cultural framework by directing part of their bundle of resources into this maintenance), this would cut down the amount of resources that they have available for leading their lives - thus putting them in a disadvantaged position to that of the majority (who still have their whole bundle of resources to be utilized). This, according to Kymlicka, is the point at which the equality of resources should be

"efficiently" as the members of the majority, should they be forced to do so in an alien cultural framework. See e.g. Kymlicka 1989, 176.

${ }^{90}$ Kymlicka 1989, 188-189.

${ }^{91}$ Kymlicka is careful to note that, in accordance with the Dworkinian model, the members of minority cultures might well be happy with their bundle of resources, and not envy the resources of the majority as such (thus fulfilling the Dworkinian envy test). Even if this was the case, however, the members of minority cultures may still be envious of the majority, albeit not qua their bundle of resources, but because of the fact that the majority can utilize their resources in their own cultural context. Kymlicka 1989,188. 
Part I Justifying Minority Rights

measured, thus putting the baseline of equality not at the point in which people have equal resources to start with, but at the point in which people have these resources and their own cultural framework within which to use them.

\subsection{Culture as a context of choice}

In order to place the base line of equality to the point in which people are already able to live their lives within their own cultural framework, Kymlicka needs to show why having one's own cultural framework would be something that people cannot be expected to abandon or pay the price for. Part of the support for this claim comes from Kymlicka's treatment of cultural membership as one of the primary goods, part from his assumptions about the involuntary nature of cultural membership. These lines of support can best be examined in the light of Kymlicka's conception of culture as a context of choice, and the elements incorporated in this conception. I identify three distinct, although interrelated, arguments within the context of choice -view that, together, form the support needed for placing the base line of equality to the point of being able to live one's life in one's own cultural framework. Later on (in part 1.2.) I use these arguments to show that, although supportive of Kymlicka's new base line, these arguments also pose certain restrictions on the ways in which the rationales for the liberal state to rectify different kinds of disadvantages can be conceived of.

\section{The prerequisite for choice-argument}

In order to show why people should not be required to abandon, or pay the price for their own cultural framework, Kymlicka looks at the role of cultural membership in the constitution of a good life. According to Kymlicka, cultural membership can be conceived as one of the primary goods - something that all rational persons can be expected to want, ${ }^{92}$ and that the state should (based on

92 Kymlicka 1989, 166; 1995, 86; for Rawls's original account of primary goods, upon which Kymlicka builds, see Rawls 1971, 62; 92. 
requirements of justice) attempt to guarantee. Drawing from a specifically liberal framework, Kymlicka emphasizes the role of individual freedom and the importance of the individual's capabilities to view, assess and make choices about one's life. Contrary to the traditional liberal theories, however, Kymlicka argues that one's freedom of choice is both enabled as well as restricted by one's cultural framework. Culture, as a context of choice, is a prerequisite for individual freedom and autonomy as "it is only through having a rich and secure cultural structure that people can become aware, in a vivid way, of the options available to them, and intelligently examine their value." ${ }^{, 93}$

This view of culture as prerequisite for individual choice is essentially related to Kymlicka's understanding of culture as a specifically societal culture. ${ }^{94}$ By societal culture Kymlicka refers to a framework that "provides its members with meaningful ways of life across a full range of human activities, including social, educational, religious, recreational, and economic life, encompassing both public and private spheres." 95 Societal culture is encompassing both in the sense of it being regulative of people's lives in a wide area of activity, as well as in the sense of it being institutionally embedded, for example in the school, court and financial systems of society. ${ }^{96}$ Despite its encompassive nature, however, Kymlicka argues that societal cultures do not determine the ways in which people should live their lives but, rather, provide the context within which people can make their lives meaningful. The societal cultures thus have two important functions. Firstly, they provide options that people can, should they so wish, take

\footnotetext{
${ }^{93}$ Kymlicka 1989, 165.

${ }^{94}$ Esp. Kymlicka 1995, ch. 5. For different conceptions of culture used in debates on multiculturalism, including societal, normative, constructivist / semiotic, see: Festenstein 2005, 13-26.

${ }^{95}$ Kymlicka 1995, 76.

${ }^{96}$ Similar accounts of culture as encompassing in the sense of it being regulatory of a wide variety of human behaviour have been given for example by Margalit \& Raz 1994 (emcompassive cultures) and Shachar 2001 (nomoi communities).
} 
Part I Justifying Minority Rights

advantage of. And secondly, they also provide the framework - the cultural narratives ${ }^{97}$ - through which people can mediate and make value judgments about these options. Notably, for Kymlicka, it is only through one's membership in a societal culture that one gains access to the options provided by culture, as well as learns to make intelligible choices among them. Thus, for Kymlicka, one's cultural membership comes to be seen as a prerequisite for individual freedom of choice and, consequently, as one of the primary goods that the liberal state should attempt to guarantee.

Kymlicka's argument for cultural membership as one of the primary goods does not, however, justify as yet the move for positing the base line of equality at the point in which people are already able to use their resources within their own cultural context. All Kymlicka has been able to demonstrate so far, is that some cultural context is needed, in order for the individuals to become aware of their options and to make intelligible choices among these options. But the requirement of some cultural context for individual freedom of choice is still far from the requirement of having some particular cultural context - the requirement of having one's own cultural context being, in fact, something of a misnomer, as culture is hardly something that people cannot not have. ${ }^{98}$ Recognizing this, Kymlicka has to bring in a further argument for why it would be precisely one's own (born into) cultural context that, as one of the primary goods, should be guarded by the liberal state.

The importance-argument

In order to argue for the status of one's own (born into) cultural context as one of the primary goods guaranteed by the liberal state, Kymlicka turns to look at the identity-forming functions of cultural

\footnotetext{
${ }^{97}$ Kymlicka 1995, 83.

${ }^{98}$ As Kwame Anthony Appiah has aptly noted: "the problem with grand claims for the necessity of culture is that we can't readily imagine an alternative. It's like form: you can't not have it." Appiah 2005, 124. See also: Tomasi 1995, 588-589.
} 
membership. ${ }^{99}$ Drawing from empirical evidence, Kymlicka argues that one's born into culture plays an extremely important role in the development of that person's identity. The view of oneself is, at least partially, constituted by one's cultural membership, and one's self-respect can be inherently tied up with this membership. Being such a constitutive element of one's identity and self-respect, people (at least generally) also wish to maintain and protect this membership, and the cultural context to which they belong. ${ }^{100}$ Further, it is not only that people would (generally) have a strong wish to maintain their cultural membership, but that the consequences of losing this membership and the cultural context that one belongs to, can be catastrophic. By linking one's cultural membership with one's identity and self-respect, Kymlicka argues that it is not reasonable to expect people to abandon their membership and the cultural context to which they belong to, but to preserve this context, due to the importance that that this context (that is, one's own born into cultural context) has for the identity and self-respect of its members. ${ }^{101}$

What should be noted, however, is that the claims about the identity forming functions of one's own cultural membership and the magnitude of the harm that the loss of this membership may produce are independent of the argument for the need of having one's own cultural context due to it catering for one's abilities to view, assess and make choices about one's life (the prerequisite for choice-argument). Whereas one can, undoubtedly, make choices

\footnotetext{
99 Esp. Kymlicka 1989, 175-176; 192-193; 1995, 89-90; for alternative views on the role of culture and/or cultural membership for the constitution of people's identities, see e.g. Margalit \& Halbertal 1994; Young 1990; Taylor 1989; 1994; Raz 1998; I will return to the identityforming functions of cultural membership in more detail in chapters 4 and 5.

${ }^{100}$ Kymlicka 1989, 175-176; see also: 1995, ch. 5, esp. 89-90.

101 Thus, for Kymlicka, "respecting people's own cultural membership and facilitating their transition to another culture are not equally legitimate options." Kymlicka 1989, 176.
} 


\section{Part I Justifying Minority Rights}

within an alien cultural context, ${ }^{102}$ it may not be reasonable to expect one to abandon one's own (born into) cultural context, due to the importance of one's cultural membership to one's identity and self-respect. The reasons for one not to be expected to abandon one's own (born into) cultural context thus come from the importance -argument, whereas the prerequisite for choice argument simply establishes the role of cultural contexts for individual freedom and autonomy. ${ }^{103}$ As will be seen, there is

\footnotetext{
${ }^{102}$ At times, Kymlicka does seem to lean towards the view according to which the range of options from which individuals can choose their courses of life could only be provided by the particular cultural context to which the individual happens to be born to (see e.g. Kymlicka 1989, ch 8 \& 9 for Kymlicka's discussions on the dangers of rapid changes within cultures, and of the losing of one's own cultural context). This view, however, is rejected both by Kymlicka $(1995,84-85)$ as well as by the majority of other theorists on multiculturalism. In contemporary circumstances of cultural diversity, it is hardly sustainable to argue that people could not live in other cultural contexts, and make meaningful choices within these contexts. The options provided by the majority culture are surely options that are open also to the members of the minority (although, as I discuss in chapter 3, this can, in certain occasions, be debated), and the choices either to take advantage or not to take advantage of these options surely indicate the capability of the minority members to make value judgments about these options. As many have argued, it is a gross misunderstanding to think of cultures as completely isolated, holistic entities that would have nothing in common, and between which people could not negotiate. (For a cosmopolitan market-place view of cultures, see Waldron 1992; against so-called billiard-ball conception of cultures, see Tully 1995, ch. 1.) Although living in a different cultural context may, at times, be difficult for those who are not accustomed to the norms and practices of that context, it is surely too strong a claim to insist that the meaningful options among which individuals are able to make meaningful choices could be provided only by one's own (born into) culture.

${ }^{103}$ Rainer Forst makes a similar observation emphasizing that it is culture as a context of identity (rather than choice) that provides an argument for one's need to live in one's own cultural context rather than in the context of the majority. Forst 1997; for Kymlicka's attempted response based on
} 
certain tension between these two arguments, the prerequisite for choice-argument somewhat constraining the kinds of cultural contexts Kymlicka views as worthy of protection, whereas the importance-argument makes no such restrictions. ${ }^{104}$

\section{The involuntariness -argument}

The importance argument, connected to the other supporting strand of Kymlicka's model - that of the assumption of the involuntariness of one's cultural membership (the involuntariness argument) supposedly brings forth the support needed for positing the base line of equality at the point in which people are already able to utilize their resources in their own cultural context. As cultural membership is something that (at least in most cases) is not chosen by the members themselves, and as this membership is (at least in many cases) something of a tremendous importance for the members themselves, it is not reasonable to expect people to abandon this context, nor is it fair that the resources given to the members of minority cultures would have to be used (solely or extensively) for the preservation of that context. Being more of an unchosen circumstance rather than a choice (to be responsible for), members of minority cultures should not be disadvantaged by their efforts to live within their own cultural context - something which it is not reasonable to expect them to abandon, and which they did not choose to belong to. ${ }^{105}$

the interdependency of the considerations based on choice and identity, see: Kymlicka 2001, 55.

${ }^{104}$ I will return to this tension in more detail in Ch. 2 .

105 Despite obvious dissimilarities, Kymlicka's treatment of cultural membership can be conceived as on a par with some of the factors discussed by Dworkin, such as physical or mental disabilities, the disadvantages of which people should not be required to pay for. This parallel, it should be emphasized, needs not presume that one's cultural membership (like one's physical or mental disability) would be a disadvantage in itself, but simply that, in a society, organized in accordance with the cultural norms of the majority (or, in accordance with the needs of the able bodied or minded), one's membership in a minority 
Part I Justifying Minority Rights

\subsection{The scope of Kymlicka's arguments}

Although Kymlicka's prerequisite for choice, importance and involuntariness arguments, taken together, would thus seem to provide the support needed for positing the base line of equality at the point in which people are, already, able to live their lives in their own cultural contexts, it is also important to keep these arguments separate, in order to establish what kinds of inequalities Kymlicka's model is able to incorporate and what kinds of reasons there may be for the liberal state to try to alleviate these inequalities. Before turning into assessing the kinds of minority rights that Kymlicka's model may justify, I wish to elaborate on the scope of these arguments, as the cultural disadvantages faced by minority members are of various kinds. Importantly, one needs to distinguish between the kinds of disadvantages that Kymlicka's model is able to identify from the reasons that the liberal state may have for trying to rectify these disadvantages. Further (as discussed in the latter part of this chapter), these two aspects of Kymlicka's account need to be separated from the kinds of minority rights that may be used to alleviate these disadvantages.

\section{Two types of disadvantage}

Following, roughly, Kymlicka's own distinction between the inequalities faced by 'national minorities' and 'ethnic groups', ${ }^{106}$ there are two major types of disadvantages that can be identified

cultural group may result in disadvantages that one should not end up paying the price for.

${ }^{106}$ Kymlicka 1995, 10-11. Kymlicka's typology of minority groups is, to be fair, much more complex, incorporating national minorities, indigenous peoples, immigrants and religious groups (see e.g. Kymlicka 1995; 2001) as well as some "hard cases and grey areas" (Kymlicka 1995, 24-25) that do not fit neatly into the fourfold distinction above. For critical remarks on Kymlicka's typology, see e.g. Young, 1997; Mason 2000, ch. 3; Carens 1997; 2000, ch. 3. For the sake of clarity, I discuss only the two major types of disadvantages that correspond, roughly, to Kymlicka's distinction between national minorities and ethnic groups. 
within Kymlicka's modified, resourcist account of equality. On the one hand, those minority members striving to lead their lives in their own cultural contexts are disadvantaged by not having an automatic access to their own cultural context and by having to spend large amounts of their resources on maintaining this context. As the western liberal societies are already organized in accordance with certain cultural norms (reflected, for example, in public holidays, school curriculums, and official languages), the members of the majority get their cultural context for free whereas the members of the minority do not. On the other hand, the disadvantages resulting from the need to spend extra resources, due to one's membership in a minority culture are not only encountered by those who are striving to keep their own cultural contexts (such as those aboriginal people who wish to maintain their traditional ways of living, or those religious minorities who wish to separate themselves from the modern life), but also by those who, due to adhering to some particular cultural practices, have difficulties in taking part in the public life of society (organized in accordance with the cultural norms of the majority). Even if the members of a minority would not aim at maintaining their cultural context as a whole, it may well be that the adaptation of some of their cultural customs (such as dress codes, religious holidays, languages) to the cultural context of the majority will require a substantial amount of time and effort that is not required of the majority (whose dress codes, religious holidays, and languages coincide with the general norms and practices of the society). A minority member who is, say, not capable of speaking the official language, will (unless assisted) need to use a substantial amount of her resources in order to, say, be able to communicate in governmental offices, thus leaving her less resources for her other endeavors.

Reasons for the liberal state to be concerned about these disadvantages

At the level of explanation, Kymlicka's modified, resourcist account of equality would thus seem to be able to account for both the disadvantages encountered by those striving to live their lives 


\section{Part I Justifying Minority Rights}

within their own cultural context, as well as of those who, due to adhering to some particular cultural practices, have difficulties in participating in the workings of the society. These two types of disadvantages are, however, very different with respect to the reasons that the liberal state has for being concerned about them and for trying to alleviate those disadvantages.

As already indicated, Kymlicka puts forward three distinct arguments for why the liberal state should be concerned about and try to alleviate the disadvantages caused by one's cultural membership (the prerequisite for choice, importance and involuntariness -arguments). ${ }^{107}$ However, the prerequisite for choice -argument gives no independent support for the state to be concerned about the disadvantages caused by the lack of one's own cultural context, but merely establishes the role of cultural context for individual freedom and autonomy. The prerequisite for choice argument is important for showing that the claims based on culture are not necessarily incompatible with the liberal values of individual freedom and autonomy, although the rationale for the state being concerned about the disadvantages caused by the lack of one's own cultural context must come from other sources - those of the importance and involuntariness arguments. As one's own cultural context can be conceived of as being of a potentially tremendous importance for the bearer of that culture, and as people have not normally chosen to belong to one culture or another, it may not be reasonable to expect one to abandon such a context, nor to pay the price of being able to maintain it. The importance and involuntariness -arguments, taken together, thus provide a rationale for the state to be concerned about and try to rectify those disadvantages that result from not being able to live within one's

${ }^{107}$ Kymlicka also discusses two further arguments, those of the argument from historical agreements and the argument from the value of cultural diversity, but acknowledges that these two arguments should only be seen as complementing the concerns based on equality. See: Kymlicka 1995, ch. 6 . 
own cultural context (provided that this context is, indeed, compatible with individual freedom and autonomy). ${ }^{108}$

With respect to the second kind of disadvantages (that is, the disadvantages relating to particular cultural customs or practices), it may not, however, be possible to use the same kind of rationale conjoining the importance and involuntariness -arguments. As established by the prerequisite for choice -argument, Kymlicka views cultural contexts as frameworks within which people make choices and the cultural practices (that may, no doubt, result in disadvantages when in conflict with the general norms and rules of society) must, in accordance with the context of choice -view, be conceived precisely as choices made by the members of the particular cultural or religious minority. As Kymlicka argues, it is perfectly right and proper for the character of a culture to change as a result of the choices of its members ${ }^{109}$ - this context of choice (cultural community or structure) being strongly distinguished from any particular cultural norms or practices (character of that community ${ }^{110}$. Moreover, Kymlicka argues that it is not only that the prevalent practices of any particular cultural community can change in time, but that the individual members of cultural groups should, at any given time, "be free to choose what they see to be most valuable from the options provided". ${ }^{111}$ The particular cultural practices, such as the Muslim women's usage of the veil or the American Indian's usage of peyote, must, in line with the context of choice -view, be conceived as choices, not as unchosen circumstances the disadvantages of which the individuals should not be held responsible for. But, if this is the case, it becomes increasingly difficult to see why those disadvantaged by their adherence to some particular cultural practice should not also be

${ }^{108}$ I will come back to this constraint in Kymlicka's account in Ch. 2, when I discuss the critique of Kymlicka from the so-called 'diversity liberals'.

${ }^{109}$ Kymlicka 1995, 104-105.

${ }^{110}$ Kymlicka 1989, 166-167.

111 Kymlicka 1989, 198. 


\section{Part I Justifying Minority Rights}

held responsible for the disadvantage created - if, indeed, their adherence to this practice is (or at least should be) a choice that they have made from the options provided by their culture.

Perhaps Kymlicka could argue that, as the context within which the choice to wear a veil or to use peyote has been made is not chosen by the people themselves, they should not be held responsible for making such choices, enabled by their own, unchosen cultural context. If the Muslim religion or the American Indian culture embraces these options as viable, perhaps even desired options for their members, and if these options nevertheless conflict with the general rules and norms of the society, people should not be held responsible for the disadvantages of these choices, as the general structure of society clearly supports only options provided by the majority culture and not others. Even if those adhering to minority cultural practices can (in accordance with the context of choice -view) be conceived of as having chosen this adherence (and should thus, strictly speaking, be held responsible for the resulting disadvantage), it may still be that, due to the institutional bias of society, they should not be held responsible for making such choices because of the unchosen nature of their cultural context (that embraces these options as viable options for their members). As Kymlicka argues, the liberal society, necessarily organized in accordance with some of the norms and practices of the majority fails to treat people equally by being (necessarily) supportive of some cultural norms and practices, but not others. ${ }^{112}$ Even if the adherents of the minority cultural practices could be seen as having chosen these practices, the disadvantage caused by this choice may still be a proper concern of the liberal state, due to the institutional bias of the society. ${ }^{113}$

\footnotetext{
${ }^{112}$ Esp. Kymlicka 1995, 113-115.

${ }^{113}$ As Anne Phillips has forcefully argued, it may well be that, due to the institutional bias of society, it may not always be reasonable to apply the chance/choice -distinction to identify those disadvantages that people should not be held responsible for. Phillips 2007, 111-112.
} 
However, whereas it may thus be possible to argue that some of the disadvantages caused by the incompatibility of one's cultural practices and the general rules and norms of the society are, indeed, proper concerns for the liberal state, it is worth noting that not all cases of cultural disadvantage fall into this category. Most notably, Kymlicka's framework fails to incorporate cases where the disadvantage is faced by voluntary immigrants ${ }^{114}$ who, according to Kymlicka, have chosen to leave their own cultural contexts and have thus also forfeited their right to live their lives in their own cultural context. ${ }^{115}$ Although Kymlicka tries to emphasize that the choice of the immigrants would only cancel out their claims to live their lives within their own cultural contexts - and not their claims to preserve some of their particular cultural practices within the framework of their new context - it is difficult to see how Kymlicka could defend his argument. If the immigrants have, indeed, chosen to leave their own cultural contexts, and if they have also chosen to enter a context which does not cater for their specific cultural practices, why would this choice cancel out only their claims to their own cultural contexts, but not their claims to preserve some of their specific cultural practices? By choosing to leave their own cultural context, and by choosing to enter a context within which their practices do not fit, the immigrants would seem to have forfeited also their right to preserve their conflicting cultural practices, even in cases where the disadvantage they were faced with (due to continuing to adhere to these practices) could be traced to the institutional bias of society.

The importance -argument and specific cultural practices Kymlicka's involuntariness -argument, when joined with his prerequisite for choice -argument, would thus seem to fail in giving

114 Similar criticism about the applicability of Kymlicka's theoretical framework to the case of immigrants has been put forth for example by Carens 1997; 2000, 56-59; Quong, 2006.

${ }^{115}$ Kymlicka 1995, 95-100; 113-115. 


\section{Part I Justifying Minority Rights}

conclusive ${ }^{116}$ support to the claim that the state should be concerned about and try to alleviate those disadvantages resulting from the incompatibility of the general norms and practices of the society and the particular cultural practices of the minority. Being so, it is left for the importance -argument to do the work required and, with certain modifications, I believe that the importance argument can do at least some of this work. This rationale, provided by the importance -argument is, however, very different from the rationale that Kymlicka gives for the liberal state to be concerned about and try to alleviate the disadvantages caused by the lack of one's own cultural context and, as will be seen, also rationale that requires certain modifications to Kymlicka's original framework.

Recall that, according to the importance -argument, one's cultural membership could be seen as of such importance for a person's identity and self-respect that it would not be reasonable to expect a person to abandon this membership, or the cultural context to which they belonged to. The importance -argument alone could not, however, provide anything as strong as a requirement for the liberal state to safeguard people's own cultural contexts, but was supplemented with two other arguments: those of the involuntariness -argument (establishing why the minority members should also not be expected to pay for the maintenance of their own cultural context) and the prerequisite for choice -argument (establishing that the maintenance of such context is compatible with the liberal values of individual freedom and autonomy). However, as I tried to argue, there was a certain tension between the involuntariness and prerequisite for choice -arguments, disabling the same kind of rationale for the liberal state to be concerned about and to try to rectify those disadvantages that resulted from the incompatibility of particular cultural practices and the general rules and norms of the society.

${ }^{116}$ That is, it would seem to fail at least in cases of voluntary immigrants who have not only forfeited their right to live in their own cultural contexts, but also their right to preserve some of their specific cultural customs and practices within their new context. 
It is, however, possible to extend the scope of the importance argument in a way that provides support for Kymlicka's claims that the minority members (including voluntary immigrants) should, as a default, be able to continue to adhere to some of their specific cultural practices. According to the modified importance argument, it is not only one's cultural membership or cultural context that provides for the identity and self-respect of its members, but also the particular cultural practices that the minority members are engaged in. People do not only conceive themselves as members of cultural groups (such as Muslim, American Indian, Inuit or French) and view this membership as one of the defining features of their identity, but they also attach meanings - contents to these identities and act in ways they conceive the proper Muslims, American Indians, Inuits or French to behave. ${ }^{117}$ It is thus not only that people would find their being a Muslim or American Indian or Inuit or French as something of crucial importance for their identity and self-respect, but they may also find the engagement in particular cultural practices (such as being dressed in a certain way, earning one's living in a particular way, or communicating in a particular language) as something of tremendous importance for their identity and self-respect. ${ }^{118}$ Being

${ }^{117}$ The different kinds of expectations to "the proper modes of behaviour" of a particular X (Muslim, Aboriginal etc.) and their normative implications will be discussed in more detail in Ch. 4. For the time being, it suffices to say that people who conceive themselves as $\mathrm{X}$ often also have certain views on how they, as an X, should behave. These views need not have anything to do with any objective criterion for how it is proper or improper for and $\mathrm{X}$ to behave, but are simply views of the person themselves, how they, as an X, should behave.

${ }^{118}$ Margalit and Halbertal (1994) make a similar point in their critique of Kymlicka's views on the value of culture to its members. According to them, Kymlicka's account fails to capture something important about the ways in which people - the culture bearers themselves - value their cultures. According to Margalit and Halbertal, people do not necessarily value the structure or membership in a cultural community as such, but they value precisely those cultural contents that they happen or choose to possess. (Margalit and Halbertal 1994) 


\section{Part I Justifying Minority Rights}

such an important element of one's identity, it may not be reasonable to expect people, as a default, to abandon such practices, due to the magnitude of the harm that abandoning such practices may cause to the identity and self-respect of the practitioner. Independent of the involuntariness and prerequisite for choice arguments, it would thus seem that there would already be good reasons for the liberal state to be concerned about the disadvantages caused by minority members' particular cultural practices, due to the importance of these practices to their practitioners, and the unreasonableness of expecting, as a default, people to abandon such practices.

It should, however, be emphasized, that the modified importance argument is only able to provide rationale for the state to be concerned about the disadvantages caused by people's adherence to particular cultural practices, but is not, on its own, able to establish anything as strong as a requirement for the state to also rectify these disadvantages. Within Kymlicka's framework, the requirement for the liberal state to rectify cultural inequalities is still based, primarily, on the involuntariness -argument and, as I have tried to argue, one's adherence to particular cultural practices cannot be conceived as involuntary. The modified importance argument can, however, be used to argue why the disadvantages resulting from one's participation in particular cultural practices can be considered as proper concerns of the liberal state and why the state should not simply disregard the claims of those minority members who find themselves in a disadvantaged position due to their cultural commitments. ${ }^{119}$ Whether the state should then propose measures, and what kinds of measures, to alleviate this disadvantage would then depend on several other considerations,

119 The argument advanced here can perhaps better be interpreted as an argument against the view according to which the liberal state should bracket cultural claims from the realm of public policies, although it is not an argument for a requirement of the liberal state to also rectify those disadvantages that one's adherence to particular cultural practices may cause. 
including the nature of the practice in question, the costs of the measures implemented, as well as the type and magnitude of the disadvantage $\mathrm{e}^{120}$ - all of which, no doubt, would need to be assessed in context. Although the modified importance argument would thus seem to provide rationale for the liberal state to take cultural considerations into account, it does not provide any definitive guidance into how to respond to these considerations. ${ }^{121}$

\section{Minority rights and the limitations of Kymlicka's framework}

So far, I have concentrated on Kymlicka's theoretical framework that tries to both, explain the kinds of disadvantages faced by minority members, as well as give reasons for why the liberal state should be concerned about and try to rectify these disadvantages. I argued that, at the level of description, Kymlicka's framework is capable of taking into account both the kinds of disadvantages faced by minorities due to them lacking their own cultural context, as well as the kinds of disadvantages caused by the incompatibility of the general norms and practices of society and the specific cultural practices of the minority. I did, however, argue that Kymlicka's view of culture as a context of choice, and the three distinct (although interrelated) arguments incorporated in this view, gave very different rationales for the liberal state to be concerned about and to try to rectify these disadvantages. Whereas the prerequisite for choice, importance and involuntariness -arguments

${ }^{120}$ Whether of the minority in question, its individual members, other minorities, or the so-called majority.

${ }^{121}$ To clarify, I do not think that the combination of the prerequisite for choice, importance and involuntariness -arguments provide any definitive guidance into how the liberal state should respond to the inequalities caused by one's lack of one's own cultural context either. The combination of these three arguments, in Kymlicka's framework, does, however, provide slightly stronger case for the liberal state to aim at rectifying these disadvantages than the modified importance argument. Whether Kymlicka is right in placing such emphasis on the involuntariness-argument is, of course, another matter, the treatment of which will have to wait for later. 


\section{Part I Justifying Minority Rights}

could provide a case for the liberal state to try to guarantee (some) people's own contexts of choice, the rationale for the state to be concerned about the disadvantages caused by one's specific cultural practices was much weaker, based only on a modified importance argument - something that Kymlicka does not explicitly subscribe to himself, but on which his claims about the right of minority members to preserve some of their cultural practices must, nevertheless, be based upon. ${ }^{122}$

During this discussion, I have not, quite purposefully, said much about the measures that Kymlicka proposes for rectifying these disadvantages - that is, minority rights. This has been due to the importance of distinguishing between the reasons that the state has for being concerned about the disadvantages in question and the kinds of responses that may be adopted in order to rectify these disadvantages. Even if there were good reasons for the liberal state to be concerned about and try to alleviate the disadvantages faced by minority members (as, within Kymlicka's framework, there clearly are), these reasons do not, as yet, provide any definitive guidance into how the state should respond to these disadvantages. Rather, the possible responses need to be assessed in their own right, taking into account both, the rationale given, as well as any other considerations that may affect the justifiability of the policy in question. Even if there were good reasons for the state to be concerned about and try to rectify the disadvantages faced by

\footnotetext{
${ }^{122}$ In cases of immigrants and other ethnic groups, Kymlicka does, in fact, bring forth a modified context of choice -argument claiming that, although not entitled to their own cultural contexts, the immigrants should be provided with access to the cultural context of the majority. This, Kymlicka continues, may require two-way integration, including the accommodation of minorities' specific cultural practices into the framework of the majority. (Kymlicka 1995, 14; 96-97) It should, however, be noted that such accommodation is not a prerequisite for the minorities' access to the context of the majority, but is based on the importance-argument discussed above. For an analysis of such an accommodation as potentially operating also for the enrichment of majority's context of choice, see Goodin 2006.
} 
minority members, there might also be other good reasons for adopting (or refraining from adopting) particular kinds of policies in response to these disadvantages. ${ }^{123}$ What I wish to do next, therefore, is to assess, whether the policies proposed by Kymlicka are consistent with his own theoretical framework, and whether there may also be good reasons (within Kymlicka's own account) not to adopt the kinds of policies Kymlicka promotes.

\subsection{Typology of minority rights}

Kymlicka's typology of minority or group-differentiated rights ${ }^{124}$ incorporates three relatively broad categories, those of selfgovernment rights, polyethnic or accommodation rights ${ }^{125}$ and special representation rights. ${ }^{126}$ These three categories are distinguished from each other, partially, by the different aims of the rights within each category, but also by the kinds of minority groups that Kymlicka sees as eligible for these rights.

The rights of self-government, according to Kymlicka, are accorded to a cultural group by virtue of it being a distinct "nation" or "people" - a historical community, occupying a certain territory, with distinct language and/or culture. ${ }^{127}$ Indigenous people, such as the Maori or Sami people, and national minorities, such as the

\footnotetext{
${ }^{123}$ Kymlicka, too, acknowledges this is passing, claiming that in certain cases granting minority rights may come at "too high a price in terms of other liberal goals" or be "unnecessary or too costly" (Kymlicka 1995, 106). He does, however, maintain that, "certain group-differentiated rights are required by the principles of liberal justice" (ibid.), although, as I try to show, such requirement may be misplaced, even in Kymlicka's own terms.

${ }^{124}$ Kymlicka uses these terms interchangeably.

${ }^{125}$ In Multicultural Citizenship, Kymlicka uses the term polyethnic rights, reflecting the kinds of groups potentially eligible for such rights. In response to criticism (e.g. Carens 1997), Kymlicka changes the term used to accommodation rights, as this term emphasizes the actual aim of these rights to accommodate some of the specific cultural practices of minorities into the larger framework of the majority. Kymlicka 1997; 2001, 51.

${ }^{126}$ Kymlicka 1995, esp. ch. 2.

${ }^{127}$ Kymlicka 1995, 11; 18; 27-30.
} 


\section{Part I Justifying Minority Rights}

Quebecois or Welsh, would be potential claimants for rights of selfgovernment. These groups, according to Kymlicka, are groups that are in possession of the kind of societal culture that Kymlicka is concerned with, and they are also potentially capable of maintaining this culture. Further, they are the kinds of groups that have not forfeited their right to their own cultural context (by choosing to leave and enter another), but who have rather been, either forcefully or by some historical agreement, incorporated into the societal culture of the majority.

The aim of the rights of self-government is to enable these people to enjoy and maintain their own societal cultures, with their own cultural norms and practices, including their own institutions organized in accordance with these norms and practices. The rights of self-government vary from full secession to partial autonomy, ${ }^{128}$ and can involve measures that restrict the rights of non-members to the benefit of the minority (such as restrictions on occupying land in minority territories, or language laws, like the restrictions on immigrants' access to English services in Quebec). ${ }^{129}$ Importantly, for my purposes, Kymlicka maintains that the rights of selfgovernment do not pose any duty for the people in question to maintain the traditional or prevailing norms or practices of their culture (or even a duty to maintain themselves as distinct cultural communities) ${ }^{130}$ but merely enable these people to be in control of their own destiny by being able to decide for themselves how they wish their communities to be run. ${ }^{131}$

\footnotetext{
${ }^{128}$ As will become clear later on, most of the rights of self-government are, in fact, partial, also incorporating particular views on the conceptions and contents of culture. For a useful distinction between two types of minority claims: autonomist (recognition from the state) and secessionist (recognition as a state), see Valadez 2007.

${ }_{129}$ Kymlicka calls these external protectors, Kymlicka 1995, esp. 35-44.

${ }^{130}$ Kymlicka 1995, 100; 113.

${ }^{131}$ Kymlicka 1989, 166-167; 1995, 104-105. As will be discussed in more detail in Ch. 2, there are some substantive limits on the minorities' right to govern their internal affairs given by the prerequisite for choice argument.
} 
Polyethnic or accommodation rights, on the contrary, aim at accommodating people's cultural backgrounds within the institutional framework of the larger society. According to Kymlicka, immigrant groups (with their distinct ethnic, religious, linguistic and/or cultural backgrounds), religious groups (such as the Amish) and territorially dispersed non-immigrant groups (such as the Roma) should have a right to maintain some of their culturally distinct ways of living within the institutional framework of the larger society. These groups, Kymlicka argues, may not be eligible for the rights of self-government as they have either forfeited their right to their own cultural context by leaving and entering another (voluntary immigrants), or they may be too territorially dispersed to be able to maintain their own societal cultures (Roma). The multicultural policies with respect to these groups may include policies against discrimination (such as antiracism policies), ${ }^{132}$ funding for private associations (such as religious associations or art-centres) as well as exemptions from general laws or norms (such as Sunday-closing regulations or professional dress-codes). The general aim of these rights is, unlike the rights of self-government, not to enable members of these groups to enjoy a societal culture of their own, but to allow them to express their distinct cultural identities without being disadvantaged from this expression within the institutional framework organized in accordance with different cultural norms and practices. ${ }^{133}$ Like in the case of the rights of self-government, Kymlicka argues that the accommodation rights should not create a duty for minority members to maintain any of their particular cultural practices, although (and I will come back to this in more detail in the

${ }^{132}$ For Kymlicka, the anti-racism policies operate on a different level to other polyethnic rights as they are not, strictly speaking, groupdifferentiated citizenship-rights but rather aim at the effective exercise of the common rights of citizenship. (Kymlicka 1995, 30-31) It should, however, be kept in mind that many of the group-differentiated rights promoted by Kymlicka (such as exemptions and assistance rights) can also be conceived as ensuring the equal rights and opportunities of citizenship. ${ }^{133}$ Kymlicka 1995, 30-31. 


\section{Part I Justifying Minority Rights}

following subsection) he also argues that both the rights of selfgovernment as well as the accommodation rights should not be considered as temporary but, rather, as permanent arrangements through which the minority members can preserve some of their cultural heritage. ${ }^{134}$

With respect to the third category of group-differentiated rights - that of rights for special representation - the main aim of these rights is to reduce the under-representation of oppressed groups (such as groups eligible for the two above rights, but also of women, gays or the poor) in public positions of power. Contrary to the two previous categories that aim at maintaining the minority members' abilities to preserve (some of) their cultural heritage (without being disadvantaged for doing so), the rights for special representation do not, necessarily, have this as their target. Rather, the special representation rights can be seen as ways of tackling the kinds of structural disadvantages that prevent some groups from being fairly represented in public bodies, ${ }^{135}$ although in some cases the special representation rights can also be seen as corollaries for the rights of self-government, ensuring that those groups, eligible for the rights of self-government also have a say in determining the rules of such self-government. ${ }^{136}$

\footnotetext{
${ }^{134}$ Kymlicka 1995, 31.

${ }^{135}$ Kymlicka compares this form of special representation to affirmative action policies that can be seen as temporary measures to tackle oppression or systematic disadvantages. (Kymlicka 1995, 32) These measures, once the oppression has ceased and systematic disadvantages rectified, may be seen as losing their rationale and are no longer needed. As an example, quotas for women, ethnic minorities or other underrepresented groups in certain professions can beseen as temporary measures, the need for which becomes extinct once the desired proportion of women, ethnic minorities etc. has been reached and is also going to remain at the desired level without such quotas. For alternative arguments for affirmative action, including backward-looking arguments, see Boxill and Boxill 2003.

${ }^{136}$ Kymlicka 1995, 31-33.
} 
Kymlicka’s Liberal Multiculturalism

\subsection{The rationale for concern vs. the rationale for minority rights}

Kymlicka's account of minority rights has attracted much criticism, both with respect to the kinds of groups that Kymlicka views as eligible for each type of right, as well as with respect to the force of Kymlicka's arguments to create an obligation for the liberal state to grant such rights in practice. ${ }^{137}$ These critiques, although addressing important issues relevant to both the justifiability as well as the applicability of minority rights in practice, have, however, largely side lined the question of whether the original rationales given for the liberal state to be concerned about cultural disadvantages, can even be extended to an argument for minority rights, or their application in practice. As argued in the previous section, there is a case, within Kymlicka's framework, for the liberal state to be

\footnotetext{
${ }^{137}$ For example, it has been argued that Kymlicka's typology is based on a rather simplistic account of the kinds of groups that Kymlicka thinks to be eligible for each type of minority right. This typology is largely based on his distinction between national minorities and voluntary immigrants, and may thus not be able to take into account the vast variety of minority groups, some of which may fall between, or beyond, these two (e.g. Young 1997, Kukathas 1997a; Mason 2000, ch. 3). It has also been claimed that Kymlicka's account confuses the actual justification of minority rights with the limitations that there may be for applying such rights in practice. According to Kymlicka, those groups eligible for the rights of self-determination, for example, are only those national (or indigenous) minorities that are, already, sufficiently territorially concentrated and strong enough to be able to maintain their own societal cultures. But the fact that a national (or indigenous) minority is weak or territorially dispersed should not be relevant in assessing whether it is, indeed, justified in claiming rights of self-determination, only whether it is, in practice, capable of successfully executing such right. (Carens 1997) Further, many have argued that, regardless of whether Kymlicka's typology is correct or useful, his normative claims about these rights as being required by justice are too strong. According to these critics, Kymlicka does not manage to build a convincing case for any of these rights as being required - only, at the most, as being allowed, based on other considerations than requirements of justice. (e.g. Barry 2001; Kukathas 2003)
} 


\section{Part I Justifying Minority Rights}

concerned about and to try to rectify disadvantages faced by minority groups and their members, but this case, it should be emphasized, is directed precisely at giving rationales for the state's concerns, not necessarily to giving rationales for any particular types of policies. The kinds of policies adopted by the liberal state would, of course, need to be consistent with the original rationales and, as I now will argue, there are certain difficulties in the minority rights for living up to this task.

Minority rights as promoting certain conceptions and contents of culture

According to Kymlicka, the disadvantages faced by minority members should be a proper concern of the liberal state due to, either, the importance and involuntariness of one's own cultural framework as context of choice, or - along the lines of the modified importance argument - due to the importance of one's particular cultural commitments (norms and practices) for the identity and self-respect of that person. Constrained by the prerequisite for choice-argument, however, Kymlicka emphasizes that, in order to alleviate these disadvantages, the state should only create circumstances in which people are able to preserve their own cultural contexts or their particular cultural practices, but it should not aim at-, nor in effect come to promote-, any particular cultural contents or create any obligation for minority members to do so. This is important, as Kymlicka is committed to the value of individual autonomy and the importance of being able to revise one's conceptions of the good, should one so want to. Keeping this in mind, Kymlicka argues that minority rights should not promote any particular conception or character of culture, but rather, enable people to express their cultural identities - their cultural memberships - in ways they themselves see fit. ${ }^{138}$

It is, however, questionable, whether the minority rights especially the rights of self-government and polyethnic or

${ }^{138}$ Kymlicka 1995, 113. 
accommodation rights ${ }^{139}$ - succeed in fulfilling any of the requirements in Kymlicka's framework: that is, of not promoting any particular contents or character of culture, of enabling people to express their membership in ways they themselves see fit, or of protecting people's cultural memberships as primary goods. ${ }^{140}$

With respect to the rights of self-government, Kymlicka stresses that the rights of minority groups to decide about their own affairs do not dictate what the contents of these decisions should be. ${ }^{141}$ Rather, the rights of self-government only give people the right to decide for themselves which norms, values, beliefs or practices they wish their community to work upon. Whether the people in question wish to promote certain cultural norms and practices, and organise their institutions in accordance with these norms and practices, is a question following the right of self-government, not whether such right would, in itself, promote any particular contents of culture.

If we look at the rights of self-government, and the aims of such rights, more closely, it does, however, become apparent that these rights do, in fact, promote certain conceptions of culture, as well as

${ }^{139}$ In this work, I will not discuss the issues of special representation in any great detail. This is due to the specific character of such rights as not (at least directly) aiming at accommodating people's cultural memberships and the specificity of normative questions relevant for such rights. The issues of special representation have also been discussed extensively within more general debates on democratic theory. For some classical accounts of special representation of marginalized groups, see Phillips 1995; Young 1990; 2000; see also: Williams 1996; articles in Benhabib 1996.

140 For the crucial role of the state in deciding which groups are accommodated and how, see e.g. Shachar 2001, 37-40.

141 Notably, the prerequisite for choice-argument provides certain limitations to these decisions, although Kymlicka is reluctant to admit that even a failure to conform to these limitations would give a right to others (including the liberal state) to intervene or dictate the decisions of the group (Kymlicka 1992, 144-145; 1995, 164-170). I will return to the issues on non-intervention in more detail in Ch. 2, 1.2. 


\section{Part I Justifying Minority Rights}

- albeit indirectly - certain contents of culture. ${ }^{142}$ Considering that the aim of the rights of self-government is to enable certain groups of people to live within their own cultural contexts, including the institutional framework organized in accordance with the prevailing norms and practices of that culture, this already incorporates a conception of culture according to which culture is viewed, not only as an informal system of norms and practices, but also as a basis for institutional organisation. This conception of culture as societal culture is, no doubt, one of the building blocks of Kymlicka's theory, but it does create some difficulties for Kymlicka's claims about minority rights as not advancing any particular contents of culture. Recall that, according to Kymlicka, any institutional framework (incorporating a wide variety of educational, social, financial etc. systems) cannot but advance some cultural contents at the expense of others (as manifested, for example, in official languages, public holidays etc.). If the aim of the rights of selfgovernment is to enable certain groups to live within their own societal cultures (including these institutional frameworks), it becomes apparent that these rights also promote certain cultural contents, albeit indirectly. If the aim of the right of self-government is to give certain groups a right to decide how their communities should be run (including those institutions that, necessarily, advance certain cultural contents over others), then this right also indirectly advances those cultural contents that these institutions end up advancing.

Not all rights of self-government are, however, rights of full secession or national self-determination, but rather, rights that grant the group relative autonomy in matters particularly important to the group in question. The rights of self-government granted to, for example the Sami people in Lapland or to the Welsh people in Wales, may not be rights to govern all of their social and

\footnotetext{
${ }^{142}$ The distinction between conceptions and contents of culture coincides roughly with the distinction given in Background 2.2. between (the homogeneity of) scope (Hscope) and (homogeneity of) contents (Hcontents).
} 
institutional affairs, but perhaps only affairs regarding, say, their traditional sources of livelihood or language policies. Conceived in this manner, the rights of self-government (as rights to govern certain, but not all, of the group's affairs) promotes an even more specified conception of culture, as well as - albeit indirectly certain contents of culture. Granting the Welsh people in Wales a right to decide about their own language policies advances a conception according to which language is an integral ingredient of one's culture and identity, and may also advance a conception of the Welsh language as being an integral and inalienable element of Welsh culture. Although the right of the Welsh people to decide about their own language policies does not, in itself, promote Welsh language as an essential element of Welsh culture (the Welsh may, in fact, come to reject all policies aimed at promoting the Welsh language), this right, nevertheless, promotes a certain conception of culture (where language is seen as an essential element of this particular culture) and, indirectly, it also promotes those conceptions of cultural content that the Welsh - having decided their language policies - come to promote.

Further, given that, according to Kymlicka, the aim of the rights of self-government is to enable national or indigenous groups to live within their own cultural contexts, it is clear that most of the rights of self-government (such as the rights to decide about one's language policies, land claims, or family law) fall well short of this task. ${ }^{143}$ Rather than being able to live their lives in their own societal cultures (incorporating a wide variety of social institutions organized in accordance with the wide variety of cultural norms and practices), these groups can only make decisions about those

143 In his discussions on separatism and the possible responses to separatism (including federalism), Kymlicka does recognize the often partial nature of the rights of self-government. (Kymlicka 1995, 181-186; 2001, esp. ch. 5). He does not, however, seem to acknowledge the inconsistency of this partiality and his claims for the right of national minorities to preserve their own cultural contexts. 
Part I Justifying Minority Rights

matters that are already conceived of as important, even essential elements of their culture. ${ }^{144}$

With respect to polyethnic or accommodation rights, the promotion of certain cultural contents is even more straightforward. As Matthew Festenstein has noted, cultural policies are not produced in a vacuum, but are always specified in certain contexts. ${ }^{145}$ Whereas the anti-discrimination policies and funding for private associations can perhaps still be seen as only indirectly promoting certain cultural contents, ${ }^{146}$ an assessment of legal exemptions provides us with a different story.

As an example, let us take a well-documented and much discussed case of the exemption of the Sikh men from wearing safety helmets on construction sites. ${ }^{147}$ Although this exemption does not, as such, oblige the Sikh men to wear a turban instead of a safety helmet (and thus allows for different interpretations within

\footnotetext{
${ }^{144}$ I should emphasize that my intention is not to claim that, for example, language policies would not have an effect on a variety of social institutions with an overall impact on the ways in which the society in question is organized. To the contrary, I do think that a group's right to decide about its own language policies will have a tremendous influence on many of the ways in which the society is run, although it will (on its own) also fail to allow the group in question to live fully in their own cultural contexts. Further, the language rights also have an impact on the ways in which the culture in question is conceived of as primarily a matter of language and, debatably, also a matter of a particular language.

${ }^{145}$ Festenstein 2005, 81-82.

${ }^{146}$ For example, banning discrimination on the basis of religion, skin colour, dress etc. may promote a conception of culture in which, for example, certain dress codes can be seen as important elements of a particular culture or religion, although it will still leave open the question of the actual contents of these dress codes. Similarly, funding a particular cultural arts centre only advances a conception of certain arts as inherent elements of this culture, but leaves open the question of which arts this particular centre wishes to promote.

${ }^{147}$ UK Employment Act (1989); another exemption, The Motor-Cycle Crash Helmets (Religious Exemption) Act (1976) gives Sikhs the right to wear a turban instead of a crash helmet when riding a motor bike. I will return to the possible rationales behind these exemptions in Ch. 3 .
} 
Sikh culture), the policy nevertheless explicitly acknowledges the importance of wearing a turban for Sikh culture and identity. Further, it can be argued that such exemption not only acknowledges but also promotes the conception according to which wearing a turban is an important, even essential ingredient of Sikh culture and identity. Sikh men are allowed to wear turbans instead of safety helmets precisely because it is recognized that the wearing of the turban is an important element of their identity, and the minority right - in this case, an exemption - is aiming to cater for this fact.

It should, however, be borne in mind that the acknowledgement of the wearing of the turban as an important element of Sikh culture and identity, and the granting of a right that allows Sikh men to wear the turban instead of the safety helmet does not, as such, create anything as strong as an obligation for Sikh men to wear the turban. Sikh men are still perfectly free not to wear the turban, even in the face of the public recognition of this practice as an important element of Sikh culture. In this sense, the legal exemptions would seem to succeed in not creating a duty on minority members to preserve some particular cultural contents, although, as I now will argue, there are some important considerations that, nevertheless, cast some doubt on Kymlicka's claims about minority rights as simply enabling people to preserve their particular cultural contexts or specific cultural practices, if they so wish.

\section{Problem of permanency}

As a preliminary point, Kymlicka argues that both the rights of selfgovernment as well as accommodation rights should not be considered as temporary measures directed to alleviating the disadvantages faced by minority members, but rather as permanent measures through which the minority members are able to preserve their own cultural contexts or some of their cultural practices. The rights in question should not, according to Kymlicka, be considered as temporary, as they do not aim to eliminate, but rather to protect 


\section{Part I Justifying Minority Rights}

people's cultural differences. ${ }^{148}$ The purpose of giving territorial autonomy to aboriginal people is not that, in due time, the aboriginal people could be incorporated back to the main stream political system, and the purpose of granting exemptions to Sikhs from wearing safety hats in construction sites is not to pave way to the gradual abolishing of the wearing of turbans on construction sites. Rather, these rights aim to cater for the possibility of aboriginal people being in charge of their own land in the future, and for Sikhs to continue wearing turbans, even when working on construction sites.

However, given the already established link between minority rights and certain conceptions and contents of culture, and the already mentioned constraints of the prerequisite for choice argument, it is difficult to see how Kymlicka could support the idea of different kinds of minority rights as permanent. If the rights in question do, as I have tried to show, promote certain conceptions as well as contents of culture, and if these rights do (as in the case of exemptions) acknowledge certain cultural practices as inherent, important elements of that culture, then the idea of the permanency of that right would also seem to incorporate a presumption about the continuing importance of that practice in the future. But if, as Kymlicka argues, people are perfectly free to change their views about what they view important and worth preserving in their culture, then they should also be free to decide that those practices (such as the wearing of the turban) might not, some time in the future, be considered as inherent, essential elements of their culture. Once the importance of a particular practice within a culture disappears, however, so disappears the rationale for granting (or maintaining) the exemption that aims to accommodate this practice.

${ }^{148}$ Kymlicka 1995, 31. It is noteworthy that Kymlicka uses the expression of "protecting cultural differences" as a shorthand for the protection of people's abilities to preserve their particular cultural commitments, if they so wish. By doing this, Kymlicka does, already, seem to acknowledge that the rights he is proposing are not neutral with respect to cultural contents, but do, in fact, promote some cultural contents - that is, those contents that are distinctive to the group in question. 
Kymlicka could respond by saying that the idea of minority rights as permanent is only to ensure that the minority members can, if they so desire, continue to observe those cultural norms or practices that these rights aim to accommodate. That is, the rights in question should not, as a default, be considered as temporary, although it is possible that, at some point in time in the future, the rationale for granting (or maintaining) any particular right may have also disappeared (due to the changing views of minority members). In these instances, the minority right in question will end up being temporary, although we should not, as a default, expect this to happen. The presumption of the permanency of any particular right could be understood in terms of these rights as not being inherently temporary (or permanent), but simply in terms of these rights as retaining their rationale, as long as otherwise indicated.

\section{Problem of status quo}

Whereas Kymlicka's claims about the permanency of minority rights could, therefore, be seen as incorporating both the possibilities of minority members not adhering to those practices that the right in question is trying to accommodate, as well as (although debatably) changing their views about the centrality of these practices in their culture, it is important to keep in mind that these possibilities, once the minority right in question has been established, may come at a substantive cost. That is, it may well be that, due to the inherent linkage of minority rights with some conceptions and contents of culture, it may be far more difficult for the minority members to do either of these things. That is, the minority rights may make it substantively harder for the minority members not to adhere to the particular cultural contents that the right in question aims to accommodate, as well as to decide against the centrality of these contents in the future.

Firstly, with respect to the accommodation rights, such as exemptions, it is clear that granting an exemption for minority members to do $\mathrm{X}$ (wear a turban) in circumstances $\mathrm{C}$ (construction sites), promotes a view according to which $\mathrm{X}$ is seen as an important element of the minority members' culture. Although the 


\section{Part I Justifying Minority Rights}

exemption itself does not create anything as strong as an obligation for the minority members to do $\mathrm{X}$, it does, nevertheless, give $\mathrm{X}$ a special status by recognizing it as (one of) the "proper" practices of that culture. Consequently, the legal recognition of $\mathrm{X}$ as (one of the) proper practices of that culture may, in fact, contribute to the maintenance of that practice, as well as making it much harder for those who do not agree with the practice not to adhere to it. This is especially so in cases where the exemption is granted in order to accommodate practices that, according to some minority members, are seen as being required by their culture. ${ }^{149}$ Rather than simply enabling the members of minority cultures to $\mathrm{X}$ - if they so wish the minority right in question may thus end up restricting the opportunities of minority members not to $\mathrm{X}$, due to the special status that $\mathrm{X}$ now enjoys as one of the proper practices of that culture. $^{150}$

With respect to the rights of self-government, such as the right of the cultural group to decide about its own language policies, land distribution or family law, it is equally unclear whether these rights

149 The debates on the French case of laïcité and the 'head scarf -affair' may help demonstrate this point. One of the main arguments against the allowing of head scarves in public schools is that allowing them would create undue pressure on the Muslim girls to wear the veil in order to be considered good Muslims (see e.g. the findings of the Stasi Report/ O'Brien 2005; for debate, see: Laborde 2005; 2008; Bowen 2007, 112127; McGoldrick 2006, 83-89). Although the French case of laïcité is a very special case of cultural accommodation (or lack of; see also Background 2.3.), there is no reason to presume that other forms of exemptions, legitimizing particular cultural practices as proper practices of some culture or religion, could not, also, create pressures for the minority members to adhere to those practices that the right in question is aiming to accommodate.

${ }^{150}$ It should be noted that this is not an inherent effect of minority rights, such as exemptions, but rather a byproduct, the coming into existence of which may well depend on several issues, including the nature (authoritativeness) of the group in question. The worry expressed here is, however, very genuine, especially in cases where the rights are granted to those illiberal groups that tend not to tolerate dissent or differing views among their members. 
do, in fact, manage to give the minority groups a right to decide about their own affairs (in those matters that the right proscribes), without creating at least strong incentives for the group to also preserve certain cultural contents. As already argued, it is clear that the granting of a right to a cultural group to decide, for example, about its own language policies promotes the view according to which language is an important and inherent element of that culture and thus gives a special status to language as one of the defining features of that culture. However, the rationale behind giving a group a right to decide about its language policies lies not simply in the importance of language (any language) for the culture in question, but also in the fact that the particular language(s) of the group are not the same as the official language(s) of the majority, and that the members of the minority do not thus enjoy the same kind of access to their own language (and services provided in this language) as the majority. If the group's language was the same as the official language of the majority, there would be no need to grant the group a right to decide about its own language policies as the minority members' access to their own language would already be guaranteed. But, if the rationale for the group to decide its own language policies comes from the fact that the minority members do not have access to their own language (due to it being different from the official language), then the rationale for such right would also cease to exist should the group decide to run down its traditional languages and not support people's access to these languages (or services provided in these languages). In order to retain its right to decide about its own affairs (something that the group members may, nevertheless, wish to retain), the group thus needs to preserve at least some of its cultural distinctiveness, often by preserving precisely those cultural contents that have created the need for the rights in the first place. ${ }^{151}$

151 See also: Kukathas 1997a, 416. Matthew Festenstein makes an even stronger claim, arguing that the rationale of having secure access to one's own cultural context creates a duty, not only on the minority group itself but also on the state, to preserve precisely those traditional ways of living 


\section{Part I Justifying Minority Rights}

All in all, it would seem that both the rights of self-government as well as (at least some) accommodation rights fail to escape the accusation that these rights promote certain conceptions-, as well as (either directly or indirectly) certain contents- of culture. Although neither create anything as strong as an obligation for the minority members to preserve or to adhere to any particular cultural contents, it would nevertheless seem that, in effect, both of these rights give support for maintaining the prevailing cultural contents by explicitly recognizing these contents as proper elements of the culture in question. The members of cultural groups are, no doubt, still free to choose not to adhere to their traditional ways of living and to alter their views about the contents of their culture, but this is made substantially more difficult by the legitimation of certain cultural practices as proper elements of the culture in question.

\subsection{Minority rights and cultural membership}

Instead of promoting certain conceptions and contents of culture, Kymlicka argues that minority rights should protect people's cultural memberships, and their possibilities to express their memberships in ways they themselves see fit. The difficulty of distinguishing minority rights from specific cultural contents was already mentioned, although it was also noted that these rights

that the group is currently accustomed to (Festenstein 2005, 77-79). I do not think that this is the case, as one's access to one's own cultural context does not mean that the options provided by one's culture should stay precisely the same. I do, however, agree with Festenstein that the rationale of having secure access to one's own cultural context may somewhat limit the speed with which the cultural group can make changes to its traditional ways of being (partially due to Kymlicka's claims about rapid changes as causes of loss and disorientation). The argument I have advanced here, however, is somewhat different from that of Festenstein's in so far as my intention has not been to argue that the rationale behind a differentiated right would create an obligation for the group members to use this right in a particular way, but that, once the right has been granted, it might create strong incentives for the group members to preserve those very circumstances that have provided the rationale for the right in the first place. 
created nothing as strong as an obligation for the minority members to preserve these particular cultural contents. Being thus, the difficulty of minority rights as promoting certain contents of culture could perhaps be accepted, should the minority rights in question nevertheless manage to perform the task they were set to perform that is, to protect people's memberships in minority cultural groups. ${ }^{152}$ Unfortunately, as I try to show, the minority rights hardly managdo not manage to live up to this task either, or, if they do, only to an extent that falls short of the liberal individualist commitments prescribed to by Kymlicka.

Terminological issues: contents, structures and memberships Kymlicka views one's cultural membership as one of the primary goods that the liberal state should attempt to guarantee. This view of cultural membership as one of the primary goods comes from two sources. Firstly, one's membership provides one access to opportunities among which to make meaningful choices. And secondly, one's membership also operates as one of the integral elements in the constitution of people's identities. ${ }^{153}$ People do not only see themselves as individual human beings, but they also see themselves as members of cultural groups - as Inuits, Muslims, Sikhs or Roma. Given these two important functions of cultural membership, the liberal state is seen to have good reasons for applying different types of minority rights in practice - should these

\footnotetext{
${ }^{152}$ According to this line of argument, the promotion of certain conceptions as well as contents of culture could, perhaps, be viewed in terms of unavoidable by-products, necessary for the protection of people's memberships. Provided that minority rights were the only means of protecting people's memberships and provided that they did also perform this task, the idea of an unavoidable, and acceptable, by-product may be sound. As will be shown, however, neither of these presumptions are correct, thus rendering the thought of an unavoidable (and acceptable) byproduct suspect. I will return to Kymlicka's own analysis of unavoidable by-products with respect to internal restrictions and external protections in Ch. 2, 1.1.

${ }^{153}$ Kymlicka 1989, ch. 8; 192-193; 1995: 84-93.
} 
Part I Justifying Minority Rights

rights, indeed, protect people's memberships in minority cultural groups.

In order to understand why I think minority rights may, nevertheless, fail to protect people's cultural memberships (or either of the two functions attached to this membership), it is worth looking at a distinction between what Kymlicka labels as cultural structure and cultural membership. Although this distinction is clearly present in Kymlicka's work, there are also certain implications to this distinction that, I believe, are largely ignored by Kymlicka.

In order to understand the distinction between cultural structure and cultural membership, one must start from a slightly different distinction: that of cultural structure and cultural contents. In Liberalism, Community and Culture, Kymlicka attempts to open up this distinction as follows:

In one common usage, culture refers to the character of a historical community. On this view, changes in the norms, values, and their attendant institutions in one's community (e.g. membership in churches, political parties, etc.) would amount to loss of one's culture. However, I use culture in a very different sense, to refer to the cultural community, or cultural structure, itself. On this view, the cultural community continues to exist even when its members are free to modify the character of the culture, should they find its traditional ways of life no longer worth while. ${ }^{154}$

It should be noted, right from the outset, that Kymlicka uses the terms cultural community and cultural structure interchangeably. Cultural community refers not only to an aggregate of individuals, but also to the social or institutional framework that bonds these individuals together. The cultural community, conceived of in terms of cultural structure, incorporates some cultural contents (most notably, those social norms and institutions that bond the people of

${ }^{154}$ Kymlicka 1989, 166-167, emphasis in the original. 
this community together), although these contents are changeable, and are also open to a variety of interpretations. ${ }^{155}$

Given Kymlicka's illuminating distinction between cultural contents and cultural structure (or community), it is somewhat strange that Kymlicka, nevertheless, fails to make (or at least make good use of) another distinction - that of cultural structure and cultural membership. When discussing the value of cultural structures, Kymlicka argues that cultural structures do not possess any moral status of their own, but are only valuable in so far as they provide their members meaningful options and secure structures to identify with. ${ }^{156}$ There is no rationale for protecting cultural structures qua them being cultural structures, but only qua what these structures do to their members. The differentiation between cultural structures and their individual members is thus clearly present in Kymlicka's work (otherwise, it would not make sense to talk of the value of cultural structures per se versus its value for individual members), but the utilization of this distinction, as will be seen, is far from satisfactory. For Kymlicka, the status of one's cultural membership as a primary good leads to the view according to which the existence of cultural structures should be protected by the liberal state, ${ }^{157}$ but this inference, I believe, does not pay enough

155 There are certain 'constants' that Kymlicka attaches to cultural communities, such as shared language and history (Kymlicka 1989, 168), although these 'constants' should not be thought of as incorporating any thick conceptions of what, for example, this shared history of a particular cultural group may contain. For the problemacy of defining cultural communities in terms of shared history, see e.g. Appiah 2005, 136-137.

${ }^{156}$ Kymlicka 1989, 165-166; for Kymlicka's views on the moral status of groups, 241-242.

${ }^{157}$ In his discussions on Lord Devlin's remarks about homosexuality in England, Kymlicka makes this conflation most pronouncedly, shifting from the primary good of cultural membership to the primary good of cultural structure: "Thus liberalism requires that we can identify, protect, and promote cultural membership, as a primary good, without accepting Devlin's claim that this requires protecting the character of a given cultural community. It is the existence of a cultural community viewed as 
Part I Justifying Minority Rights

attention to the distinction between cultural structures and cultural memberships and the implications that this distinction may have for liberal political theory.

Two senses of protecting membership

The distinction between cultural structures and cultural memberships can be illustrated by looking at the ways in which minority rights, promoted by Kymlicka, can be viewed as protecting cultural structures but not, necessarily, any particular individual's cultural memberships.

Take, firstly, the rights of self-government that give a group a right to decide about its own affairs (in most cases, about some particular affairs, such as language policies, land distribution or family affairs). Granting a group a right to self-government may, indeed, protect the cultural structure of the group by enabling the group to maintain those bonds - social and institutional frameworks - that tie the group members together, and also provide these members their contexts of choice and bases of identification. But the rights of self-government remain silent about how the members of the group eligible for this right should be identified. In many cases, the rights of self-government are, in fact, precisely rights that enable the group, not only to decide about how their communities are run, but also to decide who they accept as members of their group. ${ }^{158}$ Keeping this in mind, the rights of self-government fail to protect the membership of any individual to the structure in question, as the group may, in fact, come to restrict some people's

a context of choice that is a primary good, and a legitimate concern of liberals." Kymlicka 1989, 169.

${ }^{158}$ Kymlicka's discussion on the membership rules of Pueblo Indians puts this point forth most clearly. Although Kymlicka admits that the sexually discriminatory membership rules of the Pueblo Indians are something that the liberals are right to criticise, he nevertheless maintains that the group in question should be allowed to apply its own rules of membership without external intervention from the liberal state. (Kymlicka 1995, 165170) The difficulties of allowing group members to decide their own rules of membership will be returned to in more detail in Ch. 4 and Ch. 5 . 
access (people's membership) to this structure. Without membership, these people, undoubtedly, lack access to the opportunities provided by their culture, and may also find it very difficult to identify with the group in question due to lack of recognition as a group member. ${ }^{159}$ Whereas the rights of selfgovernment can be seen as protecting the cultural structure itself and, by way of protecting this structure, creating conditions in which cultural membership (in the abstract) can be enjoyed, they nevertheless fail to protect the membership of any individual and, consequentially, of any individual's access to opportunities and bases of identification. ${ }^{160}$

Many of the accommodation rights (such as exemptions from the general rules or laws of society) would not, either, seem to protect any individuals' memberships, or these individuals' access to opportunities or bases of identification. Whereas the accommodation rights differ from the rights of self-government in so far as they are not even aiming to provide people secure access to their own cultural structure, these rights can, nevertheless, be seen as providing the two functions of cultural membership. The

\footnotetext{
${ }^{159}$ The issues of recognition-beased identities will be discussed in Ch. 5 .

${ }^{160}$ Perhaps Kymlicka could respond by claiming that giving a right to a particular group (or members of this group) already entails a conception of who are the members of that group, thus following Kymlicka's views of certain identities as given (Kymlicka 1995, 184). However, as I will argue in Ch. 4, denoting membership in a cultural group is far from being a simple and straightforward task. Further, even if Kymlicka was able to establish that the protection of cultural structures was necessary for the protection of some particular people's cultural memberships (that is, those people's memberships who are already seen as members), the problem remains. If one's cultural membership is valuable - and, in accordance with Kymlicka's claims, should be protected - due to the value that this membership has as a provider for that person's identity and opportunities, it would seem that the primary concern of the liberal state should not be the protection of cultural structures, but rather, the protection of the individuals' memberships - something that the rights of self-determination would seem to fail at protecting.
} 


\section{Part I Justifying Minority Rights}

exemption of Sikh men from wearing hard hat provides the male members of Sikh culture an opportunity to express their membership by wearing a turban. This may also operate as one of the important features through which they identify themselves as Sikh men. In accordance with Kymlicka's view of accommodation rights as easing the access of minority members to the cultural context of the majority (without having to abandon all of their cultural heritage), this exemption also provides opportunities for Sikhs to conjoin some of their cultural practices with the cultural framework of the majority. ${ }^{161}$ The question of who, and on what grounds, is identified as a Sikh man to whom this exemption is granted, however, does not feature in Kymlicka's (or many other theorists) discussions on minority rights. At the most, these exemptions can thus be seen as protecting the way in which some people may come to express their cultural membership, but they do not protect the membership of any individual, or the bases upon which any particular individual comes to enjoy the opportunities arising from the exemption, or the possibilities of expressing one's identity by the practice that the exemption accommodates. The accommodation rights, such as exemptions from general rules or laws of the society, too, say nothing about the criterion according to which those people eligible for the exemption should be identified, thus failing to protect the membership of any particular individual, but only membership in the very abstract and perhaps also very uninteresting sense.

It should be noted, that Kymlicka does not make a clear distinction between the protection of cultural membership in the abstract (that is, the protection of cultural structure that creates conditions in which cultural membership can be enjoyed) and the protection of any individuals' membership in this structure. The failure to do so, however, I believe, constitutes one of the crucial inadequacies in Kymlicka's work and in his attempt to build a genuinely liberal, individual centered approach to cultural diversity.

${ }^{161}$ This view of accommodation rights as providing for the opportunity to conjoin $X$ and $Y$ will be discussed in more detail in Ch. 3 . 
Taken that, for Kymlicka, cultural structures and cultural memberships are valuable only by virtue of them being valuable for their individual members (by providing for their opportunities and their identities), it is somewhat strange that Kymlicka should restrict his theory to the protection of cultural structures (that provide the conditions in which membership (in the abstract) can be enjoyed), without also aiming to protect the membership of those to whom these structures are, in fact, valuable.

It may be argued in response that the fact that minority rights fail to protect any particular individual's membership makes no difference to the case for the need of these rights, as without such rights perhaps no-one would be able to enjoy such membership, or the benefits of such membership. Although there may be some truth in this response, I do not think that this response fully addresses the problem I have tried to indicate here. Whereas it may well be the case that (at least some) minority rights do protect those structures within which some people can enjoy their cultural memberships, ${ }^{162}$ I do not think that Kymlicka's (or many other theorists') treatment of minority rights as protecting cultural structures take sufficiently into account the individualist commitments of liberalism, and the fact that it is not only cultural memberships in the abstract that should be the proper concern of the liberal state, but the cultural memberships of those individuals to whom these memberships really matter. Without answering the questions of who should come under the minority right in question (rights of self-government) or to whom certain rights should be accorded (accommodation rights), these rights, protecting the cultural structures and memberships in the abstract, only take us half way in protecting people's memberships, failing to protect the memberships of those

\footnotetext{
162 This, of course, may be subject to empirical evidence, and does not, in any way, preclude the possibility that such structures could not be protected by other means than minority rights.
} 
Part I Justifying Minority Rights

individuals to whom these structures are, indeed, valuable as contexts of choice and as bases of identification. ${ }^{163}$

\section{Conclusion on Kymlicka's liberal multiculturalism}

In this chapter, I have concentrated on Will Kymlicka's liberal multiculturalism as presented mainly in Liberalism, Community and Culture, and Multicultural Citizenship. ${ }^{164}$ Although Kymlicka's work incorporates several elements (all of which could be discussed in their own right), I have tried to concentrate on his basic liberal egalitarian framework, and on his proposals (minority rights) for rectifying those inequalities that this framework comes to identify. I have argued that Kymlicka's modified, resourcist account of equality manages to explain both the disadvantages caused by one's lack of one's own cultural context, as well as the disadvantages faced by those who, due to adhering to some particular cultural norms or practices, find it difficult to participate in the workings of the larger society. I did, however, point out that the rationales for the state to be concerned about and try to rectify these disadvantages were, in each case, different. A much stronger case, based on the prerequisite for choice, importance and involuntariness arguments, was made for rectifying the disadvantages caused by one's lack of one's own cultural context, whereas the

\footnotetext{
${ }^{163}$ More thorough analyses of how to address these questions of cultural membership and the protection of any individual's membership within the liberal framework needs to wait until Part II of this work.

164 The choice to concentrate on these two earlier works of Kymlicka comes from the acknowledgement of these two works as outlining Kymlicka's theoretical commitments most explicitly. Whereas in his later work, Kymlicka deepens and, no doubt, somewhat fine tunes his analysis on different cases of cultural inequality by tying his analysis more tightly to the concrete circumstances around the globe (esp. Kymlicka 2001; 2007a), I do not think that his later work makes substantive modifications or additions into his basic theoretical framework. Rather, whereas Kymlicka's later work certainly gains from being even more connected and sensitive to the multiplicity of cases of cultural inequality, it loses in being less connected with and rigorous about the theoretical problems incorporated in issues of cultural accommodation.
} 
accommodation of people's cultural differences within the context of the majority could, in many cases, only be based on the importance argument (and, as that, on the modified importance argument that Kymlicka never explicitly subscribes to himself).

Whereas Kymlicka's egalitarian framework does, therefore, manage to explain why the cultural inequalities faced by minority members should be proper concerns of the liberal state, his arguments for minority rights as appropriate responses to these inequalities are far from satisfying. Kymlicka argues that minority rights (both rights of self-government and accommodation rights) are not to advance any particular cultural contents, but to simply enable minority members to live in their own cultural contexts and/or express their cultural identities in ways they themselves see fit. It is, however, clear that neither of these categories of rights manage to stay entirely clear from promoting certain cultural contents by legitimizing certain cultural practices as proper elements of that culture. Although the minority rights do not, as such, create anything as strong as an obligation for the minority members to maintain any particular cultural contents, they do, nevertheless, promote certain conceptions as well as contents of culture, and may, in effect, also reinforce the preservation of certain cultural practices, and diminish the opportunities of the minority members to alter or reject these practices.

The problem of minority rights as promoting certain conceptions as well as contents of culture could, however, perhaps be accepted if the minority rights in question did, nevertheless, perform the task they were tasked to perform: that is, to protect people's cultural memberships. However, as argued in section 2.3., Kymlicka's treatment of minority rights as protecting cultural structures (memberships in the abstract) rather than any individual memberships (in particular), only gets us half way to fulfilling this task. The framework, given by Kymlicka, never answers the questions of who should come under any particular right (rights of self-government) or who should be eligible for the rights of cultural accommodation, and - by not doing so - also casts some doubt on the idea of minority rights as protecting people's memberships. 
Part I Justifying Minority Rights

Answering these questions, however, is of utmost importance in order for minority rights to track their targets, and in Part II, I answer these questions in more detail.

To make things clear, none of the above mentioned considerations (the different kinds of rationales for the state concern, the failure of minority rights to stay clear of promoting particular contents of culture, or the inadequacy of the membershipmodel) are intended as providing support for an outright rejection of different kinds of minority rights within the liberal framework. Such rejection (if, indeed, possible) would need to assess the question of minority rights from a slightly different perspective, partially taken in the next two chapters of this work. What I hope to have shown, however, is that the problems outlined in this chapter, even if not providing any conclusive case against minority rights, are very real and should not be ignored lightly. At the very least, they should direct us towards a far more cautious approach to minority rights, both at the level of their justification as well as at the level of application. Whereas the general liberal egalitarian framework of Kymlicka, as I have shown, gives good reasons for the liberal state to be concerned about and to try to rectify cultural disadvantages, this framework may not be extended as far as dictating the kinds of policies that the liberal state should adhere to. Rather, the actual policies of cultural accommodation need to be assessed in context, taking into account both the theoretical difficulties outlined above, as well as other possible considerations that there may be for granting, or not granting, such rights in practice. 


\section{Chapter 2}

\section{Autonomy vs. toleration}

In the previous chapter, I concentrated on Will Kymlicka's equality based arguments for (1) the liberal state to be concerned about and try to rectify cultural disadvantages, and (2) for minority rights as adequate responses to these disadvantages. I argued that Kymlicka was able to build a strong case for the liberal state to be concerned about disadvantages faced by minority members, but that this case did not extend to an argument for the requirement of minority rights in practice. Most notably, I highlighted the difficulties ensuring that minority rights steer away from promoting certain conceptions and contents of culture, as well as their incapability of protecting individual cultural memberships. Neither of these difficulties, however, provided any conclusive case against minority rights, although they did point towards adopting a more cautious approach to such rights, as well as towards the need to rethink the issues of cultural membership and the questions of the allocation of these rights anew.

During the course of these discussions, I made several references to the tensions between Kymlicka's prerequisite for choice -argument, and the two other arguments from importance and involuntariness. The prerequisite for choice -argument, it was suggested, was important for showing the compatibility of cultural claims with liberalism, but it also stood in some tension with the importance and involuntariness arguments, by creating certain constraints on the kinds of cultures and cultural commitments that the liberal framework could incorporate. These constraints, inherent in Kymlicka's theory, can be traced back to Kymlicka's emphasis on individual autonomy as one of the key values of liberalism, and the role of the liberal state in protecting, or even promoting, the autonomy of its individual members.

As the centrality of individual autonomy, and the role of the liberal state in protecting and/or promoting individual autonomy are 


\section{Part I Justifying Minority Rights}

far from uncontested issues among liberal multiculturalists, in this chapter, I focus on the issues of individual autonomy and the kinds of constraints that individual autonomy, as one of the key liberal values, brings to the liberal responses to cultural diversity. Most notably, I look at the questions relating to the rights of minority groups to govern their internal affairs, and the kinds of constraints the liberal state may impose as preconditions for non-interference. Whereas my intention is not to argue for the more stringent approaches, incorporating the role of the liberal state in promoting individual autonomy and the requirement of the imposition of liberal norms (to the affairs of illiberal groups), I do argue that alternative approaches (often discussed under the term diversityliberalism) also require protection of certain preconditions for individual autonomy, as well as certain interferences of the liberal state to the affairs of illiberal groups.

This chapter proceeds as follows. I begin (section 1, Limits of autonomy liberalism) by looking at some of the autonomy-based constraints that Kymlicka gives to the legitimate ways of using minority rights, especially the rights of self-government. ${ }^{165}$ I argue (1.1.) that these constraints, inherent in Kymlicka's account, provide much stronger guidelines to the kinds of groups eligible for the rights of self-government than Kymlicka would be willing to acknowledge, as well as grounds upon which the state's interference to the affairs of illiberal groups can be justified. Given Kymlicka's reluctance to legitimize such interference, I show (1.2.) how Kymlicka's framework does, indeed, provide strong practical reasons for not interfering with the internal affairs of certain groups,

165 The connection between minority rights and individual autonomy is, I believe, most explicit in Kymlicka's discussions on the self-government rights of national and indigenous minorities, although the discussions of this chapter can also be read as discussions of a more general problem, that of the right of (any) cultural or religious group to govern its own affairs without the interference of the state. The term "right of self-government" should, in this context, thus be understood broadly, as a right of a group to govern its internal affairs, regardless of whether this self-government incorporated full or even partial secession from the liberal state. 
although it is not able to provide any principled justification for why these groups should be eligible for the rights of selfgovernment in the first place.

After discussing the qualifications that Kymlicka's emphasis on individual autonomy creates for his justificatory framework for minority rights (rights of self-government), I turn to discuss an alternative approach, that of Chandran Kukathas's toleration-based account of multiculturalism (section 2, Diversity liberalism and the critique of autonomy). I argue that, whereas Kukathas is right to point out some of the limitations of Kymlicka's autonomy-based account (most notably, the inability of this account to accommodate those ways of living that do not place high value on individual autonomy), his attack on individual autonomy as one of the guiding principles of liberalism is far from successful. By way of analysing the requirements of mutual toleration and non-interference in Kukathas's own model, I show how his model of a free society also rests on a requirement to ensure certain (albeit very minimal) conditions for individual autonomy for all.

The final section of this chapter (section 3, Minority rights, diversity, and the state), returns to the question of minority rights and the (in)ability of the grand theories of multiculturalism to provide conclusive guidance to the liberal state with respect to these rights. This section analyses the arguments, given by Kukathas, for the rejection of minority rights as appropriate means for the liberal state to respond to cultural diversity and argues that Kukathas's own theoretical framework leaves considerable scope for the liberal state to adopt a variety of minority rights in practice. All in all, this chapter, together with $\mathrm{Ch} 1$, builds a case for rejecting the grand theorists' attempts to create too simple and straight forward accounts of (either the requirement or rejection of) minority rights, by showing that there may not be any principled answer to whether the liberal state should adopt any particular system of minority rights in practice, but that, in most cases, there are good liberal reasons both for as well as against such rights. 
Part I Justifying Minority Rights

\section{Limits of autonomy liberalism}

One of the most controversial aspects of Kymlicka's liberal multiculturalism lies in his strong commitment to individual autonomy as one of the guiding principles of liberalism, and his view of minority rights as catering for individual autonomy. To recall, Kymlicka views cultures as contexts of choice that provide people opportunities and enable them to make meaningful choices among these opportunities. The minority rights, such as rights of self-government, are needed in order to secure minority members' access to their own contexts of choice, within which they can make meaningful choices among the options provided by their culture. ${ }^{166}$ Kymlicka's emphasis on the freedom of choice of the minority members does, however, create certain limitations both to the kinds of minority rights justifiable within Kymlicka's liberal framework, as well as for the kinds of groups eligible for these rights. Some of these limitations, such as the illegitimacy of minority groups to suppress the freedom of choice of their own members, are clearly recognized and argued for by Kymlicka himself, although, as I will argue, the scope of these limitations ${ }^{167}$ extends much further than Kymlicka would be willing to acknowledge. Most notably, as I try to show, Kymlicka's commitments to individual autonomy, and the requirement of the minority rights (rights of self-government) to protect or even promote individual autonomy lead to far more stringent requirements for the kinds of groups eligible for such rights than Kymlicka would be willing to accept.

166 The difficulties of viewing one's own culture as prerequisite for individual choice were discussed in Ch. 1, 1.1.

167 My focus is on Kymlicka's discussion on intra-group relations. It should be noted that Kymlicka also argues for certain limitations on an inter-group level (see: Kymlicka 1995, 152-153), but I will not comment on these limitations in this discussion. 


\subsection{External protections and internal restrictions}

According to Kymlicka, the self-government, accommodation and special representation rights can all operate to two different effects. On the one hand, they can be used as external protections that shield the minority group from unwanted external influences by securing the conditions in which the minority members can preserve their own cultural contexts (if they so wish). The selfgovernment rights of the indigenous peoples, for example, allow these peoples relative control of their own territories, thus ensuring that, within their given territory, the minority in question is not outbid by the decisions of the majority. On the other hand, however, minority rights can also operate as internal restrictions that limit the opportunities of the minority members to question and revise their traditional ways of living. The same self-government rights of the indigenous peoples, for example, can be used to force minority members to adhere to the traditional customs of their community or to impose severe restrictions on the minority members freedom to leave their communities. ${ }^{168}$

Kymlicka is careful to note that, within the liberal framework, only external protections can be justified, whereas internal restrictions should be rejected. ${ }^{169}$ This claim is based on Kymlicka's emphasis on individual autonomy as one of the guiding values of liberalism, and his view of minority rights as catering for such autonomy. ${ }^{170}$ Whereas the external protections (providing the conditions in which the minority group can enjoy their own cultural context) cater for this task, the internal restrictions (limiting the opportunities of minority members) do not. What is not entirely clear, however, is, firstly, whether the distinction between external protectors and internal restrictions is sustainable, and, secondly, whether the minority rights, such as the rights of self-government, manage to live up to the task of catering for individual autonomy, and in what sense.

${ }^{168}$ Kymlicka 1995, 35-44.

${ }^{169}$ Kymlicka 1995, 37; 41; 152-153.

${ }^{170}$ Kymlicka 1992, 142. 
Part I Justifying Minority Rights

\section{Dealing with the distinction}

As Kymlicka recognizes, the distinction between internal restrictions and external protections is not always easy to draw. ${ }^{171}$ The same right of self-government, for example, can be used both, to protect the social and institutional framework that operates as the minority members' context of choice, as well as to restrict the minority members' opportunities to question and revise their traditional ways of living. Often, the internal restrictions (such as the restrictions on the usage of land, or the requirements to follow certain codes of conduct) are even argued for in terms of external protections aiming to minimize the outside influence within the group.

On a theoretical level, the distinction between the external protections proper, and the internal restrictions argued for in terms of external protections is relatively clear: the external protections (proper) enable the minority members to preserve their traditional ways of living, if they so wish, whereas the internal restrictions force the minority members to do so, even if they would not voluntarily choose to do so. ${ }^{172}$ The strict enforcement of religious dress codes, for example, may be argued for in terms of trying to reduce the outside influence within the group (and may even be able to do this), but only by taking away the freedom of the members not to adhere to such requirement. By taking away the freedom of the members to change such tradition, such enforcement becomes unjustifiable, regardless of its role as reducing the outside influence and, consequently, of enhancing the opportunities of minority members to preserve their own cultural contexts. ${ }^{173}$ The

\footnotetext{
${ }^{171}$ Kymlicka 1995, 42.

172 Kymlicka 1995, 42, n. 11.

${ }^{173}$ It is, of course, debatable whether the reduction of outside influences in terms of, for example, banning certain types of clothing, enhances the opportunities of minority members to preserve their own cultural contexts. Given Kymlicka's distinction between cultural contents and cultural structures, the answer would seem to be negative (see also Ch. 1, 2.3.). My point here, however, is not to argue for or against the possible impacts of
} 
external restrictions, on the contrary, should have no such consequences, preserving the freedom of the minority members to interpret and practice their cultures also in ways that do not fit the traditional conceptions of what the culture in question contains.

In the light of the discussions of the previous chapter, it is, however, debatable whether the theoretical distinction between external protections and internal restrictions can ever be maintained in practice. ${ }^{174}$ That is, whether it is ever the case that the external protections would not also create certain internal restrictions by taking away at least some of the options open to the minority members. As argued in the previous chapter (esp. 2.2.), the rights of self-government (indeed any minority rights) are never rights purely in the abstract, but incorporate certain contents through which the legitimate practices of the group are decided. The language laws of Quebec, for example, do, in effect, restrict the opportunities of the Quebecois to choose to use English in certain settings, and the land laws of the indigenous peoples do not only restrict the usage of land of outsiders, but of the indigenous peoples themselves. For Kymlicka, these internal restrictions, incorporated in the external protections, are viewed in terms of unavoidable byproducts. ${ }^{175}$ That is, as unfortunate, although acceptable, consequences of measures (external protections) that are,

such measures, but simply to show that, even if such measures (e.g. bans on certain types of clothing) did enhance the opportunities of minority members to preserve their own cultural contexts, the taking away the freedom of the minority members to change these traditions would render such measures illegitimate.

${ }^{174}$ This, it should be noted, is an altogether different question from the problem of whether it is ever possible to know in advance to which effect any particular right will be used. (See also: Kymlicka 1995, 40) Whereas the predicting of the possible usage of any particular right (such as the rights of self-government) should, no doubt, be on the agenda of the liberal state granting such rights, the problem, highlighted here, is conceptual, incorporated in the nature of minority rights themselves (rather than in their particular usages).

${ }^{175}$ Kymlicka 1995, 44. 
Part I Justifying Minority Rights

nevertheless, needed for the minority members to be able to preserve their own cultural context, should they so wish.

The introduction of unavoidable, yet acceptable, internal restrictions into the discussions on justifiable minority rights creates a pressing need to draw a distinction between the unjustifiable internal restrictions proper (such as the strict enforcement of religious dress-codes) and restrictions that come as unavoidable (yet acceptable) by-products of external protections (such as certain restrictions on using particular languages in particular situations). One way of drawing such a distinction would be to look at the kinds of restrictions that the minority members are faced with and assess whether these restrictions limit the basic civil rights and liberties of the group members. ${ }^{176}$ To an extent, this is also the approach adopted by Kymlicka, for whom the rights of minority groups should not limit the basic rights and freedoms of the group members, such as the freedom of speech and expression, liberty of conscience, the right to physical integrity etc. Most notably, Kymlicka argues that minority rights should not restrict the minority members' capabilities to assess and to also revise their traditional ways of living, but (on a much stronger note) provide for their autonomy - for their capabilities to choose and to pursue the kinds of lives they themselves see fit. ${ }^{177}$

These two requirements (1. that minority rights should not prevent people from assessing (and possibly changing) their current ways of life, and 2. that they should also cater for or even enhance people's capabilities for doing so) are, of course, very different, providing either weaker or stronger limitations to the kinds of minority rights justifiable within Kymlicka's liberal framework. The first requirement (that of non-prevention) may, at the most, be

176 The key distinction between internal restrictions proper and unavoidable (yet acceptable) by-products does not thus lie in the way in which these restrictions have come into being (whether by their own or as by-products of external protectors), but rather on whether these restrictions can be justified within the liberal framework.

${ }^{177}$ Kymlicka 1995, 152-153; 1992, 142. 
seen as a requirement for the minority rights to protect individual autonomy, whereas the latter (that of enhancement) provides a much stronger claim, not only of protection, but also of promotion of the autonomy of minority members. ${ }^{178}$ Depending on which one of these views one subscribes to, one will also have slightly different views of the kinds of groups that, within the liberal framework, can be seen as eligible for such rights - or so I try to argue.

\section{Protecting vs. promoting individual autonomy}

Take, first, the stronger claim that minority rights should promote individual autonomy - that is, to cater for or enhance people's capabilities to assess and to pursue the kinds of lives they themselves see fit. In order to cater for individual autonomy, it seems, it is not enough that the minority right in question enables the members of the cultural group to preserve their own cultural context, but that this context is also of certain kind. At the very minimum, this context needs to incorporate a sufficiently complex set of options that the minority members can take advantage of, as well as a system of education that enables the members to make meaningful choices among these options. ${ }^{179}$ In order for the

178 Kymlicka's own terminology incorporates expressions such as "promoting", "enabling" and "protecting" individual autonomy (ibid.), and it is not always clear which position Kymlicka himself subscribes to. Whereas my distinction between the promotion and protection of individual autonomy reflects, partially, the ambiguities of Kymlicka's own position, it does (as will become clearer later on) also capture something important about the kinds of responses that the liberal state may take in its responses to cultural diversity.

${ }^{179}$ It could even be argued that, for the promotion or enhancement of individual autonomy, it is not enough that the context in question provides sufficiently complex set of options for the members to choose from, but that this context should also provide "a better" set of options than the context of the majority (that is, the context should be such that will enable the minority members to practice their autonomy to fuller extent than in the context of the majority). Should the context of the minority, however, provide substantively lesser (or "worse") opportunities for its members 


\section{Part I Justifying Minority Rights}

minority members to make autonomous choices among the options provided by their culture, the culture needs to, already, be such that caters for individual autonomy, incorporating both, an environment within which the members' capacities for autonomy can develop, as well as a sufficiently varied set of options for the minority members to choose from. ${ }^{180}$ But if, say, the options provided by the minority culture are very few and far between (as is often the case when the community in question continues to live in relative isolation in accordance with its age old traditions), ${ }^{181}$ it becomes questionable whether the options provided by these cultures can really be conceived of as varied enough for the members to have any meaningful choice with respect to how to lead their lives. The minority groups, eligible for the rights that enable them to preserve their own cultural contexts would thus seem to be restricted to groups that are, already, sufficiently pluralistic and heterogeneous that is, to groups that are, already, liberal. ${ }^{182}$

A liberal multicultural theory should not, however, be a theory that can only accommodate liberal cultural groups and liberal ways of life, and to answer this worry, many have come to argue for

than the context of the majority (even if sufficiently complex), it would from the perspective of promoting individual autonomy - be better not to grant rights of self-government for these groups, as the preservation of these contexts would fail to enhance individual autonomy. For my purposes, I use the term "promoting individual autonomy" not in this stronger sense, but in the sense in which the context in question must provide 1) sufficiently complex set of options to choose from, and 2) environment within which the capabilities of the minority members to reflect and to make informed choices about these options can develop.

${ }^{180}$ As Joseph Raz has forcefully argued, a choice made in the face of lack of alternatives may not be counted as an autonomous choice, as autonomy involves the idea of having an adequate range of options to choose from. Raz 1986, ch. 14 \& 15. See also: Christman 2001; 2005; Colburn 2010.

${ }^{181}$ Such as certain indigenous peoples in Latin America, or certain religious communities that have chosen to isolate themselves from the rest of society, including the Amish in USA.

${ }^{182}$ I will come back to the second (liberal) requirement of these groups not suppressing the basic rights and liberties of their members shortly. 
much weaker requirements for the kinds of groups that, within the liberal framework, can be seen as eligible for minority rights, such as the right of self-government. According to these thinkers, those minority groups that provide only very limited sets of options for their members can still be seen as having the right to organize their internal affairs in ways they wish, as long as they provide their members information also of other ways of living (that is, of other ways than their "own"). ${ }^{183}$ Being provided such information, it is argued, the members would at least be aware of other opportunities and other ways of life (even if their own group could not provide them with these opportunities), and may also be able to leave their own cultural community for the wider variety of options and ways of life provided by the culture of the majority. ${ }^{184}$

Whereas this weaker position (that is, not the requirement of the minority groups to provide sufficiently complex sets of options themselves, but the requirement of these groups to provide information about alternative options outside the group), would seem to have the benefit of incorporating somewhat wider variety of minority groups to be eligible for minority rights, this response, however, is not open to Kymlicka himself. Most notably, this response stands in stark contrast with Kymlicka's original rationale for why people should be able to live in their own cultural contexts in the first place - that is, because these contexts, by definition, provide people meaningful options to choose from. Nor does this response seem to fit well with Kymlicka's commitment to the primacy of one's own cultural context and the view according to

${ }^{183}$ Most prominently, William Galston has promoted a view according to which the group's right to govern its internal affairs is dependent on the requirements of providing its members certain minimal knowledge about alternative ways of life. (Galston 1995; 2002; 2005) I will come back to Galston's view and its implications to other diversity-liberal theories of multiculturalism in the second part of this chapter (esp. 2.2.).

${ }^{184}$ The requirement of providing information about alternative ways of life is also inherent in Kymlicka's account (e.g. Kymlicka 1995, 81-82), although, as I will argue, this cannot operate as a sufficient requirement for the minority groups to be allowed to govern their internal affairs. 


\section{Part I Justifying Minority Rights}

which it is not reasonable to expect people to leave their own cultural contexts. If the group to which the individual happens to belong to, however, only provides a very limited set of options for that individual to choose from, it is not enough that further options are available outside the community, as the taking of advantage of these options would require the individual to leave. ${ }^{185}$ Rather, the requirement of the minority rights to cater for, or to promote the autonomy of the group members would seem to create a requirement for the minority groups, not only to provide information about alternative ways of life outside their community, but also to incorporate these alternatives into their own cultural context, at least to a point in which the options provided by the culture in question would be complex enough for the minority members to make meaningful choices from.

This requirement for a cultural group to provide its members a sufficiently varied set of options to choose from does not, however, say anything yet about when a particular set of options provided by any particular culture is, indeed, sufficient to be considered as catering for people's autonomy. Quite obviously, the sets of options provided by different cultures vary, and it may be too strong a requirement to insist that the minority cultures would need to provide their members a maximally varied set of options or even a set of options that would be as diverse as the options provided by majority culture. In order to live autonomous lives, it is enough that the minority members have a relatively varied set of options to choose from, but this set needs not be as varied as, or identical with the set provided by the majority culture. ${ }^{186}$ On the contrary, what is

185 Recall that, for Kymlicka, "respecting people's own cultural membership and facilitating their transition to another culture are not equally legitimate options” Kymlicka 1989, 176.

${ }^{186}$ This may also be a question of lacking common metrics for measuring the variety of options inherent in any particular culture. As David Miller has forcefully argued, in circumstances of cultural diversity, it may be difficult, even impossible, to find any uncontested metric for measuring whether the members of any particular group (in Miller's case, nation) enjoy equal, or relatively equal opportunities. Miller 2005. 
important, according to Kymlicka, is that the options provided by the minority culture are the kinds of options that the minority members find meaningful, not that they resonate (in scope or content) with the options of the majority.

Whereas I do believe that, for Kymlicka, the minority rights should perform precisely this stronger task of promoting individual autonomy, ${ }^{188}$ it is also clear that the constraints this requirement creates for those groups eligible for such rights are, not only extremely stringent, but also extremely difficult to measure or assess. Due to these difficulties (of measuring the kinds of options, meaningful to the minority members, as well as of establishing the threshold above which the set of options provided by the minority culture would be sufficiently complex), it may be worth looking at those requirements that the minority culture must, minimally, fulfill, in order for the group in question to be even considered for those rights that enable them to preserve their own cultural contexts, if they so wish. These requirements, I believe, are incorporated in Kymlicka's weaker claim - that is, that the minority rights should not prevent people from assessing (criticizing or reaffirming) their current customs and ways of life. That is, the cultural group, to which the minority rights are granted, should not use these rights to force people to adhere to any particular cultural customs or practices, nor should it prevent people from acquiring information about alternative ways of life, although it does not need to be the kind of group that provides its members sufficiently varied

187 Provided that different cultures provide different cultural narratives through which to view one's ways of life, it is clear that those options, conceived as meaningful for the minority can vary tremendously from the options conceived as meaningful for the majority. This does not, of course, take away the fact that, in order to make meaningful choices, some threshold of sufficiently complex set of options needs to be established only that this set needs not be identical with the set of the majority.

188 That is, of providing minority members freedom not only to choose their own courses of life, but also of providing 1) sufficiently complex set of options from which these choices can be made, as well as 2) supporting those capacities that are requires for autonomous choice. 


\section{Part I Justifying Minority Rights}

sets of options to choose from, nor specific ways through which the members learn to make meaningful choices among their alternatives (however scarce or abundant they be).

Whereas this weaker requirement - let us call it the requirement of protecting individual autonomy ${ }^{189}$ - would seem to be able to incorporate a much wider variety of groups ${ }^{190}$ eligible for minority rights (rights of self-determination), it is worth noting that, even with this weaker requirement, there are still certain, indispensable, requirements that those groups eligible for minority rights must fulfill. In Kymlicka's framework - regardless of whether one views minority rights as promoting or merely protecting individual autonomy - the groups in question cannot restrict their members' basic rights or freedoms to question their traditional ways of living, or their attempts to acquire information about alternative ways of life. Those groups, eligible for minority rights are, in Kymlicka's framework, only those groups that are, already, operating in accordance with certain liberal principles, protecting the basic rights and freedoms of their members. The right of the group to govern its own affairs and to maintain its own cultural context (should it so wish) is, in Kymlicka's own terms, justifiable only in cases where this context is of a certain kind - that is, a liberal cultural context of a liberal cultural group.

\subsection{Liberal rights and liberal imposition}

Kymlicka's emphasis on individual autonomy and his consequent view of minority rights as subordinate to the basic rights and freedoms of individuals, has prompted a critique according to

189 This requirement of "protection" should be understood in a very minimal sense of "not preventing" people from questioning their current ways of life.

${ }^{190}$ For example, groups that are only able to offer very limited set of options to their members (such as isolated tribal communities or extremely poor nation states) can be conceived as eligible for the rights of selfdetermination (broadly construed), as long as they do not prevent their members from questioning their traditional ways of living or of acquiring information from outside their own community. 
which Kymlicka's theory of minority rights is simply a form of cultural imperialism that justifies the imposition of liberal values on groups that would not, voluntarily, be willing to endorse such values. ${ }^{191}$ The idea being that, by prioritizing the basic rights and freedoms of individuals over the rights of the group to govern its own affairs, Kymlicka does not only reduce the kinds of groups, eligible for the right of self-determination, into groups that are already liberal, but also opens the door for interference, forcing the other, illiberal groups to change.

Being reluctant to accept such implications, Kymlicka attempts to make a differentiation between two questions: (1) what sorts of minority claims are consistent with liberal principles? and (2) whether the liberals should impose their views on minorities which do not accept some or all of these liberal principles? ${ }^{192}$ According to Kymlicka, "the first is a question of identifying a defensible liberal theory of minority rights; the second is the question of imposing that liberal theory." ${ }^{, 193}$ Moreover, Kymlicka explains that his task (especially in Multicultural Citizenship) has been the first rather than the second, ${ }^{194}$ and that, in order to answer the second (that of imposition), several further considerations would need to be taken into account. ${ }^{195}$ Further, Kymlicka argues that, in many cases, there are no legitimate grounds for imposing liberal principles upon

\footnotetext{
${ }^{191}$ E.g. Kukathas, 1992; 2003, 181-189; Galston 1995; 2005; Gray 2000; see also: Mendus, 1989.

${ }_{192}$ Kymlicka 1995, 164

${ }^{193}$ Kymlicka 1995, 164, emphasis in the original.

${ }^{194}$ In his later works, Kymlicka does, to an extent, attempt to answer the second question of imposition by discussing some of the difficulties as well as appropriate mechanisms for enforcing basic human rights within illiberal groups. See e.g. Kymlicka 2001, ch. 4; for Kymlicka's account on the role of the international community in such processes, see Kymlicka 2007a.

${ }^{195}$ In Kymlicka 1992, Kymlicka identifies at least three steps between the questions of liberal theory and the imposition of liberal principles in practice, each incorporating several considerations that would need to be answered to. Kymlicka 1992, 144.
} 
Part I Justifying Minority Rights

illiberal groups. ${ }^{196}$ Most notably, one would need to answer the question of who, and on what grounds, would have the authority to impose liberal principles upon illiberal groups - a question that Kymlicka finds no clear answer to, as this imposition would require the relevant authority to infringe on the internal affairs of a selfgoverning entity. ${ }^{197}$

\section{The self-governing status of illiberal groups}

Although I agree with Kymlicka that the answer(s) to the second question (imposition) are not determined by the answer(s) to the first (identification), I also think that Kymlicka's response is somewhat ad hoc, and lies on an unjustified presupposition about the self-governing status of illiberal groups. In order to see this, one needs to look at the reasons for why certain groups should have a right to decide about their own affairs, and the kinds of groups that, in Kymlicka's own terms, qualify for such right.

To recall, Kymlicka claims that the rights of self-government are needed in order for the cultural groups in question to be able to maintain their own cultural contexts. The cultural contexts, however, are only important in so far as they cater for individual autonomy, and the importance of the ability to maintain one's own cultural context can only be argued for in terms of individual

196 It should be noted that Kymlicka's argument is conditional, only applying to national minorities (incl. indigenous peoples), rather than to immigrants. According to Kymlicka, it is justifiable to enforce liberal principles on immigrant groups, as the immigrants have normally left their own cultural contexts voluntarily and have also been aware of the liberal principles that they will be living under. (Kymlicka 1995, 170, see also: Ch. 1, 1.1.) Further, Kymlicka maintains that, even in the case of national (or indigenous) minorities, there is a limit to the kinds of illiberal practices that should not be interfered on. Kymlicka mentions the cases of gross and systematic violations of human rights (such as genocide and torture), although he does not build any systematic argument for why, precisely in these cases, intervention would be justified, whereas in others (such as denial of freedom of conscience or sexual discrimination) it would be not. Kymlicka 1995, 169-170; for criticism, see e.g. Kukathas 1997a, 418-420. ${ }^{197}$ Kymlicka 1995, 164-170. 
autonomy. Keeping this in mind, however, there does not seem to be any reason why a cultural group that infringes the autonomy of its members should be self-governing in the first place, as the rights of self-government are argued for precisely in order to protect that context within which members' autonomy can be enjoyed. ${ }^{198}$ As argued in the previous section (1.1.), it is built into Kymlicka's framework that those groups, eligible for the rights of selfgovernment, only are groups that have already organized in accordance with certain liberal principles, and to infringe upon the internal affairs of a group that is not organized in accordance with these principles, is to infringe upon the affairs of a group that should not be self-governing in the first place. Whereas it may well be the case that no legitimate authority can easily be found to infringe upon the internal affairs of a self-governing group, Kymlicka's own framework does not provide justification for the illiberal groups to be self-governing. Rather, the minority groups within the liberal state are, by definition, still under the jurisdiction of the state, thus giving the state authority to intervene in the illiberal practices of these groups. ${ }^{199}$

${ }^{198}$ It may be objected that this interpretation downplays the role of the importance -argument (see also Ch. 1, 1.1.). To recall, Kymlicka supplements his prerequisite for choice -argument by saying that it is precisely one's own cultural context and membership in one's own cultural group that are important for people's self-respect and for their identity, and that it is for this reason that the liberal state should be concerned about the disadvantages resulting from not being able to live in one's own cultural context. However, as I argued in Ch. 1, it is important to distinguish between those reasons that the liberal state may have for being concerned about the disadvantages faced by minority members and the appropriate responses to these disadvantages. Whereas the importance argument gives reasons for the liberal state to be concerned about people's own cultural contexts (even if these contexts were illiberal), it does not as yet provide justification for the cultural groups to be given rights of self-government. The rights of self-government, in Kymlicka's framework, are conditional, requiring the group to respect the basic rights and freedoms of its members.

${ }^{199}$ See also: Mason 2000, 86-88. 
Part I Justifying Minority Rights

\section{Practical reasons for non-interference}

Having said that, it should be noted that, despite there being no liberal justification for the internal restrictions of illiberal groups, nor any principled grounds for why the liberal state could not interfere in the illiberal practices of illiberal groups within its jurisdiction, there may well be other reasons for the liberals and the liberal state to refrain from imposing liberal principles upon illiberal groups. The forceful imposition of liberal principles may, in fact, be counterproductive, and only weaken the situation of those whose rights the minority group is already suppressing. ${ }^{200}$ The minority group that has, already, been given substantive rights to govern its own affairs may not be willing to accept the authority of the impostor and respond by aggression or by making stricter its own illiberal rules. Even if successful, the imposition and the consequent adoption of liberal principles may only be superficial and not work in the long run. As Kymlicka observes, "liberal institutions can only really work if liberal beliefs have been internalized by the members of the self-governing community, be it an independent country or a national minority", ${ }^{201}$ and the forceful imposition of liberal principles may well be more harmful (from the liberal perspective) than the refraining of intervention.

None of these reasons, however, are reasons that would take away the right of the liberal state to interfere in the affairs of illiberal groups in its jurisdiction, or (on the other side of the coin) reasons that would justify the self-governing status of the illiberal groups in question. On the contrary, as far as I can see, in Kymlicka's theory, there is no principled justification for the illiberal practices of the group, no principled basis for their right of

\footnotetext{
${ }^{200}$ Andrew Mason identifies this as one of the circumstances in which the liberal state may have strong reasons not to interfere in the illiberal practices of a cultural group - that is, the circumstances in which the costs of the liberal imposition would fall mainly on the victims of the illiberal practices rather than on the perpetrators. Mason 2000, 84 .

${ }^{201}$ Kymlicka 1995, 167.
} 
self-determination, and no principled reason for the liberals to refrain from imposing liberal principles upon these groups. Whereas it may, for sure, be wise for the liberal state to refrain (in certain circumstances) from intervening in the illiberal practices of the group, the reasons for doing so are practical rather than reasons derived from Kymlicka's theoretical framework itself. ${ }^{202}$

\section{Diversity liberalism and the critique of autonomy}

Kymlicka's theoretical framework, and his views on minority rights as catering for individual autonomy, would thus seem to create rather robust conditions for those minority groups eligible for these rights. The groups eligible for minority rights (such as the rights of self-government) would, already, need to operate in accordance with certain liberal principles, and refrain from infringing upon their members' capabilities to assess and to choose their own courses in life. As already indicated, Kymlicka was able to provide reasons for why the liberal state should not (always) intervene in the internal affairs of those groups that failed to live up to these requirements, although these reasons were practical, rather than reasons incorporated in Kymlicka's theoretical framework itself. This mismatch (between Kymlicka's theoretical framework and his practical recommendations) has prompted many to question the actual background commitments of Kymlicka's theory that, quite obviously, do not lead to the conclusions that Kymlicka would want them to. Most notably, the so-called diversity liberals ${ }^{203}$, such as William Galston and Chandran Kukathas, have questioned

202 As Chandran Kukathas has noted, Kymlicka may have been able to provide an excuse for non-intervention, but no justification. Kukathas 1997a, 418-420; 2003, 183-186.

203 The term "diversity liberalism" comes from Galston (1995) who labels Kukathas's (as well as his own) toleration-based accounts under such term. Whereas Kukathas and Galston do, to substantive extents, differ on their views on diversity and its value (Kukathas explicitly rejects diversity as valuable in itself (Kukathas 2003, 29; 32; 37; 69), and views it, at the most, as an indication of free society (ibid., 116), I stick to this commonly used term, as nothing, in my argument, needs to hang on the term itself. 


\section{Part I Justifying Minority Rights}

Kymlicka's commitment to individual autonomy as one of the guiding principles of liberalism, and attempted to formulate alternative theories of cultural accommodation. Most notably, both Galston and Kukathas have expressed their concern that Kymlicka's autonomy-liberalism fails to acknowledge those ways of life that do not place high value on individual autonomy, and that the liberal state, committed to being neutral with respect to people's conceptions of the good, should also allow for these kinds of lives to flourish ${ }^{204}$ - something that Kymlicka's theoretical framework would not seem to accommodate.

In this section, I look more closely into Chandran Kukathas's alternative account of liberalism and his attack on individual autonomy as one of the key values of liberalism. I argue that the socalled diversity-liberal attack on autonomy-liberalism goes only half way, and that even the most stringent diversity-liberal approaches to cultural diversity need to be committed to securing certain (albeit very minimal) conditions for individual autonomy for all. In the final section, Minority rights, diversity and the state, I return to the more general question of whether Kukathas manages to provide a genuine alternative to Kymlicka's autonomy-liberal approach, and whether this approach manages to escape some of the pit falls identified in Kymlicka's theory, namely those of failing to give any definitive guidance to the liberal state with respect to its responses to cultural diversity. ${ }^{205}$

204 This "allowing of different kinds of flourishing" means not that the liberal state should be in the business of enhancing or promoting human flourishing. As Kukathas explicitly notes, the liberal state should not be directly interested in human flourishing, nor promote any particular type of flourishing, but simply to uphold a system within which people can live peacefully. Kukathas 2003, 249.

${ }^{205}$ To anticipate a little, I will argue that Kukathas's account leaves substantive scope for the liberal state to adopt different kinds of minority rights in practice. To an extent, this is also recognized by Kukathas who views many of the issues of public policy as practical compromises rather than principled solutions (Kukathas 2003, 244). At the theoretical level, however, Kukathas maintains that minority rights should be rejected, 


\subsection{Chandran Kukathas's account of a free society}

Chandran Kukathas rejects Kymlicka's emphasis on individual autonomy, and the state's role in catering for autonomy, on the basis that this would prevent those groups that reject the value of autonomy from living in accordance with their conscience. According to Kukathas, a free, liberal society is a society that allows people to live in accordance with their conscience, even if this means that some people's autonomy, and their freedom to choose their own conceptions of the good, would be suppressed. For Kukathas, the free society is guided by the fundamental principle of freedom of association that allows people to associate with, as well as to disassociate from, those they wish or do not wish to associate with. This freedom of association (and disassociation) is to guarantee that people can live their lives in accordance with their conscience, without being forced to accept those values (including the value of individual autonomy) they would not voluntarily be willing to accept. ${ }^{206}$

In order to highlight the differences in Kymlicka's and Kukathas's accounts, and in order to identify the scope of Kukathas's criticism of Kymlicka, it may be helpful to begin by outlining some of the things these two thinkers have in common.

Like Kymlicka's, Kukathas's theory is a liberal, individualist account of a good society. It is individualist in the sense that its starting point lies in the interests and well-being of individuals. According to Kukathas, groups or collectives have no independent value of their own, but they matter only in so far as they contribute to the well-being of individuals. This is not to say that a group's character or its interests could always be reduced to the character or

although, as I try to argue, this theoretical framework is far from convincing.

${ }^{206}$ Kukathas 1992a; 1997a; 2003: esp. ch. 3. Importantly, the liberty of conscience is not to be held as the fundamental value of a free society, as those wishing to reject the value of the liberty of conscience should also be free to do so, and free to associate with those they can associate with in accordance with their conscience. 


\section{Part I Justifying Minority Rights}

the interests of its members, but only that the group and its interests are valuable only by virtue of their effects on individual well-being. Nor is it therefore to say that the individual members of groups could not be (partially) constituted by their group membership - to the contrary, the view acknowledges the importance of group membership (and the possible adherence to shared norms and values) as inherent elements in the constitution of one's identity. ${ }^{207}$ Kukathas's individualist commitments, and the value that Kukathas attaches to one's culture, thus resonate with Kymlicka's, who also emphasizes that culture, and one's cultural membership, should be conceived as valuable only in so far as it caters for individuals' well-being. ${ }^{208}$

Like Kymlicka, Kukathas also acknowledges the diversity of moral, cultural and religious outlooks in contemporary societies. The nation states (that are often the default units of political organization $)^{209}$ are far from being homogenous, and the views and values of different people within the nation can vary tremendously. Being committed to the idea that the state should stay neutral with respect to people's conceptions of the good, ${ }^{210}$ both Kukathas and Kymlicka argue that the liberal state should not be in the business

\footnotetext{
${ }^{207}$ Kukathas1992a, 112; 2003, 85-93.

208 As will be noted later on, Kukathas and Kymlicka do, however, draw very different conclusions from how the instrumental value of culture should effect the kinds of policies, legitimate in a liberal state.

209 Whereas both Kymlicka and Kukathas view nation states as the common units of social organization, they disagree on the role that the nation state should play in contemporary circumstances of cultural diversity. Whereas Kymlicka can well be described as a cultural nationalist (viewing societal cultures also largely as features of nations), Kukathas questions the primacy of nation states as locus of political authority, viewing states simply as transitory political settlements that should not be concerned with cultural issues. Kukathas 2003, 15.

${ }^{210}$ That is, the state should not base its policies in an assesment of people's different conceptions of the good, although both Kukathas and Kymlicka also acknowledge that, by default, the state is bound to privilege certain ways of living by creating certain rules for the peaceful cohabitation of different groups.
} 
of imposing any particular moral, cultural or religious outlooks on people, but allow, as far as possible, people to live the kinds of lives and to pursue the kinds of projects they themselves see worthwhile. $^{211}$

Despite these preliminary commitments (to the instrumental value of culture, existence of cultural diversity and state neutrality), Kymlicka and Kukathas come to argue for very different responses to cultural diversity. What they disagree upon is, fundamentally, what it means for people to be able to live the kinds of lives they themselves see fit, and what the role of the state should be in allowing for them to do so. Whereas Kymlicka holds that, in order to live the kind of life one finds meaningful requires one to also be able to assess, and to possibly change, one's ways of living (and one's views of a good life), for Kukathas, it is not necessary for a person to have this ability in order to live a perfectly meaningful life. In fact, Kukathas argues that, in some cases, this ability may even be detrimental to the individual in question, making her life go worse for her, as not all individuals have an interest in being able to revise or to change their ways of living (or thinking). ${ }^{212}$ What is important, according to Kukathas, is not that people are free to judge, reaffirm or reject their current ways of living or thinking, but that they acquiesce (for whatever reason) to the kinds of lives they are leading, and to the kinds of values, norms or practices that they are subscribing to. ${ }^{213}$

Consequently, Kukathas argues that, rather than building a framework within which people's freedom to choose their own conceptions of the good would be protected, the liberal society should be organized in accordance with the principle of mutual toleration that allows people to live as their conscience dictates. The two building blocks of a liberal society, freedom of association and

\footnotetext{
${ }^{211}$ Kymlicka 1989; 1995; Kukathas 2003, esp. ch. 5.

${ }^{212}$ Kukathas 2003, 58-59. Kukathas's view thus reflects the idea that it is impossible for a person's life to go better for her against her own judgment. For discussion, see e.g. Dworkin, R. 1989; Dworkin, G., 2005. ${ }^{213}$ Kukathas 2003, 101.
} 
Part I Justifying Minority Rights

mutual toleration cater, not for individual autonomy, but for freedom of conscience - even in cases where one's conscience rejects the value of individual autonomy and one's freedom to choose between alternative courses of life. Further, Kukathas argues that the role of the state, in a liberal society organized in accordance with the principles of freedom of association and mutual toleration, should be very minimal, operating only as an umpire that secures the peaceful coexistence of different cultural (religious, or other) groups. The liberal state, in Kukathas's model, holds no right to infringe upon the groups' internal affairs, but it also holds no obligation to cater for the groups' interests (or existence) with any system of minority rights. ${ }^{214}$

\subsection{Freedom of association, exit and autonomy}

Two important clarifications need to be made about Kukathas's account of a free society governed by the principles of freedom of association and mutual toleration. Firstly, it should be noted that the scope of the principle of mutual toleration is, in Kukathas's framework, restricted by the principle of freedom of association. As the individuals of a free society should be free to associate with whomever they can associate with in accordance with their conscience, in order to guarantee this freedom to all individuals, the associations (and members of associations) must refrain from interfering with the internal matters of other associations. The principle of mutual toleration does not, however, operate as the guiding principle between all interactions of all individuals of the free society. Rather, mutual toleration can only be seen as holding at the level of interactions between associations (and between members of different associations). Although an association (say, a religious sect) can be tolerant towards the differing views of its own members, it is not obliged to be so. It is, however, obliged to tolerate the differing views and ways of lives of others (members of other associations), and not interfere with them. The freedom of

${ }^{214}$ I will discuss Kukathas's views on the role of the state as well as his account of minority rights in the upcoming section 3 . 
association, in Kukathas's model, is to guarantee that people can associate with those they wish associate with in accordance with their conscience, and if one cannot associate with those of different (perhaps reprehensible) world views, one should not be obliged to do so. ${ }^{215}$

Secondly, although the freedom of association, conjoined with the requirement of mutual toleration, prevents outsiders (including the liberal state) from interfering with the internal affairs of cultural (or religious, or other) groups, the freedom of association is also intended to give certain (minimal) protection to the individual members of such groups. In Kukathas's model, the groups (and their members) are perfectly free not to tolerate internal dissent and also to continue to engage in their (sometimes illiberal) practices, ${ }^{216}$ but they are not free to force anyone to become, or to remain as, a member. The freedom of association, conjoined with the requirement of mutual toleration, gives groups substantive authority over their members, but this authority does not override any individual's right to associate (or disassociate). On the contrary, this individuated freedom of association (and disassociation) entails

215 Kukathas 2003, ch. 3 \& 4. It should also be noted that mutual toleration, in Kukathas's view, is a very minimal form of toleration. Kukathas 2003, 23-24. Tolerating different values and world views of different associations (or members of these associations) does not entail any forms of respect (towards the associations or towards the differing views), nor does it require that the associations (or their members) would need to value the existence of this plurality. The different associations (and members of different associations) simply need to tolerate each other in the sense of "not objecting to coexist" (ibid., 210), and thus not also interfere with the internal matters of other associations. Kukathas 2003, esp. ch. 4. For alternative, more substantive accounts on toleration, see e.g. Galeotti 2002; see also: articles in Williams and Waldron 2008.

${ }^{216}$ Kukathas does claim that there are some limits to the kinds of illiberal practices that should be tolerated (most notably those of "cruel, inhuman or degrading treatment" Kukathas 1992a, 128; see also Kukathas 1997b; 2001), although it is not entirely clear where and how to draw the line between tolerable and intolerable illiberal practices. See also: Mason 2000: 74-77; Barry 2001, 141-146. 
Part I Justifying Minority Rights

that, even if subject to the group's authority, the individual members of groups have one fundamental right against their group - that is, the right of exit. ${ }^{217}$ Individuals should be free to leave their associations, and they should also be free to form new associations with those who they wish to associate with.

In broad outline, Kukathas's model of a free society thus builds upon four interlinking elements: that of (1) mutual toleration between (but not necessarily within) groups, (2) freedom of association (and disassociation) aimed to cater for (3) individual freedom of conscience, and (4) the right of exit derived from freedom of association (and disassociation) catering for the individual freedom of conscience. Given Kukathas's emphasis on freedom of conscience and his rejection of individual autonomy as something that the liberal state should attempt to provide conditions for, it is worth looking at whether Kukathas's model in fact manages to protect individual freedom of conscience without also incorporating some minimal conditions for individual autonomy into this model.

\section{Formal right of exit}

I believe that the problems of Kukathas's model - that tries to secure freedom of conscience without also securing individual autonomy - lie in the first and fourth of the above mentioned elements (those of the requirement of mutual toleration and the right of exit) and the rather robust preconditions that these requirements provide for all members of the liberal society. To recall, in Kukathas's model the individuated freedom of association also entails individuated right of exit - that is, the right of the individual to leave her group. According to Kukathas, this right of exit is fundamental and one that holds even if the group in question does not recognize it as such. The group cannot thus force the individual to stay in the group, but she should be free to leave should she no longer find the group worthy of her allegiance. ${ }^{218}$

${ }^{217}$ Kukathas 1992a, 116; 2003: 96.

${ }^{218}$ Kukathas 1992a, 116-117; 2003, 96-97. 
Kukathas's account of the right of exit is a very formal one. According to Kukathas, the existence of the right of exit does not depend on one's capabilities of taking advantage of such right, or even on one's ability to comprehend (or be aware of) this option or the alternative courses of life that one could exit to. Rather, the right of exit prevails as long as the individual is, at least in principle, free to leave her group, should she ever become aware this option, or the alternative courses of life that she could lead. ${ }^{219}$ For Kukathas, the only substantive requirements for the right of exit to be effective are, firstly, that the individual is not forced by others to remain in her group (for example, by being locked up or enslaved) ${ }^{220}$ and, secondly, that the wider society is also open for those who use this right to leave their communities. ${ }^{221}$ None of this, however, requires that the individual members of groups should also be autonomous - that is, capable of assessing (and possibly changing) their own conceptions of the good - or that the state (or the group itself) should protect or promote the individual members' autonomy.

Kukathas's account of a formal right of exit has, of course, prompted extensive critique in its own right, especially from those who view the right of exit as meaningless if people have no realistic opportunities to use it. The critics argue that, in order for the right

\footnotetext{
${ }^{219}$ As an example, Kukathas talks of Fatima, who lives in a small fishing village in Malaysia with no desire to live elsewhere or otherwise, and who might even be fully ignorant of the possibility of leaving or living differently, see Kukathas 2003, 113-114. For Kukathas's restatement of the plain exit -principle, see Kukathas 2012.

${ }^{220}$ Kukathas thus claims that the right of exit must clearly have "some substantive bite" (Kukathas 1992a, 128-134.), although it is clear that some of the legitimate (in Kukathas's view) practices of groups that wish to prevent their members from leaving (such as the threat of "shunning" or "banishing") may have precisely the same effects as the illegitimate practices of for example enslavement. See: Kukathas 1992b, 677.

${ }^{221}$ Kukathas 1992a, 133-134. Kukathas conceives this wider society as a liberal society, or "much more like a market society" (Kukathas 1992a, 134), although he does not think this necessarily needs to be so. Kukathas $1992 b, 677$.
} 


\section{Part I Justifying Minority Rights}

of exit to be meaningful, the preconditions of the lack of physical coercion and the existence of a society to be exited to, would need to be supplemented by the person's capacity to make use of exit. At the very minimum, this would entail that the group members should be aware of alternative ways of life, although many also argue that, in order for the right of exit to be realistic, the members should also possess certain capabilities of critical reflection, as well as not be overwhelmed by the high costs of exit. ${ }^{222}$

For Kukathas, none of these conditions (1. knowledge of alternative ways of life, 2. capability to reflect upon these ways of life, or 3. reasonable costs of exit) should be taken as necessary conditions for a person to be free to leave, nor therefore as something that the liberal state should attempt to guarantee. For Kukathas, a person who is not aware of any alternative courses of life, has no capabilities of assessing these (or even her own) courses of life, and who may be discouraged (even disabled) by the high costs of exit would still be free to leave, as long as she was not (physically) forced to stay in her group, and the wider society was such that the person could exit to. Further, Kukathas argues that it is perfectly possible for this kind of person to live a meaningful life, and that the imposition of knowledge about alternative ways of living or the teaching of basic skills of critical thinking may even be detrimental to her well-being. The person, fully unaware of and unable to assess any alternatives, may still be considered as living her life in accordance with her conscience - something that she should, according to Kukathas, not be prevented from doing.

Whereas it is, no doubt, debatable whether the acknowledgement of the worthiness of an unexamined life and the possibility of this kind of life being a life led under the dictates of conscience would lead to the view according to which it would

${ }^{222}$ I will return to some of the preconditions of exit, and the exit debate in more general in Ch. 5. For alternative perspectives on the realistic right of exit, see e.g. Shachar 2000; 2001; Spinner-Halev 2000; 2005; Okin, 2002; Holtzleithner, 2012; For the costs of exit debate, see: Barry 2001; Borchers 2012. 
never be justifiable to expose these people to some knowledge of alternative courses of life, or to teach them some basic skills of critical thinking, my interest, for the time being, lies not in this worry. Nor does it lie in the well rehearsed debate on whether a person can really be conceived as free to leave her community if she possesses no capabilities for exercising such freedom. Rather, what I attempt to show is that the two elements - the right of exit and the (soon to be discussed) requirement of mutual toleration create much stronger requirements for all members of the society to fulfill and, by doing so, also undermine Kukathas's formal account of the rights of exit by incorporating certain (minimal) conditions of autonomy into his theoretical framework.

\section{Mutual toleration}

In Kukathas's model, in order to guarantee freedom of association (catering for the freedom of conscience) to all individuals, the free society would need to operate in accordance with the principle of mutual toleration. That is, the different associations would need to "not object to coexist" 223 with other associations, and they would also need to refrain from interfering with the internal affairs of other associations. Although Kukathas emphasizes that these requirements operate primarily at the level of different associations rather than at the level of (all) individuals, it is difficult to see how the requirement of mutual toleration would work if it did not also operate as a guiding principle for interactions between different individuals of different associations. Although the individuals within any particular group are not required to tolerate the dissenting views of their fellow members (but, depending on their position in the group, they can either leave or excommunicate the dissenters), they are, nevertheless, required to tolerate and refrain from interfering with the affairs of others, who do not belong to the same cultural/religious/other group.

Provided that the individual members of groups (as well as groups as collectives) are required not to interfere with the affairs of

${ }^{223}$ Kukathas 2003, 210. 


\section{Part I Justifying Minority Rights}

other groups or members of such groups, the question arises, what would be the conditions within which this toleration and noninteference would be secured. As Kukathas notes himself, it is very unlikely that different groups (or individual members of these groups) would, or even could, stay in complete isolation from one another $^{224}$ - and even if they did, certain conditions would need to be met, in order to ensure that, should the different groups or their members come in contact with one another, the principle of mutual toleration and non-interference would be followed. ${ }^{225}$

Contrary to Kukathas, who gives no clear answer to how the principles of mutual toleration and non-interference would be secured, Willian Galston attempts to address this point in his discussions on the preconditions that the liberal society, allowing for the fullest possible scope for diversity, should fulfill. ${ }^{226}$ Like Kukathas, Galston questions the view according to which the liberal state should be in the business of protecting (let alone promoting) individual autonomy, and also holds that only a strong system of toleration will ensure that different views and ways of life (including those ways of life that do not value individual autonomy) are able to flourish. ${ }^{227}$ Contrary to Kukathas, however, Galston

\footnotetext{
${ }^{224}$ Kukathas 2003, 132-133.

${ }^{225}$ This, I believe, is fully consistent with Kukathas's remarks on the role of the state to preserve order in which different people and different associations can coexist peacefully (Kukathas 2003, 147; 213). I will come back to the role of the liberal state in Kukathas's account in more detail in section 3 (esp 3.3.).

${ }^{226}$ Galston 1995; 2002; 2005.

${ }^{227}$ It should be noted that, for Galston and Kukathas, the primary reasons for promoting toleration are somewhat different. Whereas Kukathas sees mutual toleration as necessary for the protection of individual freedom of conscience, for Galston, toleration is also necessary for the preservation of deep diversity . (An aim that Kukathas explicitly rejects, Kukathas 2003, 29) This difference need not, however, affect the point that I am making here. What is important, for my purposes, is that both Galston and Kukathas view toleration as one of the guiding principles of a liberal society, and that they both also interpret toleration in fairly minimalist terms: as refraining from interference and not objecting to coexist
} 
worries that toleration, in the sense of non-interference, could not be secured without at least minimal awareness of the existence and nature of ways of life other than those of one's family and community. ${ }^{228}$ If individuals of cultural groups are kept in complete isolation and ignorance of other ways of life than their own, it may well be that, should they ever come across these alternative ways of life, their reaction would not be that of toleration, but that of hostility and (forceful) intervention. Consequently, Galston argues that the liberal state, committed to safeguarding deep diversity, should also incorporate a vigorous system of civic education that teaches toleration to all, including the teaching of some information about the existence and nature of different ways of life. ${ }^{229}$

Whereas one does not need to go as far as Galston does in arguing for a vigorous system of civic education on behalf of the liberal state, ${ }^{230}$ I do believe that Galston's concerns about how to ensure mutual toleration between different groups and members of these groups should be taken seriously. If, as Kukathas seems to hold in his discussions on the right of exit, it is perfectly all right for the minority groups to keep (some of) their members in complete ignorance about other ways of life, then there is nothing that would ensure that these members would be tolerant and not try to interfere with the affairs of others, should they ever come across these other ways of living. It is not, of course, that the civic education such as the teaching of toleration, would necessarily need to be provided by the state, but it does seem that the minority groups would need to comply with certain general guidelines, including the requirement that they provide their members some (minimal) knowledge about

(Kukathas), and as refusing to use coercive power to impose one's views on others (Galston, 1995, 528).

${ }^{228}$ Galston 1995, 529; 2002, 127.

${ }^{229}$ Galston 1995, 528-529; for further elaboration on Galston's views on education, see e.g. Galston 2002, ch. 8.

${ }^{230}$ That is, one does not need to agree with Galston on the exact contents of such education (Galston's views on civic education do, in fact, incorporate much more than the teaching of toleration), nor on the provider (liberal state) of such education. 


\section{Part I Justifying Minority Rights}

different ways of life, as well as teach them to tolerate and not interfere with these ways of living.

As Galston maintains, none of this needs to entail that the minority members should also be taught to question and to be critical about their own ways of living. ${ }^{231}$ All that is required is that the minority members are given some knowledge about alternative ways of life and that they are also taught to respond to these alternatives appropriately. ${ }^{232}$ But, if this is the case, then it would seem that the principle of mutual toleration, and especially the ensuring of this toleration, would require that at least some (albeit very minimal) conditions for individual autonomy should also be protected. Firstly, it must be ensured that the minority members have some knowledge about alternative ways of living and, secondly, it must also be ensured that these alternatives are portrayed, not as something to be gotten rid of, but as viable options, at least for some (other) people. The minority members do not need to be taught to be critical of their own ways of living, but they do need to be shown that the other ways of living may also be worthwhile, thus also providing some tools for the minority members to mirror their own ways of life to the alternatives presented. $^{233}$

\footnotetext{
${ }^{231}$ Galston 1995, 529.

${ }^{232}$ That is, by refraining from forcefully interfering with these ways of life.

233 It could be argued (as Galston does) that these conditions (the requirement of the minority members to have at least some (minimal) knowledge of alternative ways of life as well as the portraying of these ways of life as worthwhile for at least some (other) people) do not, as yet, constitute conditions for the protection, let alone promotion, of individual autonomy. The minority groups are still perfectly free to deny their members certain ways of life, and they can even prevent their members from acquiring information about alternative ways of life (Recall that, for securing mutual toleration, only some minimal information about alternative ways of life are needed, and the groups are perfectly free to block any further information from their members.) Nevertheless, these conditions are, as will be argued in more detail with respect to the conditions relating to the right of exit, far more substantive than, for
} 
Taking Galston's insight about the necessity of certain minimal information about alternative ways of life for the securing of mutual toleration on board, it would seem that Kukathas's own framework - especially his commitment to the fundamental right of exit provides even stronger requirements for the illiberal groups to comply with. That is, contrary to what Kukathas says, his commitment to the fundamental right of exit would, in fact, seem to require that the minority members must also be aware of the possibility of exit. ${ }^{234}$ This, however, needs to have nothing to do with the question of whether an individual is free to leave her community should she not even be aware of such possibility, but rather with the requirements that the right of exit, and the ensuring of the right of exit, creates for others. As Kukathas maintains that the individual members of groups should have one fundamental right - that of the right of exit - and that this right requires the group (as well as its individual members) not to force anyone to remain or to become a member, in order to ensure that the members do not attempt to forcefully prevent others from leaving, they should also have knowledge of the possibility of exit, and the appropriate response to it (non-intervention). Surely, this need not entail that the minority members should be given knowledge of the possibility of exit in the sense in which it was portrayed as a viable option for them, but they nevertheless need to be aware that, at times, their own group members may decide to leave their community and that, should this happen, they should not try to forcefully prevent them from doing so.

Whereas it is clear that these requirements (of being aware of alternative ways of living and the possibility of exit, and of viewing these options as something one should not interfere with) are still

example Kukathas, would be willing to acknowledge, thus also providing some (albeit not necessarily sufficient) preconditions for individual autonomy. For discussion on whether Galston's liberal pluralist model as a whole manages to steer away from autonomy-liberalism, see Crowder 2007; 2009; Thunder 2009.

${ }^{234}$ In his discussions on Fatima, Kukathas explicitly denies this. Kukathas 2003, 113-114. 


\section{Part I Justifying Minority Rights}

far from the requirements given by the autonomy liberals, that the minority members should also be taught the basic skills of critical reflection, they are, nevertheless, substantially stronger than the conditions given by Kukathas in his discussions on the formal right of exit. Whereas it may well be that the formal right of exit itself does not require even these minimal conditions to be protected, it would seem that, in order to ensure peaceful coexistence of different groups and the non-violation of the right of exit, certain (albeit very minimal) conditions for individual autonomy must be secured. Kukathas's attack on individual autonomy as one of the guiding principles of liberalism, and his insistence on the protection of freedom of conscience rather than autonomy, would thus seem to go only half way. Whereas Kukathas can still maintain that it is not the business of the state to try to protect (let alone promote) individual autonomy, it would seem that in order to ensure that people can live in accordance with their conscience (entailing the conditions within which the principle of mutual toleration and the right of exit prevail), will nevertheless require certain (minimal) conditions of autonomy to be protected. These are the awareness of alternative ways of life and the possibility of exit, and the viewing of these options as viable options at least for some (other) people.

\section{Minority rights, diversity and the state}

In the light of the original critique that Kymlicka's autonomy liberalism creates too stringent requirements for those minority groups that the liberal state can justifiably accommodate, the toleration-based approach of Kukathas would seem superior - at least in the sense of it being able to incorporate a far wider variety of different ways of life legitimate within the liberal framework. Whereas I have shown that Kukathas's own model may incorporate far stronger conditions for the minority groups to comply with than he would himself be willing to accept, these conditions are substantially weaker than those given by Kymlicka. In order for the minority groups to be allowed to manage their internal affairs without the interference of the liberal state, I have argued, they need to comply with the requirement of equipping their members with 
knowledge of alternative ways of life, the possibility of exit, as well as the acceptability of these options (alternative ways of life and exit) at least for some (other) people. The groups do not, however, need to teach their members to question or to assess their own ways of living or view these alternatives as viable options for themselves. Nor do they - contrary to Kymlicka - need to provide their members with a sufficiently complex set of options that the minority members can choose to take advantage of. Rather, the groups can continue to live in accordance with their (sometimes) very restrictive rules, impose standards incompatible with the basic liberal values of individual freedom and equality, and expect their members to comply with the norms and values of the community. All this, as long as the basic requirements of equipping the members knowledge of alternative ways of life and exit, and of portraying these options as viable options, are fulfilled.

Whereas the problems of Kymlicka's account are manifested, most prominently, in the failure of his theoretical framework to support the vast variety of minority rights he comes to advocate, the toleration-based approach of Kukathas would not, at least at first sight, seem to encounter this problem. Rather, the minimal requirements of the diversity liberals could, in fact, give support to a far wider variety of minority rights, including the self-government rights of those groups who do not themselves subscribe to the liberal values of individual autonomy, freedom and equality. Interestingly, despite this prospect, Kukathas comes to advocate a very different approach to minority rights - that of their rejection although, as I argue, the reasons for doing so are more practical than incorporated in the theoretical framework itself.

As Kukathas's arguments against minority rights take several different forms, it is worth outlining the main arguments that Kukathas uses, and the ways in which these arguments operate with respect to different kinds of minority rights. In this section, I will thus give a brief overview of the three main bundles of arguments given by Kukathas (the critique of groups, the critique of equality, and the role of the liberal state), and assess these arguments with respect to different types of minority rights. My purpose is to show 
Part I Justifying Minority Rights

that, far from providing a conclusive case for rejecting the kinds of minority rights promoted by Kymlicka, Kukathas's theoretical framework also leaves substantive scope for the liberal state to adopt such rights, depending on the actual circumstances and contexts within which these rights are debated.

\subsection{Critique of groups}

In his correspondence with Kymlicka, ${ }^{235}$, Kukathas questions the approach, adopted both by Kymlicka and Vernon van Dyke, ${ }^{236}$ that the liberal state should accommodate cultural minorities by giving them special cultural rights. By cultural rights, Kukathas refers primarily to those rights and forms of assistance that are accorded to cultural groups as collectives, such as the rights of selfgovernment and linguistic rights. ${ }^{237}$ Provided that Kukathas's focus is primarily on the group rights proper (rather than on the rights of individual members of cultural groups), ${ }^{238}$ it is not surprising that one of the main critiques posed by Kukathas comes in the form of questioning the status of cultural groups as proper claimants of rights.

According to Kukathas, the idea of cultural (or other) groups as proper claimants of rights fails to take sufficiently into account the fluidity, malleability and internal diversity of such groups. Rather than being fixed and unchanging entities, groups are fluid and changeable, not least in response to the institutional frameworks and public policies that are in place. Being historical and political formations (and continuing to be such), it makes no sense to argue for specific cultural rights of cultural groups, as it is precisely through these rights (and other institutional measures) in response

\footnotetext{
${ }^{235}$ Kymlicka 1989; Kukathas 1992a; Kymlicka 1992; Kukathas 1992 b

${ }^{236}$ Esp. Van Dyke 1977.

237 For example, in terms of special support for minority language schooling.

238 Kukathas does mention, in passing, affirmative action/preferential treatment policies (Kukathas 1992a, 114) although, as his focus is clearly on the cultural rights of cultural groups, I will, for the time being, concentrate on these.
} 
to which the groups are shaped and formed. ${ }^{239}$ Further, although Kukathas does not deny that groups could have interests that are not reducible to the interests of individuals, he does not think it appropriate to justify group rights on the basis of group interests. The group interests, like the composition of the group, also change in response to historical, economic and political circumstances, and the granting of group rights would, in itself, have an effect on those interests that a group comes to have. ${ }^{240}$ Not only does the idea of group rights fail to acknowledge the instability of groups (both in their composition as well as their contents), but, Kukathas worries, these rights would have an illegitimate impact on the kinds of groups that are allowed to be formed or continue to exists, as well as on the kinds of interests, values and ways of life that are given scope to flourish.

Whereas I fully agree with Kukathas that cultural groups (both their composition as well as their contents) are, to a large extent, formed by the historical, economic and political circumstances, and that the non-fixedness, malleability and internal diversity of groups should raise some concerns about group rights proper, I do not think that Kukathas's account of groups is, on its own, enough to reject the kinds of cultural group rights that Kukathas attempts to reject. Firstly, there is no reason to think that the way in which groups have come into existence - whether by being part of some natural order or by being responses to the historical or political circumstances - should have an effect on how we think of groups and their status as rights-bearers. The fact that the existence of cultural groups is not independent of the surrounding circumstances should not, on its own, make us think that groups cannot have rights (just like the social embeddedness of individuals should not lead us to think that individuals cannot have rights). Secondly, the cultural rights, such as the rights of self-determination or language rights,

${ }^{239}$ Kukathas 1992a, 110-113; see also Kukathas 1998, 692-693; 2003, 7880; 197-200.

${ }^{240}$ I will return to the question of the contestability of group interests in more detail in the upcoming section 3.2. 
Part I Justifying Minority Rights

are not necessarily as insensitive to the indeterminacy and malleability of groups as Kukathas would seem to think. Whereas it is the case, as I will argue in more detail in Part II, that the proponents of minority rights have often ignored the problems of the indeterminacy of group composition (group membership), the cultural rights do not necessarily need to be insensitive of this fact. Thirdly, the acceptance of group rights, such as rights of selfdetermination or language rights, does not necessarily need to entail a view of the group as a right bearing entity, but could be understood as being derivative of individual rights, without the need to grant any independent moral status to the group itself. ${ }^{241}$

Whereas Kukathas's view of cultural groups as historically, economically and politically formed entities is, no doubt, warranted, it does not, on its own, suffice to reject the kinds of cultural rights that Kukathas attempts to reject. At most, Kukathas's analysis of groups and their interests points out to some of the difficulties that the proponents of group rights must address, although it does not, on its own, suffice to reject such rights.

\subsection{Critique of equality}

Provided that the fluidity and malleability of cultural groups (both their composition and their content) is not enough to warrant outright rejection of cultural group rights, some other support must be given. The main bundle of arguments, given by Kukathas, relates to the rationale that the supporters of minority rights (such as Kymlicka) have given for minority rights. To recall, Kymlicka argues that minority rights, such as rights of self-determination, language rights or land claims, are required, in order for the members of cultural minorities to be able to start from the same line with the members of the majority. That is, the minority rights (most prominently, the rights of national minorities) are argued for on egalitarian grounds, as attempts to rectify the unequal circumstances that the minority members face.

${ }^{241}$ See also: Gould 2001, 46-50. 
It should be noted, right from the outset, that Kukathas's critique of the egalitarian rationale behind minority rights is not only a critique of these rights failing to rectify the kinds of inequalities they are set to rectify, but a more general critique against the search for equality in circumstances of cultural diversity. According to Kukathas,

[d]iversity and equality are incompatible; and attempts to promote one can only be made at the expense of other. In these circumstances, we should abandon the ideal of equality as incapable of offering us an adequate understanding of the nature of the good society. ${ }^{242}$

Whereas there is, no doubt, more to Kukathas's arguments against the egalitarian rationale behind cultural accommodation (some of which I will return to in section 3.3.), what is important, for the time being, are the ways in which Kukathas attempts to reject minority rights based on the failure of these rights to deliver equality, or to do so without substantive and (in Kukathas's view) unacceptable side costs.

Kukathas's critique of minority rights as failing to rectify the kinds of inequalities they are set to rectify relates, in part, to his analysis of cultural groups. The cultural groups, within liberal societies, are not only fluid and changeable, but they are also heterogeneous, both between (e.g. small/large, dominant/nondominant groups) as well as within (elites/masses, majorities/minorities, dominant groups/subgroups). The problems this creates for the egalitarian proponents of minority rights are at least threefold. Firstly, the minority rights, such as rights of selfgovernment or language rights, can only feasibly be given to a certain number of groups and, as Kukathas rightly points out, these rights are normally given to those groups that are sufficiently large and exert certain amount of political power within the liberal society. This, however, creates or (in most cases) reinforces the inequality between minority groups by enhancing the situation of

${ }^{242}$ Kukathas 2003, 214-215. 
Part I Justifying Minority Rights

those who are, already, sufficiently large and powerful at the expense of small and politically weak groups. ${ }^{243}$ Secondly, Kukathas argues that minority rights do not only enforce the inequality between groups, but are also likely to create inequalities within groups. Often, the minority rights are claimed and most extensively argued for by a small number of minority members (normally, the leaders or the elites), whose views about the interests, values or ways of life of the group do not necessarily coincide with the views of the other group members. The minorities, or the sub-groups within minority groups, do not all agree on which direction the group should be led, and the granting of minority rights, Kukathas claims, would unduly prioritise the views of the group leaders at the expense of the group's subgroups. ${ }^{244}$ Thirdly, Kukathas argues that not all minorities, or their members, face the same kinds of inequalities with respect to the majority, and to try to rectify these inequalities by minority rights fails to recognize that, not only different groups, but also members within these groups, are differently disadvantaged. ${ }^{245}$

To take these three arguments in turn, it becomes clear that Kukathas's critique of minority rights on egalitarian grounds does not build a conclusive case against cultural rights, although it does, no doubt, point towards some important considerations that the egalitarian proponents of minority rights, and the liberal state in charge of distributing such rights, should take into account.

\footnotetext{
${ }^{243}$ Kukathas 2003, 229-234.

${ }^{244}$ Kukathas 1992a, 113-114; 130-132; 2003, 87-89; 156-158. Kukathas goes as far as to claim that the granting of minority rights could create substantive inequalities and conflicts between subgroups, when the benefits of these rights (for example, the distribution of land or fishing/hunting rights) are unequally distributed between the subgroups of the community. Kukathas 2003, 234. These inequalities, it should be noted, can also be manifested at the level of decision making processes, when different people or sub-groups have different amounts of say on deciding how to organise the internal affairs of the group.

${ }^{245}$ Kukathas 1992a, 123.
} 
Firstly, with respect to the claim that minority rights enforce inequality between different groups and, as Kukathas is also keen to point out, may also create conflict and resentment between groups,${ }^{246}$ Kukathas seems to be in the right track. That is, he is in the right track in pointing out to some of the practical difficulties in applying minority rights in the concrete political arena. For example, it may not be possible (due to limited financial or other resources) for the state to grant support to all linguistic minorities for minority language schooling or for access to public services in their own language, but only to some - normally, those linguistic groups that are relatively large and/or exert certain amount of political power within the liberal society. ${ }^{247}$ But the fact that concrete political practices tend to favour those groups that are already large and politically powerful should not affect the rationale behind minority (linguistic) rights to start with. ${ }^{248}$ As is well known, Kukathas attempts to reject such rationale (to which I will come back to in the next subsection), but this rejection should have nothing to do with the tendency of the actual policies to favour some groups and not others. Provided, for the sake of an argument, that there was a case for granting minority linguistic rights to all linguistic groups (regardless of their size or political power), the granting of these rights to some and not others would surely create an embarrassment to the policies in question, but it would not take away the rationale behind the need for such policies in the first place. Whereas Kukathas worries that the unequal allocation of minority rights will only fortify inter-group inequality and cause resentment between different minorities, this worry, it would seem,

\footnotetext{
${ }^{246}$ Kukathas 1997a, 148.

${ }^{247}$ Kukathas 2003, 239-240.

${ }^{248}$ See also Carens 1997 for a similar critique of Kymlicka's position on the granting of the rights of self-determination only to those groups that are, already, sufficiently large and powerful to maintain their own societal culture.
} 


\section{Part I Justifying Minority Rights}

relates primarily to the application of minority rights in practice, not to their principled justification. ${ }^{249}$

Secondly, whereas Kukathas is right to point out that not all minority members, or minority sub-groups, have the same views on the interests, values or ways of life of their group, it is somewhat unclear whether Kukathas is able to use this observation as extensively as he would like to. The primary worry, with respect to intra-group inequality, is that those minority members who argue most extensively for differentiated treatment or minority (group) rights are only a certain fraction of the group - the group leaders or the elite - whose visions of the group's internal affairs may be very different from the views of the other group members or sub-groups. By granting minority rights to cultural groups, the state, in effect, gives priority to the views of those most dominate within the group, thus privileging the status quo and the (inevitable) inequalities within the group. ${ }^{250}$

It should, at this stage, be recalled that earlier (Ch. 1, esp. 2.2.), I expressed some concerns about minority rights as advancing (either directly or indirectly) certain conceptions as well as contents of culture by giving formal recognition to certain group customs or practices as proper elements of that culture. Minority rights, it was argued, were never rights purely in the abstract, but always incorporated certain views about the nature as well as the contents of the culture in question. In the light of these discussions, Kukathas's worries about minority rights as prioritizing the views of the elite / leaders of the group do not seem far fetched. Provided that it is often the leaders or the elites of the group who articulate their claims in the public arena, it is not surprising that minority rights, granted by the liberal state, often reflect the views of the group leaders. It is, however, debatable, whether Kukathas manages to use this point to the extent that he does, aiming to reject a vast

\footnotetext{
${ }^{249}$ I will come back to the question of how not granting certain kinds of minority rights may also create inequality and resentment in section 3.3.

${ }^{250}$ Kukathas 1992a, 114.
} 
variety of minority rights - including the rights of selfdetermination. ${ }^{251}$

Recall that, for Kukathas, people should be free to associate with whomever they wish to associate with in accordance with their conscience. Consequently, Kukathas argues that people should also be free to repudiate authority and to leave, alone or together with others, to form new communities in which they can live as their conscience dictates. For Kukathas, it is essential that "each community enjoy certain amount of independence and integrity" 252 and that (should they so wish) they should also be left alone to live as they please. ${ }^{253}$ Despite these commitments (to individual freedom of conscience and group independence), Kukathas is sceptical, to say the least, of granting cultural groups rights of selfdetermination. The reasons for this scepticism, however, stem from a misunderstanding of what the right of self-determination amounts to and the conflation of the right of self-determination with the group's preserving its particular ways of living. As Kukathas points out, "it has to be recognized that there are considerable limits to the extent to which collective self-determination is possible. Once cultures come into contact with others and trade and other forms of social intercourse develop, it is very difficult for the community to preserve its ways." ${ }^{254}$ The right of self-determination, however, equates not with the community preserving its own ways, but simply with the right of the community to decide, for itself, what these ways may be. As Kymlicka has forcefully argued (and I have to agree with Kymlicka here), the right of self-determination does not necessarily entail that the group would stay immune to the

\footnotetext{
${ }^{251}$ Much of what is said here is based on Kukathas's initial position, as outlined in Kukathas 1992a, and repeated (with minor modifications) in Kukathas 2003, esp. 103-106. Later, Kukathas somewhat weakens his position by accepting that there may be some cases in which legitimate claims for self-determination can be made (Kukathas 2003, 196-205), although the general scepticism remains intact.

${ }^{252}$ Kukathas 1992a, 127.

${ }^{253}$ Kukathas 1992a, 116.

${ }^{254}$ Kukathas 1992a, 130.
} 


\section{Part I Justifying Minority Rights}

external influences (although it may, for sure, attempt to do so), but simply that the group is given a right to decide for itself which external influences it wishes to welcome and which not. ${ }^{255}$ Whereas there may be limits to the extent to which collective selfdetermination is possible (that is, even with the right of selfdetermination, the group may not be fully in control of its own affairs), there is no reason to equate the right of self-determination with the preservation of a particular way of life, or the group's isolation from the rest of society.

This conflation of the right of self-determination with the group's preserving a particular way of living is reflected in Kukathas's concerns about the minority rights (including the rights of self-determination) as prioritizing the views of the group leaders or group elites. According to Kukathas, "self-determination is problematic because there is considerable internal disagreement about the direction it should take" ${ }^{256}$ But the question about the direction of self-determination - that is, about the contents of the decisions made - is, to an extent, independent of the question about who should make these decisions in the first place. If Kukathas wants to maintain that people should be free to associate with whomever they wish to associate with and that, consequently, these associations should enjoy certain measure of independence (to the extent of being left alone to live as they please), Kukathas's position would, in fact, seem to require that the liberal state grant rights of self-determination to the groups in question. Even if the views of the members, with respect to the contents of the decisions made, would differ, the freedom of association would require that these decisions can, indeed, be made by those willing to associate with one another, rather than by the larger liberal society or by those not recognizing the terms of association. Kukathas's whole framework - including freedom of association and group independence - would thus be a framework precisely for the rights

${ }^{255}$ Kymlicka 1995, 104-105.

${ }^{256}$ Kukathas 1992a, 130; see also 113-114. 
of self-determination, understood as the right of the group to decide about its own affairs.

A more promising avenue (that, to be fair, Kukathas also recognizes) would be to question whether the views of the group leaders or the elite about the need for self-determination itself would coincide with the views of the other group members. ${ }^{257}$ That is, whether all members of the group do, in fact, wish to associate in terms of a self-governing community or, to put it in other words, whether all those coming under the rule of the self-determining community are willing to accept the authority of this community. ${ }^{258}$ The underlying worry, it seems, would be that by giving a group rights of self-determination, some members would be subject to the rule they do not wish to be subject to, simply by virtue of being members of the group to which the right of self-determination has been granted.

However, whereas I believe that this worry (about some people being subject to the rule they do not consent to) is a genuine one, I fail to see how it would be any more pressing in relation to groups that enjoy rights of self-determination than in relation to Kukathas's own model that gives groups relative independence derived from the individuated freedom of association. In order to distinguish the two cases, Kukathas needs to subscribe to yet another misconception about the right of self-determination - that is, to the view that this right would be insensitive, not only to the heterogeneity of different views about the cultural contents of the group (which it certainly need not be), but also to the non-fixity and malleability of group boundaries in terms of group membership. As Part II of this book is dedicated, in large part, to analysing the problems of group membership, and the defining of politically relevant group membership, for the time being, I will leave aside these problems and simply note the misconception of viewing the right of self-determination as necessarily insensitive to the fluidity

${ }^{257}$ See e.g. Kukathas 1997a, 416-417.

${ }^{258}$ For Kukathas's views on self-determination and individual consent, see esp. Kukathas 2003, 196-204. 


\section{Part I Justifying Minority Rights}

of such membership. As many group theorists have argued, the existence of a group does not need to entail fixity in its constituent parts, but the group may continue to exist even when all of its members have changed. ${ }^{259}$ Consequently, even if a group as a collective is given a right to decide about its own affairs (that is, given a right to self-determination), this does not need to entail that those people, coming under the authority of the self-determining community, would need to remain the same, but the group's membership can undergo even drastic changes. This, I believe, should have been noted by Kukathas himself, who spends a substantial amount of time emphasizing the fact that the composition of a group can, and does, change in response to the economic and political circumstances - including the circumstances of granting the group rights of self-determination. Whereas I will come back to giving a more thorough analysis of Kukathas's rejection of the rights of self-determination (and a number of other group differentiated rights) in the next sub-section (3.3.), what I wish to have shown by now, is that the worries about this right as prioritizing the views of the group leaders or elite, or of unduly fixing the group boundaries are not sufficient for an outright rejection of such rights, as the rights of self-determination need not be insensitive to the differing views within the group, nor to the malleability of group membership.

Finally, Kukathas argues that the egalitarian rationale behind minority rights is unfounded, as not all groups nor all of their members face the same inequalities, and that the cultural (group) rights fail to acknowledge this fact. Again, I agree with Kukathas in his analysis - not all cultural groups are the same, nor do all members of a particular cultural group face precisely the same disadvantages as others - but fail to see how this analysis could

\footnotetext{
${ }^{259}$ Examples of such groups entail practically all nation states that have foregone such change in their membership simply by virtue of old members leaving (dying) and new members being born. Other examples include companies (with changing board members or employees), schools (with changing teachers, pupils) etc.
} 
lead to an outright rejection of minority rights. With respect to the differences between minority groups, Kukathas worries that the granting of cultural (group) rights bundles cultural groups into the same mould, and fails to acknowledge that groups differ in both size as well as power, and that the state responses should be able to take these differences into account. ${ }^{260}$ This worry seems somewhat absurd, especially in the light of Kukathas's earlier remarks about minority rights being (feasibly) granted only to those groups that are already considerably large and exercise sufficient political power, but it is also a worry that is clearly based on a far too simplistic view of cultural rights. Whereas the linguistic rights (linguistic assistance, linguistic self-determination etc.) attempt to rectify the inequalities faced by linguistic minorities, exemptions on religious grounds, for example, are a very different matter, aiming to alleviate those disadvantages that stem from the conflict between one's religious norms and practices, and the (cultural) norms and practices of the wider society. Further, there is no reason why both linguistic as well as religious rights could not be formulated to be sensitive to the particular needs as well as the size of the groups in question: it would be absurd to grant a minute linguistic minority superfluous assistance to run their own educational institutions or to guarantee that all governmental offices provided service also in the minority language, whereas it may not be absurd to grant them support for some minority language tuition within the larger education system, or for interpretation services in governmental offices. Nor is there any principled reason to think that the minority rights, once being granted, should stay intact, not taking into account the changing needs or the changed composition or size of the minority group in question. As Kukathas notes with respect to the larger liberal society, there must be scope for redesigning the structure of the society in order to take into account the differences as well as the changing composition of this society, ${ }^{261}$ and I see no reason to think why minority rights (such as linguistic assistance or

${ }^{260}$ Kukathas 1992a, 132.

${ }^{261}$ Kukathas 2003, 243-246. 
Part I Justifying Minority Rights

religious exemptions) could not also change, along with the changing needs as well as the composition of the minority groups in question. ${ }^{262}$

With respect to the inequalities faced by different members of cultural groups, Kukathas worries that the cultural (group) rights fail to acknowledge the internal heterogeneity within groups. According to Kukathas, not all members of a particular cultural group are similarly disadvantaged with respect to the members of majority, and some members of a minority may, in fact, be much better off than some members of the majority. ${ }^{263}$ Whereas this may be true - some members of minority cultures may be better off than some members of the majority, for example in financial terms, in terms of formal education or in terms of social competency - it is equally true that all members of a minority are in an unequal position to the members of majority in certain cultural terms - that is, in terms of not being able to live their lives and pursue their chosen conceptions of the good in a society that would be organized in accordance with the norms and practices of their own cultural community. ${ }^{264}$ Whereas this is not to say that all members of a

\footnotetext{
${ }^{262}$ In the previous chapter (Ch. 1, esp. 2.2.), I did express some worries with respect to certain types of minority rights prioritizing certain cultural norms and practices, even to an extent of upholding the status quo and making it much more difficult for those, disagreeing with these norms and practices, to change them. Whereas this is a genuine worry, and one that should be taken into account in actual political decision making, I do not believe it to be a worry that could be used for an outright rejection of such rights.

${ }^{263}$ Kukathas 1992a, 123. In the same context, Kukathas attempts to give another argument against minority rights, claiming that it is not only cultural minorities that face disadvantages that are due to their non-chosen circumstances rather than their choices, but also the disabled, people from poor economic backgrounds etc. (ibid.) The acknowledgement that some other groups of people are also disadvantaged by their non-chosen circumstances, however, is hardly sufficient to reject the claims of cultural groups, but can equally well be interpreted as support for differentiated rights and assistance to them all.

${ }^{264}$ See also Kymlicka's response to Kukathas in Kymlicka 1992.
} 
minority would be equally disadvantaged by not being able to lead their lives in their own cultural contexts (some may, in fact, be very well accustomed to-, and even prefer to live in the so-called alien cultural context), they can, nevertheless, all be considered as being in an unequal position to that of the members of the majority, in terms of not being able to live in a society organized in accordance with the norms and practices of their own cultural community. Provided that minority rights (such as the rights of self-government, linguistic rights or religious exemptions) attempt to rectify this inequality (rather than the financial, educational, or other social inequalities), it would not seem to matter that, in these other respects, some minority members may well be better off than some members of the majority as it is not these inequalities that minority rights are set to rectify.

\subsection{Role of the state}

Whereas the concerns about different kinds of groups and group members, as well as the forms of inequality both between as well as within groups are - and should be - very much concerns for the proponents of minority rights, they are not, on their own, enough to build a convincing case for an outright rejection of such rights. Firstly, it is not an inherent feature of minority rights (whether cultural (group) rights or individually exercised differentiated rights) that they be insensitive to the heterogeneities within group, or to the fluidity of group composition. ${ }^{265}$ Although concrete political practices may, as currently practiced, treat groups as if they were fixed and unchanging entities (both in their boundaries as well as in their contents), it is not necessary that minority rights remain fixed to a particular group of people, or that they could not change along with the changes in group composition and content. Secondly, whereas minority rights do, as argued in Ch. 1, always advance (either directly or indirectly) certain conceptions as well as contents of culture, there is a difference in the extent to which different types of minority rights do so. Further, the mere

${ }^{265}$ I will analyse this second aspect in more detail in Part II of this book. 


\section{Part I Justifying Minority Rights}

observation of the fact that minority rights may benefit some people more than others is far from sufficient grounds for rejecting such rights. As Kukathas notes himself, any state policies will have consequences - including the granting or denial of minority rights and the fundamental question is whether (and on what grounds) to accept these consequences. ${ }^{266}$

Rather than from his critique of groups or his critique of equality, the main basis for rejecting minority rights, in Kukathas's account, would seem to come from his view of the state, and the role of the state in a liberal, free society. Most prominently, Kukathas argues that the liberal state should not be interested in anything except securing peace and order among different people and different groups within society. The liberal state should not be interested, nor should it base its policies on, people's interests or attachments; it should express no group preferences; nor should it promote any particular individuals or individual interests. In the end, the liberal state should not even be interested, or base its policies on, how people's lives go, as it occupies no independent standpoint from which this could be assessed. ${ }^{267}$ For Kukathas, the only concern of the liberal state should be "with upholding the framework of law within which individuals and groups can function peacefully." ${ }^{268}$ Consequently, Kukathas argues that it is no business of the state to take a stand on how the society or different groups in society should be organized, but the state should restrict its operations to the minimum, operating only as an umpire, ensuring the peaceful coexistence of different groups within society. ${ }^{269}$ The liberal state, in Kukathas's model, will not deny people the freedom to organise their affairs in whichever way they wish (provided they do not violate the requirements of mutual toleration and non-

\footnotetext{
${ }^{266}$ Kukathas 1997a, 422-423; 2003, 237. I will return to the problematic of the differentiated impact of universal rules in the next chapter (Ch. 3, esp. 1.2.)

${ }^{267}$ Kukathas 2003, 228.

${ }^{268}$ Kukathas 2003, 249.

${ }^{269}$ Kukathas 2003, 213-214.
} 
interference), but it also gives no support to any individuals or groups to pursue their ways of living. In the face of cultural diversity, Kukathas argues, the liberal state should do nothing apart from securing the peace among different groups and individuals. ${ }^{270}$

It is relatively easy to see how Kukathas constructs his argument for rejecting minority rights from his views on the interests of the state and the role of the state in a liberal society. As minority rights always advance (either directly or indirectly) certain conceptions as well as contents of culture, the granting of minority rights would mean that the liberal state was taking a stand on which cultural groups and which conceptions of their culture were to survive, flourish, or simply die out. This, however, would be unacceptable: "the state should not be in the business of trying to determine which cultures will prevail, which will die, and which will be transformed." 271 As a solution, Kukathas suggests, the liberal state should stay clear of the cultural market place, and let the market place decide which cultural groups, and which conceptions of their culture, are to prevail.

The obvious problem with Kukathas's solution is that the liberal state cannot stay clear of the cultural market place and avoid taking a stand on which cultural groups or which conceptions of culture are to prevail. Even in a minimalist state advocated by Kukathas ${ }^{272}$ there will be common institutions (such as the court system dealing with the conflicts between different groups), ${ }^{273}$ and most contemporary liberal democracies (to which Kukathas clearly wishes his model to be applied) also incorporate public systems of

\footnotetext{
${ }^{270}$ Kukathas 2003, 254; see also Kukathas 1998.

${ }^{271}$ Kukathas 2003, 252

${ }^{272}$ Kukathas does not build a clear picture of what kinds of institutions his conception of the liberal state would include, although it is clear that any state, however limited or minimal, must include some institutions necessary for the fluent functioning of society.

${ }^{273}$ Some of the difficulties incorporated in the cultural embeddedness of criminal courts and juridical systems within liberal democracies will be discussed in Ch. 6.
} 


\section{Part I Justifying Minority Rights}

education and various other state institutions that cannot operate without affirming some cultural contents and thus prioritizing some cultural group(s) instead of others. By doing nothing, the liberal state, in effect, supports those groups and those conceptions of culture that are incorporated in the state institutions and, by way of doing so, also takes a stand on which cultures and conceptions of culture are most likely to prevail.

The response, given by Kukathas, is based on his view of state neutrality, and the bracketing of cultural claims from the sphere of public policies. According to Kukathas, by upholding institutions organized in accordance with the rules and norms of the majority, the state makes no deliberate decision to support one culture over other, whereas by granting minority rights the state would be making such a decision. ${ }^{274}$ The prevailing state institutions, the rules and norms of the society, are, in Kukathas's view, justified because their rationale makes no reference to culture. On the other hand, the granting of minority rights is not, as the rationale for these rights would necessarily incorporate claims of culture and more specifically claims for cultural equality. However, provided that the state institutions and the rules and norms of society have some historical grounding - they have been adopted precisely because they fit the beliefs and ways of life of a particular cultural group Kukathas's claim that the state would not be making a deliberate decision to support one culture over others is cast in doubt. Provided that the current set of institutions, the rules and norms of the society, have been adopted precisely on cultural grounds and that, staying intact, they are systematically disadvantaging members of minority cultural groups, it becomes difficult to maintain that, by doing nothing, the liberal state would not also be making a deliberate decision to support one culture over others. Although Kukathas aims to bracket cultural claims from the sphere of public policies, the cultural embeddedness of state institutions and the

${ }^{274}$ Kukathas 2003, 237. 
disadvantages that these institutions create for members of (other) cultural groups, make his claims rather dubious. ${ }^{275}$

Moreover, even if Kukathas was able to argue that the upholding of current institutions, rules and norms of society, involved no deliberate decision on behalf of the liberal state to support one cultural group over others, and that the cultural claims could be bracketed from the sphere of public policies, this would not, in itself, be sufficient for an outright rejection of minority rights. The bracketing of cultural claims from the sphere of public policies would only deny the using of culture or cultural identity as rationale for such rights, although it would not take away the possibility of justifying such rights, and applying such rights in practice, as long as they were argued for in terms other than culture. It would not, in Kukathas's framework, be justifiable to argue for, say, linguistic assistance on the grounds that the official language(s) of public institutions were systematically disadvantaging certain linguistic minority; it could, however, be justifiable to argue for such assistance on the grounds that the systematic disadvantaging of the minority could lead to serious social disruption and unbalance the peace and order of society. Kukathas is eager to emphasize the extents to which the granting of minority rights could cause resentment, even violence, between as well as within cultural groups, but he seems to ignore the potential upshots of upholding the status quo should this status quo systematically benefit the dominant group in society, and disadvantage others.

The question of whether cultural claims can be bracketed from the sphere of public policies, and whether the denial of such claims also leads to an outright rejection of minority rights, however, seems to leave the main issue of whether cultural claims should be allowed in the sphere of public policies intact. As Kukathas argues that there should be room to modify the common organisation of the society (the state institutions, public holidays, working week etc.) should the composition of the society change and the majority

${ }^{275}$ For an excellent critique of Kukathas's account of the neutrality of the state, see: Festenstein 2005, 96-100. 


\section{Part I Justifying Minority Rights}

of the, say, previously dominantly Christian population become, for example, Muslim, ${ }^{276}$ it becomes difficult to see how Kukathas could sustain his claim that the rationale of state policies should not involve claims of culture. Provided that cultural claims were rejected, as a default, from the rationale of state policies, this would not only prevent cultural claims from being used in support of minority rights, but it would also prevent cultural claims from being used in an attempt to modify the general rules and norms of the society in the first place. ${ }^{277}$ The upshot would seem to be that Kukathas needs to allow cultural claims to operate as rationales for state policies as, otherwise, he would not have a case for modifying or changing the prevailing state institutions, the rules and norms of society, in the face of one cultural group becoming dominant instead of another. But, if this is the case, then why does Kukathas not allow cultural claims to be used in support of minority rights?

The response goes back to the unattainability of cultural equality and the idea that achieving equality in one sense inevitably creates inequalities in another. In the face of an impossible task of achieving perfect equality, or of accommodating claims of all cultural groups (as well as their sub-groups), Kukathas surrenders and claims that "no resolution is possible in philosophical terms; and it would be better not to try" ${ }^{278}$ But, as argued in the previous subsection, the fact that, in concrete political practice, it may not be possible to respond to all claims of culture, and that the granting of minority rights to some may, at times, be disadvantageous to others, is not sufficient grounds to not even try. The disadvantages faced by minority members are very real and, should the state be able to rectify- or at least ease some of these, it should at least try (provided that the disadvantages caused to others do not override

\footnotetext{
${ }^{276}$ Kukathas 2003, 244-245.

277 See also: Festenstein 2005, 99.

278 Kukathas 2003, 251. This comment, it should be noted, is made in response to identity politics and competing claims for recognition, although it is clear that no resolution, in Kukathas's view, is possible for the competing claims for (other) minority rights either.
} 
the benefits produced to some). Provided that Kukathas does, indeed, let cultural claims operate as rationales for state policies at the level of the general rules and norms of society, there is no particular reason for why this rationale could not also operate at the level of minorities as potential support for a variety of minority rights. This, of course, is not to say that the response of the liberal state to cultural diversity should, as a default, come in the form of granting different types of minority rights, but it is to say that the liberal state can, and also should, take cultural claims into consideration and that there is no reason why the disadvantages, resulting from the differing norms and practices of minorities and the general norms and practices of society, could not also be responded to by a variety of minority rights - should these rights be conceived of as the best alternatives available.

\section{Conclusion on autonomy vs. toleration}

In this chapter, I have concentrated on one of the much debated issues within liberal multiculturalism, that of the centrality of individual autonomy and the role of the liberal state in catering for autonomy. I started by assessing Will Kymlicka's arguments for minority rights as catering (either protecting or promoting) individual autonomy, and argued that Kymlicka's emphasis on individual autonomy as one of the guiding principles of liberalism created far stronger preconditions for those minority groups that could be seen as eligible for minority rights. I then turned to an alternative approach, that of Chandran Kukathas's toleration based account and argued that, whereas Kukathas's account was able to accommodate much wider variety of minority groups within liberal society, Kukathas's framework (most notably, the requirements of mutual toleration and the right of exit) created much stronger conditions for all groups within the liberal society to conform to than Kukathas was willing to recognize.

Whereas the toleration based account of Kukathas was able to incorporate a much wider variety of minority groups within the liberal society (although not quite as wide as Kukathas would claim), this approach was also defective from the perspective of 
Part I Justifying Minority Rights

giving any definitive guidance on the ways in which the liberal state should respond to cultural diversity. Whereas Kukathas's own, no doubt controversial, approach was to argue against minority rights by also arguing against the usage of culture as a rationale for state policies, I tried to show that, within Kukathas's own framework, cultural claims could not be bracketed from the sphere of public policies. This, however, left open the possibility of the liberal state taking cultural considerations into account in public policies and in public decision making, as well as to responding to cultural claims by minority rights. Whereas Kukathas was able to point out to several practical problems of applying minority rights in practice, his theoretical framework failed to provide any outright rejection of such rights. Rather, as with the autonomy based account of Kymlicka, Kukathas's toleration based account provided no definitive guidance into how the liberal state should response to cultural diversity, although it did (contrary to Kukathas's claims) leave substantial scope for the liberal state to take cultural considerations into account, and to respond to the disadvantages faced by minority groups and/or their members possibly, although not necessarily, with the help of minority rights. 


\section{Chapter 3}

\section{Liberal egalitarianism and equality of opportunity}

In the two previous chapters, I concentrated on some of the classical arguments for as well as against minority rights within the liberal framework. The arguments from equality, autonomy and toleration were discussed both in the light of the rationales for the liberal state to take cultural considerations into account, as well as in the light of the need or the rejection of different kinds of minority rights. Whereas these approaches provided slightly different platforms from which the issues of cultural accommodation could be approached, none of them, it was argued, provided any conclusive case for or against minority rights within the liberal framework. Rather, as I tried to argue, the discussed approaches left substantive scope for legitimate variation to the liberal approaches to cultural diversity, including the possibility, albeit not a requirement, for the liberal state to grant different kinds of minority rights in practice.

One of the main criticisms, not only against these classical debates on multiculturalism, but also against my own argument based on these debates, would be that they fail to take sufficiently into account the complexity of issues involved in debates on multiculturalism and, especially, on minority rights. Minority or culturally differentiated rights are of various kinds and the normative issues relevant for each may be very different, depending on the kind of right in question as well as on the context within which this right is argued for. ${ }^{279}$ It may, therefore, not be sensible to talk of minority rights as a bulk, nor should it come as a surprise that the attempts to justify (or reject) these rights by a recourse to a simple guiding principle (be it equality, autonomy or toleration) are bound to encounter some serious difficulties. Due to the

\footnotetext{
${ }^{279}$ See also Background, esp. 2.3.
} 


\section{Part I Justifying Minority Rights}

heterogeneity of normative issues relevant for any particular minority right, the debates on the justifiability (or unjustifiability) of these rights should rather be done in context, as the justificatory framework of, for example, exemptions, rights of self-government, symbolic recognition, or special representation, are bound to be very different as well as more complex than the classical debates on multiculturalism would make it seem.

Whereas it is far beyond the scope of this work to try to build a comprehensive account of the vast variety of minority rights or their (no doubt, equally varied) justifications, in this chapter, I wish to look at one, rather specific debate among liberal multiculturalists - that of the debate over the rule and exemption -approach, and the justificatory framework of equality of opportunity within which this debate has largely been conducted. This case of "rule and exemption" is chosen for two reasons. Firstly, I believe that the cultural exemptions granted for minority members, in the face of the incompatibility of certain norms and practices of the majority with those of the minority, constitute a relatively easily identifiable group of rights, although as will be seen not all exemptions should fall within precisely the same justificatory schema. Secondly, and more importantly, the liberal egalitarian critique of cultural exemptions can also be seen as an attempt to counter the arguments presented in Ch. 1 for the egalitarian rationale of the liberal state to be concerned about people's cultural disadvantages - this rejection being based precisely on the same grounds of equality.

Some of the concerns posed by the liberal egalitarian critics of minority rights will be revisited in more detail in Part II. ${ }^{280}$ Putting these concerns aside, in this chapter, I aim to show that the rejection of both, the egalitarian rationale for the state to be concerned about cultural disadvantages, as well as of differentiated treatment such as exemptions, may be too swift and theoretically unfounded. By looking at different conceptions of equality of opportunity and,

280 Most notably, I will return to the liberal egalitarians' critique of allocating minority rights on the basis of one's group membership, and develop my own account of the appropriate modes of allocation. 
especially, the proper object of opportunity, I argue that, contrary to the critics, there are strong equality-based reasons for the liberal state to be concerned about cultural disadvantages, and that a default position of trying to rectify these disadvantages should be adopted. This default position, however, constitutes nothing as strong as a requirement for the liberal state to grant cultural exemptions in all cases, although it does explicate the rationale through which these exemptions may be justified.

This chapter is divided into three sections. In the first section Multiculturalism and equality of opportunity I outline the framework within which the discussions on cultural exemptions have taken place, starting from some of the rationales that the liberal state may have for being concerned, not only with equality of resources, but also with equality of opportunity. I also look at some of the ways in which the incompatibility of the norms and practices of the majority and those of a minority may affect the minority members' opportunities to function as full members of society, and the ways in which certain rules, albeit seemingly neutral, may nevertheless be considered as disadvantageous to certain groups of people. In section 2 Opportunities, opportunity sets and equality of opportunity to $X$, I concentrate on some of the definitional debates within discussions on equality of opportunity, and further qualify the scope of the argument given in this chapter. In the final section The proper object of opportunity, I defend a properly construed conception of equality of opportunity - that is, an opportunity to combine one's cultural commitments with one's aspirations in public life - and argue that, should one's adherence to a particular cultural practice prevent one from fulfilling some criteria for a particular job or educational institution, there are strong egalitarian reasons for the liberal state to be concerned about and to aim to rectify this inequality.

This chapter concludes (3.2.) with some important qualifications to the extent to which my argument can be used in defence of the rule and exemption -approach, outlining some of the benefits as well as constraints of the joint conception of equality of opportunity in debates on multiculturalism and cultural exemptions. Whereas I 


\section{Part I Justifying Minority Rights}

argue that the conception of equality of opportunity in terms of joint opportunities has the benefit of shifting the burden of proof from those disadvantaged to those who claim these disadvantages to be justified, I also show that this conception does not, in itself, provide any conclusive guidance to the ways in which the liberal state should respond to these disadvantages. Rather, in line with the arguments of the two previous chapters, this chapter argues for a strong rationale for the liberal state to be concerned about and to try to rectify those disadvantages that result from the incompatibility of the general rules and practices of the society and those of the minority, but cautions against too straight forward ab applicability of this rationale as a basis for any particular types of cultural policies.

\section{Multiculturalism and equality of opportunity}

In chapter 1, I built a strong case for the liberal state to be concerned about as well as to try to rectify those disadvantages that the members of minority cultural groups faced due to them living in an alien cultural context. The argument developed was based on Will Kymlicka's resourcists account of equality and the modified importance argument showing why it was not reasonable, as a default, to expect people to abandon their own cultural contexts or particular cultural practices. ${ }^{281}$ The disadvantages, faced by minority members, were explained, primarily, in terms of the inequality of resources, covering a variety of cases where the minority members had to use substantive amounts of time and effort in order to preserve their own cultural contexts, or to continue adhering to their specific cultural traditions or practices.

Whereas the resourcist account, combined with the modified importance-argument, was thus capable of both explaining a vast variety of cultural disadvantages as well as of providing rationale for the liberal state to be concerned about these disadvantages, this pronouncedly resourcist account may not be able to capture all types of (in)equalities that are, nevertheless, important from the

${ }^{281}$ See Ch. 1, esp 1.2. 
liberal point of view. As argued by many, it is not only that the state should be concerned about whether people have equal resources with which to pursue their chosen ways of life, but also whether (a) pursuing certain ways of life is possible for people, and (b) whether these ways of life are equally open to all. What the liberal state should be concerned about, is not only the inequalities resulting from people's efforts to maintain their own cultural contexts / practices, but also with people's opportunities in other spheres of life - that is, whether people have equal opportunities to achieve certain prospects in life, regardless of their cultural background. The emphasis put forth by the proponents of equality of opportunity is thus not so much on whether the members of minority cultures can begin from the same line with majority when choosing their courses of life, but whether - once their choices have been made they also have equal prospects of success. ${ }^{282}$

282 This account of equality of opportunity has obvious similarities to Richard Arneson's conception of equality of opportunity to welfare (Arneson, 1989; 1990). However, whereas Arneson argues that people should have equal opportunities to the welfare that they have - after rational reflection - come to aspire, the account discussed here is more limited in scope. Whereas Arneson's account incorporates the possibility of people's welfare being defined in very different ways, the account discussed here has a fixed point of reference, that is, the way of life $\mathrm{X}$, or the prospect $\mathrm{Y}$ that people should have equal opportunities to achieve. Although it is, of course, an important question whether people should have equal opportunities to their welfare, I believe that it is an equally important question to consider whether people have equal opportunities to some objectively defined prospect of $Y$, should they find this prospect as important for their welfare. Furthermore, the equality of opportunity in this sense fits much better the concerns of multiculturalists for whom, apart from the subjectively experienced welfare of members of cultural groups, it is also of tremendous importance that the members of minority groups should also have equal opportunities to achieve those positions in society that are, generally speaking, perceived of some status. 
Part I Justifying Minority Rights

Equality of opportunity is, of course, a notoriously difficult concept, the definition of which remains contested. ${ }^{283}$ In order to open up some of the ways in which equality of opportunity has been understood in multiculturalism, I start by giving a brief (and no doubt incomplete) account of the classical Rawlsian position, before turning to some of the implications that a properly construed conception of fair equality of opportunity may have for discussions on multiculturalism.

\subsection{The Rawlsian framework of fair equality of opportunity}

According to John Rawls, certain positions (such as public offices, jobs and educational careers) should be open to all, regardless of those characteristics of the applicants that can be conceived as arbitrary from a moral point of view. ${ }^{284}$ According to Rawls, social contingencies, such as one's social class or status, should not affect one's eligibility for the positions of advantage, but everyone regardless of their social status - should be allowed to compete, as well as to have fair chances of success in attaining these positions. By one's social status, Rawls refers primarily to one's income class, although it is now fairly commonly accepted that things such as race, religion, gender or cultural background should also be conceived as contingent facts that should not influence one's eligibility or one's chances of success.

This broad notion of fair equality of opportunity (that is, the construction incorporating race, religion, cultural background, etc.) has two important consequences. Firstly, if one's social status

283 Williams 1973; Radcliffe-Richards 1997; for useful overview, see: Arneson 2002; Mason 2006; for an excellent attempt to give a formal definition and critique, see: Hansson 2004.

${ }^{284}$ Rawls 1971, 73. In his restatement, "Justice as Fairness" (2001), Rawls formulates the second principle of justice as follows: "Social and economic inequalities are to satisfy two conditions: a. They are to be attached to offices and positions open to all under conditions of fair equality of opportunity; b. They are to be to the greatest benefit of the least-advantaged members of society (the difference principle)." Rawls 2001, 42-43. 
(including one's gender, race, and cultural background) should not affect one's eligibility or one's chances of success, it is quite clear that the criteria used for fulfilling the positions of advantage should not be based on these characteristics. Setting certain social background, skin colour, or gender as a requirement for a job or an educational career is unjustifiable, as this takes away the opportunity of those with different social backgrounds, skin colours or genders to attain these positions. As has come to be commonly accepted, the criteria for fulfilling such positions should be based on the skills required, so that those equally equipped for successfully performing in such positions also have equal prospects of success in attaining these positions (careers open to talents). ${ }^{285}$ This, irrespective of their social class, gender, skin colour, cultural background etc.

Secondly, Rawls also maintains that it is not enough that those positions, open to all, are filled in accordance with criteria relevant for the successful performance in that position. One's social status often affects the ways in which one is capable of developing one's talents, and concentrating solely on the criteria for fulfilling certain positions of advantage ignores these effects. Thus, Rawls argues that the whole structure of society should be organized in a way that enables those with equal talents and ambitions to also develop these talents and to pursue, with equal prospects of success, their ambitions. For such a state of affairs to exist, Rawls proposes that the state should try to ensure equal chances of education through subsidized public schooling, police the economic activities and conduct of firms, and guarantee social minimum income (including effective health care etc.) for everyone. ${ }^{286}$ This, Rawls calls fair equality of opportunity - that is, formal equality of opportunity

${ }^{285}$ It should be noted that the Rawlsian "careers open to talents" is, by no means, the only justifiable criterion from the perspective of equality of opportunity, but for example certain types of lotteries may well also be used for the allocation of positions of power. See e.g. Stone 2007; Saunders 2010. In this work, I will, however, subscribe to the more commonly accepted view of "careers open to talents".

${ }^{286}$ Rawls 1971, 73; 275; 2001, 43-44. 
Part I Justifying Minority Rights

defined in accordance with non-morally arbitrary criteria, conjoined with an institutional structure that enables those with equal talents and ambitions to fulfill these criteria.

\subsection{Fair equality of opportunity in multiculturalism}

It is not entirely clear what kinds of implications this (broad) conception of fair equality of opportunity should have on issues on multiculturalism, or on minority rights such as cultural exemptions. Quite obviously, the Rawlsian framework does not allow public offices, educational institutions or job opportunities to be filled on the basis of one's cultural or religious background, nor does it allow the members of minority cultures to be excluded from such positions simply by virtue of them being from a particular cultural background. This implication, of course, is nothing new (or novel to Rawls), but it does pave the way to a more interesting (as well as much more complex) question about the actual criteria that is used for fulfilling those positions that should be equally open to all. That is, it brings out the further question of whether the criteria, supposedly relevant for the successful performance in a position, is, in fact, consistent with the principle of fair equality of opportunity, if this criteria, nevertheless, excludes members of certain minority groups from gaining such positions. ${ }^{287}$

To recall, the Rawlsian conception of fair equality of opportunity states that certain positions (educational careers, jobs, public offices) should be open to all. ${ }^{288}$ Anyone, regardless of their gender, religion or cultural background, should be able to pursue his/her ambition of, for example, becoming a police officer, and to compete on equal terms with others who share the same ambition. Further, the Rawlsian conception of fair equality of opportunity

${ }^{287}$ For debate, see also Barry, 2001; Festenstein 2005.

288 In Rawls's conception, this obviously refers to people within a particular society, that is, the citizens of the nation state. Rawls's own view of equality of opportunity on the global level is very different (see esp. Rawls, 1999; for debate see Martin and Reidy 2006), although some work have been done to apply the Rawlsian framework of domestic justice also to the global sphere, e.g. Beitz 1979; Pogge 1989; 1994. 
also states that the criteria used for deciding who wins the competition of becoming a police officer should be based on those qualities that are relevant for a successful performance as a police officer, not on the morally arbitrary characteristics of gender, religion, cultural background etc. If successful performance as a police officer requires, say, certain educational qualifications, the criteria for fulfilling the positions of a police officer should also be based on if one has attained these qualifications. Finally, and most importantly, fair equality of opportunity also states that the structure of the society should be organized in a way that everyone, regardless of their cultural background etc., have equal chances of becoming a police officer, the chance being only dependent on their natural talents and the amount of work they put into fulfilling the criteria for such position. This entails that the educational institutions, including the institutions for police training, should be accessible to all, but it may also entail that the criteria for being a police officer itself should not disadvantage people from different cultural backgrounds.

It should, at this stage, be noted that, having criteria that is not based on the morally arbitrary characteristics of gender, religion, cultural background etc., is not necessarily the same thing as having criteria that does not put members of certain cultural groups in a disadvantaged position to that of the majority. For example, if one of the requirements of being a police officer is the acceptance of a strict code of appearance (including, say, a certain kind of uniform, short hair and cap), this does, in effect, make it much more difficult for those to become police officers who's own cultural or religious commitments (such as the wearing of a veil or a turban) are in conflict with such requirements. Although the requirement is not, in itself, based on the morally arbitrary characteristics of one's cultural or religious background, ${ }^{289}$ this requirement, nevertheless, has a very different impact on people from different cultural backgrounds, as for some, fulfilling this requirement means giving

289 That is, the requirement is not intended to prevent those with conflicting dress codes from joining the police force. 
Part I Justifying Minority Rights

up a (potentially very important) aspect of their culture, whereas for others, no such sacrifices are required. As a consequence, it may be much more difficult for members of those cultural groups with conflicting dress codes to become police officers than others, thus also cutting down the amount of people who, from such backgrounds, manage to both fulfill these requirements as well as to become police officers. With respect to these consequences, two issues should be kept separated:

\section{Proportional underrepresentation}

Firstly, there is the issue of proportional underrepresentation of members of certain groups. Although this may be a concern in itself (it can be argued that public institutions, such as the police force, should have equal representation of all groups in society), this does not, in itself, entail that the requirements of becoming a police officer would be discriminatory against the members of some groups. As Brian Barry has pointed out, there may be several reasons for why members of certain groups do not even wish to aim at certain positions, irrespective of the criteria that is required for such positions. ${ }^{290}$ The proportional underrepresentation of some groups may, of course, be a result of discriminating criteria (and should thus also give good reasons for the state to investigate the used criteria in order to identify this (possible) discrimination), but the underrepresentation itself does not suffice to establish that the criteria used for fulfilling such positions would be discriminating against the members of some groups. ${ }^{291}$

\section{Differentiated impact of a rule}

Secondly, and more interestingly for the purposes of this chapter, there is the issue of whether the differentiated impact of criteria violates the principles of fair equality of opportunity, and whether such criteria can be considered as leading to unfair

${ }^{290}$ Barry 2001, 97-98; 117.

${ }^{291}$ See also: Barry 2001, 97-98. 
discrimination. ${ }^{292}$ Again, it is Brian Barry who has taken the stand to the contrary, arguing that the differentiated impact of a rule (in this case, the criteria for becoming police officer) does not necessarily mean that the people who are burdened by the rule would also be discriminated against. ${ }^{293}$ Whereas I think that Barry is right - a differentiated impact of a rule does not necessarily mean discrimination - I also believe that the argument Barry gives in support of this position is flawed, and that in many cases, rules that have a differentiated impact on members of cultural groups are, in fact, discriminating.

To start with Barry's own argument, Barry states that all rules treat different people differently, and the fact that a rule has a different impact on some people due to their religious or cultural commitments does not suffice to show that this rule would be unfair or discriminatory. As examples, Barry points towards laws that prevent rapists from raping or pedophiles from interfering with children - both clearly laws that have much harsher impact on those who would want to rape or molest than those who do not. ${ }^{294}$ Needless to say, these laws are not considered as unfair or discriminatory, even if the impact of the law is clearly different for different people.

The attempted analogy between the anti-rape laws and the criteria that put an extra burden on members of certain cultural groups in the employment market is, however, clearly flawed. In order to see this, one needs to look at the difference in the intention of the laws or rules in question. Whereas it is the intention of the anti-rape laws to put a burden on the would-be rapists (justified by the rights of those not wishing to be raped), it is not, and should not

\footnotetext{
${ }^{292}$ For the sake of simplicity and shortness, I will from now refer to "discrimination" instead of "unfair discrimination" although it should be kept in mind that there may also be positive forms of discrimination that aim at fair or just outcomes or distribution, and that not all forms of discrimination are necessarily inherently unjust or unfair. Cf. LippertRasmussen 2006; 2007.

${ }^{293}$ Barry 2001, 34.

${ }^{294}$ Barry 2001, 34.
} 


\section{Part I Justifying Minority Rights}

(in accordance with the principle of fair equality of opportunity) be the intention of the criteria of employment to put a burden on those members of cultural groups whose cultural practices (such as dress codes) are in conflict with the used criteria. ${ }^{295}$ Whereas the anti-rape laws are designed to prevent those wishing to rape from raping, the criteria for becoming a police officer is, and should be, designed in accordance with the requirement of everyone having an equal chance of becoming a police officer. ${ }^{296}$ Moreover, whereas one's interest to rape can easily be conceived as an illegitimate interest (overridden by the interests of those not wishing to be raped), most cultural practices - including dress codes - are perfectly legitimate. Whereas rape is, inherently, a violation of another person's rights, cultural dress codes are not. ${ }^{297}$ In order for Barry to build a convincing argument from analogy to show that the differentiated impact of a rule, due to one's cultural commitments, would not be discriminatory, he should have at least picked other rules that were, in relevant senses, analogous to the cases at hand..

Showing the flaws in Barry's argument does not, however, show that his conclusions would also be flawed. Nor does it answer the question of whether the principle of fair equality of opportunity is violated, should some criteria (such as the dress codes of the police officer) put an extra burden on those whose cultural commitments are in conflict with the criteria. Although I will elaborate on this issue more fully in the following section, what I wish to suggest, for the time being, is that it is at least an open question whether the

\footnotetext{
295 See also: Barclay 2005.

296 This is not to say that the primary aim of the criteria would be to provide everyone equal chances of being a police officer. Rather, the dress code is designed to benefit the performance of both the police force as well as the individual officers. However, unlike the anti-rape laws that are designed to put a burden on certain people, the dress codes are not, and in accordance with fair equality of opportunity - should not.

${ }^{297}$ It is, of course, a different issue whether the enforcement of a dress code (such as the wearing of a veil) violates the rights of, or causes harm to, those to whom it is enforced. An illegitimate enforcing of the code, however, does not make the code itself as inherently illegitimate.
} 
differentiated impact of a rule or criteria (designed to fulfill the requirements of fair equality of opportunity) is (unjustifiably) discriminatory.

A comparison between Barry's example of anti-rape laws and the example of the professional dress codes of the police officer should help clarify this point. Whereas it is clear that in both cases, the universally applicable rule has a different impact on different people, what the multiculturalists would wish to maintain is that, in the first case, the differentiated impact is justified, whereas in the second, it is not. Although it is certainly true that in the first case, it is the intention of the anti-rape law to burden the would-be rapists, and that in the second case it is not, the intention of the rule does not, in itself, suffice to establish whether this burden would be justified. Having a law that is intentionally burdensome to some people does not make it justified, nor does the un-intentionality of the burden establish that it would be un-justified. ${ }^{298}$ There are, however, other differences in the two cases that may be helpful for the multiculturalists for explaining the difference between the two cases.

Whereas in the case of rape, the question can be framed in terms of balancing the interests of the would-be rapist and his victim, in the case of professional and cultural dress codes no such obvious comparison can be found. In the case of rape, it can (fairly noncontroversially) be argued that the interests of the would-be rapists are overridden by the (more fundamental) interests of others to bodily integrity, thus justifying the differentiated impact of the law to would-be rapists and non-rapists. ${ }^{299}$ In the case of professional dress codes, however, it is not quite as clear, between what, let

\footnotetext{
298 As an example, most contemporary liberal thinkers would probably agree that the apartheid system of South Africa was hardly justified, although it was certainly intentional.

${ }^{299}$ This is not to say that the only wrong of rape would be that it violates the basic rights or interests of the victim, although this certainly is one aspect of the wrongness of rape. For more thorough analyses of the wrongness of rape, including interest-base accounts, see Archard 2007; entries to Burgess-Jackson 1999.
} 


\section{Part I Justifying Minority Rights}

alone how, the balance should be struck. On the one hand, there are the interests of those wishing to maintain their own cultural dress codes - something that, following the importance argument given in Ch. 1, it is not, as a default, reasonable to expect them to abandon. On the other hand, however, there are the benefits of a uniform dress code - something that (at least to an extent) can be considered as necessary for both the successful operation of the police force, as well as the successful performance of the individual police officers. ${ }^{300}$

Whereas I will, in the final section of this chapter, come back to some of the different reasons (as well as the weight of these reasons) there may be for insisting on particular rules or criteria in various situations, for the time being, it suffices to note that, contrary to the case of rape, the balance of interests in many cultural cases may be far less straight forward than many multiculturalists, or their critics, would hope it to be. Once we take seriously the differentiated impact (burden) of the criteria, the (potentially very strong) consequences that following this criteria may have to one's cultural commitments, and the principle of fair equality of opportunity, it becomes far more difficult to argue that those burdened by the criteria due to their cultural commitments should, as a default, be expected to either abandon their cultural commitments or their professional aspirations. If one's cultural commitments are of such (potentially) tremendous importance that it is not (as a default) reasonable to expect people to abandon these commitments, it would seem odd to argue that any rule, imposing a burden due to these commitments, could be deemed justified without any further ado. This is not so say that, in some cases, the particular universal rules or criteria could not be deemed of such importance that the burdens created for minority members would be

\footnotetext{
${ }^{300}$ For the time being, I will set aside the question of whether it is precisely that particular dress code that is necessary for the functioning of the police force, or whether some other uniform dress code would also suffice.
} 
justified, ${ }^{301}$ or that, in all cases, those burdened by the rule or criteria should automatically be exempted. ${ }^{302}$ It is simply to point out that, in many cases, it is not at all obvious where, and between what, the balance should be struck.

Although this observation may, at first, seem somewhat trivial and unimportant, I nevertheless believe it to be an important observation, showing that it is at least an open question, whether the reasons for having certain criteria are weighty enough to justify the differentiated impact of the criteria due to one's cultural commitments. If one's cultural commitments are of such (potentially) tremendous importance that it is not reasonable to expect people to abandon these commitments, it must also be that the reasons for having criteria that impose a burden due to these commitments, must be extremely weighty - in order to change the unreasonable expectations of abandoning one's cultural commitments into reasonable ones. This idea of balancing the reasons between having generally applicable criteria and of not requiring (some) people to adhere to this criteria will be discussed in more detail in the last section of this chapter (esp. 3.2.). Before that, however, a more systematic analysis of what it means to have an opportunity, and when equality of opportunity prevails, is in order.

\section{Opportunities, opportunity sets, and equality of opportunity to $\mathrm{X}$}

So far, I have focused on the possible rationales that the liberal state may have for being concerned about the disadvantages resulting from the incompatibility of general rules and norms of society and the specific cultural or religious practices of the minority. I argued

\footnotetext{
${ }^{301}$ For example, bans on implementing grievous bodily harm, or rules necessary for the ensuring of public safety may be such. What these rules are exactly, and whether there can ever be exemptions to such rules are, of course, contested issues that can only be solved on a case to case basis.

302 The rule and exemption -approach will be discussed in more detail in section 3 .
} 


\section{Part I Justifying Minority Rights}

that, within the framework of fair equality of opportunity, there were strong reasons for the liberal state to investigate the criteria used for fulfilling positions of advantage, should the members of minority cultures be a) underrepresented in these positions, or b) seen to encounter extra burdens by virtue of having to abandon their cultural commitments due to the criteria used to fill these positions. Whereas I did not argue that, in all such cases, the used criteria could be seen as (unfairly) discriminatory, I did, nevertheless, try to show that the extra burden of abandoning one's cultural practices (conjoined with the not least obvious balancing of interests) gave strong reasons for the liberal state to at least investigate whether the burden in question was justified.

In this section, I turn to look at some of the background debates on equality of opportunity within debates on multiculturalism, and clarify some of the terminology used in these debates. I begin by looking at Brian Barry's two conceptions of equality of opportunity (general and narrow), including his presumptions of opportunities (options) as objective states of affairs (2.1.). I then move to look at the difficult questions relating to the costs of opportunities and the relevancy of different types of costs for equality of opportunity to prevail (2.2), and suggest that, from the perspective of those disadvantaged, the questions of the existence of costs and their (possible) justification should be kept separated. As will be seen in the final section of this chapter (3.The proper object of opportunity), the taking into account the perspective of the disadvantaged also affects the questions about the proper focus of discussions on equality of opportunity, shifting the locus of discussions from the relevant costs of opportunities to the proper object of opportunity, and the appropriate notion of having joint opportunities to $\mathrm{X}$ and $\mathrm{Y}$.

\subsection{Brian Barry on equal opportunities}

In this polemic attack on multiculturalism, Brian Barry questions the view according to which one's cultural commitments could be seen as restricting the opportunities of those adhering to these commitments. In constructing his argument, Barry gives two, rather 
different, formulations of equality of opportunity. On the one hand, Barry argues that, in order for equality of opportunity to obtain, people must have roughly identical opportunity sets to choose from (equality of opportunity, general). ${ }^{303}$ For Barry, these opportunity sets are provided, first and foremost, by rules that are universally applicable, regardless of one's cultural, religious or social background. It is not, Barry maintains, that those adhering to certain cultural practices would be denied equal opportunities, should these practices collide with the general rules, norms or laws of society (such as, for example, the general health and safety requirements, gender equality legislation, animal welfare legislation, or (with some qualifications) with the general dress requirements of a work place). If, say, a certain profession requires people to wear certain outfits, or work on designated hours on designated days, it is not a question of inequality of opportunity that some people cannot participate in these professions due to them observing their cultural or religious dress codes, designated praying times or religious holidays. ${ }^{304}$ The observants of the conflicting cultural or religious

${ }^{303}$ What is meant by opportunity sets is the pool of options - including options of employment and education - that people can choose (with some prospects of success) to aspire to. By roughly identical opportunity sets, it is meant that one's options of, say, employment or education, should not be restricted to, for example, a very limited number of jobs, but that everyone should have roughly the same pool of options (different jobs) that they can (with some prospects of success) aspire to. This view of roughly identical opportunity sets (that Barry ascribes to) takes from the resourcist account of equality the insight of emphasizing the equality of initial opportunity sets. Thus, choosing certain options may limit the pool of options available in later life, without violating the basic requirement of the state to guarantee people roughly identical opportunity sets to begin with.

${ }^{304}$ Barry qualifies his position by saying that these requirements (such as dress codes that prevent people with other, conflicting, dress codes from being chosen for the job) can be justified only if they are necessary for a successful performance in the job. (Barry 2001, 59-60; 2002, 216) I will return to this shortly. For the time being, it suffices to say that, in Barry's general formulation of equality of opportunity, even if these requirements were not justified by their necessity for the performance in the job, people 


\section{Part I Justifying Minority Rights}

practices are not devoid of the opportunity to participate in these professions, as they are perfectly free to choose whether they wish to hold on to their cultural commitments, or abandon these commitments in order to take advantage of the opportunity in question. What is important, Barry maintains, is that people have roughly identical opportunity sets to choose from (including the number of jobs, educational institutions or public offices), and it is no business of the state to interfere in which opportunities (and on what grounds) people wish to take advantage of.

Besides the general formulation of equality of opportunity (in terms of roughly identical opportunity sets), Barry also constructs another, narrower definition of equality of opportunity. This definition, according to Barry, should be primarily used in specific cases of employment or education, although, as I try to show, the scope of this conception is far more restricted than would at first seem. According to Barry, this narrower notion of equality of opportunity requires that "those who are equally well qualified to do a job have an equal chance of getting the job. If some people who are as well qualified as others are denied an equal chance of employment in some job, they can complain of (unfair) discrimination.". ${ }^{306}$ As an upshot, Barry argues that any job that, for no good reason, denies people the right to adhere to their cultural commitments (such as certain dress codes or times of prayer) violates the requirements of equality of opportunity if the denial of such commitments cannot be shown as required for the successful performance of such job. ${ }^{307}$ However, should such restrictions be required for the successful performance of the job,

would not be lacking an opportunity to work in such a job even if the adherence to the conflicting dress codes would prevent them from being chosen for the job.

${ }^{305}$ Barry 2001, esp. ch. 2.3.

${ }^{306}$ Barry 2001, 55; see also Barry 2002, 216-221.

${ }^{307}$ For example, Barry defends the right of the Muslim women to wear head scarves for example in office jobs or department stores where there are no non-trivial reasons to insist on banning such attire. Barry 2001, 57$62 ; 2002,216$. 
no issues of inequality of opportunity arise. Due to one's cultural commitments, in these cases, one is simply not as qualified for the job in question, although one would still have the opportunity (in the general sense) to qualify for the job, if one was willing to abandon one's conflicting cultural practices.

Objective and subjective conceptions of opportunity

Barry's broader notion of equality of opportunity - that of the equality of opportunity defined in terms of roughly identical opportunity sets to choose from - is based on two important assumptions. Firstly, it is based on the assumption of the objective nature of opportunity, and secondly, it is based on the interpretation of equality of opportunity as incorporating no further elements than the existence of the opportunity set in question.

With respect to the nature of opportunity, Barry argues that an opportunity is an objective state of affairs. ${ }^{308}$ For an option $\mathrm{X}$ to be an opportunity that is open to me, it only needs to be an option that I can (bar my physical constraints) do. A turban wearing Sikh, for example, has an opportunity to wear a policeman's hat (and thus work as a police officer), as he is not physically constrained from taking off his turban in order to do so. ${ }^{309}$

As opposed to Barry's view, Bhikhu Parekh has argued that opportunity is also subject-dependent. According to Parekh, it

\footnotetext{
${ }^{308}$ Barry 2001: 37.

${ }^{309}$ Much of the literature on job opportunities and cultural dress codes have utilized two classic examples: the traditional head gear of the Royal Canadian Mounted Police, and the wearing of safety helmets on construction sites. (see e.g. Parekh 2000, 243-245; Kymlicka 1995, 177; Phillips 2007, 113; Barry 2002, 216-217; Caney 2002, 87-88) The two cases are, quite obviously, different, and have also attracted different responses, due to one (the requirement of wearing the traditional hat of the Canadian Mountain Police) being a requirement based mainly on tradition, whereas the other (safety helmet) being a question of work place safety. Although I will return to the question of how the reasons for having particular criteria may, or may not, affect equality of opportunity later on in this section, my current discussion on the nature of opportunity itself needs not take into account the reasons for why certain criteria is in place.
} 


\section{Part I Justifying Minority Rights}

makes no sense to say that one has an opportunity $\mathrm{X}$ unless one also has a cultural disposition to take advantage of $X{ }^{310}$ In the case of the turban wearing Sikh, it may not be a feasible option for him to take off his turban (in order to wear the police hat), thus (provided that one of the requirements of being a police officer is the wearing of the hat) denying him the opportunity to work as a police officer.

It should be emphasized that, so far, both Barry's as well as Parekh's accounts are only concerned with how to understand the concept of opportunity, or option, itself - not with how this concept relates to the wider notion of equality of opportunity (understood in terms of roughly identical opportunity sets). Although it is clear that Barry and Parekh come to argue for very different conclusions with respect to the wider notion of equality of opportunity, a closer analysis shows that this need not be so. In fact, one's views of whether one has an opportunity $\mathrm{X}$ in any particular situation need not depend on the dichotomy of objective vs. subjective conceptions of opportunity. ${ }^{311}$ Rather, depending on how one interprets the subjectivity of opportunities in Parekh's position, the objective and subjective conceptions of opportunity would seem to lead into either identical or completely different conclusions with respect to whether one has an opportunity $\mathrm{X}$ (for example, an opportunity to work as a police officer) and whether this opportunity is thus also included in the opportunity sets of the person in question. Moreover, as I try to show, it is only if one accepts the stronger (and, in my view, untenable) interpretation of the substantive conception of opportunity that the differences arise.

\section{Subjective opportunities and opportunity sets}

Criticizing Parekh's position, Barry argues that Parekh's subjective conception of opportunity blurs the distinction "between limits on the range of opportunities open to people and limits on the choices that they make from within a certain range of opportunities". ${ }^{312}$

\footnotetext{
${ }^{310}$ Parekh, 1997: 150-151; 2000: 241.

${ }^{311}$ This dichotomy has also been criticised in Mendus 2002; Miller $2002 \mathrm{~b}$.

${ }^{312}$ Barry 2001, 37.
} 
Although my cultural commitments may impose certain limits to how I am supposed to choose to live my life, this does not take away the existence of the option that I still could (at least in principle, although perhaps not in practice) take advantage of, even if taking advantage of this option would mean abandoning some of the requirements of my culture.

However, whereas Barry's distinction between the limits on the range of opportunities and limits on the choices made within this range is, no doubt, an important distinction, it is not necessarily the distinction that Parekh fails to note. To be fair to Parekh, he does not argue that an option $\mathrm{X}$ would not (at least in principle) be open to those whose cultural commitments conflict with the requirements of taking advantage of $\mathrm{X}$, but merely that this option should be considered as "mute" and "passive", should one not be culturally dispositioned to take advantage of it. ${ }^{313}$ What Parekh would seem to be concerned about, is thus not only whether people "have an objective opportunity X" in the sense described by Barry (that is, an option that one could (bar one's physical constraints) take advantage of), but whether people also "have the capacity to choose to take advantage of X". That is, not only whether one has the option of becoming a police officer should one choose to adhere to its requirements, but whether one also has the capacity, or a cultural disposition, to make that choice, and adhere to these requirements.

Presuming that this is what Parekh is trying to say, and that the notion of "having an opportunity X" should not only include the existence of the option $\mathrm{X}$ but also the capacity to choose $\mathrm{X}$, the interesting question remains: would this alter the view on whether the turban wearing Sikh has an opportunity to work as a police officer, should the criteria for such work require him to take off his turban? Hardly so. It would not seem that such element of subjectivity would alter the fact of whether such opportunity existed for the Sikh man to take advantage of. Presuming, in accordance with the first chapter of this work, that we wish to maintain the view according to which people's cultural commitments are not

${ }^{313}$ Parekh 2000, 241. 


\section{Part I Justifying Minority Rights}

something that people cannot not adhere to, and that it is, indeed, possible for people to change as well as to abandon their cultural commitments, ${ }^{314}$ it is difficult to see how one could maintain that the turban wearing Sikh, although having an objective option $\mathrm{X}$ (opportunity in Barry's sense), would not be capable of choosing to take advantage of $\mathrm{X}$. The turban wearing Sikh has an opportunity, both in the sense of having an option to take away his turban as well as having the capacity to make this choice, and to argue otherwise would require a seriously restricted conception of this person's autonomy and agency. ${ }^{315}$ Unless one subscribes to the view of culture as a determining element of people's actions, it makes no sense to say that one's cultural or religious commitments would take away, either the option X or one's capacity to choose $\mathrm{X}^{316}$

Perhaps Parekh could still argue that my interpretation of the subjective conception of opportunity (as an option X conjoined with a capacity to choose $\mathrm{X}$ ) would be an oversimplification and that being culturally dispositioned to take advantage of the option does not mean merely that one has a capacity to choose to take advantage of the option in question, but that one is also likely to do so. ${ }^{317}$ This, however, might be stretching the concept of opportunity a bit too far. Whereas it is certainly possible to incorporate a subjective element into the concept of opportunity (as described above), it is difficult to see how the likelihood of one's choice to

${ }^{314}$ Esp. Ch. 1.1.

315 For an excellent critique of how some multiculturalists (including Parekh) have ended up subscribing to a very restricted view of the agency of minority members, see Phillips 2006, 28; 2007, 112-113.

${ }^{316}$ This is not to say that, at times, people might not even contemplate of choosing $\mathrm{X}$, nor that the pressures for not choosing $\mathrm{X}$ could not be overwhelming - so much so that, in effect, the person cannot realistically be expected to choose $\mathrm{X}$. The fact that one has the capacity to choose $\mathrm{X}$ does not necessarily mean that one can also be expected to make that choice, nor that one should also be held responsible for making / not making that choice. I will return to these issues of responsibility shortly.

${ }^{317}$ For an account of equality of opportunity incorporating the likelihoods of taking advantage of opportunities, see Roemer 1998. 
take advantage of the option could affect the existence of the opportunity in question. ${ }^{318}$ Provided that one has an option that one could choose to take advantage of and that one also has the capacity to make this choice, it would seem irrelevant - for the mere existence of the opportunity - whether one chooses to take advantage of the opportunity, or how likely or unlikely one is to make such choice.

Rejecting the idea that the question of whether one "has an opportunity X" would depend on how likely one was to take advantage of $X$, it would seem that the two plausible candidates for a conception of opportunity in the literature on multiculturalism would remain Barry's objective conception of opportunity (an option X that one can, bar one's physical constraints, take advantage of) and the subjective conception described above (the objective conception conjoined with the capacity to choose $\mathrm{X}$ ). According to both of these conceptions, however, it is not the case that the turban wearing Sikh would not have the opportunity to work as a police officer, nor would it thus seem that the requirement preventing the turban wearing Sikh from working as a police officer would go against the principle of equality of opportunity - that is, at least if one conceives equality of opportunity in Barry's broad sense of having roughly identical opportunity sets within which to make one's choices.

\subsection{Opportunities and costs}

Within the framework of equality of opportunity in terms of roughly identical opportunity sets to choose from, the above conceptualizations of opportunity (whether as an objective or (partially) subjective state of affairs) would seem to lead to the same conclusion. The turban wearing Sikh has the opportunity to

${ }^{318}$ It should be emphasized that, at this stage, the question is merely about the existence of an opportunity, and equality of opportunity in the sense of the roughly identical opportunity sets to choose from. Whether this notion of equality of opportunity (as a roughly identical opportunity set to choose from) is viable, will be discussed in the following subsection 2.2. 


\section{Part I Justifying Minority Rights}

take off his turban and work as a police officer, regardless of whether this opportunity is understood in purely objective or partially subjective terms. Despite this upshot (with respect to the existence of the opportunity in question), it is still possible to argue that, despite having an opportunity $\mathrm{X}$, one might not have equal opportunities, in the sense in which the liberal state should be concerned about equality of opportunity. To recall, according to Barry's broad conception, it is enough for equality of opportunity to obtain, if people are given (roughly) identical opportunity sets of $\mathrm{X}, \mathrm{Y}, \mathrm{Z}$ etc. to choose from. Within these sets, people are free to make their choices, and it is perfectly justifiable for a choice of $X$ to cancel out $\mathrm{Y}$, and vice versa. For example, it is perfectly justifiable that one's choice of becoming a police officer cancels out the prospect of one becoming a brain surgeon, or that one's choice of not wanting to conform to the requirements of a particular job cancels out the prospects of getting that job. What is important is that, initially, people have roughly identical opportunity sets within which to make their choices, not that these opportunity sets would remain intact, once certain choices have been made and taken advantage of.

It has, however, been noted that Barry's view of equality of opportunity as the provision of roughly identical opportunity sets may fail to capture something important about the kinds of equality of opportunity that the liberal state should be concerned about. As David Miller has argued, it is not only that the liberal state should be concerned about people having roughly identical opportunity sets to start with, but it should also be concerned with the contents of these sets (as measured against people's actual ambitions), as well as about the costs that the taking advantage of these opportunities may involve. ${ }^{319}$ According to Miller, it is, firstly, not enough that people are given roughly identical opportunity sets of $X, Y, Z$, if the ambitions of (some) members of society are rather $\mathrm{Q}, \mathrm{P}, \mathrm{R}$. And, secondly, it is not enough for a liberal state to be concerned about people having any particular opportunity to $\mathrm{X}$, but

${ }^{319}$ Miller 2002b, 46. 
that people have this opportunity to $\mathrm{X}$ without excessive costs. ${ }^{320}$ This incorporation of costs into the notion of equality of opportunity deserves some further attention. ${ }^{321}$

The excessive costs - argument and strategies for its denial

According to Miller, an opportunity X is not merely a physical possibility to $\mathrm{X}$, but a possibility to $\mathrm{X}$ without incurring excessive costs or risks of such costs. One does not have an opportunity $\mathrm{X}$, in Miller's account, if the prospective costs of taking advantage of $\mathrm{X}$ are sufficient to deter a reasonable person. ${ }^{322}$ In the case of the turban wearing Sikh, it would thus be that the turban wearing Sikh would not have an opportunity to work as a police officer, if the costs of working as a police officer were high enough to deter a reasonable person from doing so. ${ }^{323}$

\footnotetext{
${ }^{320}$ Miller 2002b, 51 .

${ }^{321}$ For the time being, I ignore Miller's first claim about the need of the opportunity sets to reflect people's actual ambitions. In the light of our example case (that of the turban wearing Sikh and the dress requirements of the police force), it is not entirely clear how this would fit into the case at hand - that is, into the questions of equality of opportunity for a particular position or job X. Even if it was the case that the liberal state should be concerned about people having, not only roughly identical opportunity sets, but opportunities that reflected their actual ambitions, in the case of the turban wearing Sikh and the dress codes of the police officer, the ambition (that is, of being a police officer) would already seem to be fixed. The important question, in this case, would thus seem to be, not whether the opportunity to become a police officer was reflecting the actual ambitions of those to whom this opportunity was open, but whether people, regardless of their cultural background, would have equal opportunities to fulfill this particular ambition.

${ }^{322}$ Miller 2002b, 51.

${ }^{323}$ One could question the way in which Miller incorporates costs (or risks of costs) into the concept of opportunity itself, but one's side of this debate need not determine one's views on whether the dress codes of the police officer (that prevent turban wearing Sikhs from working as police officers) are consistent with the principles of equality of opportunity. Even if one took the view that the costs of doing $\mathrm{X}$ should be viewed as separate from the existence of the opportunity itself, one could still argue that, in order
} 


\section{Part I Justifying Minority Rights}

In my discussions on fair equality of opportunity (section 1), I utilized the modified importance argument ${ }^{324}$ to show that, due to the potentially tremendous importance of one's cultural commitments or practices and the harm that may be endured from abandoning these practices, it could not be argued that those adhering to the conflicting cultural practices would have, with the same amounts of talent and effort, the same prospects of success as those whose cultural practices did not conflict with the used criteria. Translated into the language of equal opportunities (in terms of an opportunity to $\mathrm{X}$ without excessive costs), it could be argued that those adhering to the conflicting cultural practices, despite having an opportunity $\mathrm{X}$ could not take advantage of $\mathrm{X}$ without encountering the costs resulting from the abandonment of their cultural practices. Provided that the modified importance argument is correct, and that the consequences of abandoning one's cultural practices could be of such magnitude as the loss of one's identity or self-respect, it could be argued that these costs would, indeed, be excessive, deterring a reasonable person from taking advantage of the opportunity in question. Criteria that would require certain people to abandon their deep-most cultural commitments would thus be in conflict with equality of opportunity, as the abandoning of these commitments would constitute a cost no reasonable person would be willing to bear in order to take advantage of the opportunity in question.

for equality of opportunity to exist, these costs should not be excessive. Whereas for an opportunity to exist, one does not need to think of the costs that taking advantage of the opportunity would result in, for equality of opportunity to prevail, one does. To put it in other words, for one to have an opportunity $\mathrm{X}$, it only needs to be the case that one has "an option that is either conjoined or non-conjoined with a capacity to choose this option", whereas for one to have equal opportunity to $\mathrm{X}$, one also needs this option to be such that one can take advantage of this option without excessive costs.

324 That is, that one's cultural practices could be conceived of such potentially tremendous importance to people that it would not be reasonable to expect them to abandon such practices due to the harm that this could cause to their identity and self-respect. See also Ch. 1.1. 
Not all liberal multiculturalists, including Brian Barry, would, of course, accept the excessive-costs -argument, but rather insist that, at least in some cases, the existence, or even the excessiveness, of the costs involved had no impact on whether equality of opportunity would prevail. In order to make such case, three different strategies could be utilized. Firstly, one could try to reject the view of one's cultural practices as of potentially tremendous importance to one's identity and self-respect. That is, one could refute the modified importance argument. Secondly, one could deny that the costs resulting from abandoning these commitments would be of such a kind as to constitute a relevant kind of cost for the denial of equality of opportunity. Or thirdly, one could reject the claim that equality of opportunity would have anything to do with the costs that may result from taking advantage of these opportunities.

As one of the starting points of this work has been the acknowledgement of people's cultural commitments as something of potentially tremendous importance to their bearers, and as this acknowledgement is shared, not only by those who worry about equality of opportunity in cultural cases (such as Parekh and Miller), but also by their critics (such as Barry), I will not discuss the implications of denying this to the questions of equality of opportunity in cultural cases. ${ }^{325}$ The two other strategies, those of denying the kinds of costs incurring in cultural cases as relevant for the assessment of equality of opportunity, or denying the relevance of (any type of) costs, however, deserve some further attention. Both of these strategies, I believe, are also present in Brian Barry's

${ }^{325}$ Perhaps it is sufficient to say that, if one denied the fact that people's cultural practices were of any importance (let alone tremendous importance) to their practitioners, one would most likely also deny that abandoning such practices would constitute a cost to those abandoning these practices. Thus, the thesis according to which one would be denied equal opportunities if the costs of taking advantage of these opportunities would be sufficiently high to deter a reasonable person would not be applicable, as the abandonment of one's cultural practices would not constitute a cost in the first place. 
Part I Justifying Minority Rights

work, although neither of these strategies manages to fully refute the excessive-costs-argument, or so I try to argue.

\section{Rejection of costs}

With respect to Barry's general conception of equality of opportunity (in terms of roughly identical opportunity sets to choose from), it is important to note that there is no mention about the costs, or the kinds of costs, acceptable (or unacceptable) for equality of opportunity to obtain. This general conception refers to and is only concerned with the initial situation within which people start making their choices. ${ }^{326}$ It is perfectly legitimate, according to Barry, that one's choice of X cancels out one's choice of $Y$ - or, in terms of the cost terminology, that the cost of choosing $\mathrm{X}$ is the loos of the prospect $Y$.

Importantly, however, this strategy of denying the relevance of costs (any costs) for equality of opportunity is strictly restricted to Barry's general conception, and is not available once we move to the more narrow conception applicable in cases such as education and employment. According to Barry, equality of opportunity in the specific cases of employment or education requires a very different, and much narrower interpretation, stating (roughly) that those, similarly suited or qualified, should have roughly same prospects of success. As Barry himself argues, this narrower conception of equality of opportunity entails, among others, that, in the context of education, those endowed with similar qualifications and motivation should also encounter roughly equivalent financial hurdles, ${ }^{327}$ thus placing at least some costs (i.e. financial costs) at the very center of equality of opportunity in the case of education. Equality of opportunity, as defined with respect to education or employment, must, according to Barry, be refined from the general

\footnotetext{
${ }^{326}$ For the time being I ignore the debate on the extent to which people can be seen to make choices in cultural matters. For an illuminating critique of the role of the chance / choice -distinction in multiculturalism, see Mendus 2002.

${ }^{327}$ Barry 2002, 217.
} 
conception (of roughly identical opportunity sets), and the strategy for arguing that the turban wearing Sikh (of our example case) would not be denied equal opportunities cannot thus lie in the strategy of denying that costs - whatever they be - would be irrelevant in deciding whether equality of opportunity, in this specific case, would prevail.

This would seem to leave us with the second strategy, that is, the denial that the costs of abandoning one's cultural commitments would be of such a kind as to be relevant for the assessment of equality of opportunity, in order to refute the excessive-costs argument.

\section{Types of costs}

As noted by David Miller, the conception of equality of opportunity in terms of opportunities without excessive costs brings forth the difficult questions about what kinds of costs are relevant, as well as at which point these costs can be considered as excessive. ${ }^{328}$ Noting that Barry subscribes to an objective conception of opportunity (independent of one's cultural disposition to take advantage of the opportunity), it could be anticipated that Barry would, also, consider the relevant kinds of costs as somehow objectively defined. That is, as costs that could be objectively measured, such as financial or material costs. Consequently, many of the costs involved in cultural cases could be deemed as irrelevant, such as the necessarily subjectively experienced costs of abandoning one's cultural commitments in terms of the psychological costs of losing one's sense of self, or one's identity as a member of a particular cultural community. ${ }^{329}$

\footnotetext{
${ }^{328}$ Miller 2002b.

${ }^{329}$ When analysing the costs of exit, Barry does, indeed, note that there are bound to be certain intrinsic costs (that is, costs relating inherently to the fact that one is no longer a member), and that there is nothing that the state can or should do about these kinds of costs. Barry 2001, 150-151. For the measuring problem within egalitarianism more generally, see e.g. Sen 1997; Temkin 1993.
} 
Part I Justifying Minority Rights

Curiously, the approach taken by Barry does not rest on an assumption that the costs relevant for the assessment of equality of opportunity should be objectively defined. Barry is perfectly happy to maintain that the wearing of a head scarf or a turban may be of tremendous importance to those who wear them, and that, in certain cases, requiring one to abandon such head gear for being able to work in certain occupations (such as office jobs or retail outlets) or to attend certain educational institutions (with particular kinds of school uniforms) is in conflict with equality of opportunity. ${ }^{330}$ This, Barry argues, is due to the excessive cost or sacrifice ${ }^{331}$ that the wearer of the head scarf or turban would need to make in order to take advantage of the opportunity in question.

Provided that the cost of abandoning one's cultural practice can thus, at least in some cases, be seen as a relevant kind of cost for the assessment of equality of opportunity, it becomes interesting to see, how, in the example case of the turban wearing Sikh and the dress codes of a police officer, the case either against or for the existence of equality of opportunity could be made. To be fair to Barry, he would, most likely, argue that the turban wearing Sikh would, in this particular case, be denied equality of opportunity, ${ }^{332}$ although he would also insist that in several other cases (such as when the cultural practice of wearing a turban collides with the safety requirements on a construction site) no complaints, based on equality of opportunity, could be made. The apparent mismatch between the two cases, I believe, rests on a strategy of incorporating reasons for upholding certain criteria in the conception of equality of opportunity itself, and on a rather dangerous conflation (or so I try to show) of inequality of opportunity per se, and justification of such inequality in particular instances.

\footnotetext{
${ }^{330}$ Barry 2001, 54-62.

331 "Sacrifice" is the term used by Barry. (Barry 2001, 59.)

${ }^{332}$ See Barry 2001, 49.
} 
Costs vs. justification

In order to show why I think Barry conflates the notion of inequality of opportunity itself and the possible justifications for this inequality, one needs to look at the way in which the case for the inequality of opportunity in the case of the police officer, and the equality of opportunity in the case of the construction worker are made. The strategy adopted by Barry is to look at the reasons for upholding criteria that, in effect, prevent some people from working in these occupations. According to Barry, the dress codes, required by certain occupations, are, in most cases, merely conventional, and cannot thus be argued as essential for the performance of that particular job. ${ }^{333}$ Wearing (or not wearing) a particular type of head gear is not, in most cases, essential for a successful performance as an office worker or as a police officer, ${ }^{334}$ nor is it essential for attending school or some other educational institution. Lacking proper justification (apart from convention), these criteria can be seen as imposing an unjustified burden on those whose cultural commitments are in conflict with such criteria, denying them equality of opportunity with respect to these occupations.

On the other hand, Barry argues that, in the case of the turban wearing Sikh and the requirement of wearing safety helmets on construction sites, there are good reasons for upholding this requirement, even if it imposed a burden on those whose cultural commitments (such as wearing a turban) were in conflict with the requirement. $^{335}$ Being a justified requirement, conceived as

333 Barry 2001, 59; 2002, 216. As Barry notes, there may be certain symbolic value to the dress codes, although this is true both of the professional dress codes as well as, and especially, of the dress codes of a certain culture or religion.

${ }^{334}$ There may be exemptions to this, such as that of the motor cycle police, required to wear a helmet for safety reasons. Barry 2001: 49.

${ }^{335}$ As it stands, in the UK, the turban wearing Sikhs are exempted from wearing hard hats (Employment Act 1989), although the liability for injuries is restricted to the injuries that would have been sustained if a hard hat was used. 
Part I Justifying Minority Rights

necessary for a successful (and safe) performance on the construction site, Barry holds that it is not a question of inequality of opportunity if those wearing a turban are faced with the burden of abandoning this commitment, should they wish to take advantage of the opportunity to work on the construction site. ${ }^{336}$

However, even if it made perfect sense to argue that the difference in the rationale of the conventional dress-codes (of office workers or police officers) and safety helmets (of those working on construction sites) should be taken into account when thinking of whether those with conflicting cultural practices can be required to abandon these practices (in order to do the job), what I disagree with, is that this rationale should affect our judgments on whether, in these particular cases, equality of opportunity would prevail, or whether one could make claims - based on considerations of equality - to be allowed to maintain one's cultural practices despite the conflicting criteria.

My skepticism about including the reasons for having certain rules in the assessment of the existence of equality of opportunity comes from two sources. Firstly, it is important to notice that, in both cases (those of conventional dress codes and safety helmet requirements) the costs that the used criteria impose on those whose particular cultural practice (such as the wearing of the turban) conflict with the criteria are identical. Regardless of the rationale of the criteria or the rule in question, the person with the conflicting cultural practice cannot conform to such rules without encountering the burden or the costs of abandoning such practice. Provided that the abandoning of the conflicting practice can be seen as resulting in such costs that would deter a reasonable person from taking advantage of the opportunity (the job) in question, it is clear that, the person with the conflicting practice, does not have equal opportunity to be chosen to or to perform in such job - that is, she

\footnotetext{
336 See Barry 2002, 219. It should be noted that Barry does give other, purely practical arguments for allowing Sikhs to work on construction sites without safety helmets (Barry 2001, 49-50), although he denies that these rationale would have anything to do with equality of opportunity.
} 
lacks the opportunity to take advantage of such an opportunity without excessive costs. From the perspective of those whose cultural practice conflicts with the rules or criteria in question, the situation is identical, regardless of the rationale behind the rule or criteria in question.

Secondly, whereas it may well be that, in some cases, the rationale for the rule or criteria in question is strong enough to overrule the claims of those disadvantaged by the rule, it is by no means the case that all rules (with perfectly justifiable rationales) would do so. For example, the dress codes in work places or educational institutions can be argued for on several grounds, including pure convention, internal coherence, public recognition, worker safety, public safety etc., and it is not the case that these rationales should be considered as creating equally pressing reasons for upholding the rule or criteria in question. Rather, there may be several kinds as well as levels of reasons for having a particular rule or criteria, some of which may be strong enough to justify the upholding of the rule for everyone (and the consequent requirement for those with conflicting cultural practices to abandon these practices), some of which may not. What would seem to be important, is thus not whether there are good reasons for having the rule in question (in most cases, there are), but whether the reasons for having such rules are strong enough to counter the claims that the upholding of such rules creates. Such an act of balancing, however, can only be done once both the rationale for the rule as well as the extent of the cost have been assessed, and to claim that, in the face of justified rules or criteria, no issues of equality of opportunity arise, would be to deny two important things. Firstly, it would be to deny the experiences of those whose cultural practices conflict with the rules or criteria in question, ${ }^{337}$ and secondly, it would also diminish the rationale that those, not being able to conform to a rule without excessive costs, could have for their

337 Recall that, from the perspective of those whose cultural practices conflict with the rule or criteria in question, the experience is the same, regardless of the justification of the rule or criteria 


\section{Part I Justifying Minority Rights}

complaints. Instead of claiming that the rationale of the rule or criteria would affect the existence of (in)equality of opportunity itself, a better approach, I believe, would be to accept that, should one's cultural practices prevent one from conforming to the existing rules or criteria without incurring excessive costs, then a case of inequality of opportunity is made. Whether this inequality is, in some cases, justified, is, of course, another matter, only assessable once both the rationale for the rule as well as the excessiveness of the cost have been assessed and balanced against one another.

\section{The proper object of opportunity}

David Miller's conception of equality of opportunity in terms of opportunities without excessive costs does, as already discussed, manage to capture something important about the kinds of equality of opportunity that the liberal state should be concerned about. At the same time, however, this conception brings forth the difficult questions of whether and when the costs of abandoning one's cultural commitments or practices can be seen as excessive. Quite clearly, not all cases of having to abandon one's cultural practices constitute the relevant kinds of excessive cost, as these costs may well vary from relatively minor discomfort to the serious alteration or even loss of one's identity. Depending on both the practice in question, as well as on any particular person's relation to this practice, the costs of abandoning such practice may be excessive or non-excessive, leaving considerable scope of disagreement into whether any particular conflict between certain cultural practices and the existing rules or criteria should be viewed as leading to inequality of opportunity. In order for any particular case to be judged in terms of inequality of opportunity, one must judge the excessiveness (or non-excessiveness) of the costs in question, and in many cases, it is only once the excessiveness of the cost has been established (or convincingly argued for) that the claims, based on considerations of equality, are given proper attention.

In order to be clear, I do not believe that the difficulties incorporated in the notion of equality of opportunity in terms of opportunities without excessive costs lie solely (or necessarily) in 
the indeterminacy of whether the costs of abandoning certain cultural practices can be conceived as excessive. Certainly, there is always scope for disagreement in judging the excessiveness of the costs in question, and I perfectly agree that, at the level of cultural policies, it is not the case that a conflict between any cultural practice and any existing criteria should be viewed as the kind of inequality that the liberal state must rectify. Rather, the answer to the question of whether any particular conflict should be viewed as constituting the kind of inequality that the liberal state should rectify should take into account the importance of the practice to its practitioner, the excessiveness of the costs that abandoning such practice would result to, as well as the strength of the rationale for having the rule that the cultural practice in question is in conflict with. Not all conflicts between people's cultural practices and the existing rules or criteria are, or should be, viewed in such strong terms, and the understanding of equality of opportunity in terms of opportunities without excessive costs is right to take this insight on board.

Having said that, I do worry about the way in which the notion of equality of opportunity in terms of opportunities without excessive costs utilizes the default position of "having an opportunity X". By doing so, it puts the burden of proof on those who, being disadvantaged by the rule, are left with the task of establishing that the costs of taking advantage of the opportunity in question are, indeed, excessive. That is, this conception of equality of opportunity starts from the presumption that, for example, the turban wearing Sikh of our example case does, indeed, have the opportunity to $\mathrm{X}$ (be a police officer), and the possible problem of inequality of opportunity is brought in only as a qualification of the initial position of "having an opportunity X". Despite having an opportunity $\mathrm{X}$, the turban wearing Sikh could be seen as lacking equal opportunities, but only if the taking of advantage of the opportunity in question is viewed as resulting to excessive costs. The utilization of the default position of "having an opportunity X", would thus seem to put the burden of proof on those disadvantaged (that is, the Sikhs themselves), who are, from the very beginning, 
Part I Justifying Minority Rights

required to prove that the costs of taking advantage of $\mathrm{X}$ are such that they would deter a reasonable person from taking advantage of $\mathrm{X}$ - that is, that the costs of abandoning one's cultural practices are, indeed, excessive.

Contrary to this view, the view that I outline in this section that of equality of opportunity in terms of joint opportunities - aims at shifting the burden of proof from those disadvantaged by the rule in question to those who claim that a conflict of one's cultural practices and the rule in question does not amount to inequality of opportunity. This shifting of the burden of proof is done by changing the focus of the debates on equality of opportunity from the questions of whether one can take advantage of an opportunity without excessive costs back to the very basic questions of whether one has an opportunity in the first place. However, rather than asking whether one's having an opportunity should be conceived as an objective or subjective state of affairs, ${ }^{338}$ the central question asked in this section is, rather, what exactly one should have an opportunity to - what should the proper object of opportunity be. The following conception of equality of opportunity in terms of joint opportunities, it is argued, has the advantages, not only of simplicity (being primarily concerned with the question of "having an opportunity" rather than with the questions of excessive costs), but also of taking the disadvantages faced by minority members seriously.

\subsection{Opportunity to what?}

According to Jonathan Quong, much of the discussion on equality of opportunity within multiculturalism misconceives the level upon which the inequality (that is the proper concern of the liberal state) lies. ${ }^{339}$ Whereas for theorists such as Barry and Miller, equality of opportunity is often discussed within the framework of singular cases - such as (equal) opportunity to X (employment), or (equal)

\footnotetext{
${ }^{338}$ A question that, as seen in the previous section, creates no difference to the actual existence of the opportunity in question.

${ }^{339}$ Quong 2006.
} 
opportunity to $\mathrm{Z}$ (education) - Quong argues that the main issue of equality of opportunity should not be whether people have (equal) opportunities to $\mathrm{X}$ or $\mathrm{Y}$ or $\mathrm{Z}$, but whether they have (equal) opportunities to $\mathrm{X}$ and $\mathrm{Y}$ and $\mathrm{Z}$. For Quong, equality of opportunity is not simply about having roughly identical opportunity sets $\mathrm{X}, \mathrm{Y}, \mathrm{Z}$ to choose from (Barry's general position), or about being able to take advantage of an opportunity without excessive costs (Miller's position), but about having an opportunity to $\mathrm{X}$ and $\mathrm{Y}-$ that is, to combine one's cultural commitments with one's aspirations is public life, such as education and employment. ${ }^{340}$

Quong's notion of equality of opportunity in terms of joint opportunities utilizes the idea of certain basic opportunities as being primary opportunities, and the non-tradability of these opportunities. ${ }^{341}$ By basic or primary opportunities, Quong refers, not only to employment and education, but also to things such as having a family or pursuing of religious values - those aspects of human life that are generally conceived as fundamental opportunities in human life. Given the centrality of these opportunities, Quong argues that a system, requiring certain people to make choices between these basic opportunities (say, one's cultural or religious commitments and one's employment), would not fulfill the requirements of equality of opportunity. ${ }^{342}$

The idea of the non-tradability of basic opportunities can be demonstrated by a rather uncontroversial case of combining family and employment. According to Quong, it is not enough that people have equal opportunities either to have a family or to have

\footnotetext{
${ }^{340}$ Quong 2006, 62-66.

${ }^{341}$ Quong 2006, 66.

${ }^{342}$ Quong's argument is based on the utilization of the Rawlsian veil of ignorance. Although Rawls does not include family, religion or culture into his original list of primary goods, these are, however, central elements of people's conceptions of the good. Thus, Quong argues that people (behind the veil of ignorance) would prefer a system in which one can combine one's family, religion and culture with employment and education over a system in which one would be required to make a choice between, for example, culture and employment. (Quong 2006, 66.)
} 


\section{Part I Justifying Minority Rights}

employment, as it would not be reasonable to ask people to make a choice between these two. Within liberal societies, we already think that having a family should not be something that creates a disadvantage in the employment market, and it is thus the equality of opportunity to combine family with employment that the liberal state should be concerned about. ${ }^{343}$ Transferred into the more controversial case of culture, the argument goes, it is widely held that one's culture or religion should not create a disadvantage in the employment market, and it is therefore not only the provision of roughly identical opportunity sets of $X, Y, Z$ (e.g. employment, culture, religion) that the liberal state should be concerned about, but the opportunities to combine the different variables within these sets. $^{344}$

General categories vs. particular cases

The obvious advantage of Quong's model, I believe, lies in its ability to bring the discussions on equality of opportunity back from the debates on the excessiveness of costs to the more basic questions of whether one has an opportunity (to $\mathrm{X}$ and $\mathrm{Y}$ and $\mathrm{Z}$ ). As already indicated, the incorporation of costs (and the assessment of the excessiveness of costs) into the notion of inequality of opportunity itself brings forth several difficulties with respect to the assessment of whether any particular situation should be viewed in terms of inequality of opportunity. The utilization of the default position of "having an opportunity X" would also seem to put the burden of proof on those who are already disadvantaged by the rule in question, and who thus have to show that, despite having an opportunity $\mathrm{X}$, they may not have equal opportunities to $\mathrm{X}$, due to the excessive costs that the taking advantage of $\mathrm{X}$ creates. In Quong's model, however, the assessment of the excessiveness of costs plays no role in the initial assessment of whether equality of

${ }^{343}$ Quong 2006, 63-64.
${ }^{344}$ Quong 2006, 62-65. 
opportunity prevails, ${ }^{345}$ as the question of equality of opportunity is assessed purely in terms of whether one has an opportunity to join one's cultural commitments (Y) with employment $(\mathrm{X})$ or education (Z).

On the down side of Quong's model, however, lies its generality that may prevent it from being applicable to the specific cases of, for example, the turban wearing Sikh and the dress requirements of a police officer. Whereas Quong holds that people should have equal opportunities to combine X (employment) with Y (cultural commitments), in the case of the turban wearing Sikh, the question is not of the general case of combining one's culture $(\mathrm{Y})$ with employment (X), but of combining a particular cultural commitment $\mathrm{Y}^{*}$ (wearing of a turban) with a particular job $\mathrm{X}^{*}$ (working as a police officer). Provided that, in most cases, the turban wearing Sikhs were allowed to wear turbans in the work place, it would certainly stretch the argument to claim that a denial of an opportunity to $\mathrm{X}^{*}$ and $\mathrm{Y}^{*}$ would also be a denial of an opportunity to $\mathrm{X}$ (employment) and $\mathrm{Y}$ (culture). Apart from becoming police officers, the turban wearing Sikhs would have an opportunity to work in all sorts of other professions, and may even work in the police force, albeit not in areas that require the wearing of the hat, or other particularly specified head gear. ${ }^{346}$

\footnotetext{
${ }^{345}$ This is not to say that the assessment of the costs, and the balancing of these costs against the rationale of the rule in question, would not play any role in assessing whether such inequality may, nevertheless, be justified. The viewing of equality of opportunity in terms of joint opportunities does, however, better job in acknowledging the situation of those disadvantaged by utilizing the default position of inequality of opportunity (when the opportunity to $\mathrm{X}$ and $\mathrm{Y}$ does not exist), after which the questions about the justifiability of such inequality are attended to.

346 Barry makes this point when discussing the requirements of the motorcycle police officers to wear safety helmets: "If not being able to ride a motorcycle ruled out a significant proportion of all the jobs in an area open to somebody with a certain level of trained ability, that would be relevant [for the liberal state that is concerned of equality of opportunity]. But it does not. It would also be a matter of specific concern if the inability to ride a motorcycle prevented Sikhs from joining the police force,
} 


\section{Part I Justifying Minority Rights}

Whereas I believe this objection to hold some force, I also think that, in many cases, the scope of equality of opportunity to $\mathrm{X}$ and $\mathrm{Y}$ can be extended to cover cases in which either $\mathrm{X}$ or $\mathrm{Y}$ or both are modified into specific instances of $X^{*}$ (having a particular job) or $\mathrm{Y}^{*}$ (adhering to a particular cultural commitment). Two such examples (an opportunity to $\mathrm{X}$ and $\mathrm{Y}^{*}$, and an opportunity to $\mathrm{X}^{*}$ and $\left.\mathrm{Y}^{*}\right)$ are discussed below.

\section{Opportunity to $X$ and $Y^{*}$}

Take, first, an instance in which a particular cultural or religious practice $\left(\mathrm{Y}^{*}\right)$ is seen to prevent those who participate in this practice from gaining employment or education (X). An interesting example of this kind of case would be the French case of laïcité, and the banning of conspicuous religious signs in educational institutions. For the most part, the debate has concentrated on Muslim head scarves, and the ways in which the banning of head scarves has affected the school attendance of Muslim girls. ${ }^{347}$ Notably, like most cases in which one's cultural or religious commitments conflict with the general rules or criteria, the head scarf -affair, too, fails to fall neatly into the model of having an opportunity to $\mathrm{X}$ (education) and $\mathrm{Y}$ (culture). The wearing of the scarf is, no doubt, only a particular, as well as a contested, manifestation of Muslim culture, ${ }^{348}$ and should thus be referred to as $\mathrm{Y}^{*}$ rather than as $\mathrm{Y}($ general $){ }^{349}$

because it is important that the police should be open to all, and should in fact contain representatives of all minorities. This is not so much a matter of doing a favor to Sikhs as one of pursuing a benefit to all of us. But there is nothing to prevent police forces from organizing themselves so that Sikh members are not assigned to duties that entail riding a motorcycle." (Barry 2001, 49)

347 For the complexity of the head scarf -affair, see e.g. Bowen 2007; McGoldrick, 2006; Scott 2007; Laborde 2008.

${ }^{348}$ For some of the rationales behind the wearing of the scarf, see Lyon and Spini 2004; Hirschmann 2003, ch. 6.

${ }^{349}$ With respect to the other variable, that of education $(\mathrm{X})$, no such modifications to specific instances of education $\left(\mathrm{X}^{*}, \mathrm{X}^{* *}\right.$ etc.) are required. In the case of the French laïcité, the banning of head scarfs does, 
Regardless of this modification (from $\mathrm{Y}$ (general) to $\mathrm{Y}^{*}$ ), it is, however, possible to argue that the principle of laïcite denies the scarf-wearing Muslims equal opportunities to combine their cultural commitments with their educational aspirations, in the sense in which the liberal state should be concerned about equality of opportunity to conjoin $\mathrm{X}$ and $\mathrm{Y}$. Most obviously, the principle of laïcité denies the scarf wearing Muslims an opportunity to $\mathrm{X}$ (education) and $\mathrm{Y}^{*}$ (wearing of a scarf), whereas for those with no equivalent religious signs, no such denial of opportunity exists. Provided that, as a general rule, one should have an opportunity to conjoin education $(\mathrm{X})$ with one's cultural commitments $(\mathrm{Y})$, it would not seem to matter which particular cultural commitment $\left(\mathrm{Y}^{*}\right)$ was preventing one from enjoying the prospects of education. The general formulation of an opportunity to conjoin education (X) with one's cultural commitments $(\mathrm{Y})$, although not referring to any particular cultural commitments $\left(\mathrm{Y}^{*}\right)$, is general enough to incorporate a wide variety of these commitments, any of which may be enough to deny one's opportunity to enjoy the other variable of education (X). Although the principle of laïcité by no means prevents the scarf wearing Muslims from engaging in several other manifestations of their culture (apart from the wearing of the scarf in public schools), it is clear that it does, nevertheless, create a situation in which the scarf wearing Muslims need to make a choice between their education and a practice that (in accordance with the modified importance-argument given earlier) can be viewed of (potentially) tremendous importance for the well-being and selfrespect of its practitioner. Provided that, as a default, it would be unreasonable to ask people to abandon those cultural commitments that they so deeply cherish, it would, I believe, also be

in effect, deny access of those wearing a head scarf to all public schools (with a curious exemption of universities). Whereas there are, no doubt, also ways around the ban, I believe the case of laïcité to be general enough to justify the keeping of the other variable of education as X (general). 
Part I Justifying Minority Rights

unreasonable, as a default, to ask them to make a choice between these particular commitments and their education. ${ }^{350}$

Opportunity to $X^{*}$ and $Y^{*}$

Whereas the French case of laïcité can be used to demonstrate why the lacking of an opportunity to $\mathrm{X}$ (education) and $\mathrm{Y}^{*}$ (wearing a scarf) could be seen as falling within the more general instance of lacking an opportunity to $\mathrm{X}$ and $\mathrm{Y}$, a further argument for including cases of $\mathrm{X}^{*}$ (particular education or particular job) and $\mathrm{Y}^{*}$ (particular cultural or religious commitment) is needed. Whereas the importance -argument given in Ch. 1 strongly suggests accepting that, should one's adherence to a particular cultural commitment prevent one from gaining education or acquiring employment, the principle of equality of opportunity to $\mathrm{X}$ and $\mathrm{Y}$ is violated, this is not necessarily the case, should one's specific cultural commitments $\left(\mathrm{Y}^{*}\right)$ prevent one from gaining some particular employment $\left(\mathrm{X}^{*}\right)$. As Brian Barry argues, there is a difference between whether the turban wearing Sikhs are being denied an opportunity to work in some particular profession (that, for a good reason, requires taking off the turban) and them being systematically excluded from the job market as a whole. ${ }^{351}$ In

\footnotetext{
${ }^{350}$ The acceptance of a particular cultural practice as one of the variables of an opportunity to $\mathrm{X}$ and $\mathrm{Y}\left({ }^{*}\right)$, is thus supported (as well as possibly constrained) by the importance -argument given in Ch. 1. Provided that a particular cultural practice (such as the wearing of a head scarf) can be seen as an integral element of a person's identity and well-being, and that it would not thus be reasonable, as a default, to expect one to abandon such practice, a choice between such practice and education would seem to be equally unreasonable. This does not, it should be emphasized, imply that any $\mathrm{Y}^{*}$ should thus be allowed in public schooling or workplaces, as there may well be other strong reasons for prohibiting such practice. It is simply to say that, should one's cultural commitment, $\mathrm{Y}^{*}$, conflict with the general criteria for education (or employment), inequality of opportunity obtains. Whether this inequality is, nevertheless, justified, is another matter that needs to be assessed with all the relevant information at hand.

${ }^{351}$ Barry 2001, 49; 104-105.
} 
Barry's view, only the latter kinds of instances (involving systematic exclusion) should be viewed in terms of inequality of opportunity, whereas the exclusion of the turban wearing Sikhs from a relatively small number of jobs should not, due to this kind of exclusion still leaving the majority of jobs open. As long as the pool of options (jobs) available for the turban wearing Sikhs is not substantially cut down by not allowing the wearing of turbans in a (relatively small) number of jobs, equality of opportunity, in Barry's account, prevails.

Barry's position of excluding the specific cases of $\mathrm{Y}^{*}$ and $\mathrm{X}^{*}$ from the realm of inequality of opportunity would, at least at first sight, be perfectly consistent with the idea that people should have equal opportunities to combine their cultural or religious commitments $(\mathrm{Y})$ with employment $(\mathrm{X})$. Provided that the number of jobs not available to the turban wearing Sikhs was relatively small, one could argue that equality of opportunity to $\mathrm{X}$ and $\mathrm{Y}$ would still prevail, as the number of jobs with which the wearing of the turban could be conjoined was only minutely smaller (and, thus, roughly identical) to the number of jobs available for those not wearing a turban. The case of turban wearing Sikhs being prevented from working as police officers (or, in Barry's account, as motor bike officers or as construction workers) ${ }^{352}$ could not thus be conceived of as constituting inequality of opportunity, as long as the vast majority of other jobs did not prevent the wearing of the turban in the work place.

There is, however, something afoul in arguing that the equality (or inequality) of opportunity in specific cases $\left(\mathrm{X}^{*}\right.$ and $\mathrm{Y}^{*}$ ) would be dependent on the equality (or inequality) of opportunity in the general case ( $\mathrm{X}$ and $\left.\mathrm{Y}^{*}\right)$. That is, as Barry seems to claim, that the assessment of whether the lacking of an opportunity to $\mathrm{X}^{*}$ and $\mathrm{Y}^{*}$ constitutes inequality of opportunity would depend on whether one has an opportunity to $\mathrm{X}$ (sufficient number of other jobs) and $\mathrm{Y}^{*}$. In

352 As already indicated, Barry does not advocate an immediate repudiation of the hard hat exemptions, although reasons for doing so are more practical than principled. (Barry 2001, 49-50.) 


\section{Part I Justifying Minority Rights}

order to see this, it may be worth utilizing a parallel case of having an opportunity to have both employment and raise a family. Provided that we already think that one's choice of having a family should not be a disadvantage in the employment market, and that people should have equal opportunities to conjoin having a family with employment, would it not constitute a case of inequality of opportunity if one was denied access to a particular profession due to one having a family? Or, to make the case reflect more closely the particularity of the cultural case, would it not be a case of inequality of opportunity if a particular profession $\left(\mathrm{X}^{*}\right)$ was not open to those who, say, had children $\left(\mathrm{Y}^{*}\right)$ on the basis that people with children would still have a wide variety of professions to choose from?

Whereas one could, no doubt, consistently argue that, as people with children would still have a wide variety of professions to choose from, and that a denial of access to a particular profession due to one having children would not constitute inequality of opportunity, I doubt that this is the conclusion that many liberals would be willing to endorse. As there is already an agreement that having a family (or, a particular aspect of having a family, having children) should not create a disadvantage in the employment market, it would seem that any case, denying one the opportunity to combine employment with having children, should be viewed as constituting a case of inequality of opportunity. In a parallel vein, as there is already agreement that one's culture or religion should not create a disadvantage in the employment market, any case violating this principle should be viewed as constituting a case of inequality of opportunity - irrespective of the number of other jobs with which the adherence to a particular cultural practice was compatible.

It should be emphasized that the above is, of course, a purely structural argument against the view according to which people with certain cultural commitments are not relevantly disadvantaged by not having an opportunity to $\mathrm{X}^{*}$ and $\mathrm{Y}^{*}$ because the denial of $\mathrm{X}^{*}$ and $\mathrm{Y}^{*}$ does not sufficiently hamper their opportunities to $\mathrm{X}$ and $\mathrm{Y}^{*}$. As discussed in the previous section (2.2.), Barry's argument for denying that the specific cases of denying opportunity 
to $\mathrm{X}^{*}$ and $\mathrm{Y}^{*}$ would constitute inequality of opportunity is based, not only on the number of other jobs (with which the cultural commitment in question is compatible), but also on the reasons for why one is prevented from adhering to this particular commitment in some particular job. In the above cases of having children and wearing a turban, it could be objected that, whereas having children does not necessarily effect one's successful performance in the job (at least if children are not brought to the work place or result in excessive leaves of absence), the wearing of the turban does. For example, in jobs that require the wearing of safety helmets, the wearing of a turban can be seen as lowering safety at the work place, and in the example case of the dress requirements of the police officer, it could be argued, the identifiability, internal morale, or public respect of the police force may be substantially reduced.

However, as I already tried to show (2.2.), I believe that the incorporation of the reasons for upholding certain rules or criteria into the assessment of equality of opportunity ignores the important distinction between the existence of equal opportunities and the possible justification for their denial, as well as undermines the experiences of those who are, as a matter of fact, disadvantaged by the incompatibility of their cultural practices with the rule in question. Instead of arguing that only those cases of denying opportunity to $\mathrm{X}^{*}$ and $\mathrm{Y}^{*}$ qualify as cases of inequality of opportunity where there clearly is no justification for the rule in question (or where the exclusion is systematic), the proposed account of assessing equality of opportunity simply in terms of "having an opportunity to $\mathrm{X}\left({ }^{*}\right)$ and $\mathrm{Y}\left({ }^{*}\right)$ " would seem to take better into account, both the complexity of the situations at hand, as well as the experiences of those disadvantaged.

Whereas I do not deny that, in some cases, there may well be overriding considerations that justify the denial of equality of opportunity (some of which will be discussed shortly in section 3.2.), I also believe that, from the perspective of the disadvantaged, it is essential that the claims, based on considerations of equality, are not denied in advance. The turban wearing Sikh who is faced with a rule that is incompatible with him wearing his turban is, de 


\section{Part I Justifying Minority Rights}

facto, in an unequal position to that of the majority, regardless of whether the rule in question is justified. The turban wearing Sikh lacks the opportunity to $\mathrm{X}^{*}$ and $\mathrm{Y}^{*}$ and, by virtue of lacking this opportunity, also has a claim, based on considerations of equality, to complain about this situation. Whether this case, based on the acknowledgement of the inequality of opportunity to $\mathrm{X}^{*}$ and $\mathrm{Y}^{*}$, is strong enough to warrant action (including possible exemptions or the abolishment of the rule itself), is a different matter, requiring careful assessment and balancing of the rationales on each side of the debate. ${ }^{353}$

\subsection{Joint opportunities and cultural exemptions}

Having outlined a specific conception of equality of opportunity in terms of joint opportunities (to $\mathrm{X}\left({ }^{*}\right)$ and $\mathrm{Y}\left({ }^{*}\right)$ ), it is time to conclude this chapter by looking at some of the objections that may be brought forth against this conception and, by way of doing so, also outline some of the implications that this conception may have on debates on multiculturalism and, especially, on cultural exemptions. The main claim so far was that the understanding of equality of opportunity in terms of joint opportunities had the benefit of taking the disadvantages of those who lack an opportunity to $\mathrm{X}(*)$ and $\mathrm{Y}(*)$ seriously. That is, contrary to the alternative conceptions (those of equality of opportunity in terms of roughly identical opportunity sets, or in terms of opportunities without excessive costs), the conception of equality of opportunity in terms of joint opportunities was able to recognize the

\footnotetext{
${ }^{353}$ One of the main benefits of the conception of equality of opportunity in terms of joint opportunities to $\mathrm{X}\left({ }^{*}\right)$ and $\mathrm{Y}\left({ }^{*}\right)$ thus lies in its ability to give certain kind of legitimation to the claims of those who are, de facto, disadvantaged by the incompatibility of their particular cultural practices and general rules or norms of society. Whereas it may well be that, in many of these cases, the inequality in question is deemed justified, it makes a huge difference (especially to those disadvantaged) whether this conclusion is reached by a careful balancing of reasons on each side of the debate, or by the exclusion of the claims of those disadvantaged in the face of rules that have already been deemed as justified.
} 
disadvantages resulting from the incompatibility of particular cultural practices and general rules, without imposing extra burdens of proof on those disadvantaged. Any situation, denying one's opportunity to $\mathrm{X}\left({ }^{*}\right)$ and $\mathrm{Y}\left({ }^{*}\right)$, could, in this conception, be viewed in terms of inequality of opportunity, without the need to incorporate questions about the extensiveness of costs or of the rationales for upholding the conflicting rules into the initial assessment of the situation.

One of the obvious objections to this view is that it would expand the cases, viewed in terms of inequality of opportunity, almost exponentially, as it would incorporate any case of cultural incompatibility (and the consequent lack of opportunity to $\mathrm{X}\left({ }^{*}\right)$ and $\mathrm{Y}\left({ }^{*}\right)$ ) into the realm of inequality of opportunity. Anyone, whose cultural or religious commitment prevented her from adhering to a particular rule or criteria (while simultaneously adhering to the cultural commitment in question) could complain of inequality of opportunity, regardless of what the actual commitment was, how costly/non-costly it was to abandon, or how pressing the rationale for having the conflicting rule was. Viewing equality of opportunity in terms of joint opportunities, and in terms of "having an opportunity to $\mathrm{X}(*)$ and $\mathrm{Y}(*)$ ", the objection continues, fails to differentiate between cases of serious injustice and cases in which the lacking of an opportunity to $\mathrm{X}^{*}$ and $\mathrm{Y}^{*}$ is simply an unfortunate, albeit necessary fact of the world. If the assessments of the importance of one's cultural practice, the extensiveness of the costs of abandoning such practice, and the rationale of the conflicting rule are ignored, there would seem to be nothing left to differentiate between cases in which the person disadvantaged can, perfectly legitimately, be asked to abandon their conflicting cultural commitment, and cases where the appropriate response may well be the granting of an exemption, or the reformation or abandonment of the conflicting rule or criteria itself.

Whereas I acknowledge this objection, I also believe that the objection goes only half way, misconceiving the level upon which the conception of equality of opportunity in terms of joint 
Part I Justifying Minority Rights

opportunities operates, as well as failing to recognize some of the benefits of this conception as opposed to alternative views.

The burden of proof

Firstly, it should be noted that one of the benefits of this conception lies precisely in its simplicity, and in its blindness to differentiate between cases in which the claims of those, denied an opportunity to $\mathrm{X}\left({ }^{*}\right)$ and $\mathrm{Y}\left({ }^{*}\right)$, should lead to changes (e.g. exemptions or changing of the rules or criteria), and cases where they should not. As already indicated, one of the downfalls of conceiving equality of opportunity in terms of opportunities without excessive costs was that this conception utilized the default position of "having an opportunity X" and, by doing so, placed the burden of proof on those whose cultural commitments were in conflict with the rule or criteria in question. In accordance with the conception of equality of opportunity in terms of extensive costs, the turban wearing Sikh would need to establish, not only that his wearing of the turban was incompatible with the rule or criteria in question, but also that the taking off his turban would constitute the kind of excessive cost that would deter a reasonable person from taking advantage of the opportunity in question. In order to have a claim, based on considerations of equality, the turban wearing Sikh would, already, need to prove several issues - all before being even acknowledged as lacking the kinds of opportunities readily available to the majority.

The proposed conception of equality of opportunity in terms of joint opportunities, however, shifts the burden of proof from those already disadvantaged by the incompatibility of their cultural practices and the used criteria, to those who claim this disadvantage to be justified. The lack of an opportunity to $\mathrm{X}\left({ }^{*}\right)$ and $\mathrm{Y}(*)$ is enough to give certain legitimation to the complaints of the disadvantaged, and it is the liberal state (rather than the person thus disadvantaged) that needs to prove why the denial of an opportunity to $\mathrm{X}\left({ }^{*}\right)$ and $\mathrm{Y}(*)$ would be justified. The initial situation, provided by the proposed conception, is thus far more sympathetic towards those who are, already, disadvantaged by the incompatibility of 
their cultural practices and the used criteria, providing also strong reasons for the liberal state to be concerned about these disadvantages, created by one's lack of opportunity to $\mathrm{X}\left({ }^{*}\right)$ and $\mathrm{Y}(*)$.

\section{Balancing of rationales}

Secondly, it should be emphasized that far from leading to a situation in which any case of lacking an opportunity to $\mathrm{X}\left({ }^{*}\right)$ and $Y(*)$ should lead into a substantive alteration of the situation at hand (either by the granting of exemptions or by the altering of the existing rules), this conception of equality of opportunity should not be thought of as aiming to resolve the difficult questions of how people's cultural inequalities should be responded to. Rather, the proposed conception simply points out the rationale that the liberal state has for being concerned about the inequalities in question, and why the claims of those, being thus disadvantaged, should not be left unheard. In line with the arguments of the previous chapters, the acknowledgement of inequality of opportunity in any particular situation does not necessarily lead into any specific responses to this situation, but the assessment of any particular response (be it the upholding of the status quo, the granting of exemptions, or the alteration of the rules) needs to take several other issues into account - including the difficult questions about the importance of one's cultural practice, the costs of abandoning this practice, as well as the strength of the rationale for having the rule or criteria at hand. ${ }^{354}$

\footnotetext{
${ }^{354}$ An objection could be raised that, in the end, the conception of equality of opportunity in terms of joint opportunities makes no difference to the ways in which the disadvantages faced by minority members should be responded to. The liberal state's response should, after all, depend on one's assessment of the centrality of the practice in question as well as of the rationale of the rule at hand, thus creating a need for those disadvantaged to show the centrality of their cultural practice as well as the extensiveness of the costs of abandoning this practice. One of the main differences in my proposal lies in the initial framing of the situation giving certain equality-based legitimation to the claims of the minority members
} 


\section{Part I Justifying Minority Rights}

What is important, in this model, is that the actual responses to cultural inequalities should depend more on the balancing of the rationales on each side of the debate, rather than on the one-sided assessment of the justifiability of the rule in question (Barry's position), the extensiveness of the costs of abandoning one's cultural practices (Miller's position), or, indeed, the acknowledgement of the inequality of opportunity to $\mathrm{X}(*)$ and $\mathrm{Y}\left({ }^{*}\right)$. Whereas the acknowledgement of the initial situation of inequality of opportunity gives strong reasons for the liberal state to be concerned about these inequalities, as well as legitimizes the complaints of those disadvantaged, no straight forward application to any particular cultural policies is made. Rather, the eventual assessment of the appropriate responses to such inequalities should be done in context, balancing the different types of reasons, and strengths of these reasons, on each side.

As an example, it is clear that, according to the conception of equality of opportunity in terms of joint opportunities to $\mathrm{X}\left({ }^{*}\right)$ and $\mathrm{Y}\left({ }^{*}\right)$, the turban wearing Sikh lacks the opportunity to combine his wearing of the turban $\left(\mathrm{Y}^{*}\right)$ with those forms of employment that require the wearing of alternative head gear, incompatible with the wearing of the turban. Due to this inequality, the turban wearing Sikh is, indeed, in a disadvantaged position to that of the majority, and has grounds, based on considerations of equality, to complain about this inequality. The task of the liberal state in this situation is then to assess whether the inequality in question may, nevertheless, be justified and how it should be responded to. Contrary to the "either/or" -position of Brian Barry, ${ }^{355}$ however, the

and, as will be seen, on the emphasis on the balancing of the rationales on each side of the debate.

355 As Barry states "either the case for the law (or some version of it) is strong enough to rule out exemptions, or the case that can be made for exemptions is strong enough to suggest that there should be no law anyway" (Barry 2001, 39; see also Barry 2001, 59-60; 321.) Barry does accept the possibility of there being cases in which both the law as well as an exemption would be defensible, although he does think of these cases as few and far in between. 
acknowledgement of the complexity of the situations at hand, and the legitimacy of the rationales on each side, brings forth the need to balance between the different reasons on either side of the debate, thus leaving considerable scope for the liberal state to also adopt responses of rule-and-exemption to the cases at hand.

For example, should the requirement of alternative head gear be based on important reasons for protecting the safety of the work force as a whole (as may be the case on construction sites), the balance of reasons may well tilt towards the upholding of the rule in question, regardless of the disadvantage that this may cause for those wearing a turban as part of their Sikh identity. ${ }^{356}$ On the other hand, should the rationale for alternative head gear come from the requirements of public identifiability and/or the advantages of having a particular kind of uniform for the morale of the work force (as the case may be, for example, with the Royal Canadian Mounted Police), the balance may well point towards the granting of exemptions, rather than towards either of the two extremes (of holding the status quo or of abolishing the requirements altogether). Contrary to what Barry thinks, there may well be strong enough reasons for maintaining a particular rule or law for the majority while exempting a minority that is disadvantaged by the rule in question, and these cases may be brought forth by the balancing of the reasons for having such rule, and the disadvantage that having such rule causes to those affected. ${ }^{357}$

356 Whether the balance of reasons would, indeed, tilt towards such conclusion should, of course, be more thoroughly argued, taking into account the vast variety of considerations that any particular case may involve. The purpose of the examples, given here, are simply to demonstrate the ways in which the balancing of reasons may lead into different kinds of responses.

357 This is not to say that the rule-and-exemption approach would be the only possible policy approach in these situations, but merely that, based on the balancing of the reasons on each side of the debate, such approach may be justified. 


\section{Part I Justifying Minority Rights}

The case of the Royal Canadian Mounted Police may illustrate this point. As has been noted, there may well be good reasons ${ }^{358}$ for upholding the requirement of the RCMP to wear the traditional Stetson (rule 'A'). The impact of this rule, to the members of the majority, is relatively low, creating (at the most) a fairly insignificant source of discomfort to those who wish to become part of the RCMP and have to, thus, comply with the requirement of wearing the traditional Stetson. The reasons for having the rule ' $A$ ' thus outweigh the reasons that there may be for not requiring the majority to comply with such rule, making the upholding of the rule ' $A$ ' justified. For the minority of the turban wearing Sikhs, however, the same rule ' $A$ ' has a very different impact, although the strength of the rationale for having such rule remains intact. Due to the rule ' $A$ ', the turban wearing Sikh lacks the opportunity to combine $\mathrm{Y}^{*}$ (wearing of the turban) and $\mathrm{X}^{*}$ (joining RCMP), and this inequality may, in the end, weigh more than the rationale for having the rule 'A'. Whereas the lack of opportunity to $\mathrm{Y}^{*}$ and $\mathrm{X}^{*}$ does not, in itself, suffice to outweigh the reasons for having 'A', it does, nevertheless, provide an ample starting point from which the strength of the rationale for not requiring the turban wearing Sikhs to comply with the rule 'A' can be assessed. In this instance, this rationale may be especially strong, due to the centrality of the wearing of the turban to Sikh identity as well as due to the public nature of the employment from which the turban wearing Sikhs would be excluded. Whereas with respect to the majority, the balancing of reasons may well tilt towards upholding the rule ' $\mathrm{A}$ ', with respect to the minority, this balance may be turned.

\section{Conclusion on liberal egalitarianism and equality of opportunity}

Much of the discussions on equality of opportunity within multiculturalism have revolved around the very basic questions of

358 For example, reasons of public identifiability, internal coherence, morality of the force, identitarian or symbolic reasons, etc. 
what it means to have an opportunity, which notion of equality of opportunity should be adopted, and how the adopted notion affects the ways in which cultural minorities are treated within liberal democratic societies. As I have discussed in this chapter, one's understanding of both the nature of opportunity as well as the conception of equality of opportunity have implications, both for the ways in which to think about the rationale for the liberal state being concerned about cultural disadvantages (and which kinds of disadvantages), as well as for the kinds of responses that the liberal state may adopt with respect to these disadvantages. One of the more specific debates, conducted largely within the framework of debates on equality of opportunity, has involved the justifiability of the so-called rule-and-exemption -approach that aims to rectify those inequalities that result from the incompatibility of certain cultural practices with some particular rules or norms of society.

In this chapter, I have defended a conception of equality of opportunity in terms of joint opportunities (to $\mathrm{X}(*)$ and $\mathrm{Y}(*)$ - that is, to combine one's cultural commitments with, for example, employment and education), and the strong egalitarian rationale that this conception brings for the liberal state to be concerned about those disadvantages that result from the incompatibility of minority cultural practices and the general rules of society. This conception was developed largely as a response to the liberal egalitarian critique according to which there were no egalitarian reasons for the state to be concerned about these disadvantages, apart from a small number of cases in which there were no independent justification for the upholding of the conflicting rule or criteria. The incorporation of the questions of justification into the assessment of equality of opportunity itself, however, were seen to largely ignore the experiences and the viewpoints of those disadvantaged, pointing towards the need to differentiate between the questions on the existence of (in)equality of opportunity and its (possible) justification.

The benefits of the proposed conception of equality of opportunity in terms of joint opportunities (to $\mathrm{X}\left({ }^{*}\right)$ and $\mathrm{Y}(*)$ ) come from two sources. Firstly, contrary to the alternative views (those of 


\section{Part I Justifying Minority Rights}

equality of opportunity in terms of roughly identical opportunity sets, or in terms of opportunities without excessive costs), the proposed conception has the advantage of taking the experiences of those disadvantaged seriously, and shifts the burden of proof from those thus disadvantaged to those who claim these disadvantages to be justified. The viewing of equality of opportunity in terms of joint opportunities provides certain legitimation to the claims of those who are, de facto, disadvantaged by the incompatibility of their particular cultural practices and certain rules or criteria, regardless of whether these rules or criteria are justified, or whether the disadvantage in question should, in the end, be rectified.

Secondly, the proposed conception of equality of opportunity in terms of joint opportunities may also help to understand the rationales behind different kinds of policy approaches, including the much debated approach of granting exemptions from otherwise generally applicable rules. Viewing equality of opportunity in terms of joint opportunities - although giving certain legitimation to the claims of those who lack the opportunity to combine their particular cultural practices $\left(\mathrm{Y}^{*}\right)$ with, for example, certain prospects of employment $\left(\mathrm{X}^{*}\right)$ - should not be viewed as giving any authoritative guidance into how the liberal state should respond to the inequalities at hand. Rather, the view proposed in this chapter, emphasizes the need to balance between different rationales on either side of the debate, acknowledging that there may well be good reasons both, for upholding particular rules or criteria, as well as for not applying these criteria to everyone. Whereas, at times, this balance may well turn to either, upholding the rule to everyone, or to getting rid of the rule as a whole, this balancing of reasons also leaves open the possibility that, at times, the rationale of the rule in question is strong enough to justify the upholding of the rule for the majority but not for the minority, thus legitimizing the much debated approach of granting exemptions from otherwise generally applicable rules or laws. 
This discussion on equality of opportunity and cultural exemptions concludes the Part I of this work. In this part, I have concentrated on some of the grand theories of liberal multiculturalism, and espoused some of their weaknesses as well as strengths with respect to both, the rationale of the liberal state to be concerned with issues of cultural diversity, as well as with respect to the justifiability of differentiated rights in practice. Contrary to the grand theorists themselves, the purpose of these chapters has not been to argue for any comprehensive theory of liberal multiculturalism, or any particular policy approach of responding to cultural diversity within liberalism. Each of these chapters have taken a rather critical view on whether such comprehensive theories could (consistently) be established, and on what kinds of guidance these theories could give for the liberal state to respond to cultural diversity. One of the main claims of this part has been that the grand theories of liberal multiculturalism leave considerable scope of legitimate variation into the ways in which the liberal state can respond to cultural diversity, and that any particular response should, in the end, be carefully assessed in context.

Having said that, these three chapters have also tried to show that there are strong liberal reasons for the liberal state to take issues of cultural diversity seriously. Most prominently, there are strong egalitarian reasons for the liberal state to be concerned about and to try to rectify people's cultural disadvantages, and one of the legitimate responses to these disadvantages remains the granting of differentiated rights to those disadvantaged. The arguments, presented in this part, for the strong egalitarian rationale as well as for the justifiability of differentiated treatment, are, of course, far from conclusive and leave several questions unanswered including the difficult questions of when and precisely how any particular minority right should be adopted. Moreover, they also bring forth another important question regarding the ways in which these rights are implemented in practice - that is, the questions about who, and according to which principles, should come under the differentiated rights in question. These questions of allocation are the focus of Part II, to which I will now turn. 


\section{PART II}

\section{Liberal multiculturalism and minority rights in practice}

Since the turn of the millennium, academic (as well as public) debates on multiculturalism have become ever more fragmented. The heterogeneity of normative considerations present in different kinds of right claims have - quite rightly - directed the debates away from the early emphases on the general justifiability of differentiated rights within liberalism, to more differentiated approaches, assessing each type of right on its own terms. The language rights of linguistic minorities, the land claims of aboriginal or indigenous people, the self-government rights of national minorities, integration policies, religious exemptions etc. have all prompted extensive debates of their own, taking better into account the specificities in each case. The individual case studies of different cultural and religious minorities, and the already adopted (or debated) cultural policies of different countries and jurisdictions, have provided valuable material for political theorists and philosophers to work on. Whereas this specification of debates has certainly served the purpose of developing more sophisticated understandings and analyses of different kinds of rights in different contexts, it may, however, also have made it more difficult for the theorists of multiculturalism to see the broader picture, including the kinds of background assumptions that the debates on multiculturalism (old and new) have come to take for granted.

One of these background assumptions, and the main focus of this Part II, is the assumption of minority- or differentiated rights as being specifically group-differentiated rights. That is, the assumption about the scope of culturally differentiated rights as being rights of particular cultural groups or their members. Essentially, this assumption comes down to two things. Firstly, with respect to the group rights proper (that is, rights granted to and 
Part II Liberal Multiculturalism and Minority Rights in Practice

exercised by the group as a collective), ${ }^{359}$ it is presumed that there is, indeed, some relevantly defined group of people that can, as a collective, exercise the right in question. A national minority, such as the Welsh, or an indigenous group, such as the Pueblo Indians, would be primal examples of such groups, although certain religious minorities, such as Muslims and Jews, may also be given rights that are exercised by the group as a collective, for example, by the recognition of parallel family or inheritance laws. Moreover, and more interestingly for my purposes, it is also presumed that the authority exercised by the group in question is primarily restricted to its own members, presuming that one's membership of a cultural group serves as the relevant criterion for coming under the influence of the group right in question. ${ }^{360}$

Secondly, with respect to individually exercised membership rights, such as exemption or assistance rights, it is often presumed that one's membership of a particular cultural or religious group operates as the relevant criterion for being eligible for such rights. Individually exercised membership rights are given to people by virtue of their membership in a cultural or religious group, presuming, not only the existence of cultural groups and their constituent members, but also that the group of people called "members" coincides sufficiently with that group of people whose benefit the rights in questionares trying to serve.

In this second part of my book, I aim to question these common assumptions of culturally differentiated rights as specifically groupdifferentiated rights by questioning the whole notion of group membership and its applicability as a relevant criterion for

\footnotetext{
${ }^{359}$ Such as different forms of self-government, including the recognition of parallel codes of legislation.

${ }^{360}$ Not all effects of group rights proper fall on the group members, although this is, primarily, the case. For example, the rights of territorial autonomy have an effect on everyone who resides or wants to reside within the given territory. The group rights proper also affect the ways in which others conceive and come to treat the group or its members, thus having an effect also on the relations between different groups and their members.
} 
allocating differentiated rights. By the allocation of differentiated rights, I refer to the questions of who, and on what grounds, should come under the influence of the right in question (group rights proper) and who, and on what grounds, should be eligible for the right in question (individually exercised membership rights). These questions of allocation, it should be noted, are somewhat different from the questions of justification (discussed in Part I) although, as will be seen, one's understanding of the proper aim of differentiated rights will, quite rightly, also affect one's understanding of how these rights should be allocated. By way of analysing the constitution of politically relevant group membership, I argue that, in most cases, there are no uncontested ways of establishing one's membership of any particular cultural or religious group, and that even if there were, this membership would, in most cases, fall well short of identifying those individuals whose benefit the differentiated rights are supposed to serve. As opposed to the commonly accepted criterion of group-membership, I argue for a more individual-centered approach for allocating culturally differentiated rights that is consistent not only with the basic liberal commitment to the primacy of the individual but also with the purpose of these rights as rectifying people's cultural disadvantages.

The main basis of my argument for a more individuated account of allocation is given in Ch. 4, Liberal multiculturalism, group membership, and allocation of differentiated rights, with the finer details as well as application of this framework being discussed in chapters 5 and 6 . Whereas the first two chapters $(4 \& 5)$ form the very core of my argument (concentrating more directly on the problematics of defining group memberships and the implications of this indeterminacy to cultural policies), it is clear that the theoretical framework, presented in these two chapters, needs to be filled in and modified in accordance with the context within which it is used. Thus, in the final chapter, Liberal Individualism and cultural defence, I put my theoretical findings to the test by looking at some of the difficulties incorporated in the legal-theoretical context of criminal law and criminal courts, and by doing so, also 
Part II Liberal Multiculturalism and Minority Rights in Practice

demonstrate some of the practical considerations that any approach to accommodating people's cultural differences needs to take into account.

Whereas these three chapters, by no means, aim to diminish or play down the importance that one's cultural membership or belonging to a cultural group may have for any particular individual, they nevertheless question the viability of the membership-based allocation in addressing issues of cultural disadvantages. Instead of viewing culturally differentiated rights as specifically group-differentiated rights, in this part, I argue for a liberal, more individuated approach to cultural diversity that, nevertheless, takes people's cultural commitments and their group identities seriously. 


\section{Chapter 4}

\section{Liberal multiculturalism, group membership, and allocation of differentiated rights}

Within the tradition of liberal multiculturalism, the acknowledgement of people's cultural differences is conjoined with the basic liberal values of individual freedom, autonomy and equality. People's identities - who they are and what they are able to choose - are shaped by their memberships in larger collectives, cultural groups. Culture is seen as shaping the meaningful options and opportunities of individuals, and successful participation in one's cultural group is seen as enhancing rather than diminishing individual freedom, autonomy and well-being. At the level of cultural policies, many liberal multiculturalists have come to argue for differentiated treatment of cultural groups or members of these groups, based on the protection or, at times, promotion of these key liberal values. From the perspective of liberal equality, differentiated rights aim to rectify the disadvantages faced by minority members, and the differentiated treatment, according to many, is seen to best guarantee the freedom and autonomy of those different from the majority. ${ }^{36}$

In this chapter, I start from the assumption that culturally differentiated rights may well be a way to successfully accommodate people's cultural differences. ${ }^{362}$ For the purposes of this chapter, I take it for granted that, firstly, people's cultural membership serves an important function in the constitution of their identities and opportunities, and that political decision making should also take this into account. Secondly, I acknowledge that the proposals for differentiated treatment of cultural groups or members

\footnotetext{
${ }^{361}$ See e.g. Kymlicka 1989, 1995, 2001; Raz 1994, 1998; Deveaux 2000.

${ }^{362}$ This assumption is perfectly in line with the discussions of the first part of this work, where I argued that there was a considerable scope of legitimate variation to the ways in which the liberal state could respond to cultural diversity, including the granting of differentiated rights.
} 
Part II Liberal Multiculturalism and Minority Rights in Practice

of these groups at least aim at accommodating people's cultural differences by allowing them to pursue their own conceptions of the good. ${ }^{363}$ Keeping these preliminary commitments in mind, my focus from now on is on a further theme of liberal multiculturalism - that is, the idea of allocating differentiated rights along the lines of group memberships. Having my focus on the differentiated treatment of group members, my purpose in this chapter is to look at the ways in which membership in a cultural group is constituted and the kinds of problems that this constitution creates for liberal multiculturalists, and for the idea of allocating differentiated rights along the lines of group memberships.

My argument builds upon two earlier conceptualizations of group membership, that of Joseph Raz and Avishai Margalit, given in their originally 1990 published paper "National SelfDetermination", ${ }^{364}$ and that of Kwame Anthony Appiah, given in his 2005 work Ethics of Identity. ${ }^{365}$ I argue that, whereas both conceptualizations rightly acknowledge the importance of recognition in the constitution of group membership, they may fail to take sufficiently into account the discrepancies in recognition, and the implications these discrepancies have for the allocation of differentiated rights. I show that, due to the specific nature of differentiated rights, the view of allocating these rights along the lines of group memberships is flawed, as membership in a cultural group hardly parallels the cultural contents inherent in any given policies. By developing further analysis of group membership, I show why liberal multiculturalists should reconsider their views of group membership as the relevant criterion of allocation, and why, in contemporary circumstances of cultural diversity, alternative criteria are needed.

This chapter proceeds as follows. The first part, Analysing group membership, builds upon Raz and Margalit's analysis of groups and

\footnotetext{
${ }^{363}$ Whether the differentiated rights do, in fact, manage to perform this task has been discussed in Part I, esp. Ch. 1, 2.

${ }^{364}$ Raz and Margalit 1994.

${ }^{365}$ Appiah 2005.
} 
group memberships, and lays the ground for a recognition-based account of politically relevant group membership. I start (1.1.) by giving a short overview of Raz and Margalit's conception of groups potentially eligible for rights of self-determination, and explicate some of the ways in which culture and cultural membership can be seen to affect people's lives. I then (1.2.) turn to some of the conceptual issues relevant for cultural accommodation, and discuss some of advantages of membership-based accounts of cultural accommodation over the accommodation of particular cultural contents. In this section, I also return briefly into the problem of differentiated rights as always promoting certain cultural contents (as discussed in more detail in Ch. 1, 2.2.). In section 1.3., I further specify the role, as well as the source, of recognition that, I believe, is primarily relevant for the constitution of politically relevant group membership.

The second part, Group membership and allocation, focuses on the kinds of difficulties that the discrepancies in different actors' recognition (as well as their reasons for recognizing someone as a group member) bring to the view of group membership as a relevant criterion of allocation. In the first section (2.1.), I utilize Kwame Anthony Appiah's account of a threefold structure of social identities in order to espouse some of the discrepancies that different actors may have for either recognizing, or not recognizing one as a member of a particular group ' $M$ '. This analysis is then used to question two prevailing assumptions within discussions on liberal multiculturalism. In section 2.2., I discuss the commonly accepted ideal that it should be left to the group itself to decide who it conceives of as its members, before turning more directly into the questions of allocating differentiated rights along the lines of group memberships (2.3.). All in all, I argue that the indeterminacy of group membership, conjoined with the view of cultural policies as promoting certain contents of culture, should steer us away from the membership-based allocation, and direct us towards a more individuated approach to allocating differentiated rights in practice. 
Part II Liberal Multiculturalism and Minority Rights in Practice

\section{Analysing group membership}

People's cultural membership plays a special role in discussions on multiculturalism, and on liberal multiculturalism in particular. Most (perhaps all) liberal multiculturalists would acknowledge the importance of cultural membership for individual well-being, and most (although not all) would also view this membership as relevant for the distribution of benefits and burdens in a liberal society. Minority- or differentiated rights are often labelled as specifically group-differentiated rights, ${ }^{366}$ indicating that these rights are, indeed, either rights of cultural groups (group rights proper) or members of these groups (membership rights). Despite the centrality of these notions ('cultural group' and 'group membership'), there have been surprisingly few attempts to systematically analyse these notions and their role in discussions on cultural accommodation. ${ }^{367}$ In this part, I thus aim to look at both, the role that one's membership in a cultural group may play, as well as the ways in which this membership, from a political point of view, ${ }^{368}$ may be constituted.

\subsection{Raz and Margalit on group membership}

In their influential essay 'National Self-Determination', Joseph Raz and Avishai Margalit set to find a moral case for the right of self-

\footnotetext{
${ }^{366}$ The term 'group-differentiated rights" being coined by Kymlicka 1995.

${ }^{367}$ Some such analyses can be found in Pierik 2004; Killmister 2011; for an interesting critique of "groupism" in social and political theory, see: Brubaker 2004.

${ }^{368}$ It may be helpful, already at this stage, to make a differentiation between the notions of 'cultural membership' and 'membership in a cultural group'. Although these two notions have largely been used interchangeably in the literature on multiculturalism, it is important to note that these two notions also incorporate slightly different emphases. Whereas one's cultural membership can be seen as referring more directly to one's shared identity (or belonging), one's membership in a cultural group can also be viewed in purely political terms, as an act of labelling on behalf of someone else. For the time being, these two notions are, however, used jointly, with a more proper analysis of one's belonging having to wait until chapter 5 .
} 
determination. According to Raz and Margalit, it is a fact of the world that people are members of different groups and that memberships in certain groups are also essential to the valuable and worthwhile lives of individuals. Further, they claim that, on occasions, only self-rule can guarantee that a group can conduct its affairs in a manner necessary for the well-being of its members. Thus, in certain cases, the case for the right of self-determination is made. ${ }^{369}$

In their search for a moral grounding for self-determination, Raz and Margalit build a six-stage criteria under which groups most suitable for self-rule are identified. The criteria include (1) a common, pervasive culture, (2) a strong impact of that culture on those living amongst its members, (3) formulation of membership through mutual recognition, (4) high social visibility, (5) stability of membership through non-voluntaristic criteria of membership, and (6) anonymity of members whose recognition is guaranteed by common characteristics. ${ }^{370}$ The criteria have a twofold task. On the one hand, they attempt to pick out those features that may explain the value of self-determination. On the other hand, they also work as a tool of identification. The criteria help to identify those groups that may have a legitimate claim for self-determination, although they should not be conceived as singular, straightforward criteria according to which the groups worthy of self-determination are decided. $^{371}$

Group memberships vs. groups per se

Contrary to Raz and Margalit, who attempt to find criteria most suitable for those groups potentially eligible for rights of selfdetermination, my focus, in this chapter, is on a different issue, that of the identification of members of cultural groups. In what is to follow, I thus focus mainly on Raz and Margalit's criterion 3 - the formulation of membership through mutual recognition. As my

\footnotetext{
${ }^{369}$ Raz and Margalit 1994, 110-130.

${ }^{370}$ Raz and Margalit 1994, 114-117.

${ }^{371}$ Raz and Margalit 1994, 113-114; 118.
} 
Part II Liberal Multiculturalism and Minority Rights in Practice

intention is not to contribute to the debates on self-determination as such, nor to the descriptions of those groups eligible for selfdetermination, I believe this focus to be justified. As opposed to different conceptions of groups and collectively exercised group rights, my interest lies in the - at least analytically separable conceptions of group membership and differentiated treatment of group members. Thus, the other five criteria are discussed only so far as they are relevant for the main task at hand - that is, an inquiry into the ways in which conceptualizing group membership affects, and also should affect, the principles according to which differentiated rights are allocated.

As my focus is on the differentiated treatment of group members (qua group members) rather than of groups as collectives, it may be objected that the formulation at hand - membership in groups potentially eligible for self-determination - fails in being applicable to memberships in other groups. Those groups, the objection goes, potentially eligible for the right of self-determination are groups of special status, and the formulation of group membership with respect to these groups should also be taken only to apply to the particular groups in question.

Although there may be some weight in such a claim, it is not entirely persuasive. Firstly, it is possible to make an analytic distinction between the formulation of group membership and the context of identifying those groups potentially eligible for the right of self-determination. Having certain criteria of group membership is not, in itself, sufficient to establish a group as a group potentially eligible for self-determination, and can also be interpreted as a formulation of group membership in a cultural group in general. Secondly, even if one was to insist that this formulation of group membership applied only to groups potentially eligible for selfdetermination, using this formulation for our present purposes would still make sense. Being a member of a group potentially eligible for self-determination does not as yet guarantee this group self-determination. Thus, the members of those groups potentially eligible for self-determination may, in reality, come under other 
Liberal Multiculturalism, Group Membership, and Allocation

forms of group-differentiated policies, and be accorded differentiated rights and allowances by virtue of their membership.

Groups of pervasive cultures

In order to identify some of the difficulties of allocating differentiated rights along the lines of group memberships, one must first have an understanding of how culture and cultural membership can be seen as affecting people's lives. Following Raz and Margalit, a cultural group - be it ethnic, tribal, religious, racial etc. - can be conceived as a group that has "a common character and a common culture that encompass many, varied, and important aspects of life, a culture that defines or marks a variety of forms or styles of life, types of activity, occupation, pursuit, and relationship." 372 According to Raz and Margalit, cultural groups do not need to be comprehensive in the sense that a person could belong to only one such group, but they do need to be pervasive in the sense that the common culture "penetrates beyond a single or few areas of human life". ${ }^{373}$

In Raz and Margalit's view, both cultural contents as well as membership in a cultural group are inherent elements of people's well-being. On the one hand, pervasive culture is seen as an essential ingredient in the constitution of a person's identity. Culture is not, it is emphasized, the sole determining factor of one's identity, but it is, nevertheless, an important and inalienable factor in shaping who people are and how they conduct their lives. Culture, so to speak, draws the boundaries of the imaginable and provides people with their own, culturally specified contexts of choice. As such, pervasive culture (the norms, values, beliefs, practices - the content of culture) is seen as fundamental to the well-being of those who share that culture. ${ }^{374}$

\footnotetext{
${ }^{372}$ Raz and Margalit 1994, 114.

373 Raz and Margalit 1994, 114. This conception of culture thus incorporates the view of broad culture (BC), although not the ideas of singular or determining culture (SC, DC). See also, Background 2.2.

${ }^{374}$ Raz and Margalit 1994, 118-121.
} 
Part II Liberal Multiculturalism and Minority Rights in Practice

On the other hand, it is not only cultural content that provides for the well-being of its members, but also membership in a cultural group. Membership, in Raz and Margalit's view, has a double function. (1) It is an essential part of one's self-identification and (2) it is also a prerequisite for person's full access to the contents of culture. Cultural content, its norms, values, beliefs, practices, affect all those living amongst members of a cultural group, but it is only through membership that a person can fully enjoy the opportunities created and shaped by culture. Further, membership provides persons with security and sense of belonging, also seen as central to the constitution of one's identity and well-being. ${ }^{375}$

\subsection{Membership-based accounts of cultural accommodation}

As has often been noted, the notions of cultural content and membership in a cultural group have often been mixed in contemporary discussions on multiculturalism. ${ }^{376}$ For liberal multiculturalists, however, this distinction is of central importance. Within the tradition of liberal multiculturalism, cultural policies are often justified by emphasizing the importance of membership over the importance of particular cultural contents. Cultural membership provides for people's identities, and creates meaningful options and opportunities. Consequently, the notion of culture, seen as politically relevant, has been formulated to fit these emphases. As already discussed, Will Kymlicka promotes the view of culture as referring to membership in a cultural group rather than to any particular cultural content, and also draws certain normative conclusions from this view. ${ }^{377}$ In Kymlicka's view, the accommodation of different cultures or the granting of rights to cultural groups (or their members) is tantamount to the accommodation of groups and their ways of living (whatever they

375 Raz and Margalit 1994: 114-117; see also Raz 1994, 162. The relation between one's belonging and one's membership in a cultural group will be discussed in more detail in Ch. 5.

${ }^{376}$ See e.g. Kymlicka 1989, ch. 8; Appiah 2005, ch. 4.

${ }^{377}$ Kymlicka 1989, 167-168; see also Ch. 1, 2.3. 
be), rather than to the accommodation of any particular cultural norms or practices. ${ }^{378}$ At the same time, membership - rather than the sharing of some particular cultural content - comes to operate as the relevant criterion of allocation. ${ }^{379}$

\section{Advantages of membership-based accounts}

For liberal political theory, the advantages of focusing on cultural groups and group memberships rather than on any particular cultural contents would seem - at least at first sight - obvious. Concentrating on groups and group memberships rather than on specific cultural contents would seem to be consistent with the liberal commitment that the state should stay neutral with respect to people's different conceptions of the good. Groups and group members could decide which norms, values, beliefs or practices they wish to adhere to, and the role of cultural policies would simply be to enable these groups to do so. Further, this conception would seem to have the advantage of allowing cultural contents to be understood as complex and fluid, as well as of recognizing the heterogeneity of cultural interpretations. It incorporates the possibility of change into the realm of cultural values, norms,

378 It should be noted that the idea of accommodating groups and their ways of living (whatever they may be) does not come without qualifications. In the tradition of liberal multiculturalism, much recent debate has concentrated on the limits of respecting group autonomy. Whereas some argue that a principled freedom of exit suffices to legitimate a group's right to decide about its own ways of being (e.g. Kukathas 2003; 2012), Kymlicka, for instance, has maintained that there are also substantial limits for the accommodation of different groups. According to Kymlicka, groups may preserve whatever lifestyles they wish, as long as these lifestyles are consistent with the liberal ideals of individual freedom and autonomy (Kymlicka 1989, 198; 1995, 153; 2001, 41-42).

379 For Kymlicka's views on membership as the relevant criterion for distributing benefits and burdens in society, see e.g. Kymlicka 1989, 162; 1995, 45; for other membership-based accounts of allocation, see e.g.: Miller 2002b; Loobuyck 2005. For critical remarks, see: Barry 2001, esp. ch. 4 . 
Part II Liberal Multiculturalism and Minority Rights in Practice

beliefs and practices, without necessarily prioritizing either the status quo or, for that matter, change for the sake of change. The common accusations of cultural essentialism, homogenization and reification would seem to be avoided, as accommodation of cultural groups and members of these groups in no way entails a unified conception of the members' views, nor fixity in the cultural contents that any particular cultural group is associated with.

However, if we take a more careful look at the way this conception relates to actual cultural policies, two immediate concerns arise. Firstly, it is not at all clear whether accommodating groups instead of cultural contents manages to stay clear of promoting certain conceptions of cultural content and, secondly, whether it also manages to sufficiently accommodate differences within the cultural groups in question.

\section{Cultural policies and cultural contents}

As already indicated in Ch. 1 (2.2.), granting groups or group members specific group differentiated rights does not - and cannot - avoid being committed to certain conceptions of cultural content. Group rights or other group-differentiated treatment are not produced in a vacuum, but are always specified in certain contexts. Granting a Sikh a right to wear a turban instead of a crash helmet already advances a conception according to which wearing a turban is an essential part of Sikh culture and an integral ingredient of Sikh identity. Granting a group a right to, say, decide about its own language policies - such as, for example, in the case of Welsh in Wales - advances a conception of language as being an integral ingredient of one's culture and identity, and may also end up advancing a conception of Welsh language as being an integral and inalienable element of Welsh culture. Not only do the policies granted by the state prioritize certain conceptions of culture and identity, the actual policies decided by the group also prioritize certain conceptions of the content of culture over alternative conceptions. ${ }^{380}$ Treating groups or group members in a

${ }^{380}$ See also: Festenstein 2005, 81-82. 
differentiated manner - be it in terms of group-differentiated rights, allowances or general cultural sensitivity - necessarily prioritizes certain interpretations of cultural content, and may also encourage, rather than criticize, the much contested assumptions of cultural homogeneity and stability. And, if this is the case, more harm may be done to those members of cultural groups that do not subscribe to the particular norms, values or practices that the groupdifferentiated treatment however indirectly advances.

The claims that cultural policies may rather encourage notions of cultural homogeneity and inflict harm or injury on those who do not accept the dominant interpretations of their culture are, of course, very complex, and a few clarifications are thus in order. Saying that cultural policies may encourage cultural homogeneity is not to say that any group-differentiated treatment would necessarily encourage cultural homogeneity, nor that it would necessarily do harm to those with different conceptions of cultural content and identity. However, as discussed in Ch. 1 (2.2.), cultural policies do also give certain legitimation to certain cultural practices as proper elements of that culture and, by way of doing so, may also play into the hands of those who wish to see these practices as the only legitimate elements of that culture. Nor am I claiming that the level of directness according to which cultural policies advance certain conceptions of cultural content would be indicative of the level of harm that may (or may not) be done to those not ascribing to the cultural contents advanced. Giving a group a right to decide about its own language policies (advancing a conception of culture as incorporating language rather than a conception of cultural content as incorporating a particular language) may end up causing tremendous harm - for instance, in cases where the decided policies end up upholding strict mono-lingualism and ban the usage of other languages in public. On the other hand, a policy of, say, allowing Muslim girls to wear a hijab in school (directly advancing the view of wearing a hijab as an important element of Muslim culture and identity) does not necessarily cause harm to those girls not wishing to wear a hijab. However, whereas the link between cultural policies and the harm or injury inflicted on those who do not 
Part II Liberal Multiculturalism and Minority Rights in Practice

subscribe to the dominant interpretations of culture is far from straight forward and, by no means, necessary, it is still a concern that needs to be taken seriously. As many have pointed out, those policies that aim at enabling people to live in accordance with their cultural identities may, in effect, end up necessitating that people live in accordance with the dominant conceptions of cultural content - a worry that should not to be bypassed lightly. ${ }^{381}$

\subsection{Recognition based accounts of group membership}

Granted that differentiated rights always prioritize certain conceptions of cultural content - whether directly, as in the case of granting Sikhs the right to wear a turban instead of a crash helmet, or indirectly, as in the case of granting a cultural group a right to decide about its own language policies - and that this may inflict injury on those members who do not subscribe to such conceptions, it is worth investigating what role cultural content has in the constitution of membership in a cultural group. Returning to Raz and Margalit's view, they are committed to the idea of a group of pervasive culture being, at least partially, characterized by its common cultural content. The prevailing cultural norms and practices are characteristic of any particular cultural group, and these characteristics also operate as essential clues for recognizing those belonging to such groups (criteria 6). On the other hand, however, Raz and Margalit also acknowledge that cultures are fluid and heterogeneous, and that cultural contents also affect people's lives very differently. People may be socialized into the prevailing cultural norms and practices, but they may also reject such practices, or interpret them in different ways. ${ }^{382}$ Furthermore, the different ways of being affected by cultural content applies both to

\footnotetext{
${ }^{381}$ The relations between cultural policies and the harm that these policies may inflict on those most vulnerable in cultural groups have been analysed especially by many feminists scholars. See e.g. Benhabib 2002; 2004; Deveaux 2000; Okin 1999; 2005; Shachar 1998; 2000; 2001; Song 2007; Phillips 2007; 2010

${ }^{382}$ Raz and Margalit 1994, 114-115; Raz 2001, 35 ff. 20.
} 
members and non-members alike. Thus, it is possible to be a member of a cultural group without sharing its cultural content, as it is also possible to be a non-member, even if one shared the prevailing norms, values, beliefs and practices.

Provided that cultural content cannot (at least on its own) be used to denote group membership, just like group membership cannot be seen as indicating the sharing of any particular cultural content, some alternative criteria of membership is needed. One of the candidates for such criterion is recognition.

\section{Value laden and instrumental conceptions of recognition}

In the literature on recognition, much attention has been paid to the positive, identity-forming functions of different forms of recognition. For Axel Honneth, positive recognition provides for people's self-respect and self-esteem, and lack of such recognition is tantamount to moral injury and an attack on one's personal integrity. ${ }^{383}$ Similarly, for Charles Taylor, people's identities are partly shaped by the recognition of others, and being mis- or lacking recognition can cause people harm by stunting their identities and creating demeaning or contemptible views of themselves. $^{384}$ Although Honneth's and Taylor's views on recognition are by no means identical, they nevertheless share two important features. Firstly, they both subscribe to an inherently value-laden notion of recognition, portraying recognition as entailing certain forms of respect towards the person recognized. Secondly, and more importantly for the purposes of this chapter, they also acknowledge an important group dimension of recognition. For Honneth and Taylor, people are not only recognized as individual persons of certain traits and characteristics, but they can also be recognized collectively, as groups and as members of groups ${ }^{385}$ - as Muslims, blacks, women or gay.

\footnotetext{
${ }^{383}$ Honneth 1997; 2001.

384 Taylor 1994.

${ }^{385}$ Whereas for Honneth, this group dimension of recognition can best be understood under the rubric of other forms of recognition essential for
} 
Part II Liberal Multiculturalism and Minority Rights in Practice

Whereas the value-laden formulations of recognition involving respect have dominated recent discussions, ${ }^{386}$ recognition can also be understood differently. According to this instrumental conception of recognition, recognition is used simply as an instrument for deciding people's memberships in cultural groups. In this usage of the term, recognizing people as Muslims, as women, or as gays, simply picks out people as members of groups. Although not necessarily entailing respect, this form of recognition can also operate as a positive source of people's self-identification and well-being. The crucial difference, however, is that recognizing a person as a member of a group does not, in itself, provide for that person's self-respect or self-esteem, but does so instrumentally, through the ways in which group membership provides for people's identities and meaningful opportunities.

Raz and Margalit use this instrumental notion of recognition as follows:

Membership in the group is, in part, a matter of mutual recognition. Typically, one belongs to such groups if, among other conditions, one is recognized by other members of the group as belonging to it. The other conditions (which may be the accident of birth or the sharing of the group culture, etc.) are normally the grounds cited as reasons for such recognition. ${ }^{387}$

What is important to notice is that whereas shared cultural content certainly plays some part in the process of deciding who is recognized as a member, it is ultimately mutual recognition that determines who is and who is not a member of the group. As Raz and Margalit continue: "But those who meet those other conditions

individual's self-confidence, self-respect and self-esteem (see esp. Fraser and Honneth 2003: 2.III), Taylor takes a more substantial view of recognition as involving respect also for the values and forms of life of a cultural group (Taylor, 1994).

${ }^{386}$ E.g. Taylor 1994; Honneth 1997; 2001; Galeotti 2002; Jones 2006.

${ }^{387}$ Raz and Margalit 1994, 115. 
and are yet rejected by the group are at best marginal or problematic members of it". ${ }^{388}$ Although the reasons for recognizing someone as a member often have some criteria and content - such as accident of birth (or other non-voluntary characteristic (criteria 5)) or participation in common practices and traditions (or other characteristics helping members to recognize each other (criteria 6)) - these criteria are, by no means, sufficient for indicating a person's membership, nor are they even necessary criteria for such recognition. On the contrary, in Raz and Margalit's view, a person is a full or uncontested member of a group only if other group members recognize this person's membership. Given the double function of group membership, this instrumental form of recognition comes to play a key role in controlling people's possibilities for worthy and meaningful lives. Being a member of a group - being recognized as a member - is an essential ingredient in the constitution of people's identities, and it also operates as a gatekeeper, regulating people's access to lives fully characterized by those identities. ${ }^{389}$

\section{Internal and external recognition}

Although I am sympathetic towards the above idea of recognition as operating, both as an important ingredient in the constitution of people's identities and as a regulator of their opportunities, I also believe that Raz and Margalit's characterization of recognition as primarily mutual recognition fails to capture something important about the source of recognition particularly significant in contemporary circumstances of cultural diversity. To recall, Raz and Margalit claim that it is the group's internal, mutual recognition that ultimately matters in questions of group membership: "Membership in them [groups of pervasive cultures] is a matter of informal acknowledgement of belonging by others generally, and by other members specifically." "[T]hose who [...]

\footnotetext{
${ }^{388}$ Raz and Margalit 1994, 115.

${ }^{389}$ Raz and Margalit 1994, 118-119.
} 
Part II Liberal Multiculturalism and Minority Rights in Practice

are yet rejected by the group are at best marginal or problematic members of it". ${ }^{390}$

However, whereas this may be the case in relatively isolated groups not bound by the rules and regulations of the liberal society, in contemporary contexts of cultural diversity the situation is fundamentally different. In culturally diverse societies it is primarily the external recognition - that of the state and the wider political community it represents - that comes to play the prominent role. This, of course, is not to say that that the group members themselves could not be conceived as being part of this larger political community, but merely that it is never solely through the recognition of the group members themselves that politically relevant membership is constituted. ${ }^{391}$ As the rights of self-determination and other group-differentiated rights or allowances are granted by the state, representative of the larger political community, it is ultimately the recognition of others that matters, not the recognition of other group members. People's identities as well as the means through which people are able to pursue their lives according to these identities are - in culturally diverse societies - affected largely by the recognition of others, as it is the larger political community that decides to whom differentiated treatment is applied and who is - in a politically relevant sense - a member of any particular group. ${ }^{392}$

${ }^{390}$ Raz and Margalit 1994, 118-119, my emphases.

391 It should be noted that my argument here in no way denies the possibility of internal recognition as influencing the recognition of others. However, as will be argued in the remaining sections of this chapter, it is highly unlikely that the politically relevant group membership would (or could) be dependent solely on the internal recognition of other group members, or that - at least in the case of minority groups - the recognition of others would not be ultimately decisive in the constitution of politically relevant group membership

${ }^{392}$ This is not to undermine the importance of internal recognition in the constitution of one's identity and well-being. The opportunities as well as the sense of belonging given to, say, a Muslim youngster by the recognition of the Muslim community may, indeed, be central for the wellbeing of this youngster. However, my claim is that, in the issues regarding 
Liberal Multiculturalism, Group Membership, and Allocation

\section{Group membership and allocation}

So far, I have discussed some of the ways in which one's membership in a cultural group operates as an important ingredient in the constitution of one's identity as well as a regulator of one's access to opportunities. I also showed how an instrumental conception of recognition could be used to pick out this membership and how, with respect to public policies such as groupdifferentiated rights, it was specifically the recognition of others that came to play an important role in deciding who was to come under, or be eligible for, such rights. Having laid some ground for a specifically recognition-based account of politically relevant group membership, in this part, I develop a more systematic account of group membership, including the possible indeterminacies of membership, based on the possible discrepancies of recognition. This analysis is then used to show some of the problems incorporated in the idea of allowing group members themselves to decide their own memberships, before turning into the difficulties that the indeterminacy of group membership brings to the questions of allocating minority rights in practice. These analyses, however, cannot be conducted without some understanding of what it means for a cultural group or group membership to be politically relevant, and how such relevancy is constituted.

\subsection{Politically relevant groups and group memberships}

By politically relevant groups (and politically relevant group memberships) I refer to those groups (and group members) that are, in the wider public debate, considered as potential claimants for differentiated treatment. Cultural and religious groups, but also groups described in terms of one's gender, sexual orientation,

cultural policies, what matters is ultimately the recognition of the larger political community, as it is the larger political community that decides, for instance, whether this particular youngster is provided with a certain diet in his school or is allowed to wear a particular type of garment in public. 
Part II Liberal Multiculturalism and Minority Rights in Practice

physical capability etc. are commonly viewed as politically relevant groups in this sense of the term. Not all groups, however, are viewed as potential claimants for differentiated treatment, and it is thus important to identify those criteria that a group needs to fulfil in order for it to be considered a politically relevant group.

\section{Appiah on the structure of social identities}

Following Kwame Anthony Appiah's conceptualization of the structure of social identities, there are certain requirements that should be fulfilled in order for a group to be a group in any politically relevant sense. Firstly, a minimum requirement of a general consensus regarding the existence of such a group must be established. It must make sense for people to use a particular label Muslim, black, women, gay - in order to classify people under that label. ${ }^{393}$

The mere existence of such label does not, however, suffice to make these groups politically relevant. Red-haired people or blueeyed people may well be considered sensible labels under which people are put, but they are hardly relevant in the realm of public politics. ${ }^{394}$ In addition to the formal classification, we must also

393 Appiah 2005, 65-66. Appiah's account is strongly based on the socalled dynamic nominalist view, promoted by Ian Hacking. (Hacking 1992a; 1992b; see also Appiah 2005, 23; 65.) Following Hacking, Appiah argues that social identities are produced and brought into existence hand in hand with the invention and application of the label itself, and that it may well be that the invention and application of the label have operated as producing cultural differences, rather than cultural differences having brought about such labels or people's identifications with the cultures in question. Whether Appiah is right on the origins of cultural differences or the coming into existence of labels attached to cultural groups do not, however, need to bear upon the analysis of the structure of social identities.

${ }^{394}$ Which labels are relevant in public politics is, of course, political itself, and may vary in different times and places. 
have what Appiah calls a social conception of a label. ${ }^{395}$ This, according to Appiah, consists of two further considerations. Firstly, that there are some people who - at least occasionally - identify themselves as, say, Muslim, and secondly, that there are occasions on which some people are also treated as, say, Muslims. Identifying oneself as an M, according to Appiah, refers to the way in which a person lets his belief in being an $\mathrm{M}$ operate as a reason for his behaviour (say, a person prays five times a day because he believes this to be the appropriate thing for him, as a Muslim, to do). Being treated as an $\mathrm{M}$, refers to the way in which the belief in someone being an $\mathrm{M}$ operates as a reason for a particular type of treatment (say, a person is not invited to the office Christmas party because the invitee believes this person, as a Muslim, to refuse anyway). ${ }^{396}$ The political relevance of the groups of certain labels thus flows, not from the mere existence of the labels under which people are put, but from the expectations attached to people under these labels, as well as from the behaviour resulting from these expectations.

\footnotetext{
395 For a full account of Appiah's conception of the structure of social identities and the social conception of a label, see Appiah 2005, ch. 3; see also Appiah 1996; 2001.

${ }^{396}$ Jorge J.E. Gracia gives a slightly different reading of Appiah's account of the structure of social identity. According to Gracia, the structure of social identity is constituted by 1) availability of the term in public discourse, 2) internalization of those picked by the label, and 3) the existence of the patterns of behaviour in the group picked by the label. (Garcia 2006, 289.) However, whereas Gracia may be right in distinguishing between (2) the internalization of a label (or what I have called identification as) and (3) the behaviour resulting from this internalization, he makes a mistake in ignoring what Appiah really considers as the third element of social identity, that of someone's treatment as a member of a certain group. This element, however, is an essential element of Appiah's theory of social identity, and, as will be seen, it is also an element that plays an important part in the utilization of this structure to the questions of group membership.
} 
Part II Liberal Multiculturalism and Minority Rights in Practice

\section{Discrepancy in group membership}

Apart from identifying those elements that make groups politically relevant, the threefold structure of social identities can also be used in an analysis of politically relevant group membership. As 'the expectations', 'the proper modes of behaviour' or 'the kinds of persons' denoted by certain labels are multiple, heterogeneous and flexible, ${ }^{397}$ it is of no surprise that, in Appiah's account, no particular cultural content can operate as the deciding factor of person's membership in any particular cultural group. The expectations of, say, being a Muslim may well vary from a peaceloving, God-abiding, upright person to a violent, fundamentalist zealot, and it would be rather foolish to even attempt to attach either - or, indeed, any - such described value-structure as the essential marker of Muslims, or of those considered members of a group denoted by the label 'Muslim'. Instead, much like Raz and Margalit's work, Appiah's work can also be read as promoting a conception of group membership that is primarily not a matter of any specific cultural content, but a matter of particular sorts of recognition, those of self-identification (recognition of oneself as M) and of external ascription (recognition by others as M).

Viewing recognition as the deciding factor of one's group membership does not, however, necessarily provide a very straight forward account of who is and who is not a member of any particular cultural group. By utilizing the earlier distinction between internal and external recognition, the following analysis of different sources and relations of recognition can be constructed: ${ }^{398}$

\footnotetext{
397 Appiah 2005, 67; 108; see also: Appiah 1994, 159-160; 1996, 80; 97; $2001,326$.

398 For the sake of clarity, I have divided the table to consist of a) a singular person $\mathrm{X}$ who either identifies or does not identify as $\mathrm{M}, \mathrm{b}$ ) those (others) who identify as $\mathrm{M}$ and recognize $\mathrm{X}$ in certain ways, and c) those (others) who do not identify as $M$ and recognize $X$ in certain ways. It should, of course, be noted that, due to the possibility - or even probability - of different responses within the two latter columns, the table is very much a simplification. It is also a simplification in so far as the table does
} 
Table 1

\begin{tabular}{|c|c|c|c|}
\hline & $\mathrm{X}$ & $\begin{array}{l}\text { Those (others) who } \\
\text { self-identify as M }\end{array}$ & $\begin{array}{l}\text { Those (others) not } \\
\text { identifying as } M\end{array}$ \\
\hline 1. & Identifies as $\mathrm{M}$ & Recognizes $\mathrm{X}$ as $\mathrm{M}$ & Recognizes $\mathrm{X}$ as $\mathrm{M}$ \\
\hline 2. & Identifies as $\mathrm{M}$ & Recognizes X as M & $\begin{array}{l}\text { Does not recognize } \\
\mathrm{X} \text { as } \mathrm{M}\end{array}$ \\
\hline 3. & Identifies as $\mathrm{M}$ & $\begin{array}{l}\text { Does not recognize } \\
\mathrm{X} \text { as } \mathrm{M}\end{array}$ & Recognizes $\mathrm{X}$ as $\mathrm{M}$ \\
\hline 4. & Identifies as $\mathrm{M}$ & $\begin{array}{l}\text { Does not recognize } \\
\mathrm{X} \text { as } \mathrm{M}\end{array}$ & $\begin{array}{l}\text { Does not recognize } \\
\mathrm{X} \text { as } \mathrm{M}\end{array}$ \\
\hline 5. & Not identifying as $\mathrm{M}$ & $\begin{array}{l}\text { Does not recognize } \\
\mathrm{X} \text { as } \mathrm{M}\end{array}$ & $\begin{array}{l}\text { Does not recognize } \\
\mathrm{X} \text { as } \mathrm{M}\end{array}$ \\
\hline 6. & Not identifying as $\mathrm{M}$ & $\begin{array}{l}\text { Does not recognize } \\
\mathrm{X} \text { as } \mathrm{M}\end{array}$ & Recognizes $\mathrm{X}$ as $\mathrm{M}$ \\
\hline 7. & Not identifying as $\mathrm{M}$ & Recognizes $\mathrm{X}$ as $\mathrm{M}$ & $\begin{array}{l}\text { Does not recognize } \\
\mathrm{X} \text { as } \mathrm{M}\end{array}$ \\
\hline 8. & Not identifying as M & Recognizes $\mathrm{X}$ as $\mathrm{M}$ & Recognizes $\mathrm{X}$ as $\mathrm{M}$ \\
\hline
\end{tabular}

What is important is that only lines one and five give us results in which the recognition of all three parties towards X coincide. My self-identification as a woman, coinciding with other self-identified women's as well as non-identifiers' recognition of me as a woman gives us a rather unproblematic case as to whether I am to be considered a member of the group 'women'. On the other hand, it is not difficult to imagine someone not-identifying himself as, say, a Sikh, not being recognized as a Sikh by other Sikh-identifiers nor by non-identifiers, and to conclude that such a person is, indeed, not a member of a group called 'Sikhs'. Taken in isolation, these two cases are rather uninteresting. This, of course, is not to say that they could not become interesting once connected to the wider normative questions of whether members of certain groups should

not include political actors (such as group leadership or liberal state), the role of which will be discussed in more detail in Ch. 5 . 
Part II Liberal Multiculturalism and Minority Rights in Practice

also be treated in ways specific to such groups, or whether nonmembers should also have the right to enjoy the privileges given to members of some groups. Whether I, as a woman, should be able to occupy a position reserved specifically to women by a positive act of discrimination, or whether someone non-Sikh should also be able to wear a turban instead of a crash helmet whilst riding a motor bike, a privilege normally granted to Sikhs only. However, as my purpose, in this chapter, is not to participate in discussions regarding the general justifiability of group-differentiated treatment as such, but merely to contribute to the discussions by pointing out some of the underlying difficulties in defining group-memberships, I will take cases one and five as unproblematic, as far as defining group membership is concerned.

What is of particular interest in the table above, however, are the ways in which it highlights heterogeneities in recognizing people's memberships in cultural groups. Whereas the homogeneous conception of cultural content has had its fair share of critique in recent discussions on multiculturalism, the idea of group membership, on the other hand, has in much contemporary literature remained relatively under analyzed. Whereas pleas for letting groups or group members themselves decide about their own cultural commitments are common, not too much attention has been paid to the criteria according to which those eligible for making such decisions - that is, group members - are to be decided. ${ }^{399}$

The problem, as should be fairly clear by now, is that there does not seem to be a particularly clear way of defining who, and on what grounds, should count as a member of this or that cultural group. If we take the cultural content - shared values, norms, practices and

399 To be fair, many recent thinkers have accepted the idea of cultural groups as groups of no fixed boundaries (see e.g. Benhabib 2002; Carens 2000; Mason 2000; Phillips 2007). Many have also explicitly recognized the existence of 'marginal' or 'problematic' members of cultural groups (e.g. Parekh 2000, 148; Raz and Margalit 1994, 115). However, whereas the idea of the indeterminacy of cultural groups and group memberships has acquired some prominence, a detailed analysis of the constitution of membership (and marginal membership) has often remained lacking. 
beliefs - to be the constitutive elements of group membership, we are bound to fall back to the much criticized notions of cultural homogeneity, to privilege status quo and make the ideas of cultural fluidity and change increasingly difficult to attain. If, on the other hand, we disregard the ideas of cultural content and let them operate, at the most, as some of the reasons for recognizing one as a member of a group, we come to notice that it is not only cultural content, but also membership that should be conceived of as heterogeneous and contested.

\subsection{Groups deciding their own members?}

In section 1.3. I highlighted the influence that the recognition of others, or of the larger political community as a whole, had for the constitution of politically relevant group membership. The groupdifferentiated rights and their beneficiaries were, in the end, decided by the liberal state (and the larger political community it represents), casting some doubt on whether, and to what extent, the members of minority cultures could be seen as being in charge of their own destiny. Granted the way in which treatment by others affects the ways minority groups and their members can pursue their lives, many theorists have adopted views according to which, at least in matters of content, groups should be able to decide for themselves, which customs, traditions, values or beliefs they wish to adopt. For Bhikhu Parekh, for instance, it is highly unlikely that those outside a particular culture can understand all the subtleties and complexities of that culture, and that it is therefore best that the possible changes in culture come from within. ${ }^{400}$ According to Kymlicka, "It is right and proper that the character of a culture change as a result of the choices of its members. (...) People should be able to decide what is best from within their own culture". ${ }^{401}$ Similarly, for Raz and Margalit, the right of self-determination ultimately gives groups themselves the right to decide - irrespective

${ }^{400}$ Parekh 2000, 177-178.

${ }^{401}$ Kymlicka 1995, 104-105. 
Part II Liberal Multiculturalism and Minority Rights in Practice

of the content of decisions - how to live and what norms or values to uphold. ${ }^{402}$

From the perspective of acknowledging the internal heterogeneity of cultural groups, these calls for allowing cultural groups to decide their own cultural contents would seem compatible. Far from promoting any essentialized, homogenized conception of group culture, the ideas of cultural heterogeneity are incorporated, as the group's right to decide about its own cultural contents does not necessarily entail a unity in the members' views about the appropriate contents of these decisions. It merely dictates that the group members, rather than non-members or even the larger political community as a whole, should have the principal say in deciding which ways of life, values, norms or practices they, as a group, adhere to. Thus, it is possible for group members to have different conceptions of their cultures, to express fierce critiques of their cultures, as well as even reject the whole idea of any relevantly shared cultural content. ${ }^{403}$

In the light of the discussions of the previous sections, it should, however, be clear that the idea of letting group members themselves decide about the contents of their culture is more problematic than is often acknowledged. In order to let the group members themselves decide about their own cultural contents, one needs to already have some conception of who those members are, in order to take into account the views of those who, in Kymlicka's words, "should be able to decide what is best from within". As demonstrated by the table 1 above, however, there may be several different interpretations of the question of who is a group member, as different people (the identifiers and non-identifiers alike) may have different views on who they recognize as a member of a group M.

\footnotetext{
${ }^{402}$ Raz and Margalit 1994, 124.

${ }^{403}$ See also: Raz 2001, 35, ff. 20.
} 
Liberal Multiculturalism, Group Membership, and Allocation

\section{Weaker and stronger formulations of mutual recognition}

One of the ways to address the problem of defining group membership would be to argue that group members should themselves decide not only the cultural content, but who are to be considered group members. To an extent, this is what Raz and Margalit are doing, as for them, membership in a cultural group is primarily a matter of mutual recognition. Two versions of conceiving membership in terms of mutual recognition can be distinguished. In the stronger formulation, ${ }^{404}$ group members are those who fit the criteria presented on lines one and two of the above table. To be a group member, a person needs to identify herself as a group member and those also identifying as members must recognize this person as a member. Whether others - the nonidentifiers - agree with such membership is, at least to an extent, a secondary concern. As an example, we may think of a girl (say, now 13 years of age), who turned to Islam when she was 11 , is recognized by her Muslim community as a Muslim, but is not recognized by others as a Muslim due to her youth. Or, we could think of a gay man who engages actively with the gay community, identifies himself as gay and is also recognized as gay by other gayidentifiers, but gives no sign of his sexual identity to the outside world. However, whereas defining group membership in such a way may have some advantages (such as conceiving membership as always also dependent on the person's own identification as a member), it nevertheless seems to fail to capture many of the ways in which membership operates in the wider political sphere.

In the weaker formulation, the conception of membership through mutual recognition includes not only lines one and two but also lines seven and eight. A person may be a member, even if he does not identify himself as a member, as long as other selfidentifying members recognize him as a member (again irrespective

\footnotetext{
${ }^{404}$ I refer to these two versions as stronger and weaker formulations, the "stronger" being stronger in terms of requiring unanimity of recognition from all involved, whereas the "weaker" formulation may also accommodate certain discrepancies in recognition.
} 
Part II Liberal Multiculturalism and Minority Rights in Practice

of the recognition of non-identifiers). Granted the double function of group membership as the source of one's identification and the gatekeeper of culturally defined opportunities, this formulation captures many of the ways group membership affects people's lives by regulating their opportunities. Regardless of whether one identifies oneself as a member of, say, the Catholic community, if other Catholics (or, in cases, the Catholic church) ${ }^{405}$ recognize him as a member, he has a right to a church wedding and communion, his children may have access to Catholic schooling, and - in times of distress - he may resort to and be given the support of his congregation. This, again, is irrespective of the recognition of those not identifying themselves as Catholics.

However, although the above, weaker conception of group membership in terms of mutual recognition may sound initially promising, it may also cease to be so, at least in cases where membership creates a burden on those attempting to shy away from such identification. Cases of non-identifiers being pressurized to, say, live in certain locations, dress in certain ways, or - for example - have one's children, or oneself, circumcised, strongly questions the attractiveness of letting self-identifiers choose who are to be considered as members. Further, proceeding from the results obtained in the earlier sections, the idea of defining group membership solely in terms of group's internal recognition does not match well with the contemporary circumstances of cultural diversity. In culturally diverse societies, it is often the recognition of others that operates as the main regulator of people's culturally defined opportunities. If members (and only members) of a Sikh community have been granted a right to wear a turban instead of a crash helmet, it is not the internal recognition of the Sikh community that defines whether I will be able to (legally) wear a turban while riding a motorbike. Rather, my opportunity is dependent on the recognition of the state, and thus primarily of others, irrespective of what other Sikh-identifiers may say about my membership. In this account, membership (that is politically

${ }^{405}$ I will discuss the role of institutionalised actors in more detail in Ch. 5. 
relevant) is captured by lines one, three, six and eight, excluding the lines two and seven included in the previous account.

To avoid these discrepancies, one could, perhaps, argue that the fact that group membership (of political relevance) is often decided by others who are not members themselves is an unfortunate fact of the world and that, in ideal circumstances, group membership - like cultural content - would be decided by the group itself. To an extent, this may already be the case, as the group's internal recognition may have an influence on the recognition of others. The others may wish to listen to the group itself in matters of who is to be seen as a member, and also attempt to align their recognition with the recognition of the group members.

However, whereas listening to group members themselves may, in contemporary circumstances of cultural diversity, be a very respectable effort, it is not entirely unproblematic. In order for the group to decide on its own members and in order for others to align their views with this decision, there already needs to be criteria according to which those eligible for participating in this decision are decided. Who are those members whose decisions on membership should be listened to by others? Should people's selfidentification be the relevant criteria in deciding who can participate in this decision making - qualifying lines one, two, three and four? Or should the group's internal recognition operate as the criteria for deciding who decides - qualifying lines one and two (stronger formulation) or lines one, two, seven and eight (weaker formulation)? Or should we perhaps accept that it is an unavoidable, although not necessarily unfortunate, fact of the world that, at least in contemporary circumstances of cultural diversity, any criteria of deciding people's group membership (that is politically relevant) necessarily coincides with the general public conception of group membership and, thus, primarily with the conception of others irrespective of whether this conception coincides with the conception of those identifying themselves as members of the group (lines one, three, six and eight)? If so, the idea of letting groups themselves decide their own members seems an impossibility. In circumstances of cultural diversity, group 
Part II Liberal Multiculturalism and Minority Rights in Practice

membership (that is of political relevance) is always at least partly dependent on the recognition of others, as it is the larger political community that decides to whom they listen in questions, both of cultural content, as well as of membership in a cultural group.

\subsection{Cultural policies and membership-based allocation}

Having shown some of the problems of defining group membership in terms of different kinds of recognition, it is time to conclude this chapter by looking at some of the ways these problems relate to actual cultural policies, and to the liberal multiculturalists' views on the allocation of differentiated rights. To recap, for liberal multiculturalists, membership in a cultural group is often taken as the relevant criterion according to which cultural policies - be they group-differentiated rights, allowances or other culturally sensitive measures - are granted. According to Kymlicka, "membership in a cultural community may be a relevant criterion for distributing the benefits and burdens which are the concern of a liberal theory of justice." ${ }^{, 406}$ David Miller states the case even more clearly: "[group rights] are given to group members by virtue of their membership of the group in question, and not merely by virtue of their having some feature that as it happens all members of the group share" ${ }^{407}$ Being a member of a cultural group is not, however, a matter of sharing some particular feature or particular cultural content. One can be a member of a cultural group without sharing its prevailing cultural contents, as one can be a non-member even if one shared the prevailing cultural norms, values, beliefs or practices. As commonly accepted, cultural contents are fluid and heterogeneous, and may include several, even contradictory, interpretations.

Defining group membership in terms of recognition is an attempt to avoid homogeneous and stable conceptions of cultural content. In Table 1 presented above, no cultural contents are visible, but the question is solely of being recognized (being picked out) as a member of a cultural group. Cultural contents can be thought of as

${ }^{406}$ Kymlicka 1989, 162.

${ }^{407}$ Miller 2002a, 180, emphasis in the original. 
reasons for recognition, ${ }^{408}$ but this in no way fixes the reasons to any particular cultural norms, values, beliefs or practices. Importantly, if we accept that cultures are fluid and heterogeneous (and I see no reason for rejecting such view), the table may well be better off not incorporating any cultural contents or any particular actor's reasons for recognition (or non-recognition).

\section{Reasons for recognizing one a member}

In the context of actual cultural policies and accommodation of people's cultural differences, these reasons for recognizing (or not recognizing) $\mathrm{X}$ a member, however, come to play an important role. Taking just line one of the above table, and the most uncontroversial case of being a member of $\mathrm{M}$, several combinations regarding the reasons for recognition unfold.

Table 2

\begin{tabular}{|c|l|l|l|}
\hline & X & $\begin{array}{l}\text { Those (others) who } \\
\text { self-identify as M }\end{array}$ & $\begin{array}{l}\text { Those (others) not } \\
\text { identifying as M }\end{array}$ \\
\hline 1a & $\begin{array}{l}\text { Identifies as M, } \\
\text { And a }\end{array}$ & $\begin{array}{l}\text { Recognizes X as M, } \\
\text { because of a }\end{array}$ & $\begin{array}{l}\text { Recognizes X as M, } \\
\text { because of a }\end{array}$ \\
\hline 1b & $\begin{array}{l}\text { Identifies as M, } \\
\text { And a }\end{array}$ & $\begin{array}{l}\text { Recognizes X as M, } \\
\text { because of b }\end{array}$ & $\begin{array}{l}\text { Recognizes X as M, } \\
\text { because of c }\end{array}$ \\
\hline 1c & $\begin{array}{l}\text { Identifies as M, } \\
\text { And a }\end{array}$ & $\begin{array}{l}\text { Recognizes X as M, } \\
\text { because of a1 } \\
\text { (contradicting a) }\end{array}$ & $\begin{array}{l}\text { Recognizes X as M, } \\
\text { because of a2 } \\
\text { (contradicting a and a1) }\end{array}$ \\
\hline
\end{tabular}

On line $1 \mathrm{a}, \mathrm{X}$ is identified as a member of $\mathrm{M}$, say, because $\mathrm{X}$ follows a certain practice of prayer, and this operates as a reason for everyone's recognition of $X$ as a member of $M$. On line $1 b$, however, $\mathrm{X}$ identifies as $\mathrm{M}$ and follows a certain practice of prayer, but this is not the reason for anyone else's recognition of $\mathrm{X}$ as $\mathrm{M}$. Other self-identifying M's recognize $\mathrm{X}$ as a member not because of

${ }^{408}$ Raz and Margalit's criteria 6 in: Raz and Margalit 1994, 117. 
Part II Liberal Multiculturalism and Minority Rights in Practice

his praying practices, but, say, because he follows a certain type of diet - a very important cultural practice according to other selfidentifying Ms. For non-identifiers, however, X's praying or eating practices do not operate as reasons for recognition, but $\mathrm{X}$ is recognized as $\mathrm{M}$ because he wears certain types of garments. In this account, all parties have different conceptions of the relevant cultural content of the group $\mathrm{M}$, although they all agree on X's membership.

On line $1 \mathrm{c}$ - to complicate things further - the conceptions of cultural content and, thus, reasons for recognition are, not only different, but also contradictory. For X, his self-identification is still connected to him following a certain practice of prayer, but for other self-identifiers the reason for recognizing $\mathrm{X}$ as $\mathrm{M}$ may be, that they believe $X$ to follow a different practice of prayer, contrary to the practice $\mathrm{X}$ actually follows. Further, for non-identifiers, the reason for recognizing $\mathrm{X}$ as a member may be a belief contradicting both X's actual practice as well as the practice other self-identifiers believe $\mathrm{X}$ to follow. Needless to say, the combinations regarding the cultural content of $\mathrm{M}$ and thus the different reasons for recognizing $X$ as a member are multiplied, as the interpretations of cultural contents are heterogeneous - even among both the selfidentifiers as well as the non-identifiers.

\section{Reasons and contents of cultural policies}

The acknowledgement of the possibly different reasons for recognizing $\mathrm{X}$ as $\mathrm{M}$ become particularly interesting when connected to the view, presented earlier (1.2.), of cultural policies as incorporating, necessarily, certain contents of culture. Keeping this view in mind, the allocation of differentiated rights can now be examined, firstly, with respect to definitions of group membership and, secondly, with respect to the reasons for recognizing one as a member. Considering that, in contemporary circumstances of cultural diversity, membership in a cultural group (that is politically relevant) is often denoted by lines one, three, six and eight of Table 1 , it is fairly clear that cultural policies, allocated along the lines of group memberships, come to apply to many who identify 
themselves as $\mathrm{M}$ (lines one and three), but also to many who do not identify as $M$ (lines six and eight). At the same time, some, identifying as $\mathrm{M}$, are left out, being rejected as members by the wider political community (lines two and four). This may, already on its own, question the sensibility of allocating differentiated rights along the lines of group memberships.

Moreover, if we regard the nature of cultural policies as necessarily prioritizing certain conceptions of cultural content and the heterogeneity of the reasons behind recognizing one as a member, the allocation of such rights along the lines of group memberships becomes even more problematic. This, I believe, has to do with the fact that it is not only politically relevant membership that is decided by the larger political community (and thus, primarily by others), but that the contents of cultural policies are also inherently dependent on others and, more specifically, on the reasons that others have for recognizing someone as a member.

In order to illustrate this claim, let us consider two cases. In the first case, the wider political community recognizes $\mathrm{X}$ (let us now use abbreviation $\mathrm{S}$ ) as an $\mathrm{S}$ because they believe (among other reasons) that for $\mathrm{X}$, wearing certain headgear is an important and integral element of his culture, identity and well-being. For the sake of cultural sensitivity, the wider political community passes a law which allows all members of $\mathrm{S}$ to wear this particular headgear, even in circumstances where, say, road safety regulations or professional dress codes ban wearing such gear. Of course, it may be that for $\mathrm{X}$, identifying himself as $\mathrm{S}$, wearing such headgear is an integral element of his identity and well-being and that such cultural policy benefits him by giving him equal opportunities to travel on roads or to be chosen for certain professions. This, however, only applies to those identifiers who are recognized by the larger political community as being members of $\mathrm{S}$ (lines one and three). On the other hand, it may be that for X, identifying himself as $\mathrm{S}$, wearing such headgear is not essential - or he may even consider it detrimental - for his identity and well-being as an S. Being granted such a right, he may, nevertheless, feel pressurized or 
Part II Liberal Multiculturalism and Minority Rights in Practice

even obliged to take advantage of such a right, just to guarantee his position as being recognized as $\mathrm{S}$.

In the second case, the allocation of cultural policies along the lines of group memberships is not only disadvantaging some selfidentifiers but also some non-identifiers. In this case, the wider political community recognizes $\mathrm{X}$ as an $\mathrm{M}$ because (among other reasons) they believe that for $\mathrm{X}$, maintaining strict physical separation between the sexes is an important and integral element of her culture, identity and well-being. For the sake of cultural sensitivity, the wider political community adopts a policy of assigning same-sex physicians to all members of M. Of course, it may be that for $\mathrm{X}$, identifying herself as $\mathrm{M}$, maintaining strict physical separation between the sexes is an important and integral element of her identity, and such policy benefits her by guaranteeing that every time she is in need of medical treatment she is assigned a physician of the same sex as she is. This, however, only applies to those identifiers who are recognized by the larger political community as being members of M (lines one and three), and disadvantages those self-identifiers who, for one reason or other, are not recognized by the larger political community as members of $\mathrm{M}$ (lines two and four).

On the other hand, it may be that for X, identifying herself as $\mathrm{M}$, maintaining strict physical separation between the sexes is not an essential element of her identity. However, applying a 'better safe than sorry' -policy of assigning same-sex physicians to all members of $\mathrm{M}$, she is put in a queue to see a physician of the same sex as she is - even though, due to the shortage of physicians of the same sex as she is, this queue is much longer than the queue to see other physicians. Furthermore, it is not only the self-identifiers that may be disadvantaged by the policy, but also some non-identifiers. Say, a person $\mathrm{Y}$, who does not identify herself as $\mathrm{M}$, also finds the maintaining of strict physical separation between the sexes as an integral element of her identity - only for other reasons than being self-identified M. However, due to the shortage of physicians of the same sex as she is, her opportunity to be treated in accordance with her identity is now hampered by the policy of assigning same sex 
physicians to all members of M. Of course, it may be that, on occasions, this person $\mathrm{Y}$ is also assigned to same-sex physician when in need of medical treatment, but only if there are enough same-sex physicians around or, even more awkwardly, only if she is recognized by the larger political community as an $\mathrm{M}$, even if she does not herself wish to be thus recognized (lines six and eight).

\section{Individuated allocation}

Provided that the membership-based allocation would thus seem to fail in fully tracking the proper beneficiaries of differentiated rights and, at times, even create disadvantages to certain identifiers and non-identifiers alike, it is worth asking, according to which principles the differentiated rights should then be allocated. My intention, it should be emphasized, is not to give any conclusive guidance into the questions of allocation, as I believe that, like in the questions of justification, the proper answers can only be arrived at in context. Having said that, I do believe that some general remarks with respect to the appropriate allocation of differentiated rights can be made, emphasizing the importance of steering away from the group-based model of allocation described above, to a more individual centred approaches.

One of the alternatives to the membership-based allocation promoted by many liberal multiculturalists has been outlined by Brian Barry, who argues that differentiated rights should be allocated to people by virtue of their individual needs, and needs alone. According to Barry, group-differentiated rights create both under- as well as over-inclusive groups of people, thus failing to adequately track those whose disadvantages the rights in question are trying to rectify. By concentrating on individual needs, instead of group memberships, Barry argues for a more individual centred model of accommodation that would also seem to be able to escape some of the problems that a membership-based account would inevitably seem to create. ${ }^{409}$

\footnotetext{
${ }^{409}$ Barry 2001, esp. ch. 4; 2002.
} 
Part II Liberal Multiculturalism and Minority Rights in Practice

Whether such a need-based approach manages to provide a satisfactory account of allocation in all cases, and exactly what kind of allocation such an approach leads to, depends to a great extent on how such a need-based account is interpreted. With respect to the two cases described above, the need -based allocation, properly construed, would seem to provide a more adequate way of allocating the cultural policies in question. In the first case, one's eligibility to the exemption from wearing a particular kind of head gear in particular situations would not be based on the other's views on whether one was considered a member of the group $\mathrm{S}$ (lines one, three, six and eight), but rather on the assessment of whether the wearing of the head gear was such an important element of the person's identity that it would not be reasonable, as a default, to expect that person to abandon such head gear (incorporating people from possibly every line on the table). In the second case, the allocation of the same sex physicians would depend, not on other's recognition of $\mathrm{X}$ as an $\mathrm{M}$ (lines one, three, six and eight), but on whether the maintaining of strict physical separation was, indeed, an integral element of X's identity and well-being (again, incorporating people from possibly every line of the table above). ${ }^{410}$ The need-based account of allocation would thus seem to take better into account the discrepancies in different actors' recognition as well as reasons for recognizing someone as a member, as well as be better able to track those people whose disadvantages the policies in question were trying to rectify. Instead of the allocation of differentiated rights being dependent on one's membership in any particular cultural group (S), the allocation would now depend on whether one needed such differentiated rights (say, an exemption from certain safety helmet regulations) in order to be able to use certain kinds of transport or to be chosen to certain

\footnotetext{
${ }^{410}$ It should be noted that the need-based model of allocation presented here is substantively different from that of Brian Barry's, who tries to exclude cultural considerations from the realm of justifying differentiated treatment. My reasons for including such considerations have been discussed in more detail in Ch. 3.
} 
professions, without having to abandon that element of one's culture that one should not, as a default, be expected to abandon. ${ }^{411}$

Whereas I believe that the need-based allocation, as described above, does, in many cases, a better job in tracking the proper beneficiaries of those policies commonly viewed as groupdifferentiated, it is also important to note that not all cases of differentiated rights fall within this category. On the contrary, at times, the criticised criterion of group membership (as defined primarily by the recognition of others) or self-identification may well serve as more appropriate criteria of allocation. Special representation or preferential treatment policies may help illustrate this point. As Samuel Freeman has noted, the aim of special representation rights or preferential treatment is often to effect structural changes, and/or tackle the structural discrimination that the members a certain group encounter. ${ }^{412}$ The underrepresentation of certain ethnic, cultural or religious groups in positions of power may have long historical roots and perpetuate the current power structures that, on their behalf, discourage the members of minority groups from even aiming at such positions. Such underrepresentation may, at times, also be explained by structural discrimination or by deeply held prejudices that prevent people of particular minority groups from attaining such positions. In these cases, it may well be sensible to allocate differentiated rights (such as quotas) either in accordance with membership (should the underrepresentation be based purely on external discrimination or prejudice against members of certain groups), or - as may in most cases be appropriate - in accordance with people's selfidentifications, acknowledging also the ways in which people themselves view their identities and the disadvantages that these identities may bring along. Even in these cases, however, no default position of membership-based allocation should be utilized, as it is

\footnotetext{
${ }^{411}$ For a fuller analysis of the joint notion of equality of opportunity to combine one's cultural commitments with one's aspirations in public life, see Ch. 3, 3 .

${ }^{412}$ Freeman 2002, 26-27.
} 
Part II Liberal Multiculturalism and Minority Rights in Practice

only through a careful analysis of the causes of disadvantage, as well as the aims of the policies in question, that the appropriate principles of allocation can be arrived at.

\section{Conclusion on liberal multiculturalism, group membership, and allocation of differentiated rights}

In this chapter, I have focused on one very specific aspect of liberal multiculturalism - that of the idea of allocating differentiated rights along the lines of group memberships. The first part of this chapter focused on the ways in which people's memberships could be seen as important for both people's identities and well-being, as well as for the accommodation of people's cultural differences. I also showed some of the benefits that a recognition-based account of membership had over viewing group membership in terms of cultural contents, thus laying the ground for a specifically recognition-based account of politically relevant membership.

In the second section, I developed a more systematic analysis of the constitution of group membership, pointing out the possible discrepancies that different actors may have, both in recognizing one as a member of any particular group $\mathrm{M}$, as well as in reasons for such recognition. Building upon these discrepancies, I argued that the acknowledging of the heterogeneity and contestability of group membership should put pressure on qualifying the criteria according to which differentiated rights were allocated, as the membership-based criteria hardly succeeded in tracking the proper beneficiaries of such rights. As the politically relevant membership is often primarily dependent on the recognition of others, and as the contents of cultural policies are largely shaped by the reasons for such recognition, being a member of a cultural group could not be seen as a justifiable criterion for allocating such rights. Having shown some of the weaknesses of the membership-based criterion, I suggested that a more individuated criteria, based either on individual needs or self-identifications, may be in order, in order for the differentiated rights to adequately track their targets. 


\section{Chapter 5}

\section{Exit, identity, and membership}

In the previous chapter, I discussed some of the difficulties that the constitution of politically relevant membership in terms of recognition brought to the view of allocating differentiated rights along the lines of group memberships. Much of this discussion was conducted on a fairly abstract level, analysing the discrepancies both in different actors' recognition, as well as their reasons for recognizing one as a member of any particular group. Due to the possible discrepancies and the nature of differentiated rights as necessarily incorporating certain interpretations of cultural contents, it was argued that the default position of membership-based allocation should be abandoned, giving way to more individuated approaches that would take better into account the actual aims as well as reasons for having particular differentiated rights in practice.

In this chapter, I further develop and utilize the recognitionbased account of group membership, and discuss some of the implications that this account has on the debates on the right of exit. The right of exit, in discussions on multiculturalism, has become one of the default positions and primary safeguards of individuals against their own cultural groups, operating as the minimal (although by no means always sufficient) requirement for different kinds of groups to be allowed to govern their internal affairs. In order to understand the role of the right of exit and the possible limitations of this right, however, one needs to understand what it means to exit a cultural group, and what it means to belong to or to be a member of such groups. In this chapter, I attempt to shed some light on these questions by looking at the ways in which one's belonging, one's membership and one's exit from cultural or religious groups can be understood, and what kinds of implications these understandings have for multicultural policies and the role of the liberal state in accommodating people's cultural differences. 
Part II Liberal Multiculturalism and Minority Rights in Practice

This chapter proceeds as follows. I begin the first part, "Cultural groups and the right of exit-approach", by identifying those groups most problematic from the perspective of exit as identityconferring or constitutive groups, and work on some distinctions with respect to the senses in which one's belonging to such groups can be viewed as constitutive of one's identity. I then turn to a more detailed analysis of the ways in which one's membership in an identity-conferring or constitutive group can be conceptualized by looking at the ways in which different people, as well as institutionalized actors, may have different views on who, and on what grounds, counts as a group member. This section utilizes and further develops the recognition-based account of group membership already discussed in chapter 4 .

The second part of this chapter, "Exit and membership", discusses some of the implications that the different ways and levels of understanding one's belonging and one's membership have on the right of exit -debate. Firstly, I argue that there are several ways of understanding what it means to exit one's group, and that those signs, most commonly associated with exit, do not necessarily entail that the person exiting has also renounced her belonging - her deep most identity as an $M$. Secondly, I propose a way in which the liberal state could be more sensitive to the ways in which one's membership in a cultural group operates as one of the constitutive elements of one's identity by continuing to recognize those who have exited the contours of their group as group members, should they so wish to be recognized. This recognition, on behalf of the liberal state, not only provides certain external affirmation to people's identities as group members, but also comes closer to fulfilling the idea that the liberal state should not take a stand on the substantive requirements of group membership, but rather leave it to the group members themselves to decide what these requirements may be. At the end of this chapter, I respond to some of the objections that my suggestions for continued state recognition may bring, and further strengthen the case for a more individuated, yet culturally sensitive approach to accommodating people's cultural differences. 


\section{Cultural groups and the right of exit -approach}

In recent literature on multiculturalism, much has been written about the right of exit as the primary safeguard of individuals against their own cultural group. According to a variety of multiculturalists, cultural groups (including a variety of traditional, ingenious and religious minorities) should, as a default, be able to govern their internal affairs without the interference of the liberal state, or the imposition of the liberal norms and values of the majority. The group's right to govern its own affairs, however, needs to be balanced with the rights of individuals, including the rights of those who belong to the cultural group in question. For many, the balancing act between the right of the group to govern its own affairs and the rights of its individual members comes in the form of a right of exit - that is, the right of the individual to leave her group, should she no longer find it worthy of her allegiance.

The proponents of the right of exit do, of course, come in many shapes and forms. For some, it is enough that the individual possesses formal right of exit - that is, that she is not forced to remain a member of her cultural group. ${ }^{413}$ For others, the formal right of exit carries no weight, but the right of exit should also be realistic - that is, the individual should also have the necessary capacities to take advantage of this right and to leave, should she so want to. ${ }^{414}$ Further still, some argue that a meaningful right of exit requires, not only that the individual has the capacity to take

\footnotetext{
${ }^{413}$ Kukathas 1992; 2003, see also Ch. 2, 2.2. For a restatement of the role of the plain exit principle, see Kukathas 2012

${ }^{414}$ Most of the theorists of the right of exit fall within this category, arguing for certain conditions for the right of exit to be meaningful, although there certainly is disagreement on what these conditions might be. For some accounts on the preconditions for meaningful right of exit, see Galston 1995; Spinner-Halev 2000; 2005; Okin, 2002; Phillips 2007; Holzleithner 2012. Kukathas, too, insists on some preconditions in order for the right of exit to be substantive (Kukathas 1992a, 133-134), although these preconditions are substantively weaker than those of the theorists above.
} 
Part II Liberal Multiculturalism and Minority Rights in Practice

advantage of the right of exit, but that the costs of such exit are fairly distributed. ${ }^{415}$ Much, in the right of exit debate, has been written on what it means for a right of exit to be meaningful, and what it requires, with respect to the individual, the group, or the state, to guarantee this right to everyone.

Whereas the preconditions for a meaningful right of exit, and the costs of such exit, have been widely discussed, surprisingly little has been written about how to conceptualize cultural membership, and how one's understandings of cultural identity, membership and exit may affect the liberal state's responses to exit. In this section, I attempt to address these issues by looking at, firstly, the kinds of groups in relation to which the right of exit is most problematic, and, secondly, the kinds of difficulties that the constitution of group membership in such groups create for the understanding of the right of exit. Building upon the recognition-based theory of group membership (discussed in Ch 4), my focus is on the ways in which one's identification, along with the recognition of others, creates a very complex set of variables through which one's membership in a cultural group can be understood, and the difficulties that this complexity brings to the ways in which the liberal state recognizes people as members of cultural or religious groups.

\subsection{Conceptualizing cultural groups}

Daniel Weinstock (2005) identifies five axes according to which groups, commonly discussed in liberal political theory, may differ. According to Weinstock, groups differ, ${ }^{416}$ depending on (1) how

415 For an analysis on the different kinds of costs of exit, see e.g. Barry 2001, 149-154; For critique, e.g. Levy 2004, 335-336; Brochers 2012.

${ }^{416}$ Weinstock also posits certain common requirements for groups to be considered as politically relevant groups, such as the idea of having certain degree of self-consciousness: That is, the group members must, to some degree, recognize themselves as belonging to the group in question. (Weinstock 2005, 233-234) This requirement for the group members themselves to recognize their membership may, however, be too strong a requirement, as there may also be substantive disagreements on who are those members that should recognize their membership. However, as 
the membership in such groups is acquired (birth groups / groups of choice), (2) whether they have some specific goal or agenda (issue specific / general), (3) how strongly they affect their members' sense of their selves (identity-conferring / identity-neutral), (4) how they are governed (democratic / undemocratic), and (5) how broadly they affect or regulate their members' lives (broad / narrow). In Weinstock's view, those groups, most problematic from the liberal standpoint, are groups that regulate a broad spectrum of their members' lives (4), but that are undemocratically governed (5). ${ }^{417}$

\section{Broad undemocratic groups}

By broad, undemocratic groups, Weinstock refers to those groups that have a wide ranging influence on their members' lives (regulating, for example, their members' choices of marriage and family; modes of worship; occupational pursuits etc.), and that are undemocratically governed (for example, by excluding some members (often women or younger males) from the group's decision making procedures). A good example of such group would be The Old Order Amish ${ }^{418}$ who live in almost total isolation from the modern society with hierarchical rules of leadership, but the broad, undemocratic groups need not be thus isolated. For example, some religious groups with strong charismatic leaders could qualify as broad, undemocratic groups that live within the contours of the liberal society, as would certain immigrant groups, wishing to preserve their traditional customs of origin in their new surroundings. ${ }^{419}$

discussed in Ch. 4, 2.1., some acknowledgement of the existence of the group itself may be required in order for the group to constitute a sensible category to be talked of.

${ }^{417}$ Weinstock 2005, 233-236.

418 For an illustrative collection of articles on the Amish in the United States, see Kraybill 2003.

419 This is not to say that all immigrant groups that wish to preserve some of their customs of origin would be broad, undemocratic groups. However, should these customs conflict with the norms and values of the liberal 
Part II Liberal Multiculturalism and Minority Rights in Practice

Whereas the facts that a group is undemocratically governed, or that it has an effect on a wide array of its members' lives, do not, on their own, put the group in conflict with the basic liberal values of individual freedom, autonomy and equality, many of the cases where group practices are in violation of individual rights are, nevertheless, associated with these kinds of groups. As the feminist critique has forcefully argued, many of the controversial, even violent practices that involve women and children (including clitoridectomy, forced marriage, denial of education) are practices that are often based on the wider, patriarchal norms of the community, and the unequal status of women and men in the community. ${ }^{420}$ Being based on the wider norms of gender inequality, the women (or others affected) may not have a chance to change their courses of life within their community, as the decision making, and the governing of the community is reserved for the leaders - often, the elderly men of the community. Notably, it is precisely in these cases - where some members of the group are systematically mistreated, and where the internal power structure of the group gives little hope for change - that the right of exit becomes most important. Although groups should, as a default, be allowed to govern their own affairs, no individual should be obliged to become or remain a member of a group within which her basic rights are not recognized and within which she has no prospects of changing her situation.

It should, however, be noted that some of the main challenges associated with the right of exit do not stem from the authoritarian nature of the group or (at least directly) from the fact that the group engages in regulating a broad spectrum of its members' lives. The undemocratically governed groups can, no doubt, implement

society (for example, as in requiring women's total submission to their guardians), the group (or the fraction of the group adhering to such customs) may be described as broad and undemocratic For an interesting analysis of one such conflict with respect to a Yemeni family raising their children in Germany, see Fischer 2012.

${ }^{420}$ See e.g. Okin 1999; 2002; Benhabib 2002; 2004; Song 2007; Phillips 2007; 2010. 
measures that are designed to deter their members from leaving, but this, it should be emphasized, does not rise directly from the fact that the group is undemocratically governed. As long as the group (whether democratic or undemocratic), recognizes its members' right to leave, provides the minimal conditions ${ }^{421}$ for this right to be realistic, and refrains from preventing its members from taking advantage of this right, the right of exit may be secured, rregardless of whether the group in question is democratically or undemocratically governed.

Nor is it the case that exit from those groups that govern a broad array of their members' lives would necessarily be more difficult than exit from groups that only affect certain aspects of their members' lives. Whereas it certainly is the case that both cultural as well as religious groups often have a wide ranging influence on their members - so much so, that exiting these groups may be extremely difficult - these difficulties do not, as such, come from the nature of these groups as having a wide influence on their members' lives. Rather, the difficulties of exit, and the consequent challenges of securing the right of exit, often come from two sources: from the members' lack of information about alternative ways of life, or their incapacity, or even unwillingness, to leave their group. The broadness of the influence that a cultural or religious group has on its members may, no doubt, create certain concerns with respect to whether these conditions prevail. Provided that the members' lives are overwhelmingly influenced by their cultural or religious norms, it is, indeed, reasonable to ask, whether the members do, nevertheless, have sufficient information about alternative ways of life - and, even when they do, whether there exist such conditions that are required for the members to be able to abandon their current ways of living and to start anew. Much in the right of exit debate has been written on those conditions, provided both by the group as well as by the liberal society, that are required in order for the members to be able to leave their group and to

\footnotetext{
${ }^{421}$ Whatever these may be.
} 
Part II Liberal Multiculturalism and Minority Rights in Practice

adjust to a new life that is potentially very different from the one they have been accustomed to. ${ }^{422}$

Whereas my intention is, in no way, to try to diminish or play down the importance of discussing those conditions necessary for the members of cultural or religious groups to be able to exit the contours of their group, I do, nevertheless, think that an overt emphasis on these conditions ignores that aspect of cultural belonging that makes exit, and the right of exit -approach, ${ }^{423}$ perhaps most problematic. Whereas it is the case that, in order to be able to leave, the members must, firstly, have sufficient information about alternative ways of life, and, secondly, they must also be provided, either by the group or by the wider society, such conditions in which they can leave and start a new life outside their community, these conditions are not necessarily enough to make exit a feasible option. Even if these conditions were in place, exit might not be feasible, due to the ways in which one's belonging to a cultural or religious group often has a much deeper effect on its members and on their sense of themselves. That is, exit may not be

${ }^{422}$ These conditions, as Susan Okin has forcefully argued, may incorporate both material as well as psychological conditions necessary for a person to leave. (esp. Okin 2002) Whereas I agree with Okin that, in order for the right of exit to be meaningful, the group members must not be physically or mentally harmed, manipulated or forced to stay in their group, my focus, as will very shortly be elaborated, is somewhat different from Okin's. Whereas Okin highlights the negative psychological effects that groups may have on their members, I focus on the positive - that is, on the ways in which one's belonging to a cultural group operates as an integral element of one's identity, and how people would not want to renounce this identity due to the extreme psychological harm that this abandoning of one's identity would bring. This, it should be noted, irrespective of whether one's membership in a group also incorporates those negative elements highlighted by Okin.

${ }^{423}$ By the right of exit-approach, I simply refer to the view according to which the right of exit is viewed as the primary safeguard of individuals against their own group. The critique against the right of exit -approach is thus not necessarily a critique against the right of exit as such, merely against the primacy (or, in cases, sufficiency) of the right of exit in protecting individuals from their own group. 
Exit, Identity, and Membership

a feasible option from those groups that, in Weinstock's terms, are identity-conferring. ${ }^{424}$

\section{Identity-conferring groups}

By identity-conferring groups, I refer to those groups that are, to a smaller or larger extent, constitutive of their members' identity. ${ }^{425}$ That is, the belonging to these groups defines, to some substantive extent, the ways in which the members view themselves: who they really are and how they lead their lives. For the members of identity-conferring or constitutive groups, the being a member of such group (say, being a Muslim, Catholic, American Indian, Aboriginal) plays an important and integral role in who they themselves conceive to be, and the denial of such belonging would be unimaginable, resulting in such losses in their deep most identity that exit counts as no alternative, no matter how harsh or difficult their belonging to such group may otherwise make their lives to be.

The ways in which the belonging to an identity-conferring group affects their members may vary in several different senses. Firstly,

${ }^{424}$ Weinstock 2005, 235-238. It should be noted that the category of identity-conferring groups is analytically separate from the other categories in Weinstock's analysis. The identity-conferring groups are not always broad or undemocratic, nor do they necessarily fall within either particular axis of the birth vs. choice, or issue-specific vs. issue neutral groups. Whereas it often is the case, as Weinstock aptly notes, that those groups, most problematic for the right of exit-approach, are groups that are identity-conferring, broad and undemocratic and to which one belongs by birth, they do not necessarily need to be so.

425 The idea of groups (or communities) being constitutive of their members identity comes from the communitarian tradition that emphasized the social embeddedness of individuals against the allegedly disembodied and disembedded self of liberalism. (e.g. Sandel 1982; MacIntyre 1981; Taylor 1989; Walzer 1983) Whereas many of the classical communitarians emphasized the sharing of the communal values and traditions for the constitution of one's identity, the constitutive role of one's community, as will be seen, need not entail such sharing of any particular values or traditions - that is, of any particular contents of culture. 
Part II Liberal Multiculturalism and Minority Rights in Practice

the extent to which the members' identity is constituted by their belonging to the group in question differs from person to person. For some, being a Muslim or Catholic may indicate only a certain sense of affinity, something they have come accustomed to, but plays a fairly trivial role in defining what they conceive themselves to be, or how they come to conduct their lives. For others, being a Muslim or Catholic may be viewed as one of the most important things in their lives, and the idea of having to ever abandon such identity, or the ways in which this identity manifests itself in their lives, may be simply unthinkable. Nevertheless, the belonging to an identity-conferring group (as opposed to identity neutral groups) plays an important, constitutive role in the lives of its members and, in most cases, the members of identity-conferring groups would not want to abandon such groups, as they conceive the belonging to such group as an integral element of who they really are. ${ }^{426}$

Secondly, whereas the belonging to an identity-conferring group plays an integral role in the constitution of one's identity, it is not always clear, what exactly this belonging is, through which one's identity is constituted. To anticipate the discussions of the following section, the elements that the members of an identityconferring group view as integral for their identity as members, may differ, from relatively content neutral identification as a member of such group, to a very specific form of behaviour and participation in the workings of the group as a whole. For example,

\footnotetext{
${ }^{426}$ Some identity-conferring groups may, of course, also be groups from which some members would rather leave, but fail to do so, due to the ways in which their identity is inherently connected to the belonging to the group in question. Groups of relatively low social status (e.g. "inner-city working class") but also many cultural and religious groups can operate as identity-conferring groups from which some would also want to leave. My point here is thus not to claim that all identity-conferring groups would be the kinds of groups from which all members would not want to leave (nor that some identity-conferring groups would be more so than others), but simply to point out that, in many cases, people would not want to abandon their identity-conferring groups, due to the ways in which their belonging to such groups intertwines with their deep-most identity.
} 
for some, the importance of being, say, Catholic, may simply come from the person's self-identification as Catholic and her very personal relation to God, incorporating no need to participate or be recognized as Catholic by those around her. For others, to the contrary, the importance of being Catholic may also be manifested in very specific forms of behaviour, for example in the active participation in their congregation. The belonging to a Catholic community and the participation in the workings of one's congregation may, in these cases, be viewed as precisely that which the members cannot conceive of abandoning, as it is precisely this participation - together with others - that the members view as constitutive of who they really are: their deep most identity.

Thirdly, besides the different extents and contents of one's identification, it is not always clear how exactly one's belonging to an identity conferring group relates to one's membership in such a group - that is, what part does one's own identification as an M (be it Catholic, Muslim, Aboriginal etc.) play in defining who are conceived of as members and on what grounds. Provided that there are several different ways in which people can belong (and view their belonging) to an identity-conferring group, there might also be several different ways in which one's membership in such groups is understood. The different ways of understanding membership, and the criteria of defining membership, will also prompt the question of what it might actually mean to leave or exit such groups, and how one's understandings of group membership may affect one's understandings of, and one's responses to, exit. Before turning to the questions of membership and exit, however, I need to say something more specific about group membership, and the different ways and levels of understanding membership in identityconferring groups.

\subsection{Identity-conferring groups and group membership}

In my view, those groups, most problematic from the perspective of exit, are identity-conferring or constitutive groups. That is, those groups the belonging to which plays an important and integral element in the constitution of one's identity, and from which, in 
Part II Liberal Multiculturalism and Minority Rights in Practice

most cases, one would not want to, or even contemplate of leaving, due to the extreme losses that this would cause to one's deep most identity. The constitutive elements of identity-conferring groups may, of course, vary, as may the ways in which people view their belonging to the groups in question. Moreover, it may not always be the case that one's own views - one's self-identification - as a member of such group matches the generally accepted views of membership, and it is thus important to see, what role one's selfidentification as a member plays in the constitution of membership, and how group membership, from the political perspective, is constituted.

\section{Self-identification and group-membership}

One's own identification, as belonging to a certain group, provides one of the axes through which to start analysing membership in an identity-conferring group, but it is by no means the only axes through which one's membership can be understood. ${ }^{427}$ Nor is it always clear what one's own identification as a member of any particular group means. As Steven Lukes has noted, in all groups "[t]here will be identifiers, but there will also be quasi-identifiers, semi-identifiers, non-identifiers, ex-identifiers, multi-identifiers and anti-identifiers." 428 For my purposes, Lukes's observation is important in two senses. Firstly, it shows how one's identification with a group is not an either /or -affair, but can vary, even to an extent to which members can aim not to identify with the group of which they, nevertheless, are members. Secondly, and more importantly, Lukes's observation brings nicely forth the idea that one's membership in a group is not always, or solely, dependent on

427 I restrict my analysis to identity-conferring groups (and, more specifically, to cultural or religious groups), although I see no reason for why my analysis could not also be applied to other types of groups - that is, groups that one can identify oneself as a member, but that play a fairly trivial role in the constitution of one's identity.

${ }^{428}$ Lukes 2003, 142. 
one's own identification, but incorporates some other, yet undefined, criteria.

Going back to Weinstock's distinctions, it would seem that, in some cases, one's membership in a cultural or religious group could be relatively easily established. For example, the groups that one can only be born to (such as ethnic groups or certain religious groups) ${ }^{429}$ include those, and only those, who have been born into these groups and have not explicitly renounced their membership in such groups. ${ }^{430}$ Often (regardless of the method of joining), one's membership in a cultural or religious group could be fairly easily established by a simple tick in a box, or by looking at the official membership register of the group. But these kinds of simplified means of establishing group membership fail to be particularly interesting when one starts to think of questions about how members of such groups should be treated, how the group can treat its own members, or how to guarantee that no member is mistreated against her own will. More specifically, they fail to note that not everyone has the same view of who they view to be a member and, provided that membership in a group also affects people's behaviour (either as a member, or towards a member), they fail to be satisfactory in an analysis of those instances in which one's group membership really matters, but in which this membership is also contested, either by the person herself, or by those around her.

To clarify, my analysis of group membership starts from a presumption that being a member of a group affects, to a smaller or larger extent, people's behaviour. That is, the being a member of a group called "Catholics" operates as a reason for people to behave in certain manners, either as a Catholic or towards Catholic(s). For example, as a Catholic, I might go to church every Sunday, attend

\footnotetext{
${ }^{429}$ It should be noted that not all (or even the majority of) religious groups follow the criterion of birth in defining their memberships, and even those that do (such as Judaism) give some scope for those who want to become members to do so.

${ }^{430}$ That is, if such renouncing is even principally possible, as in the case of ethnic groups it might not be.
} 
Part II Liberal Multiculturalism and Minority Rights in Practice

confession and observe lent, and I might also expect (other) Catholics to do the same (and modify my behaviour towards them to fit these expectations). My behaviour towards other people is (partially) formed by my view of them as members of different groups, and the kinds of expectations I hold of them as members of such groups. ${ }^{431}$ In discussions on exit, the idea that people's membership in a particular group affects people's behaviour (either as a member or towards a member) is particularly clear. What is at stake, in the right of exit-debate, are precisely the questions of how people, as members of certain groups, are allowed to behave, how the liberal state should respond to the behaviour of certain members (whether those willing to stay or those willing to leave), and how a group (and, consequently, its members) are allowed to treat others, based on their membership of the same group.

\section{Recognition-based account of membership}

In chapter 4, I started to develop a recognition-based account of group membership that would take better into account the possible discrepancies in different actor's recognition, as well as reasons for recognizing one as a member of any particular group. For the sake of clarity, my analysis was restricted to three categories of actors, those of the person herself (X), the (other) self-identifiers, and the (other) non-identifiers, each category of which could have different views on whether they conceived the person $X$ to be a member of the group M. (see Table 1, Ch. 4, 2.1.) In this sub-section, this analysis is taken further by incorporating explicitly institutionalized actors into the possible structures of recognition.

Taken into account the institutionalized actors or official bodies of different groups, there would seem to be five different categories that need to be taken into account when analysing people's membership in any particular group. Firstly, that of X's selfidentification as a member of the group M. Secondly, that of (other)

${ }^{431}$ My analysis here is based on Appiah 2005, 65-71; see also Ch. 4, esp. 2.1 . 
self-identifiers' recognition ${ }^{432}$ of $\mathrm{X}$ as a member of the group M. And thirdly, that of the non-identifiers' recognition of $X$ as a member of the group M. The fourth and fifth categories, those of the institutionalized actors, do, to an extent, overlap with the first three categories, but should, for my purposes, be kept separate. Thus, fourthly, one also needs to consider whether the deciding body of the group (for example, the religious leaders or the tribal council) recognizes $\mathrm{X}$ as a member of the group $\mathrm{M}$. And fifthly, whether the state recognizes $\mathrm{X}$ as a member of the group $\mathrm{M}$. The Table 1 (Ch. 4, 2.1.), may thus be modified to incorporate five different categories, multiplying the possible combinations of recognition from eight to 32 .

Table 3

\begin{tabular}{|l|l|l|l|l|l|}
\hline & Actor 1. & Actor 2. & Actor 3. & Actor 4. & Actor 5. \\
\hline & $\mathbf{X}$ & $\begin{array}{l}\text { Those } \\
\text { (others) } \\
\text { self- } \\
\text { identifying } \\
\text { as M }\end{array}$ & $\begin{array}{l}\text { Those } \\
\text { (others) not } \\
\text { identifying } \\
\text { as M }\end{array}$ & $\begin{array}{l}\text { Deciding } \\
\text { body of M }\end{array}$ & $\begin{array}{l}\text { The liberal } \\
\text { state }\end{array}$ \\
\hline 1. & $\begin{array}{l}\text { Identifies } \\
\text { as M }\end{array}$ & $\begin{array}{l}\text { Recognizes } \\
\text { X as M }\end{array}$ & $\begin{array}{l}\text { Recognizes } \\
\text { X as M }\end{array}$ & $\begin{array}{l}\text { Recognizes } \\
\text { X as M }\end{array}$ & $\begin{array}{l}\text { Recognizes } \\
\text { X as M }\end{array}$ \\
\hline 2. & $\begin{array}{l}\text { Identifies } \\
\text { as M }\end{array}$ & $\begin{array}{l}\text { Recognizes } \\
\text { X as M }\end{array}$ & $\begin{array}{l}\text { Does not } \\
\text { recognize X } \\
\text { as M }\end{array}$ & $\begin{array}{l}\text { Recognizes } \\
\text { X as M }\end{array}$ & $\begin{array}{l}\text { Does not } \\
\text { recognize X } \\
\text { as M }\end{array}$ \\
\hline 3. & $\begin{array}{l}\text { Identifies } \\
\text { as M }\end{array}$ & $\begin{array}{l}\text { Does not } \\
\text { recognize X } \\
\text { as M }\end{array}$ & $\begin{array}{l}\text { Recognizes } \\
\text { X as M }\end{array}$ & $\begin{array}{l}\text { Does not } \\
\text { recognize X } \\
\text { as M }\end{array}$ & $\begin{array}{l}\text { Recognizes } \\
\text { X as M }\end{array}$ \\
\hline 4. & $\begin{array}{l}\text { Identifies } \\
\text { as M }\end{array}$ & $\begin{array}{l}\text { Does not } \\
\text { recognize X } \\
\text { as M }\end{array}$ & $\begin{array}{l}\text { Does not } \\
\text { recognize X } \\
\text { as M }\end{array}$ & $\begin{array}{l}\text { Does not } \\
\text { recognize X } \\
\text { as M }\end{array}$ & $\begin{array}{l}\text { Does not } \\
\text { recognize X } \\
\text { as M }\end{array}$ \\
\hline
\end{tabular}

432 The term recognition, in this context, refers simply to one's acknowledgement of someone (X) as a member of a particular group (M). (See also, Ch. 4, 1.3.) 
Part II Liberal Multiculturalism and Minority Rights in Practice

\begin{tabular}{|l|l|l|l|l|l|}
\hline $\begin{array}{l}\text { Etc. } \\
5-32\end{array}$ & $\ldots$ & $\ldots$ & $\ldots$ & $\ldots$ & $\ldots$ \\
\hline
\end{tabular}

What should be noted, as demonstrated by the table above, is that the answers to the question of whether X counts as a member of $\mathrm{M}$ may differ, depending on which category of actors one asks. ${ }^{433}$ The liberal state (category 5) may, for example, have very different views on whether $\mathrm{X}$ counts as a member than $\mathrm{X}$ herself, or the other self-identifiers, or the group's deciding body (as demonstrated by line 2).

Whereas the possible combinations of recognition extend to 32 , there may also be certain amount of inter-linkage, making certain combinations of recognition more common than others. For example, the deciding body of the group (category four) may at least try to follow the views of the self-identifiers (categories one and two) when deciding who to count as a member, and the state's response (category five) into whether it views someone a member may at least aim to track the views of the self-identifiers or the group itself (categories one, two and four). Problematically, however, the tracking of the views of self-identifiers (whether categories one and two in the case of the group body, or categories one, two and four in the case of the liberal state) may only be partial, due to the possible discrepancies between the views of these categories.

To illustrate this point, let us look at a widely discussed example of Santa Carla Pueblo v. Martinez (1978) that addressed the membership rights of the children of Julia Martinez (the respondent), a full member of the Santa Carla Pueblo, who had

\footnotetext{
${ }^{433}$ For the sake of simplicity, I have ignored the possible variations within different categories of actors. Most notably, categories two (selfidentifiers) and three (non-identifiers) are subject to internal variation in terms of how they conceive someone's membership in a particular group although, for the sake of simplicity, I treat these categories as if their views were homogeneous.
} 
married outside her tribe and whose children, although raised and living among the tribe, were not recognized as Pueblo due to the traditional rules of membership that passed tribal membership on paternal lines. ${ }^{434}$

In this case, as in most cases of cultural or religious groups, the default position rested on the right of the group to decide its own rules of membership, but these rules were not broad enough to include any particular identifier (category one) as a member. The majority of the self-identifying members (category two) or the leaders (category four), could refuse to recognize the membership of those who did not fit to the traditional membership criteria of the group (Martinez's children), even if they would identify themselves as Pueblo and, for all practical purposes, lived as members within the group. Problematically, from the perspective of the liberal state, these kinds of discrepancies render the attempts of the liberal state to track the self-identifiers themselves in questions of membership partial, as the self-identifiers (categories one, two and four) may have very different views on who counts as a member. In effect, the view of the state, although aiming to track the views of the selfidentifiers, often manages only to track the views of the deciding body (category four), which may, in itself, be in conflict with the views of any particular self-identifier (category one) or, in some cases, even with the majority of the identifiers (category two). In the case of Santa Carla Pueblo v. Martinez, the Supreme Court aligned with the views of the group leaders in upholding the traditional rules of membership against the views of particular selfidentifiers - that is, of Julia Martinez and her children.

\section{The rationale for state recognition}

Apart from the possible discrepancies between the views of the different actors with respect to who they conceive to be members (recognition of membership), there may also be very different

${ }^{434}$ Santa Clara Pueblo v. Martinez, 436 US 49 (1978). For discussion, see e.g. Resnik 1989; Shachar 2001, 18-20; Gutmann 2003, 44-47. 
Part II Liberal Multiculturalism and Minority Rights in Practice

views on the contents of this membership - that is, on what one conceives to be required for one to count as a member (reasons for recognition). For example, the reasons for the tribal council of the Pueblo (category four, partially overlapping with category two) to deny membership from certain self-identifiers (category one) may simply be a result of differing views on what they conceive to be required for one's membership. ${ }^{435}$ In the Martinez -case, the disputed requirements had to do with birth and the requirement of the male parent to be Pueblo, ${ }^{436}$ but, depending on the group in question, they may include various things, such as the following of certain codes of conduct, participation in certain rituals or subjecting oneself to the authority of the group leaders. Importantly, however, not all identifiers may agree with what the group leaders conceive to be required for group membership, thus creating a situation in which there is discrepancy, not only on the questions of who counts as a member, but also on what is required in order for one to count as a member.

Taken that the self-identifiers (as well as the deciding body of the group) may already have different views with respect to what is

\footnotetext{
${ }^{435}$ It should be noted that the differing views on what is required for one's membership do not, necessarily, lead to differing views on who is counted as a member, as the differing criteria may be accidentally congruent. See also: Vitikainen 2009. In the case of Santa Carla Pueblo v. Martinez, however, the views of the group leaders (supported by the Supreme Court) and Julia Martinez (the respondent) were contradictory, leading to different views on who was counted a member.

${ }^{436}$ What made the case of Santa Carla Pueblo v. Martinez especially difficult was that the membership criteria of the Pueblo was explicitly sexist, conflicting with the wider society's norms of gender equality. The main question addressed by the courts was thus whether the Pueblo had a right to continue imposing unequal membership criteria in order to preserve its cultural identity, rather than who had the right to decide about the used criteria. In order for the conflict between different views on membership to arise, however, these views need not be in conflict with gender equality or with any of the prevailing norms of the wider society they simply need to be in conflict with one another, thus producing different views on who counts as a member.
} 
required for one to count as a member, it should come as no surprise that the view of the state may not always coincide with the views of (all) self-identifiers. Often, in line with the liberal multicultural view, the state may - and even should - attempt to steer clear of defining any particular contents of membership, and leave it to the group itself to decide what these contents should be. ${ }^{437}$ For the liberal state, the rationale for recognizing one as a member may thus not be the same kind of rationale as for the selfidentifiers themselves, as it is not the business of the liberal state to decide what kind of criteria any particular group uses for its membership. Whereas the rationale for the self-identifiers to recognize someone a member may (although does not necessarily have to) include various substantive requirements (such as birth or parenthood, following of certain norms and customs etc.), for the state the rationale for recognizing one's membership should lie simply in the recognition of the self-identifiers itself, regardless of what rationale they themselves have for recognizing one's membership.

There are, however, certain difficulties to the idea of the state rationale as being based on the recognition of the self-identifiers itself (rather than on any substantive criteria). Firstly, as already indicated, it may be impossible for the state to track all selfidentifiers' views on who counts as a member, and, more often than not, the state may only track the views of the deciding body (category four), thus leaving some self-identifiers without due recognition as group members. Secondly, it must be questioned

${ }^{437}$ As Will Kymlicka has forcefully argued, the liberal state should not aim at promoting any particular cultural contents, including contents of membership, but rather leave it to the group members themselves to decide what they view as integral elements of their culture. (Kymlicka, 1989; 1995.) Ayelet Shachar makes a similar point, emphasizing the right of the identity groups (nomoi communities) to retain their right to decide their own memberships. (Shachar, 2001.) For Kymlicka's treatment of the Santa Carla Pueblo v. Martinez -case, and the upholding of the group's right to impose sexually discriminatory membership rules, see Kymlicka 1995, 163-170; for Shachar's treatment of the case: Shachar 2001, 18-20. 
Part II Liberal Multiculturalism and Minority Rights in Practice

whether the state can ever refrain from taking a stand on some of the substantive requirements of membership, even if this, according to many liberal multiculturalists, is precisely what the liberal state should do. On the most basic level, the liberal state, tracking the recognition of the deciding body of the group, also comes to affirm some of the substantive requirements that the deciding body of the group has for group membership. If, for example, the deciding body views one's membership to require one to follow certain codes of conduct or to participate in certain cultural or religious rituals, then - by tracking the recognition of the group leaders - the liberal state also ends up affirming (albeit indirectly) these requirements as the requirements for one's membership.

Further, as will be elaborated in more detail in the following section, it may also be that some of the state policies - including the right of exit - have an effect of reinforcing certain conceptions of what it means to be a member of a particular group, and what is required for one to be counted a member. By emphasizing the right of exit, and by promoting this right as one of the primary safeguards of group members against their own group, the state, in effect, comes to support the view according to which it is only by one's participation and by the following of the dominant norms and rules of the community that one is counted as a proper member of the group. By exiting their group, the group members are seen as renouncing their membership, having abandoned those requirements that the group leaders have given for one to be counted a member. Even if the recognition of the state attempts to stay clear from supporting any substantive contents of group membership, it would thus seem to fail, due to the discrepancies in the self-identifiers' recognition, as well as the ways in which certain state policies feed into certain conceptions of what is required for one to be a proper member of a cultural or religious group.

\footnotetext{
${ }^{438}$ For a parallel argument with respect to the ways in which certain kinds of minority rights always incorporate certain contents of culture, see Ch. 1, 2.2.; Ch. 4, 1.2.
} 
Exit, Identity, and Membership

\section{Exit and membership}

So far, I have discussed group membership in the light of how different people (self-identifiers, non-identifiers as well as institutionalized actors) may recognize (or not-recognize) someone as a group member, and how there may be different reasons for such recognition. This analysis highlighted some of the difficulties of defining group membership, especially in cases where the views of the different actors did not coincide, either with respect to one's status as a group member, or with respect to the contents of this membership, or both. Earlier on, I emphasized the role of the identity-conferring groups and the ways in which one's belonging to these groups could be viewed as constitutive of one's identity. I argued that one of the major problems for thinking about exit from these kinds of groups was that many of the self-identifiers would not want to, or could not even contemplate of, leaving such groups, due to the extreme losses that this would bring to their deep-most identity. In this part, I attempt to bring these discussions together and show how the debates on the right of exit may benefit from taking these discussions into account. My aims in this section are twofold. Firstly, I try to show how my analyses of belonging and group membership may affect our understandings of exit, and secondly, how they may affect the liberal state's responses to exit. Finally, I discuss some objections that could be leveled at my account and, by doing so, clarify the extent to which my account contributes to the discussions on exit, and to the questions of how to secure realistic rights of exit for everyone.

\subsection{Different types of exit}

Oonagh Reitman identifies three roles, or functions, of exit that have come to play an important part in discussions on multiculturalism. ${ }^{439}$ According to Reitman, the basic role of exit is to operate as an option for the minority members to leave their group and to enter the realm of the wider society. In its basic, and most passive, role, exit provides an avenue for the individual to

${ }^{439}$ Reitman 2005. 
Part II Liberal Multiculturalism and Minority Rights in Practice

leave, although it does not, in itself, guard individuals against their group or provide incentives for the group to change. ${ }^{440}$ Apart from its basic role, Reitman also identifies, and criticizes, two other roles of exit: those of protective and transformative roles. ${ }^{441}$ In its protective role, exit is supposed to safeguard individuals against oppression; in its transformative role, it is also supposed to provide the group incentives for change. Whereas the protective and transformative roles of exit have been utilized in attempts to justify non-intervention, Reitman argues that these two roles of exit often fail to perform the task they are supposed to perform. That is, they fail to provide sufficient protection for individuals against their own group, as well as incentives for the group to change in the face of (threats of) exit. ${ }^{442}$

Whereas Reitman's analysis of the three roles of exit is illuminating, it is also clear that these normative functions of exit are also dependent on how exit is induced, and how, in any particular case, exit is manifested. The normative implications of voluntary and non-voluntary exit are different, as are the upshots of different levels of (full/partial) exit. For my purposes, it is important to make a distinction between types of physical and psychological exit, and the ways in which the external and internal signs of exit help us understand the multiplicity of ways in which a person can exit her cultural or religious group.

\section{Membership and belonging}

In order to understand what it may mean to exit a cultural group, and what types of exit there may be, it is worth beginning with a brief clarification of the notions "belonging to a cultural group" and "membership in a cultural group". So far, I have talked of one's belonging to a cultural group in terms of how one, herself, would view one's relation to the group in question. In my account, one is seen to belong when one identifies oneself as an $M$ (be it Catholic,

\footnotetext{
${ }^{440}$ Reitman 2005, 190-191.

${ }^{441}$ Reitman 2005, 192-204

${ }^{442}$ Reitman 2005.
} 
Muslim, Aboriginal etc), and, in the case of identity-conferring groups, this sense of belonging operates as one of the constitutive elements of one's identity. This belonging, however, is seldom entirely internally produced, but may also require certain external affirmation. More often than not, one can only feel to belong if others (at least, some significant group of others) affirm one's belonging. This affirmation may come in the form of relatively content neutral recognition (I recognize you to be M), but it may also incorporate certain types of behaviour, such as one being allowed to participate in certain group practices together with others.

Although the notions of belonging to a cultural group (one's self-identification) and membership in such a group are closely related, these notions are not interchangeable. Whereas one's belonging is primarily dependent on one's own view of oneself (that, one must admit, is often dependent on the recognition of others) ${ }^{443}$ one's membership is never solely dependent on one's view of oneself, but is primarily constituted by the recognition of others. Notably, different people (as well as institutionalized actors) may have different views on who counts as a member, and there may not be any uncontested, objective criteria for defining who, in any particular instances, counts as a member, and who does not. ${ }^{444}$

\footnotetext{
443 The importance of external recognition for one's views of oneself has been discussed extensively for example by Axel Honneth $(1997 ; 2001)$ and Charles Taylor (1994). However, whereas these theorists of recognition often emphasize the importance of positive recognition to people's self-respect and self-esteem, the notion of recognition used in this essay is relatively value neutral. To recognize someone as an $\mathrm{M}$ is simply to acknowledge that person's status as a member of a group $\mathrm{M}$, without making any value judgments about the nature of $\mathrm{M}$. As will be seen, the effect of such recognition may also be positive (in terms of providing external affirmation for one's status as a group member) although, contrary to Honneth's and Taylor's views, this recognition involves no value-judgments about the thing recognized (M). For alternative conceptions of recognition, see e.g. Kenny 2004: ch. 8; Jones 2006.

${ }^{444}$ As discussed in section 1.2. above, it may be possible to impose some objective criteria of membership (such as birth or official registration) to
} 
Part II Liberal Multiculturalism and Minority Rights in Practice

Exit as leaving group influence vs. exit as renouncing belonging With respect to what it might mean to exit one's cultural group, both of these perspectives - that of one's sense of belonging and that of one's membership dependent on the views of others - need to be kept in mind. From the perspective of one's belonging, exit can, in its most extreme form, be understood in terms of one's renouncing one's belonging to the group in question. ${ }^{445}$ This renouncing may be manifested in a variety of ways, but the idea, from the perspective of the person exiting, is the same: that of abandoning that sense of belonging to which one has grown accustomed to. In the case of identity-conferring groups, however, this renouncing of one's belonging may not be a feasible option due to the ways in which this belonging affects one's sense of oneself. To renounce one's belonging would be to renounce oneself, one's deep-most identity - something not many (if any) of us would be willing to do.

In the right of exit -discussions, however, exit is often understood in very different (and more concrete) ways. To exit a cultural or religious group is often understood in terms of leaving behind the influence that the group has on its members. This leaving may include (1) concrete physical separation from the group in question (especially highlighted in those groups that have isolated themselves from the rest of society, such as the Amish and Hutterites), but it does not necessarily need to involve such physical separation. In many cases (in fact, in most cases of cultural or religious communities that reside within the larger liberal society), exit may simply mean (2) the leaving behind those cultural or religious practices and ways of life that are characteristic of the

some groups, but these criteria hardly manage to escape the kinds of contestations that make questions of membership, in the political context, most interesting. For further difficulties of using objective lists in defining group memberships, see e.g. Killmister 2011.

445 As highlighted by Lukes's observation about different types of identification, this renouncing may also be partial. Lukes 2003, 142, see section 1.2. above. 
group in question. It may also mean (3) the renouncing of (some of) the dominant norms and rules of the community, or (4) the denial of the group authority (group jurisdiction), without having to physically separate oneself from the community in question. ${ }^{446}$

It should be noted that, although analytically separate, these ways of understanding exit (physical separation, lack of participation, renouncing of the dominant rules and norms, and denial of group authority) often go hand in hand. The renouncing of the dominant rules or norms of the community, for example, may lead to a situation in which the person in question is no longer allowed to participate in the group practices or even be able to associate with those willing to affirm such norms and practices (thus akin to physical separation). Depending on the group in question, the other group members (paralleling categories two and four of the previous section) may impose much stronger forms of separation on the person in question, making her exit much more robust than it would otherwise be. In these cases, the person's voluntary exit (for example, in terms of the renouncing of the dominant rules and norms of the community), may turn out to be involuntary (in terms of being forced to separate oneself from the group). ${ }^{447}$ Importantly, however, none of the above ways of exit necessarily entail that the person has also renounced her belonging to the group in question: her sense of herself as Catholic, as Muslim, as Aboriginal etc. Despite all the external signs, the person

\footnotetext{
${ }^{446}$ These four examples of exiting one's cultural group are, by no means, meant to be exhaustive. They do, nevertheless, demonstrate the multiplicity of ways in which one can be seen to exit one's cultural community, incorporating also different forms of exit in relation to whether one's exit is primarily from one's social connections, or from the dominant cultural contents (norms and values) of the group in question. For further analysis on these two elements of exit, see Borchers 2012.

${ }^{447}$ Whereas there may well be some limitations into the ways in which groups can enforce the expulsion of their members, the involuntary exists may also be viewed as the other side of the coin of the freedom to refuse association (Barry 2001, 150). Whereas individuals should be free to refuse association by exit, so should the other group members be free to refuse association with the individual in question.
} 
Part II Liberal Multiculturalism and Minority Rights in Practice

may still feel like they belong to the group in question, and would not, under any circumstances, be willing to abandon this sense of belonging: her deep most identity as an $M$.

Before going further, it should be clarified that my intention is not to say that exit, in the sense in which exit is commonly understood (as leaving behind the group influence) would not be problematic due to it not necessarily entailing one's renouncing of one's belonging, or one's deep-most identity. Quite the contrary, those aspects of one's belonging that can be viewed as integral for the constitution of one's identity may include both physical as well as psychological closeness with the group in question, including active participation in group life together with others. In these cases, exit (in the senses in which it is commonly understood) might not be feasible, due to it involving the abandoning of those aspects of one's belonging that one views as integral for one's identity.

Nor is my intention to say that the only problems associated with exit would be those associated with one's identity as an M. Quite clearly, regardless of whether one's belonging operates as one of the integral elements of one's identity, exit may be problematic, due to, for example, one's economic dependence on the group (or some of its members), or the lack of alternative places to go to. As my focus, in this chapter, is on those elements and difficulties of exit that are brought about by the identity-conferring features of cultural groups, however, I will largely leave aside the other possible difficulties of exit, brought about by other considerations than those connected to one's identity as an $M$.

\subsection{Reducing the costs of exit by state recognition}

Taking into account the different ways in which one's belonging and one's membership in a cultural group may be understood, also helps to understand some of the ways in which people can be seen to exit their cultural groups. The main distinction, made in this chapter, has been the distinction between 'exit as renouncing one's belonging' and 'exit as leaving behind the group influence' (or exit, as commonly understood), and the acknowledgement that these two 
ways of exiting a cultural group do not necessarily (although they certainly can) go together. Keeping this distinction in mind, it is time to turn to look at the ways in which the analyses of one's belonging, membership and exit can be utilized in the right of exitdebates, especially with respect to the liberal state's responses to issues on exit.

As indicated, many of the difficulties - and costs - of one's exit from a cultural or religious group can be traced back to the fact that people do not want to, or cannot even contemplate of abandoning those senses of belonging that they view as central to their identity. The costs of abandoning that through which one's identity is constituted would simply be too high, and the guarantees of the right of exit would be meaningless. This is especially problematic with respect to those identity-conferring groups that mistreat some of their members, but to which those mistreated have a strong sense of affinity and would not even contemplate leaving. As Weinstock aptly points out, "exit rights do nothing for the person who feels she has no choice but to continue adhering to a group that treats her badly. Her preference would be to continue to affirm her membership while not having to put up with the poor treatment."

Whereas I agree with Weinstock's observation that the right of exit might do nothing for those to whom the belonging to her cultural group operates as an integral element of her identity, I also think that this observation is somewhat typical of the ways in which the debates on exit often ignore the different types of exit, and the ways in which the variations on exit and on one's membership could be used in order to ease the costs of those for whom staying with the group proves too much. As noted by Weinstock, what many of the members of identity-conferring groups would like to do - and what they often cannot conceive not to do - is to affirm their membership in such groups. This want to affirm one's membership links inherent in one's want to belong, and to one's view of oneself as an $M$ (be it Catholic, Muslim, Aboriginal etc.). However, one's belonging may not be solely dependent on the view

${ }^{448}$ Weinstock 2005, 238. 
Part II Liberal Multiculturalism and Minority Rights in Practice

of the person herself, but also on the views of others, whose affirmation of one's membership may well play an important role in the ways in which the person is able to feel to belong - that is, to self-identify herself as an M. From the perspective of the liberal state, this linkage between one's belonging (self-identification) and external affirmation (recognition of others) should, I believe, be of special importance, bearing also upon the state's responses to exit, and to the recognition of those who either have, or are contemplating leaving the contours of their group.

In order to see how this linkage may affect the liberal state's responses to exit, let us return briefly to the ways in which the liberal state is said to track the recognition of the group itself on issues of group membership. As already indicated, it is often held that the state should stay clear of defining any substantive criteria of membership and, rather, leave it to the group to decide who they count as members and what is required for such membership. Due to the discrepancies in different actors' recognition, however, it is not possible for the liberal state to track the recognition of all those who self-identify themselves as members, but the state needs to take a stand on which of the self-identifying members it chooses to listen to - that is, whose views of group membership it decides to track. To put it bluntly, in order for the liberal state to track the recognition of the group itself in questions of membership, the state already needs to have some view of who are those members that constitute the group whose views it is tracking. Interestingly, in trying to track the views of the group itself, the state often comes to track the views of those most powerful in the group in question the group leaders or the deciding body - and, consequently, refuses to affirm the membership of those who are no longer counted as group members by the deciding body of the group. ${ }^{449}$

${ }^{449}$ The case of Santa Carla Pueblo v. Martinez provides a good example of this kind of tracking on issues of membership, although it is clear that the instances of the state following the views of those most powerful within cultural groups are not restricted to issues of membership, but constitute a far wider pattern of biased state recognition. As particularly 
For the debates on exit, this tracking of the views of the group leaders or the deciding body (category four of the previous section) have interesting consequences. Firstly, by tracking the recognition of the group leaders, the liberal state does, in effect, also come to affirm those criteria that the group leaders have for group membership. Even if the state would not explicitly confirm the substantive criteria decided by the group leaders, in recognizing the authority of the leaders, the state in effect also gives certain legitimation to its decisions (including decisions on the criteria of membership).

Secondly, it would also seem that without making the distinction between exit in terms of leaving the influence of the group (or, exit as commonly understood) and exit in terms of renouncing one's belonging, the state may enforce much stronger forms of separation on those who have decided to leave the contours of their group than would be necessary. Without this distinction, the state, tracking the views of the group leaders, views those who have decided to leave the contours of their group as having also renounced their membership in such groups, thus further feeding into the dominant view of what "proper" membership in any particular group entails. In the eyes of the liberal state, those who choose to take advantage of exit (as commonly understood) are seen, not only as leaving the influence of their group, but also as having renounced their belonging to such groups. Not only does the state thus track (and confirm) the views of the group leaders as appropriate criteria for group membership, it also encourages the view of exit as far more drastic and complete than it would need to be. Those who have left behind the group influence (be it in terms of physical separation, lack of participation, renouncing of the dominant rules and norms,

the feminist critique has pointed out, it is often the group leaders (usually, the elderly men of communities) that are given priority in articulating the "authentic" views of their culture, including the criteria of membership, thus side-lining the views of those who may object to these traditional interpretations. See e.g. Okin 1999; Benhabib 2002; Song 2007; Phillips 2010. Some of the problems relating to this bias in criminal courts will be discussed in Ch. 6. 
Part II Liberal Multiculturalism and Minority Rights in Practice

or the denial of group authority) are no longer conceived of as full members of that group, but as dissenters who have renounced their membership, and who, in the eyes of the liberal state, no longer count as "proper" members of the group.

What should be noted, is that this response of the liberal state to view those who have decided leave the contours of their group as non- or ex-members may, in itself, make the prospect of exit (as commonly understood) even harder for the group members to take advantage of. For a person to whom being an M (Catholic, Muslim, Aboriginal etc.) operates as one of the integral elements of her identity, leaving behind the influence of her group may count as even less of an option, should this entail, not only the rejection of the group leaders (category four) or other group members (category two), but also the rejection, or lack of recognition, of the liberal state (category five). Whereas there is not much the liberal state can do, should the group (whether its leaders or the majority of the selfidentifiers) no longer wish to recognize one as a member, what it can, and perhaps should, do is to give due recognition to those who have decided to leave the contours of their group, but who, nevertheless, still wish to affirm their membership in the group in question. Instead of viewing those who have left the influence of their group as non- or ex-members, the liberal state could, at the very least, still recognize them as members and, by doing so, reduce some of the costs of leaving the influence of one's group by affirming the belonging of those who, despite having left the contours of their group, still deeply identify themselves as belonging to the group in question.

\subsection{Objections}

My proposal that in cases where a person has decided to leave the influence of her group without, nevertheless, renouncing her belonging to that group (her identity as an M), the liberal state should carry on recognizing her as a member of the group, is bound to encounter several objections. In this section, I outline and respond to three of these: those of the argument from insufficiency, 
the problem of the source of recognition, and the argument against external interference.

\section{Insufficiency}

From the perspective of those who worry about the realistic rights of exit and the conditions required for such rights, two objections ensue. Firstly, it may be objected that my call for the liberal state to continue recognizing those who have left the influence of their group as group members (should they so wish to be recognized), is insufficient in providing those conditions in which the formal rights of exit become realistic. From a practical point of view, it is more important that the members of cultural groups are provided information about the life outside their group, and that they also have both material as well as psychological means for accessing this life outside their group. The continued state recognition hardly provides for these conditions, but may, on the contrary, discourage people from leaving, as it encourages the impression that it is never possible to fully exit one's cultural group (as demonstrated by the continued state recognition).

Whereas I completely agree that the continued state recognition does not, on its own, provide sufficient conditions for the exit to be realistic, I do not think that the insufficiency of state recognition takes away the important role that this recognition can, nevertheless, play in easing the costs of exit and, consequently, in making exit more realistic. Instead of indicating that it is never possible to fully exit one's cultural group, the continued state recognition aims to show that it is, indeed, possible to leave the contours of one's group without having to abandon one's deep most identity as a member of such group. My argument for continued state recognition, it should be emphasized, is thus a qualified one. By no means do I claim that the liberal state should continue to recognize all those who have decided to leave the influence of their group as group members, but rather, that those who have, and who still wish to affirm their belonging - their deep most identity as an M - should be thus recognized. Conversely, should a person, having left the contours of her group, no longer wish to affirm her 
Part II Liberal Multiculturalism and Minority Rights in Practice

belonging, she should also not be obliged to do so. Importantly, by tracking the self-identification of those who have left the contours of their group (rather than the recognition of the group leaders), the liberal state affirms both possibilities: those of exiting one's cultural group by also renouncing one's belonging, as well as of exiting the influence of one's group without renouncing that aspect of one's identity one may be most strongly connected to - one's deep-most identity as an $M$.

Secondly, it could be objected that the continued state recognition, although fine in principle, fails to do much in practice, as for most people, their identity is inherently tied up with their living with the group in question and with their participating in the group activities together with others. For most people (most problematic from the perspective of exit), it is precisely this aspect of sharing one's life with other group members that one cannot contemplate of abandoning, as it is precisely this participation that one views as central to one's identity. The recognition of those who have decided to leave the contours of their group thus fails to give enough to those whose identity is inherently connected to the group practices and to living with the group in question, as it is precisely this aspect of one's identity that one cannot contemplate of leaving.

Although I acknowledge that the continued state recognition of those who have, already, left the contours of their group may not lower the burdens of exit enough to make exit (as commonly understood) a realistic option for all, I do, nevertheless, think that the continued state recognition can operate as one of the ways in which the burdens of exit can be lowered. For someone who still wishes to stay with her group and who still wishes to live the kinds of life characteristic of her group together with others, there will, no doubt, be costs, should she decide to leave the contours of her group. ${ }^{450}$ These costs could, however, be reduced (sometimes to the extent of tipping the balance between staying and leaving) by the

${ }^{450}$ As Brian Barry has noted, some costs of leaving a cultural group may be both inevitable as well as impossible to compensate. Barry 2001, 149154. 
state continuing to recognize her as a group member and by continuing also to treat her as one, should her membership entail certain benefits or privileges that she can enjoy, despite having left the influence of her group. ${ }^{451}$ The continued state recognition would provide, not only certain affirmation for her sense of herself as an $\mathrm{M}$, but also enable her to live as close to the kind of life she would want to live, should she have remained with her group. Whereas the continued state recognition is far from giving any absolute guarantees for a meaningful right of exit, it does, nevertheless, make exit (as commonly understood) more feasible for those to whom identifying oneself as an M (Catholic, Muslim, Aboriginal etc.) is an inherent element of their identity.

\footnotetext{
${ }^{451}$ By benefits and privileges I refer to those measures that the state may have adopted in order to accommodate the differing values, world views and ways of life of cultural or religious minorities - for example, certain levels of self-determination, exemptions from the dominant rules and norms of society, preferential treatment policies, or financial benefits, aiming to enable the group members to live in accordance with their own culture without being unduly disadvantaged by the infrastructure that has been organized in accordance with the norms and values of the majority. Undoubtedly, the benefits of those who have left the influence of their group may not be quite as extensive, as some of these benefits can only be enjoyed collectively, but they may, nevertheless, include measures that are not dependent on the beneficiary's relation to other group members (most notably, individually exercised group rights such as exemptions, or eligibility for membership-based benefits such as housing, health care or educational opportunities, including membership-based quotas). A more thorough analysis of the kinds of measures (minority rights) that those who have left the contours of their group should be entitled to, as well as the extents to which the liberal state may enforce these rights is beyond the scope of this chapter, as is the question of the justifiability of such membership-based measures in the first place. For my purposes, it suffices to say that, should there be such benefits, allocated to people on the basis of their group membership, then one's leaving the influence of her group should not, necessarily, take these benefits away.
} 
Part II Liberal Multiculturalism and Minority Rights in Practice

\section{Source of recognition}

A slightly different objection, with respect to my proposal for continued state recognition, focuses on the kinds of recognition conceived as especially important for one's identity. As many theorists of recognition have noted, recognizing one as an $M$ (be it Catholic, Muslim, Aboriginal, but also female, black or gay) may operate as an important source of one's self-respect and selfesteem, with mis-recognition or lack of recognition operating to an opposite effect. ${ }^{452}$ Although my usage of the term "recognition" is somewhat different from these traditional notions of recognition, ${ }^{453}$ it is clear that the external affirmation of one's membership - of one's status as an $\mathrm{M}$ - can nevertheless play an important role in one's understanding of one's belonging - of one's most profound identity as an M. As already mentioned, one's self-identification as an $\mathrm{M}$ is seldom entirely internally produced, but may require certain external affirmation - that is, recognition by others as a member of the group $\mathrm{M}$.

There may, however, be objections raised that my call for continued state recognition fails to acknowledge the kind of recognition most important to the affirmation of one's identity as an M. For those to whom the belonging to a cultural group means the most, it is often of secondary importance whether the liberal state recognizes their status as a group member, if the group itself - the other group members - refuses to recognize such membership. For most, it is the recognition of those one cares most about (other group members) that is of the utmost importance, and the recognition by the state can only operate, at the most, as a poor substitute for such recognition.

Again, I need to acknowledge that there is some weight in this objection, although I do not think that it makes my call for the continued state recognition redundant. Whereas it often is the case that the most important affirmation of one's identity comes from those one feels the strongest relation to - that is, other group

${ }^{452}$ Honneth 1997; 2001; Taylor 1994.

${ }^{453}$ See note 443, p. 289 above; see also: Ch. 4, 1.3. 
members - one should not underestimate the importance and influence that the recognition on behalf of the state may have. As many recognition theorists have pointed out, one of the most pressing issues for many oppressed or discriminated against groups has been precisely the acquiring of due recognition from the state, and the acknowledgement of the group members' worth as M's (as gays, as women, as blacks) instead of lacking recognition or being recognized despite being an $\mathrm{M}^{454}$ Whereas there is no denying the importance of the recognition of one's peers for one's sense of oneself, there is not much that the state can do to convince the other group members to recognize one as a member. However, by continuing to recognize the person who has left the contours of her group as a member (should she so want to be recognized), and by continuing to also treat her as a member (insofar as feasible), this person does acquire some recognition as a group member, and is also provided with some tools for affirming her identity as an M. Provided that one's belonging, and one's deepest sense of oneself, is often dependent on some external affirmation, it is essential that at least the state provides this affirmation, even if the other group members would not.

\section{External interference}

The two first objections, those of insufficiency and the source of recognition, point out some important limitations of the continued state recognition in lowering the burdens of exit (as commonly understood) from identity-conferring or constitutive groups. My call for the liberal state to continue recognizing those who have exited the contours of their group without renouncing their belonging as group members should not thus be thought of as a grand solution to the problems associated with the realistic rights of exit. Quite the contrary, the continued state recognition operates

\footnotetext{
${ }^{454}$ On the construction of positive, collective identities through positive recognition as an $M$, see e.g. Appiah 2005, 108-109. For an illuminating critique of the strategy of claiming recognition as $M$ instead of claiming recognition and $M$, see Moody-Adams 2006.
} 
Part II Liberal Multiculturalism and Minority Rights in Practice

only as one of the means through which the burdens of leaving the influence of one's group can be lowered, but gives no guarantees for realistic rights of exit. Contrary to the two first objections that manage only to establish certain limitations of my suggestion, the third objection, if successful, may lead to rejecting my proposal of continued state recognition altogether. According to this objection, the continued state recognition diminishes the group's right to decide about its own membership and constitutes an illegitimate external interference into the group's internal affairs.

This objection - let us call it the argument against external interference - can be best understood from the perspective of those who argue for the right of the cultural groups to decide their own memberships, complemented by the requirement of the liberal state not to interfere in these decisions. To recall, the rationale for the liberal state to recognize $X$ as a group member was - and also should be - distinguished from the rationale that the group itself (whether the deciding body or the self-identifiers) could have as criteria of membership. In order to steer clear from defining any substantive criteria of membership, the state should simply track the recognition of the group itself, and to recognize as group members those, and only those, who have been accepted as group members by the group itself (see 1.2. above). By continuing to recognize those who have exited the contours of their group as group members, the objection goes, the liberal state interferes in the internal affairs of the group, imposing a view of membership that is not accepted by the group itself.

In response to this objection, two things need to be said. Firstly, let us presume for the time being that the continued state recognition does, indeed, constitute interference to the group's internal affairs. Should this be the case, it is worth imagining what this interference would look like. Those who would have exited the contours of their cultural group (exit as commonly understood) would continue to be recognized by the liberal state as group members (should they so wish to be recognized). Due to state recognition, they would also be entitled to many of the group-based 
benefits (e.g. preferential treatment, legal assistance, exemptions) ${ }^{455}$ enabling them to live as close to the kind of life they would wish to live should they still have been able to stay within the contours of their group. The continued state recognition does not, however, in any way force the other group members to recognize the dissenter's membership, nor can it force the other group members to treat the dissenter as a member of their group. On the contrary, the continued state recognition is compatible with the group itself (whether its leading body or other self-identifiers) having the right to expel dissenters from its midst and to shun those they no longer view as belonging to the group in question. Keeping this in mind, the continued state recognition, should it constitute an interference to the group's internal affairs, is very minimal, having more of an effect on the person who has decided to leave the contours of her group than on those who have decided to stay.

Secondly, one must question the claim that my proposal for continued state recognition would constitute an illegitimate interference into the internal affairs of the group. As already indicated, in order for the liberal state to respect the group's right to decide its own membership, the state needs to steer away from trying to define any substantive criteria of membership and, rather, attempt to track the recognition of the group itself in issues of group membership. However, in order to track the recognition of the group itself in issues of membership, the state already needs to have some conception of who constitutes that group, the recognition of which it is supposed to be tracking. Often, this problem is solved by the state tracking the recognition of the group leaders or the deciding body of the group (as demonstrated by Santa Carla Pueblo v. Martinez). However, by tracking the recognition of the group leaders or the deciding body, the state can no longer be seen as staying clear from the issues of defining membership, as it has already acknowledged the group leaders as the legitimate spoke persons of the group and, by doing so, also given certain

455 The list of such benefits would naturally depend on the group in question and on the existing membership benefits for the group. 
legitimation to those criteria that the group leaders have for group membership.

The tracking of the recognition of group leaders or the deciding body of the group is not, however, the only way for the liberal state to attempt to respect the group's right to decide its own membership. ${ }^{456}$ By tracking the recognition of the group leaders (or, indeed, any fraction of the group), the liberal state does, in effect, interfere in the internal affairs of the group by giving its support to those most powerful within the group. As already demonstrated, the tracking of the group's own recognition on issues of group membership is bound to encounter several difficulties as the recognition of different actors (be they the group leaders, majority of self-identifiers, or any individual self-identifier (X)) may be very different with respect to who they conceive to be members. The alternative approach, that of tracking people's self-identifications, on the contrary, would seem to be able to take these discrepancies into account and also come closer to fulfilling the requirement of the liberal state to stay clear from defining any substantive requirements of membership. Whereas the self-identifiers themselves (be they those who are staying firmly within the contours of their group, or those who have decided to exit (as commonly understood) from their group) may have very different views on who counts as a member of the group, these discrepancies no longer carry weight, as it is not the recognition of the selfidentifiers that the state attempts to track, but the self-identification itself. The tracking of people's self-identifications rather than any particular recognition may, no doubt, lead the liberal state to recognize very different groups of people as group members (as demonstrated by the continued state recognition of those who have left the contours of their group), but it would also seem to do a

${ }^{456}$ Indeed, my intention is not to argue against the view according to which the liberal state should steer away from defining any substantive criteria of membership and let the group itself define its own membership, but rather to show that an alternative approach, that of tracking people's self-identifications, may do a better job in this. 
better job in allowing the group itself decide its own membership by resisting to give support to any particular fraction's views on who counts and who does not count as a group member.

\section{Conclusion on exit, identity, and membership}

In this chapter, I have focused on the difficulties that one's identification with a cultural or religious group may bring for thinking about exit from such groups. I started by analysing the different ways and extents to which one's belonging to a cultural group could be understood before turning into the possible linkages between one's self-identification as belonging to the group in question and one's membership in such group. My analysis of the different ways and extents of one's belonging on the one hand, and of one's membership on the other was then used to analyze the different ways in which exit from a cultural group could be understood. The main distinction, made in this chapter, was between exit in terms of renouncing one's belonging and exit in terms of leaving behind the influence of one's group (or, exit, as commonly understood). I argued that this distinction should be kept in mind, not only in order to have a more sophisticated understanding of what it might mean to exit one's cultural group, but also for developing more satisfactory approaches for the liberal state to respond to issues of exit.

My proposal, with respect to the liberal state's responses to exit, was that the state should continue to recognize those who have decided to leave the contours of their group (exit, as commonly understood) as members of the group should they so wish to be recognized. This approach, it was shown, had several benefits. Firstly, the continued state recognition would give at least some affirmation to the person's identity as an $\mathrm{M}$, thus contributing to the possibilities of this person continuing to identify herself as an $\mathrm{M}$ despite having left the contours of her group. Secondly, the affirmation of one's identity as an M would operate as one of the ways in which the burdens of exit (as commonly understood) could be lowered, thus contributing to making the formal rights of exit more realistic. Thirdly, the continued state recognition would also 
Part II Liberal Multiculturalism and Minority Rights in Practice

take better into account the discrepancies that different actors may have for recognizing (or not recognizing) someone a member, and refuse to prioritize any particular fraction's views on who counts as a member. This tracking of people's self-identifications (instead of any fraction's recognition) would also better fulfill the requirement of the liberal state to stay away from defining any substantive criteria of membership, as the state recognition would depend, not on any fraction's views on who counts as a member, but on people's self-identifications themselves. All in all, the continued recognition of those who have exited the contours of their group without renouncing their belonging would take better into account both the importance that one's belonging to a cultural or religious group may have for the constitution of one's identity, as well as acknowledging the multiplicity of ways in which one's group membership, as well as the requirements for such membership, may be understood. 


\section{Chapter 6}

\section{Liberal Individualism and cultural defence}

One of the overarching themes of this study has been its focus on individuals as cultural beings, and the assessment of the issues of cultural accommodation from the perspective of these individuals. Subscribing to liberal individualism - that is, to the view according to which it is ultimately the well-being of individuals that matters, and that the assessment and implementation of cultural policies should also keep this in mind - I have argued for an approach that attempts to take people's cultural commitments seriously by emphasizing the person's own views of her culture and her belonging to the cultural group in question. Most notably, I have argued against the commonly accepted criterion of membership as the default criterion for allocating differentiated rights and discussed some of the ways in which a more individuated approach could better perform the job of tracking the proper beneficiaries of these rights.

Whereas the two previous chapters (Ch. $4 \& 5$ ) form the very core of my theoretical argument for a more individuated approach to accommodating people's cultural differences, they do not, as such, say much about the ways in which this approach should be implemented in practice, or what kinds of consequences this would have on actual cultural policies. Although it is well beyond the scope of this work to develop any comprehensive account of the individuated approach in practice (no doubt, different cases should also be assessed in context), in this final chapter, I attempt to shed some light on these questions by looking at one instance of cultural accommodation, that of the usage of culture in criminal courts. This discussion builds upon the analyses of the previous chapters on group membership (Ch. 4) and cultural identity (Ch. 5), and also deepens my analysis, moving on from the issues of membership and belonging to questions of how people's actions can be motivated by culture, and how these motivations should be taken into account in 
Part II Liberal Multiculturalism and Minority Rights in Practice

criminal courts. By looking at a variety of ways in which people's actions can be culturally motivated, and the difficulties in identifying these motivations, I show some of the deficiencies in the current practices of using culture in criminal courts. ${ }^{457}$ I argue that, as currently practiced, cultural defence fails to treat all members of minority groups fairly and equally, and that, in order for it to do so, more attention should be placed on the identification of the subjective elements of culturally motivated actions, rather than on the seemingly objective elements of membership or the existence of any particular cultural practice or tradition.

As the debates on cultural defence are rather specific and, to certain extent, distinct from the more general debates on multiculturalism, I begin this chapter by outlining the general framework of these debates, including the different types of cultural defence and the standard arguments both for as well as against such defence. The first part, What is cultural defence?, focuses on different types of cultural defence and the basic presumptions behind these defences. It highlights both the variety of ways in which culture can be used in criminal courts, as well as the multiplicity of ways in which culture is seen to affect people's behaviour depending on the type of defence in question.

In the second part, Normative issues, I discuss some of the main arguments that have been laid out both for as well as against the allowing of the defendant's cultural background as a mitigating factor in criminal courts. I argue that, whereas there are good reasons both for as well as against cultural defence (especially, formal cultural defence), there are also significant variations to the kinds of cases to which cultural defence may be applied. Whereas in some cases, cultural evidence can, fairly non-controversially, be

457 It should be noted that my discussions are not dependent on any particular legal system, but concentrate on an analysis of some of the normative suggestions given for the usage of culture in criminal courts. As with most of the literature on cultural defence, the framework of this chapter is in the Anglo-American tradition, although I see no reason why some of the more general suggestions of this chapter could not be applied also in relatively different contexts. 
used as a mitigating factor in the assessment of the defendant's culpability, in others there are strong reasons to resist allowing cultural defence in criminal courts.

In the final part, Cultural defence and culturally motivated actions, I develop my main argument for more individuated usage of culture in criminal courts. I distinguish between several ways in which people's actions can be motivated by culture and argue that not all of these cases fall within the scope of "having a good-faith belief in the propriety of one's actions" (as required by cultural defence). In several instances, it is shown, identical actions can be performed from a multiplicity of cultural motivations. By looking at the ways in which culture is currently used in criminal courts, I propose a further challenge to those in favor of formal cultural defence, by showing how the suggested guidelines for establishing people's cultural motivations prop up the status quo, and fail to treat all members of minority groups fairly and equally. As an alternative, a more individuated approach is suggested, paying more attention to the subjective elements of cultural motivations rather than to the apparently objective elements of membership or the existence of particular cultural practices.

\section{What is cultural defence?}

For the purposes of this chapter, the following working definition of cultural defence is adopted:

A cultural defence maintains that a person who has a reasonable goodfaith belief in the propriety of his/her action, based on his/her cultural heritage or tradition, should not be held fully accountable for such action, should it be in violation of the official law. ${ }^{458}$

${ }^{458}$ In the literature, there are several slightly different formulations of cultural defence, varying in the broadness as well as the formality of the definition given. As a default, the standard formulations do, however, emphasize the role of cultural defence as aiming to mitigate or negate criminal responsibility based on the defendant's good-faith belief in the propriety of their action, on the basis of their cultural heritage or tradition. e.g. Lyman 1986, 88; Magnarella 1991, 67; Van Broeck 2001, 28-29; 
Part II Liberal Multiculturalism and Minority Rights in Practice

In other words, cultural defence maintains that in certain cases one's criminal culpability may be diminished by one's cultural background, and that this can also have an effect on the establishing of one's guilt and/or the deciding of an appropriate sentence. ${ }^{459}$

The ways in which one's cultural background can be shown to diminish one's culpability do, of course, vary, and cultural defence can also be understood to refer to the variety of ways in which a person's cultural background is used as a potentially mitigating factor in criminal courts. ${ }^{460}$ These ways of using culture in criminal courts include the bringing forth of cultural evidence in conjunction with other types of defences, although, in recent years, there has also been some support for the establishment of cultural defence as a formal, freestanding defence. ${ }^{461}$ In this section, I give a brief outline of different types of cultural defences, and the underlying notions of culture within these defences, with the help of illustrative examples from actual court cases.

Golding 2002, 149. This emphasis on the "good-faith belief in the propriety of one's actions, based on one's cultural heritage or tradition" will also play an important role in my analysis of culturally motivated actions and the ways in which these motivations should be taken into account in criminal courts in the final part of this chapter.

${ }^{459}$ Apart from the guilt phase and the sentencing phase of the trial, cultural defence can also affect pre-trial processes as well as the processes of appeal. Culture can also play an important part in civil cases, although my discussion is, in most part, restricted to criminal cases. For an excellent overview of the variety of cases involving some form of cultural defence or usage of culture in legal proceedings, see: Renteln 2004. For illuminating examples from different litigations, see articles in Foblets and Renteln 2010.

${ }^{460}$ This understanding of cultural defence is somewhat different from the working definition given above in so far as it refers to those concrete, formal defences through which the defendant's diminished culpability is being established. The working definition, on the contrary, provides the rationale behind these defences and also establishes what, exactly, the defence needs to show in order to mitigate or negate the defendant's criminal responsibility.

${ }^{461}$ See e.g. Note 1986; Ma 1995; Renteln 2004; 2010. 


\subsection{Example case: Jacob Zuma's rape trial $2005-2006^{462}$}

In 2005-2006, the then future president of South Africa, Jacob Zuma, was on trial for allegedly raping a family friend. The trial was widely followed and reported on, and was a very complicated affair. It was complicated not least because the person on trial was a very prominent and powerful figure in South Africa, but also because it involved issues of HIV/AIDS, questions of the privacy of public figures, issues of gender equality, problems of the treatment of alleged rape victims in courts and in the media, as well as questions of culture at the background of very exceptional circumstances of post-apartheid South Africa. ${ }^{463}$

One of the well reported aspects of the trial was the way in which the Zulu culture of the accused was used during the trial. ${ }^{464}$ During the trial, Jacob Zuma highlighted his background as a Zulu male by dressing up in traditional Zulu outfit and by giving his testimony in the Zulu language. He also commented on several Zulu traditions, for example by indicating that, in his culture, it would have been offensive had he not slept with the alleged victim, as the woman had already indicated her willingness to sleep with him. These indications included things such as being dressed in certain way, sitting without her legs being crossed as well as having a conversation about her not having a boyfriend. Undoubtedly, there was more to Zuma's defence, but the cultural factors were, nevertheless, used to try to establish that Zuma did not, as a Zulu

\footnotetext{
${ }^{462}$ State vs. Jacob Gedleyihlekisa Zuma, SA (2006)

${ }^{463}$ It should be emphasized that my purposes for using this case are purely illustrative, and that my discussion is restricted only to those aspects of the trial that are viewed to incorporate elements of cultural defence. For more thorough analyses of the case, see e.g. Skeen 2007; Robins 2008; Hassim 2009; Waetjen and Mare 2009.

${ }^{464}$ It is debatable whether the media emphasis of the cultural aspects of the trial was fair (the cultural factors were, after all, only one aspect of the trial), but the usage of culture during the trial does, nevertheless, provide us a good example of some of the ways in which culture can be used in criminal courts.
} 
Part II Liberal Multiculturalism and Minority Rights in Practice

male, do anything wrong, but was simply acting in a way anyone from his culture would, even should, act in the given circumstances. ${ }^{465}$

Admittedly, Jacob Zuma's rape trial is a very complex case, and the verdict of the case, that of acquittal, did not, in the end, depend on the cultural factors that were brought forth during the trial. ${ }^{466}$ The Zuma rape trial is, nevertheless, a good example of a case where the defendant's cultural background was used in an attempt to establish that the defendant did not, in accordance with his culture, do anything wrong, and that this should also be taken into account in the assessment of the case at hand. Following the working definition given above, it could be argued that if Zuma did genuinely believe that the victim was consenting and if this belief was based on the behaviour of the victim being the kind of behaviour that, in Zulu culture, would be interpreted as consent, then, even if the victim was not consenting and the acts performed constituted rape, the defendant should not be held fully accountable, as - due to his cultural background - he could be seen as having had a reasonable good-faith belief in the propriety of his action (that it was not rape but consensual sex).

In most legal systems, there are several avenues that the defence may attempt to take in order to establish the defendant's good-faith belief in the propriety of his action (based on his cultural heritage or tradition). In what is to follow, I distinguish several different types of cultural defence, and also return to the Zuma -case at regular intervals in order to demonstrate, how the rationales for different types of cultural defences would work, and how one's understanding of the defendant's culture, in each case, acquires slightly different meanings.

${ }^{465}$ As Stephen Robins notes, the defence's interpretation of Zulu culture and Zulu masculinity went largely unquestioned, although alternative interpretations would also have been available. Robins 2008, 421-428.

466 The verdict of acquittal was based, mainly, on the judging of the alleged rape victim as unreliable, based on several (in part, incorrect) accusations of rape and attempted rape that she had made previously. 


\subsection{Cultural evidence in conjunction with other types of defence}

As opposed to cultural defence as a formal, freestanding defence (to be discussed in 1.3.), cultural evidence may be brought forth in connection with other, more traditional types of defences. Most commonly, cultural evidence has been brought forth in connection with mistake of fact -defences, as well as with different types of state of mind-defences, such as insanity or diminished capacity.

\section{Mistake of fact-defences}

The bringing forth of cultural evidence in support of the mistake of fact -defence is to establish that, due to the defendant's cultural background, the defendant did not know that he was committing a crime, and that this should also be taken into account in the assessment of the defendant's culpability. The usage of cultural evidence in conjunction with the mistake of fact -defence can operate in two ways.

On the one hand, it could be argued that, due to his cultural background, the defendant was mistaken about the situation that he was in, due to having misinterpreted his situation from within his own culture. A well discussed case of this kind of mistake of fact from within one's own culture is the case of People v. Moua, ${ }^{467}$ where a member of a Hmong tribe (Moua) was accused of rape after having allegedly performed a Hmong ritual of marriage-bycapture. According to a Hmong tradition, marriage-by-capture is a ritual in which a man captures a woman and has sexual intercourse with her, thus marrying her. As part of the ritual, the woman is supposed to show resistance in order to show her virtuousness. In the case of People v. Moua, the existence of this cultural ritual was considered as evidence showing that, although Moua encountered resistance from the woman he had sexual intercourse with, he did

\footnotetext{
${ }^{467}$ People of the State of California v. Kong Pheng Moua, Fresno County Superior Court (1985)
} 
Part II Liberal Multiculturalism and Minority Rights in Practice

not know that the woman was not consenting, but thought that the resistance was part of the ritual. ${ }^{468}$

The using of culture in the Zuma rape trial could also be interpreted as utilizing this kind of mistake of fact from within one's own culture. In the Zuma trial, the signs given by the alleged rape victim were argued to have been the kinds of signs that, in Zulu culture, would be interpreted as sexual advancements, thus creating an expectation on the part of any Zulu male, including Jacob Zuma, to sleep with the woman in question. In the presence of these signs (the woman's dress, behaviour and topics of conversation), and in the absence of explicit resistance (the alleged victim was said to have frozen during intercourse), it could have been argued that, even if the woman did not consent to having sex with the defendant, the defendant did not know, nor could he have known, that the victim was not consenting, and that this mistake of fact on behalf of the defendant should also bear upon the assessment of his culpability and the final verdict of the case.

On the other hand, cultural evidence could also be brought forth to show that the defendant may not have been aware of breaking the law, due to now knowing what the law was (mistake of fact with respect to the law). For example, it could be argued that, due to the fact that a specific action was considered morally appropriate in the defendant's own culture, the defendant did not know that his action was criminalized. Although ignorance of the law would not normally be considered as a legitimate excuse for breaking the law, it could be argued that, in some cases involving members of very different cultural background, the ignorance of the law should operate as a relevant factor in the assessment of the defendant's culpability. For example, it has been argued that some of the newly arrived immigrants, sometimes coming from very different legal

${ }^{468}$ In this case, the charges were eventually reduced from kidnapping and rape to a lesser charge of false imprisonment to which the defendant pleaded guilty. For further discussion on People v. Moua, see e.g.: Ma 1995; Coleman 1996; Renteln 2004, 126-128; Kim 2006; Song 2007, 8993. 
systems, may not have had the opportunity to familiarize themselves with the law of their new residence, and could not thus have been aware that the particular action they performed was criminal. ${ }^{469}$

With respect to these two ways of using cultural evidence in conjunction with the mistake of fact -defence, two important points need to be made. Firstly, it should be emphasized that neither the mistake of fact from within one's own culture nor the mistake of fact with respect to law -defences work on a presumption that, due to the defendant's cultural background, the defendant should also be allowed to act in accordance with his culture (when in conflict with the official law). Rather, what the mistake of fact -defences attempt to show is that, because of the defendant's cultural background, it is reasonable to presume that the defendant did not have all the relevant information about the situation that he was in, and that, due to not having all relevant information, the full implications of the law should not be applied. Had the defendant known about the criminality of his actions, or had he known that (in the case of People vs. Moua) the woman's resistance was genuine, the defendant should have, no doubt, been subject to the full implications of the law, regardless of whether his actions were, in his culture, considered as morally appropriate.

Secondly, it should be noted that, in order to use cultural evidence in conjunction with the mistake of fact -defence, one does not need to be committed to any particularly strong view of how culture can be conceived as 'causing' or 'motivating' people to act in certain ways. In order to use the mistake of fact -defence, all one needs to acknowledge is that, often, people do act in accordance

469 See e.g. Note 1986; Ma 1995. Veronica Ma argues for a five year transitory period for the newly arrived immigrants, during which they are expected to accustom themselves to their new society (including its legal system). During this period, the newly arrived immigrants could raise a cultural defence, after which this right would automatically expire. (Ma 1995) However, as for example Van Broeck has noted, the length of one's stay does not automatically transfer into better knowledge of the social or legal rules of the country. (Van Broeck 2001) 
Part II Liberal Multiculturalism and Minority Rights in Practice

with their culture, and that, lacking information to the contrary, they may well also continue to act in such ways. The mistake of fact defence needs not, however, rest on a view according to which people could not also act against the dictates of their culture, should their cultural norms, values or practices conflict with the official law.

Insanity and diminished capacity

Apart from the mistake of fact -defences, cultural evidence could also be used in an attempt to establish that, due to the defendant's cultural background, the defendant had no other option than to act the way he did, and that, because of this incapacity, the full implications of the law should not be applied. In these cases, the purpose of cultural evidence is to show that, despite of being in full knowledge of the facts (both of his situation and of the law), the defendant was incapable of appreciating the criminality of his action, due to his action being morally appropriate - even morally required - in his own culture. In these cases, it could be argued that the defendant's frame of mind - his incapacity to appreciate the criminality of his action - should be considered on par with insanity or diminished capacity, and that the verdict of the case should take this into account. ${ }^{470}$

Contrary to the mistake of fact -defences, the using of cultural evidence in conjunction with insanity or diminished capacity defences requires far more robust view on how culture can cause or motivate people to act in certain ways. In order to view culturally motivated actions on a par with insanity, one needs to view culture as the defendant's primary (even the only) system of norms and values that, at least in some cases, determines what the defendant is capable of doing. ${ }^{471}$ Culture, thus understood, stands as something

${ }^{470}$ E.g. Note 1986. These so-called state of mind -defences also include defences of provocation and duress that have both been successfully used in cultural cases. See e.g. Woodman 2010; Amirthalingam 2010.

${ }^{471}$ To follow the terminology used in the Background section (esp. 2.2.), culture is seen as determining the defendant's behaviour (DC) and is often, 
against which the defendant could not go, even in cases where the norms of the culture collided with the prevailing norms of the law. For example, in so called crimes of honour (including honour killings), the defence may attempt to claim that, for the defendant, in his culture, there was no other option than to commit the crime in question, and that this sense of obligation or necessity should be viewed on a par with insanity, thus diminishing the defendant's culpability. ${ }^{472}$ Whereas in the Zuma rape trial, no attempts to establish Zuma's incapacity to act against the requirements of his culture were put forth, certain elements of this more robust view of culture were, nevertheless, present. As Zuma claimed, in the Zulu culture it would have been highly offensive had he not slept with the woman in such circumstances and, although Zuma clearly also had the choice of not sleeping with the woman in question, there was a strong presumption that Zuma did what his culture in fact required him to do, making the alternative courses of action, if not impossible, very unlikely.

\subsection{Cultural defence as a formal defence}

Whereas the allowing of cultural evidence in conjunction with other types of defences has enabled the defendant's cultural background to be taken into account in criminal courts, in recent years, there have also been calls to establish cultural defence as a formal, freestanding defence. ${ }^{473}$ As a formal defence, one's cultural

although by no means necessarily, connected to the ideas of culture also being broad (BC) as well as singular (SC) regulator of the defendant's life.

472 The paralleling of culturally motivated actions with insanity is, of course, very controversial, and I will come back to the difficulties of using such defence in section 2. I will also discuss the different ways of understanding what it may mean for one's actions to be"determined" or "compelled" by one's culture in section 3 .

${ }^{473}$ As it stands, neither the American, English nor South African legal systems recognize cultural defence as a formal, freestanding criminal defence, although cultural evidence is often used in conjunction with other types of defences. For country analyses, see e.g. Phillips 2003; Woodman 2010 (UK); Renteln 2004; Song 2007 (USA); Carstens 2010 (SA); for other legal systems, see articles in Foblets and Renteln 2010. 
Part II Liberal Multiculturalism and Minority Rights in Practice

background could be taken - on its own - as a potentially mitigating or exonerating factor in the assessment of one's culpability, without being conjoined with any other, more traditional type of defence. Rather than being seen insane or lacking knowledge of the law, a member of a cultural group could use the evidence of his cultural norms, values or practices in order to show that, although against the law, his actions were, in his culture, appropriate, and that, due to having acted in a good-faith belief in the propriety of his action, the (full) implications of breaking the law should not be applied.

Contrary to the mistake of fact, insanity, or diminished capacity -defences, the formal cultural defence rests on the view that the incompatibility of the cultural norms and values of a minority and the norms and values reflected in the official law is, on its own, enough of a reason to sometimes treat members of minority cultures differently. According to this view, the defendant may well have had knowledge of breaking the law, he may have been aware of all relevant facts of his situation, and he may even have had the opportunity and capacity to refrain from acting the way he did, but, due to the conflict between the norms and values of his culture and the official law, he nevertheless acted in a way that he though was right, and should not thus be subject to the full implications of the law.

With respect to cultural defence as formal defence, a few important clarifications should be made. As already indicated, cultural defence as a formal defence rests on an assumption that the conflict between the official law and the practices, norms or values of a minority is something that should be taken into account in criminal courts. This assumption can be seen as a continuation of the general liberal multiculturalist position according to which the liberal society is organized in accordance with the general rules and norms of the majority and that, at times, this may put minority members in a disadvantaged position in comparison to the majority. Importantly, however, taking into account the defendant's cultural background, and the acknowledgement of the possible conflict between the official law and a minority culture do not, as yet, say 
anything about how these conflicts should be resolved. Cultural defence (whether formal or in conjunction with other types of defence) could operate either as a full justificatory defence or as a partial excuse and, in most cases, the proponents of cultural defence have rejected the idea that one's cultural background should operate as a full justificatory defence, exonerating the defendant entirely. ${ }^{474}$ Nor is it the case that formal cultural defence would provide an automatic excuse for any action performed in accordance with one's culture, but the applicability of cultural defence can be variously restricted. ${ }^{475}$ Whereas a formal cultural defence establishes one's cultural background as a potentially mitigating factor in the assessment of one's culpability, not all actions need to be excused, nor should one's cultural background operate as an automatic excuse, even for those actions that are deemed as generally acceptable within one's own culture.

This latter clarification - that of the denial of automatic excuses - may be best explained in the light of the working definition of cultural defence given above. According to cultural defence, the diminishing of the defendant's culpability is based on his reasonable good-faith belief in the propriety of his action, based on his cultural heritage or tradition, rather than on the general acceptability of his actions in his own culture. According to formal cultural defence, it is thus not enough that a particular action is considered as generally acceptable in the defendant's own culture, but the defendant must also have performed such action for the right reasons - that is, he must have also genuinely believed that the action he performed was right, and that this belief in the rightness of his actions was based on his cultural heritage or tradition. ${ }^{476}$

${ }^{474}$ For strong arguments for cultural defence as a partial defence, see: Golding 2002; Renteln 2004, ch. 10.

475 For example, by disallowing cultural defence in cases that involve irreparable physical harm or the undermining of basic human rights. e.g. Renteln 2004, 214-218; 2010, 78.

${ }^{476}$ I will come back to the problems of what "a good-faith belief in the propriety of one's action" might mean and how this "good-faith belief" may be established in more detail later on in this chapter. 
Part II Liberal Multiculturalism and Minority Rights in Practice

For example, in the Zuma rape trial one could argue that if Zuma did genuinely believe that the victim was consenting and if this belief was based on Zuma's cultural background as a Zulu, and the cultural interpretations of the victim's behaviour as consent in Zulu culture, then, even if the victim was not consenting and the defendant's actions constituted rape, Zuma should not be held fully accountable, as - due to his cultural background - he could be interpreted as having a reasonable good-faith belief in the propriety of his action (not being rape but consensual sex). Importantly, however, it does not follow that any case, involving a defendant of the same cultural background and an alleged victim behaving in a similar manner, should be viewed as a case in which the full implications of the law should not be applied. The defendant's cultural background (in this case, him being a Zulu male) could, according to formal cultural defence, operate as a mitigating factor, but only if this background also entailed that the defendant had "a reasonable good-faith belief in the propriety of his action" - that is, if he genuinely believed the action to be the right action to do. As often noted, cultures are heterogeneous, and two persons with the same cultural background may well have very different views on what is considered as appropriate in their culture, and the criminal courts must also take this into account. The difficulties of establishing whether the defendant did, in fact, act in good-faith belief are, of course, various, and I will return to these difficulties in the final section of this chapter.

\section{Normative issues}

In many legal systems, there is already some scope for taking cultural considerations into account in criminal courts, primarily through using cultural evidence in support of other types of defences, or by assessing, on a case to case basis, whether the cultural background of the defendant is deemed relevant for the assessment of the case at hand. In some cases, the usage of cultural evidence has been successful, affecting either the establishment of 
guilt or the actual sentencing, or both. ${ }^{477}$ Not everyone, however, would allow culture to operate as a mitigating, let alone exonerating, factor in criminal courts. To a large extent, the arguments both for as well as against cultural defence follow the traditional arguments for and against differentiated rights, starting from the more general arguments for why culture should (or should not) play a part in criminal courts, proceeding to more specific arguments that take into account the specificities of the criminal justice system and its effects on the accused, victim, as well as the rest of society. In this section, I outline some of the main arguments both for as well as against cultural defence and, by doing so, also pave the way for my own argument as developed in section 3 . Many of the discussed arguments are concerned specifically with the question of whether cultural defence should be established as a formal, freestanding defence, although most of the arguments can also be extended to the context of whether to allow cultural evidence in conjunction with other types of defences.

\subsection{Arguments for and against cultural defence} Cultural diversity and respect for different cultures

On one of the most general levels, the proponents of formal cultural defence may attempt to build their case by resorting to arguments from the value of cultural diversity or the need to give due respect to different cultures and/or their members. Whereas these arguments are not identical, ${ }^{478}$ they operate on the assumption that the official legal system, if too strictly applied, may undermine the minorities' ways of life and reduce the acceptable, legitimate ways of living to those approved by the majority (and the legal system build upon the norms and values of the majority). The arguments

\footnotetext{
${ }^{477}$ It should be noted that the usage of cultural evidence in criminal courts does not always lead into leniency, but can also operate as a basis for harsher punishment. See e.g. Siesling and Ten Voorde 2010. Most debates on the usage of culture in criminal courts have, however, concentrated on the usage of culture as a basis for mitigation, and, in this respect, my discussion will follow suit.

${ }^{478}$ See also: Background, section 2.
} 
Part II Liberal Multiculturalism and Minority Rights in Practice

from respect seem especially worthy of attention, as it is not only the ways in which the legal system responds to particular cultural practices, but also how it responds to the performers of these practices that the proponents (as well as the opponents) of cultural defence should be concerned about.

According to some classical arguments, respecting people's cultural differences is also seen as entailing respect of those cultural practices and ways of life that the minority members are engaged in. ${ }^{479}$ Within the liberal framework, these requirements of respect ${ }^{480}$ are, however, necessarily limited, excluding at least those practices that are in clear violation of basic human rights. ${ }^{481}$ In debates on cultural defence, these limitations are well in view, as the proponents of cultural defence tend not to advocate cultural defence as a full justificatory defence, but rather as a partial excuse. Whereas cultural factors may be used both to explain as well as, at times, partially excuse the criminal conduct of the defendant, this conduct, nevertheless, remains criminal, and punishable by the rule of law.

Like in other contexts, in the context of cultural defence it is important to make a distinction between respect for particular cultural practices and respect for the practitioners of these practices.

\footnotetext{
${ }^{479}$ Perhaps one of the most prominent views to this effect can be found in Taylor 1994. See also Ch. 4, 1.3.

${ }^{480}$ Objection could be made that the notion of respect (and, especially, the idea of requiring respect for different cultural practices) does not fit well with the liberal framework that is more properly concerned with whether certain practices should be tolerated or interfered with. However, as the notion of respect is not entirely alien to the liberal framework (most liberals would, for example, subscribe to at least some minimal notion of respect in term of equal respect of persons), I find it useful to assess, what kinds of limitations the liberal framework would provide for those who do argue for formal cultural defence in terms of the requirement of respect to different cultures and/or their members.

${ }^{481}$ Liberals may, and they also do, disagree on the criteria for determining those practices that cannot be tolerated (let alone respected), although they do also agree that some, exceptionally cruel or inhumane practices fit these criteria.
} 
Whereas not all practices deserve or should be respected (perhaps not even tolerated), all human beings, by virtue of being human, should be treated with equal respect and concern. However, if we look at the ways in which culture has been used in criminal courts, it is far from clear whether this requirement is being fulfilled. Having to show that the defendant was either ignorant or insane is hardly respectful of the defendant in question, ignoring many of the ways in which people can be motivated by their culture. Treating culturally motivated crimes on a par with insanity or diminished capacity props up the view of minority members as somehow captured in their culture, having no free choice, being not able to do anything except what their culture dictates. ${ }^{482}$ The association of culture with insanity, ignorance or diminished capacity feeds into the view of minority cultures as deficiencies, thus creating a strong case for more nuanced ways of using culture in criminal courts including the establishing of cultural defence as a formal, freestanding defence.

\section{Fair and equal treatment}

One of the main requirements for the law, and the criminal justice system, is that it treats individuals fairly and equally. Bracketing culture from criminal courts, it is argued, puts this requirement under strain, as it is essential, both for the understanding of the committed crime as well as for the assessment of the defendant's culpability, that relevant cultural factors are known. ${ }^{483}$ The argument from the requirement for fair and equal treatment can be discussed in two parts, the first concerning the general cultural bias of the law, the second the supposed predictability of the law.

\footnotetext{
${ }^{482}$ For excellent analyses on how the using of culture in criminal courts may reduce the defendants (as well as the victims) into objects devoid of free will and agency, see: Volpp 1994; 2000. For a more general, critical analysis on culture and agency, see: Phillips 2007, Ch. 4.

${ }^{483}$ The commitment to individualized justice and cultural pluralism is especially strongly argued in Note, 1986; see also: Ma 1995; Renteln 2004, esp. Ch. 10; Song 2007
} 
Part II Liberal Multiculturalism and Minority Rights in Practice

To rehearse the common arguments of liberal multiculturalism, it is argued that any legal system (including the criminal law system) is always a product of a particular (majority) culture reflecting the norms, values and practices of the majority - and that this puts the members of minority cultures in a disadvantaged position to that of the majority. Whereas the majority can continue to live their lives legitimately, in accordance with their own cultural norms and practices, some minority practices may, either unintentionally or intentionally, ${ }^{484}$ be in conflict with the official law. The interpretations of what it is reasonable for a person to know or how it is reasonable for him to act in certain circumstances, may also differ, depending on the cultural background of the person in question. ${ }^{485}$ The taking into account of the defendant's cultural background aims at balancing out the cultural biases of the law by providing a culturally sensitive understanding of the situation at hand.

The cultural bias of the law, and the consequent need to take cultural considerations into account in criminal courts, does not, however, say anything yet about how the cultural factors should be interpreted or whether cultural defence should also be established as a formal, freestanding defence. The allowing of cultural evidence provides minority members access to several other defences (including mistake of fact, insanity and diminished capacity), which

${ }^{484}$ This is a difference between practices that, due to the cultural bias of the law, happen to be in conflict with the law, and practices that are deliberately banned by law. Whereas in the first cases, the requirement of fair and equal treatment may well point towards the need to modify the law (or its implementation), in the latter cases, the situation is substantively different, as the purpose or the intention of the law is precisely the criminalization of the minority practices in question. See also: Background 2.3.; for the need to balance rationales for and against particular rights, Ch. 3, 3.3.

${ }^{485}$ The question of "a reasonable person" has been discussed extensively especially in the contexts of provocation -defence, raising the question of whether the behaviour of a reasonable person to certain stimuli would be different depending on his/her cultural background, See e.g. Amirthalingam 2010, Renteln 2004, 31-36. 
may well ensure that the defendant receives a fair trial, including the possibility of diminished culpability and/or mitigation of the sentencing in proportion to the committed crime and the established culpability. ${ }^{486}$

However, whereas the usage of other types of defences may well be able to ensure the desired (fair and equal) outcome, there may also be certain deficiencies in this approach. Firstly, even if the outcome of the trial could be seen as consistent with the principles of individuated justice (including the taking into account the defendant's cultural background and the proportionality of the punishment), it is debatable whether the process of the trial or the reasons for reaching such outcome would be fully satisfactory. As already indicated, the treating of culturally motivated actions on a par with insanity, ignorance or diminished capacity may not accord the defendant due respect and may also only serve to obscure the real reasons for why the defendant committed the crime in question. ${ }^{487}$ Secondly, the allowing of cultural evidence only in conjunction with the more traditional types of defence may allow for too much variation, making the supposedly predictable law unpredictable. As has been noted, the lack of formal guidelines on the ways in which culture can be used in criminal courts has lead to a situation in which it is often left to the discretion of the judges as to whether to allow cultural evidence in courts, and whether to

486 One of the main benefits of cultural defence (as argued by its proponents) lies precisely in its ability to cater for the requirement of proportionality of the punishment to the crime committed. See esp. Renteln 2004; 2010; Kim 2006. It should, however, be noted, that the argument from proportionality does not, on its own, work as an argument for formal cultural defence, as the proportionality could also be achieved by the allowing of cultural evidence in conjunction with other types of defences.

${ }^{487}$ As Nancy Kim has convincingly shown, one of the ways in which culture is used in criminal courts is by way of mystifying and exoticizing the culture in question, making it even more difficult for the courts to assess the cases at hand. (Kim 2006) This problem, I believe, is especially severe in cases where cultural defence needs to be fitted into a framework that has not been designed to take cultural considerations into account. 
Part II Liberal Multiculturalism and Minority Rights in Practice

deem this evidence as relevant to the case at hand. ${ }^{488}$ In the worst case scenario, both the process of the trial as well as the final verdict may hang on the personal prejudices or stereotypes of the judge or the jury, thus putting minority members, not only on an unequal footing with the majority, but also with one another.

Victim's perspective and legitimation of oppressive practices

So far, the requirement for the criminal law to treat all people fairly and equally would seem to create a strong case for allowing cultural evidence in criminal courts, and for taking cultural considerations into account when assessing the defendant's culpability and the appropriate sentencing. The same requirements of fair and equal treatment can, however, also pull in different direction, emphasizing that it is not only the defendant that the law should treat fairly, but also those against whom the crimes have been committed. Should one allow a system in which, for example, certain kinds of sexual assaults are considered as part of a particular culture (and, given people's propensity to act in accordance with their culture, not as harshly punishable for the perpetrators from that culture), then, depending on the cultural background of the defendant, or the victim, or both, the justice done to the victim is different. ${ }^{489}$ Whereas formal cultural defence does not, in principle, maintain that, due to the general moral acceptability of the defendant's action in his own culture, the defendant should automatically be subject to differentiated treatment in courts, ${ }^{490}$

\footnotetext{
${ }^{488}$ Renteln 2004; 2010.

${ }^{489}$ It is debatable whether the cultural background of the victim should affect the assessment of the defendant's culpability (see e.g .Renteln 2004; Song 2007, 110-111), although, undoubtedly, the background of the victim has, in many cases, been deemed relevant for the assessment of the case at hand. It is, for example, very difficult to imagine that the charges of People v. Moua would have been reduced, had the victim of the case been any average American and not a member of the Hmong themselves. (see also section 1.2. above)

${ }^{490}$ As indicated in the previous section, formal cultural defence is still based on the view that the defendant must also have performed his actions
} 
there is, no doubt, concern that the establishment of cultural defence as a formal defence may create a system in which the justice done to the victim will differ, depending on the defendant's (and, possibly, the victim's) cultural background. ${ }^{491}$

The taking into account the victim's perspective is especially important in cases where cultural evidence is brought forth to account for those practices that are conceived as oppressive towards a certain sub-section of the group, but that are, nevertheless, considered morally acceptable in the defendant's own culture. As many have argued, the establishment of a formal cultural defence may lead into a (partial) legitimation of certain oppressive practices, leaving those most vulnerable within a particular cultural group without protection. ${ }^{492}$ Many criminal cases where cultural evidence is brought forth are, indeed, cases that involve women and children (forced marriage, crimes of honour, circumcision), and the patriarchal norms of the culture in question. Allowing formal cultural defence, in these cases, may only reinforce patriarchal norms, and also give certain legitimation to oppressive practices by recognizing them as "proper" practices of that culture. ${ }^{493}$ The recognition of certain oppressive practices as inherent elements of a particular culture is not only problematic from the perspective of the victim, whose protection under the law is thus diminished, but also from the perspective of those who strive to change their culture

for right reasons, not only that he performed actions that were, broadly speaking, conceived as morally appropriate in his own culture.

491 This concern is not only a concern relating to cultural defence as a formal, freestanding defence, but is also applicable in cases where the defendant's culpability is diminished by other factors (e.g. insanity or diminished capacity) based on their cultural background. However, as I will discuss in more detail in the final part of this chapter, the methods of establishing the defendant's culpability often take a very simplified view of how one's culture may affect one's behaviour, directing the courts to too group-based assessments of the cases at hand, at the expeses of both individual defendants as well as victims.

492 See: Goldstein 1994; Volpp 1994; Coleman 1996; Shachar 1998; Phillips 2003; 2007; Song 2007.

${ }^{493}$ See also Ch. 1, 2,2; Ch.4; Ch. 5. 
Part II Liberal Multiculturalism and Minority Rights in Practice

from within. ${ }^{494}$ The formal recognition of certain practices as the proper practices of that culture often contributes to the upholding of the status quo, and makes it even harder for those who are oppressed to gain equal status within their cultures.

\section{Social cohesion}

Apart from the difficulties of according proper justice to the victims of the culturally motivated crimes, it has been argued that formal cultural defences, rather than contributing to the equal and fair treatment of all citizens before the law, would create permanent minorities, members of whom would be treated differently, solely on the basis of their cultural background. ${ }^{495}$ This may diminish social cohesion by reinforcing the gap between "us" - the liberal reasonable people, and "them" - those somehow captured in their culture. $^{496}$

The labeling of certain actions as "cultural" and the reinforcement of the ideas of specifically cultural minorities and somewhat non-cultural majority is, of course, not only a concern relating to a cultural defence as a formal defence. As already noted, the using of cultural evidence in conjunction with other types of defences (such as insanity and diminished capacity) may also prop

\footnotetext{
${ }^{494}$ It should be noted that the concern of the reinforcement of oppressive practices is not only a concern relating to minority cultures, but also to the culture of the majority. As has been noted especially by the feminist critique, cultural defences have been most successful in cases where the minority culture's norms are somewhat reflective or congruent with the norms of the majority (for example, in cases where women's "no" is portrayed as "yes" or "maybe"). This congruence between the norms of the minority and the majority may be a problem, regardless of whether cultural defence is allowed or denied as, in either case, the oppressive nature of the majority's norms may go unquestioned. For discussion, see e.g. Phillips 2003; 2007; Song 2007.

Doriane Coleman goes as far as to warn against the "dangerous balkanisation of criminal law" where different groups are subject to different rules of law. Coleman 1996, 1098. For a qualified defence of parallel legal systems, see: Shachar 2001.

${ }^{496}$ See also: Volpp 2000.
} 
up the view of minority members as somehow captured in their culture, devoid of free will and moral agency. The concern, with respect to social cohesion, can thus be seen as a product of any systematic usage of culture in criminal courts, where people's cultural background is deemed as relevant for differentiated treatment. Viewing one's cultural background as a potentially mitigating or exonerating factor will, perhaps inevitably, build into a system in which the members of minority cultures are, as a default, conceived as different from the majority - this difference being also reflected in the criminal law and the proceedings of the criminal courts. ${ }^{497}$

\subsection{Cultural defence and cultural offences}

As should be clear by now, there are strong arguments both for as well as against cultural defence and the allowing of cultural evidence in criminal courts. Whereas the taking into account the defendant's cultural background (in some form or another) seem necessary for the equal and fair treatment of minority members, the challenges for allowing cultural defence cannot be ignored. Most importantly, it must be ensured that both the defendant and the victim are treated fairly, and that cultural defence does not reduce the justice done to the victim or help reinforce the oppressive practices within the cultural groups in question. On the other hand, it should also be acknowledged that there is enormous variation, not only in the kinds of defences within which cultural evidence can be brought forth, but also in the kinds of offences to which cultural defence may be applied. Not all arguments (for or against cultural defence) may apply to all cultural offences or culturally motivated

\footnotetext{
497 As argued by Leti Volpp and Anne Phillips, cultural defence seems to also reinforce certain stereotypes, even to an extent in which the defence becomes available only to those who fit neatly into these stereotypes, and not others. Volpp 1994; Phillips 2007.
} 
Part II Liberal Multiculturalism and Minority Rights in Practice

crimes, ${ }^{498}$ making some cases of cultural defence less controversial than others.

Whereas most criminal cases, discussed in the literature on cultural defence, are cases that have involved particularly severe violence against the victim (often, a woman or a child of the same cultural origin), ${ }^{499}$ it is by no means the case that all cultural defence cases would fall within the same category. Indeed, many of the cases in which cultural evidence has been brought forth have been cases in which there is no clear victim of the crime, or which do not, strictly speaking, fall within the scope of criminal law. Cultural evidence has been brought forth, for example, in cases involving the usage and possession of illicit drugs, ${ }^{500}$ in cases of polygamous marriage, ${ }^{501}$ as well as in cases involving cultural or religious dress codes. ${ }^{502}$ In these instances, there is not necessarily a clearly identifiable victim of the crime, thus making the arguments from the victim's perspective relatively void. The allowing of cultural defence, in cases of victimless crimes, ${ }^{503}$ would thus seem to be at least less controversial than in the crimes commonly highlighted in the literature.

498 The terms "cultural offences" and "culturally motivated crimes" are used interchangeably.

${ }^{499}$ Some of the most commonly discussed cases involve those of People v. Moua (marriage by capture), People v. Chen (wife murder) and People v. Kimura (child drowning).

${ }^{500}$ For an overview of cases involving drugs, see Renteln 2004, ch. 5.

501 The cases involving Mormons in the United States may be most known (see e.g. Renteln 2004, 128-130; Song 2007, ch. 6), although it is clear that the allowing of polygamy in Islam is bound to bring these discussions back to the forefront. For some current controversies in Canada and UK, see e.g. Bala 2011; IslamToday 2011; Sona 2005.

${ }^{502}$ Most of the cases involving cultural or religious dress codes do not fall under criminal law, but are often cases that challenge the existing legislation on, for example, employment or equality of opportunity. See Renteln 2004, ch. 8; Woodman 2010; see also Ch. 3 above.

${ }^{503}$ Strictly speaking, there may not be such crimes as victimless crimes, although the identification of the victim(s) and the harm done to the victim(s) can vary tremendously depending on the crime in question. 
Whereas my intention is not to claim that the usage of cultural defence in victimless crimes would be fully without controversy, ${ }^{504}$ I do believe that the debates on cultural defence would benefit greatly from making better use of the differences between different kinds of cultural offences or culturally motivated crimes. As Jeroen van Broek has noted, much of the literature on culture and crime has concentrated either on cultural offences or on cultural defence, and the relation between the two has not always been clear. ${ }^{505}$ However, there would seem to be a big difference between the allowing the use of the defendant's cultural background as a partial excuse in cases of victimless crimes (such as drug usage or voluntary polygamy) and in cases that involve severe human rights violations (such as forced marriage or crimes of honour). Whereas in the first case, cultural defence may well be seen as simply balancing out the cultural bias of the law (without incorporating the controversies of diminishing the justice done to the victim) ${ }^{506}$ in the latter cases, the arguments against cultural defence are much stronger. Like in any case of cultural accommodation, the arguments for and against cultural defence need to be assessed and balanced on a case to case basis, and this balance may, depending on all the relevant factors of the case, be tipped to either side. ${ }^{507}$

504 The arguments from the victim's perspective are, after all, only one aspect of the debate, leaving for example the arguments from social cohesion or (more controversially) legitimation of oppressive practices intact.

${ }^{505}$ Van Broeck 2001

${ }^{506}$ The mitigation (or even exoneration) of the defendant's culpability, for example in cases of the religious usage of illicit drugs, may not, of course, be the approach approved by those who argue that the law should be universal in terms of it treating everyone the same, although I believe that even the most committed proponents of legal universalism have to acknowledge that the arguments against mitigation on cultural grounds in these cases are much weaker than for example in cases that involve severe human rights violations.

${ }^{507}$ It should be emphasized that my intention is not to give any definitive guidelines on whether the defendant's culpability should be diminished in particular cases or not, but simply to indicate that, depending on the case 
Part II Liberal Multiculturalism and Minority Rights in Practice

Moreover, it is not only the severity of the crime or the role of the victim that the assessment of the cases should take into account, but also other elements of cultural offences, including the actual motivation of the defendant to commit the crime in question. To recall, cultural defence holds that the defendant must have committed the crime "in good-faith belief in the propriety of his actions", and this requires that the action was also performed for the right reasons. ${ }^{508}$ However, whereas the literature on cultural defence does, quite explicitly, recognize the importance of establishing the motivation, and the good-faith belief of the defendant, surprisingly little has been written on the different ways in which people's actions can be motivated by culture, and how these motivations may affect the assessment of the cases at hand. In the final part of this chapter, I attempt to fill in some of this void by discussing some of the ways in which people's actions can be motivated by culture and, by way of doing so, also point out to some of the challenges that the variety of cultural motivations and the difficulties of identifying these motivations bring to the ways in which culture is used in criminal courts.

\section{Cultural defence and culturally motivated actions}

Having outlined some of the ways in which culture is used in criminal courts, as well the main arguments for and against cultural

at hand, the balance may tip to either direction. For example, it may well be conceded that, at times, the general acceptability of the defendant's actions in his own culture may result into the defendant committing a crime he simply did not know was criminalized (e.g. newly arrived immigrants), and that this concession should also be taken into account in criminal courts. However, the knowledge of the acceptability of the defendant's actions in his own culture, and his lack of knowledge of the criminality of these actions in his new surroundings do not, as such, give enough information to judge the case at hand, but should be balanced against the arguments against the mitigation or the diminishing of the defendant's culpability. These arguments, however, can only be assessed in the light of the nature of the crime in question, and may, depending on the relevant features at hand, result in quite different conclusions.

${ }^{508}$ I will come back to this shortly, in section 3. 
defence, I now turn to develop my own argument for a more individuated usage of culture in criminal courts. The starting point of my argument lies in the working definition of cultural defence given in the beginning of this chapter, and its emphasis on the defendant's "reasonable good-faith belief in the propriety of his/her action, based on his/her cultural heritage or tradition" as the main basis for the lessening of the defendant's accountability for the crimes in question. For my purposes, it is not important whether the potential diminishing of the defendant's culpability is established directly (formal cultural defence) or indirectly (with the use of other, more traditional types of defences), although it is important that the ultimate grounds for such action lie in the potential conflict between the official law and the cultural norms and values of the defendant. Some actions, although against the official law, may well be considered as perfectly appropriate in the defendant's own culture, and, in committing the crime in question, the defendant may have acted perfectly in accordance with the norms and values of his culture, having genuinely believed that what he did was not wrong and/or (in some mistake of fact -cases) against the law.

In order to build my argument, I look at some of the often ignored difficulties that the requirement of 'having a reasonable good faith belief in the propriety of one's action, based on one's cultural heritage or tradition' brings to the usage of culture in criminal courts. Most notably, I concentrate on the difficulties of establishing and identifying the defendant's cultural motivations by analysing both, the ways in which people's actions can be "required" by culture, as well as the reasons that people may have for acting in accordance with these requirements. In the latter part of this section (3.2.), I utilize my analyses of cultural motivations in the light of some of the normative guidelines for the establishing of the defendant's good-faith belief in criminal courts.

\subsection{How can an action be motivated by culture?}

In order to have "a reasonable good-faith belief in the propriety of one's action, based on one's cultural heritage or tradition", culture must be viewed as a regulatory framework through which certain 
Part II Liberal Multiculturalism and Minority Rights in Practice

actions or ways of life are deemed as acceptable (or unacceptable). The often discussed conceptions of culture as a broad system of norms and values or as a context of choice ${ }^{509}$ fit well with this view, providing certain culturally defined limits to what people may, or may not, within their own cultural framework, do ${ }^{510}$ In debates on cultural defence, however, culture is often viewed as having a much stronger role, providing also certain normative guidance into what people of that culture should or should not do. Culture is seen as directing people's behaviour, "causing" them to act in certain ways, even to an extent of "compelling" people to act in ways they do. ${ }^{511}$ The ways in which culture can "direct" or "cause" people to act in certain ways are, of course, varied, both in the extent to which culture is seen as compelling people to act in certain ways, as well as in the reasons that people may have for behaving in accordance with the dictates of their culture.

\section{Levels of compulsion}

One of the ways in which culture can be seen as motivating people to act in certain ways is by creating normative expectations on how people, of that particular culture, should act or behave. These expectations may be very different, both in terms of their strength as well as their origin. A practice or an action, conceived as appropriate in one's culture, can be so at least in the senses of it being permissible, encouraged, or required. For example, in many cultures, polygamy is permitted, giving the men of that culture an option to marry more than one wife. ${ }^{512}$ The permissibility of

\footnotetext{
${ }^{509}$ See also: Background, 2.2.; Ch. 1, 1.1.

510 This does not entail that these limits would be generally agreed upon, but is perfectly compatible with the views of culture as heterogeneous, contested and constantly changing .

${ }_{511}$ As demonstrated especially by the usage of insanity -defence.

512 In most cultures that permit the practice of marrying more than one partner, this practice is, indeed, gendered, allowing men to marry more than one wife, but not vice versa. As this is the case, I have chosen to use the practice of polygamy (as opposed to polyandry or other, more genderneutral forms) as my illustrative example. My usage of this example does
} 
polygamy does not, however, create any obligation for people to engage in polygamy, although it does give people an option to do so, if they so wish. The same practice of polygamy can, however, also be a practice that is encouraged - to an extent, even expected in one's culture. The men (as well as the women) of such cultures may face certain amounts of pressure to engage in polygamy, although the failure to do so leads to no substantive sanctions. ${ }^{513}$ Even if polygamy was encouraged, even expected in one's culture, it is still permissible for people not to engage in such practice, without going against the dictates of their culture. On the strongest level, however, certain actions or practices may also be seen as being required in one's culture, and the failure to engage in such practices constitutes a failure to follow the rules and norms of one's culture. Although I do not know of any cultures where marrying more than one wife would be obligatory, the same example is used for illustration. Should polygamy be considered as required in one's culture, the failure to engage in such practice would constitute a failure to follow the norms and values of one's culture. It would be an act that goes against the dictates of one's culture: it would be wrong, in the light of the normative requirements posed by one's culture or cultural group.

The differentiation between those practices or actions that are viewed as permissible, encouraged or required becomes especially interesting when one looks at the ways in which the strength of one's cultural, normative expectations is seen to affect one's criminal culpability. In many cases, the courts may assess the level to which the defendant could be seen as being "compelled" by his culture, taking a more accommodative view of those practices that

not, of course, reflect any normative standpoint with respect to the practice itself (or its gendered nature), but is used simply for illustration.

${ }^{513}$ It is clear that those practices that are encouraged (although not as yet required) by one's culture may also hold some negative consequences to those who fail to engage in such practices, although it is not the case that a person would be going against the norms and values of their culture, should they fail to perform those practices that are conceived as "encouraged". 
Part II Liberal Multiculturalism and Minority Rights in Practice

are seen as required (as opposed to encouraged or merely permitted) in the defendant's culture. ${ }^{514}$ The idea being that the defendant's criminal culpability should also depend on the existence of alternative options, and that there is a correlation between the strength of one's cultural, normative expectations and the possibility of the defendant acting otherwise.

Whereas I do not wish to deny the relevance of the existence of alternative options for the assessment of the defendant's culpability, I do, nevertheless, wish to point to some problems that an overt emphasis on the strength of one's cultural expectations, and on the levels upon which the defendant is seen as compelled by his culture, may bring. To recall, cultural defence maintains that the diminishing of the defendant's culpability is based on the defendant's reasonable good-faith belief in the propriety of his action, not on whether the defendant was, in the given circumstances, capable of acting otherwise. This good-faith belief, it should be emphasized, may have nothing to do with whether the practice or action in question was required, encouraged or simply permitted in one's culture, although the consequences of such a belief may be identical. Whereas one's good-faith belief in the permissibility of one's action entails that the defendant could have, in accordance with the rules and norms of his culture, also acted otherwise, it may well be that the actor, nevertheless, was incapable of appreciating the criminality of his action, due to his belief in the propriety of his action in his own culture. On the other hand, the defendant may well have had a good-faith belief in the obligatory nature of his actions in his culture, but this does not, necessarily, mean that the defendant could not also have acted otherwise. On the contrary, if we wish to hold on to the view of the members of minority cultures as free agents, capable of also questioning and

\footnotetext{
${ }^{514}$ It has, for example, been argued that in the case of People v. Moua, the courts should have taken into account the contestability of the ritual of marriage-by-capture within the Hmong tradition, as well as the fact that marriage-by-capture was far from being the only possible ritual of marriage among Hmong. Song 2007, 107-108.
} 
changing their culture, we should not think of them as being incapable of going against the dictates of their culture, even in cases where the action in question is seen as being required by one's culture.

It should be clarified that I do not wish to deny that, at times, it may well be more difficult for the defendant to act against those practices that are required in his culture than against those that are simply permitted. The pressures to act in accordance with one's cultural requirements may well be stronger, but this does not automatically mean that the culpability of the defendant should thus also be weakened. On the contrary, the pressures to act in accordance with one's cultural requirements may come from a variety of sources, and the motivation of the defendant to act the way he did may have little, if anything, to do with what he thinks is right. That is, the motivation of the defendant to perform an action conceived of as encouraged or required in his culture may not always come from his "good-faith belief in the propriety of his action", but may include (or even be solely based on) other reasons, not fitting well with the basic tenets of cultural defence.

\section{Substantive and instrumental motivations}

As Jeroen van Broeck has argued, one's motivation for engaging in certain cultural practices, or for performing certain culturally motivated actions, may be either substantive or instrumental, and the line between the two is not always easy to draw. ${ }^{515}$ On the one hand, one may wish to engage in a particular cultural practice (say, polygamy), because one considers this practice to be a valuable, perhaps even inalienable, aspect of one's culture. Due to one's cultural background, one may view polygamy as "the right thing to do", although, depending on the strength of one's cultural expectations, one may not necessarily think that it would be wrong not to engage in such practice. This kind of motivation, to participate in a cultural practice due to one's belief in the appropriateness of such action, may be called substantive

${ }^{515}$ Van Broeck 2001 
Part II Liberal Multiculturalism and Minority Rights in Practice

motivation, as it relates directly to the norms and values of one's culture, and to one's will to act in accordance with these norms and values.

On the other hand, one's motivation to engage in a cultural practice (say, polygamy) may also be instrumental, in several senses. In these cases, one does not engage in polygamy because one thinks it to be the right thing to do, but, for example, because one wishes to conform to the cultural practices of one's group, or be recognized and accepted as a member of that group. At times, one's motivation to engage in particular cultural practices flows, not from the fact that one believes that these practices are the right thing to do, but rather, from the fact that other group members expect one's participation, and one wishes to affirm one's solidarity or belonging to the group in question. Moreover, it is perfectly possible that one's motivation to engage in certain cultural practices is both substantive as well as instrumental. One may, for example, consider the practice of polygamy as a perfectly appropriate (in the sense of it being permissible) practice in one's culture, although one's primary motivation for engaging in such practice is in one's will to show to others that one takes the norms and values of one's culture seriously.

These ways of being motivated to participate in particular cultural practices (either by one's belief to be doing the right thing, one's wish to conform or to be recognized, or any combination of these) are, however, only the first level at which people's actions can be motivated by their culture. Apart from wanting to engage in certain cultural practices, people may also be culturally motivated in the senses of wanting to preserve or protect (or, alternatively, change or destroy) their culture. In the most extreme cases, one's desire to protect one's culture (either from internal dissent or external influence) may lead to acts of pressurizing, ostracizing or even physically harming those that are conceived as threats to one's culture. Although the physical harming of someone may be conceived as morally wrong also within one's own culture, these acts can also be seen as culturally motivated, although in a different sense to the cultural motivations discussed above. 
Adherence, conformity, preservation, protection and change A more systematic account of different kinds of cultural motivations and their relation to cultural defence is in order. To recall, cultural defence maintains that the diminishing of the defendant's culpability should be based on the defendant's reasonable good-faith belief in the propriety of his/her action, based on his/her cultural heritage or tradition. In the light of the motivations discussed so far, the substantive motivations of wanting to adhere to the norms and values of one's culture would seem to fit best to this description. Should one's motivation to marry more than one wife, for example, lie in one's belief that this is, according to the norms and values of one's culture, the right thing for one to do, I see no reason for why the criminal courts should not take this into account as a potentially mitigating factor in the assessment of the case at hand. ${ }^{516}$ Whereas the requirement of having a reasonable good faith belief in the propriety of one's action does provide certain qualifications to the kinds of actions cultural defence can be applied to, ${ }^{517}$ as a default, one's wish to adhere to the norms and values of one's culture should be seen as the kind of motivation fitting well with the basic tenets of cultural defence.

More difficult cases are brought forth by the variety of instrumental motivations. As already indicated, one's motivation to, say, marry more than one wife may not be based on one's belief that this is the right thing for one to do (one may, on the contrary, even think of polygamy as morally wrong), but one may, nevertheless, marry more than one wife due to one's will to conform to the views of others and be recognized by one's peers as a full member of the group. The question is, should this kind of

\footnotetext{
${ }^{516}$ As already discussed, this does not mean that all actions, conceived as the right thing to do by the defendant, should automatically diminish the defendant's culpability, as the final assessment of the case needs to take all relevant details into account, including the balancing of the interests of all parties involved.

${ }^{517}$ To be discussed in more detail in 3.2.
} 
Part II Liberal Multiculturalism and Minority Rights in Practice

motivation qualify as a good-faith belief in the propriety of one's action, if it is solely based on one's wish to conform to the expectations of others, rather than on one's belief in the rightness of one's actions. Although I do not wish to deny the importance of external recognition, ${ }^{518}$ or the very genuine pressures that people may encounter in order to conform to the expectations of others, I do, nevertheless, believe that there is something substantively different between the motivations of adherence and conformity, and that this difference should also be acknowledged by the criminal courts. Whereas one's motivation to adhere to the norms and values of one's culture fits directly to the basic tenets of cultural defence, the motivation of conformity may perhaps better be understood in terms of external pressure, and be also better assessed under defences such as duress (or provocation).

With respect to the motivation of preservation, slightly different difficulties arise. In these cases, one's motivation to engage in a particular cultural practice comes not from one's wish to adhere to the norms and values of one's culture, nor from one's wish to belong, but rather from one's wish to preserve the availability of certain practices in one's culture. One may, for example, marry more than one wife, not because one thinks this to be the right thing for oneself to do (one may even feel slightly disturbed by the prospect of oneself in a polygamous marriage), but because one views the permissibility of polygamy as one of the distinctive features of one's culture, and wishes to preserve the availability of this option also for future generations. Whereas one's motivation to engage in polygamy is not based on the view that this would be, for the practitioner himself, the right thing to do, it may, nevertheless, be based on the view that, in order to preserve the permissibility of this practice for others, one feels obliged to participate in such practice oneself.

The motivation of protection is closely related to the motivation of preservation, although, for my purposes, it is important to discuss these separately. In the case of protection, one does not only wish to

${ }^{518}$ See also Ch. $4 \& 5$. 
preserve the viability of a particular practice in one's culture, but also sees that it is necessary to act in a particular manner in order to protect one's culture from unwanted influences. Whereas in the case of one engaging in a polygamous marriage, the line between preservation and protection may be difficult to $\operatorname{draw}^{519}$, it is clear that the motivation of protection may also take much stronger forms than the mere participation in those practices that one wishes to preserve. For example, the so-called honour crimes may be done precisely from the motivation of protecting one's culture from unwanted influences by shedding a cautionary example of what happens to those who go against the rules and norms one wishes to protect. The performer of such actions does not, necessarily, need to believe that these actions are, within the norms and values of his culture, morally right, although he may believe that such actions are, nevertheless, necessary in order to protect his culture against unwanted influences. ${ }^{520}$ The complexity of these cases is highlighted by the fact that the motivations of protection (like those of conformity and preservation) may also be conjoined with certain elements of adherence. The performer of, for example, certain crime of honour may genuinely believe that his actions were in accordance with the norms and values of his culture and that, in the given circumstances, he did what was, in the lights of his own culture, the right thing to do.

What should be apparent from the above discussions is that precisely the same action can be performed from a variety of cultural motivations, but that not all of these motivations fall neatly

\footnotetext{
519 The difference being in one's views on why one fears that the viability of polygamy is being cast under doubt in one's culture. Whereas one may wish to engage in polygamy in order to preserve the viability of this practice (regardless of the reasons for why this practice is seen as ceasing), one's wish to protect also incorporates a view of an external threat against which one's behaviour is directed.

${ }^{520}$ One's belief in the necessity of one's actions despite of one's belief that these actions are, in one's own culture, wrong, may, of course, come from a variety of sources, including the sources of external pressure or one's wish to conform to the expectations of others.
} 
Part II Liberal Multiculturalism and Minority Rights in Practice

within the realm of "a reasonable good-faith-belief in the propriety of one's action, based on one's cultural heritage or tradition". As will be discussed in the upcoming section (3.2.), the current practices of identifying those cases in which cultural defence may be applied, do not, however, take the variety of these motivations sufficiently into account. In order to see why this may be a problem, let me bring in yet another type of cultural motivation, that of change.

Apart from the instrumental motivations of conformity, preservation and protection, one's actions may also be instrumentally motivated by one's wish to change one's culture or some aspects of it. For example, one may participate in a particular practice, because one thinks that this practice should be acceptable in one's culture, even if, according to the dominant interpretations, it is not permitted. One may, for example, marry more than one wife because one thinks that polygamy should be an acceptable practice in one's culture, even if the prevailing interpretations of one's cultural norms and values prohibit such practice. Or, one may resort to actions that are targeted to change the minds of others, even if one does not believe that these actions themselves are in accordance with the norms and values of one's culture. For example, in order to change the patriarchal structures of one's group to more egalitarian ones, ${ }^{521}$ one may resort to actions that one does not believe to be morally right in one's culture, but that one believes are, nevertheless, required for such change to happen. One may, for example, disobey one's elders even if, as a default, one does not believe that one's culture allows this kind of disobedience. Or, in the most extreme cases, one may resort to violence against those upholding the kinds of structures one wishes to change, even

\footnotetext{
${ }^{521}$ It should be noted that the "new" egalitarian structures may well be the kinds of structures that one genuinely believes to be in accordance with one's cultural norms and values and that, from the actor's point of view, it is not so much a question of changing one's culture, but rather of bringing the dominant practices in line with what one views as the correct interpretations of one's culture.
} 
if one does not, as a default, believe violence to be condoned in one's culture.

Whereas the instrumental motivation of change may not, along with the other instrumental motivations of conformity, preservation and protection, fit well with the idea of having a reasonable goodfaith belief in the appropriateness of one's action, it is important to note that these actions, too, may incorporate certain elements of adherence. One may, for example, marry more than one wife, because one genuinely believes polygamy to be the correct interpretation of one's culture, or one may disobey one's elders, because one genuinely believes that independent decision making and freedom of action are central values of one's culture. The crucial difference, in these cases, is that, whereas actions based on conformity, preservation or protection tend to coincide with the general, dominant interpretations of one's culture, the actions based on change are often connected to the non-dominant, even marginal interpretations of one's culture. From the perspective of cultural defence and the requirement of the defendant's reasonable goodfaith belief in the propriety of his/her action, it should not, however, make a difference whether one's belief is based on the dominant or non-dominant interpretations of one's culture, but rather, whether the defendant genuinely believes that, within the norms and values of his/her culture, what he did was a right thing to do. ${ }^{52}$

\subsection{Establishing motivations in criminal courts}

As noted by Alison Renteln, the lack of clear guidelines into when and how culture can be used in criminal courts has led to a situation where the allowing of cultural evidence has often been left to the

${ }^{522}$ One could object by saying that reasonable good-faith beliefs only include those beliefs that coincide with the prevailing, dominant interpretations of the norms and values of one's culture. In the light of the view of cultures as heterogeneous and changing, this objection does, however, lose its force. Whereas it may well be that not all interpretations of one's culture can be conceived as reasonable, there is, nevertheless, substantive scope for variation. 
Part II Liberal Multiculturalism and Minority Rights in Practice

discretion of the judges. ${ }^{523}$ In cases where cultural factors have been allowed to play part, the usages of culture have been extremely varied, and abuses of cultural defence have not been avoided. ${ }^{524}$ As the usage of culture has become more common (and accepted) in criminal courts, it has also become important to establish guidelines into the ways in which culture can operate in criminal courts. Unfortunately, as I try to show in this section, neither the existing practices nor the suggested guidelines have been able to provide frameworks that would treat all minority members fairly and equally. The existence of different kinds of cultural motivations has largely been ignored, and the basic idea of cultural defence as diminishing the defendant's culpability on the grounds of his/her "good-faith belief in the propriety of their action" has been marginalized. This, I try to argue, has largely to do with an overt concentration on the apparently objective elements of the defendant's culture at the expense of the defendant's motives, and an insufficient treatment of the alternative interpretations of the existing cultural norms and practices. Instead of concentrating on the (apparently) objective elements of minority cultures, I suggest that the criminal courts should pay more attention to the motivations of those individuals who have committed the crimes in question by utilizing a more sophisticated reading of both the minority cultures in question, as well as the variety of ways in which people can be motivated by their culture.

${ }^{523}$ Renteln 2004; 2010.

${ }^{524}$ Renteln discusses cases such as People v. Rhines (1982), a rape case in which the defence attempted to establish a link between 'the customary loud voice of African-Americans' and the presumption of consensual sex, as well State v. Bauer (1996), where the defendants' Rastafarianism was attempted as an excuse for a multi-million dollar marihuana farm. (Renteln 2010,68-71) Whereas these two cases come across as obvious attempts to misuse cultural defence, it is clear that there is always a possibility that the claims, utilizing cultural factors, are flawed, and the task of the courts is to identify which of these claims are genuine. 


\section{Expert testimony}

In cases where the defendant's cultural background is suspected to have influenced the defendant's behaviour, the question to be asked remains whether the behaviour of the defendant falls within the kinds of behaviour that should also affect the defendant's culpability in criminal courts. That is, whether the defendant can be seen as having acted in a reasonable good-faith belief in the propriety of his/her action, based on his/her cultural heritage or tradition, and whether this good-faith belief should also affect the final judgement of the case. Not all actions that are claimed to have been performed in a good-faith belief are, after all, genuine and the task of the criminal courts is to establish whether this is so in particular cases.

In order to establish the authenticity ${ }^{525}$ of the cases at hand, the criminal courts often resort to expert testimonies to explain the traditions and practices of the defendant's culture. As Renteln notes:

It is unclear who is entitled to say whether or not a practice is "genuine". The practice may never have been part of the culture, or it may have fallen into desuetude. Expert witnesses play a crucial role in cultural defence cases by verifying the existence of traditions and by helping to show whether the tradition actually influenced the individual in particular situations. Without the benefit of their expertise, courts are often incapable of making sense of the cultural arguments advanced in specific cases. ${ }^{526}$

For Renteln, the expert witnesses are ideally external experts (anthropologists, social scientists, regional experts, etc.), who are not themselves members of the group in question, although she does also acknowledge the possibility of consulting the leading

${ }^{525}$ By "authenticity" in this context I refer simply to the question of whether the defendant's claims to have acted in good-faith belief (based on his cultural heritage or tradition) are genuine.

${ }^{526}$ Renteln 2004, 11. 
Part II Liberal Multiculturalism and Minority Rights in Practice

members of the community to explain the details and the significance of any particular practice or tradition to the courts. ${ }^{527}$ This usage of the members of cultural groups is, however, questioned for two reasons. Firstly, Renteln notes that there may not be consensus on the interpretations or significance of particular cultural practices within the cultural group, and the usage of expert witnesses from within the group is likely to lead to bias, only giving validity to those interpretations that the witness in question happens to support. Secondly, Renteln worries that the internal witnesses may succumb to the pressures of misrepresenting their culture in order to save a friend or relative, thus working against rather than for the purposes of the court. ${ }^{528}$

Whereas my intention is not to question the importance of using reliable expert witnesses in cultural defence cases, I do, nevertheless, wish to point to two difficulties that the use and the role of expert testimonies may bring. Firstly, contrary to Renteln who emphasizes the role of external expert witnesses, it is quite clear that the real experts of cultural interpretations are found from within that culture - from those who adhere to the norms and values of that culture. ${ }^{529}$ The problem of acquiring biased information by listening only to the leader(s) of the group is, of course, very real and calls for a more inclusive approach to choosing the expert witnesses. The current leaders of the group cannot be given sole authority to define what is genuine in any particular culture, but the

\footnotetext{
${ }^{527}$ Renteln 2004, 11; 206.

${ }^{528}$ Renteln 2004, 206; 2010, 81. Renteln also discusses two other reasons for not using insiders as expert witnesses, one relating to the possibility that the insiders may be prohibited from disclosing all (e.g. sacred) information to the courts, the other relating to the likely level upon which different types of witnesses are able to persuade the court. (ibid.) I will not comment on these considerations here.

${ }^{529}$ As Marie Deveney (1992) has noted, the views of the actual members of the group are seldom heard in criminal courts, but the defining of cultural practices is left to the anthropologists and social scientists. Deveney 1992.
} 
non-dominant interpretations must also be heard. ${ }^{530}$ The purpose of using external expert witnesses may, of course, be precisely this, although one should not ignore the danger that the testimonies of the external experts may well follow the more prominent interpretations of culture, giving some space for disagreement, but not being able to balance out all the biases resulting from the internal power hierarchies of the group. ${ }^{531}$ In order to guarantee fair and equal treatment of all minority members (including those whose cultural interpretations deviate from the dominant norm), the courts should aim at a wide basis for understanding how and why the defendant may have been culturally motivated to commit the crime in question. This may require listening to not only the external experts or the leaders of the group but also those whose voices are not normally viewed as authoritative in cultural matters, including younger women, and the more progressive as well as radical elements of the group. ${ }^{532}$

The acquiring of a broader basis of expert witnesses may also be used to respond to Renteln's second worry, that of the possibility of the internal witnesses succumbing to the pressures of misrepresenting their culture in order to save a friend or a relative.

\footnotetext{
${ }^{530}$ The calls for listening to the non-dominant fractions of cultural groups, including younger women, are not, of course, new, nor are they restricted to the court rooms. See e.g. Okin 1999; 2005; Benhabib 2002.

531 The problems relating to the usage of external expert witnesses vary from outright flawed testimonies (see e.g. Volpp 1994 on the case of People v. Chen), to the prejudices inherent in the legal system itself. As Madhavi Sunder points out, the courts tend to reinforce static and homogeneous views of culture, making no accommodation for cultural dissenters. (Sunder 2001) See also Phillips 2007 on the tendency of the courts to favour accounts offered by older rather than younger generations. This tendency, Phillips continues, is not only inherent in the operations of the courts, but may also be prevalent among e.g. social workers, who may well be called in as external expert witnesses in cultural cases. (Phillips 2007, 74-77)

${ }^{532}$ I will return to the ways in which the broader bases of witnesses may contribute to the establishing of the defendant's motivations in more detail in my discussions of the so-called "cultural defence test".
} 
Part II Liberal Multiculturalism and Minority Rights in Practice

Obviously, the courts should ensure, as far as possible, that the credibility of the witnesses is not diminished by their too close a relation to the defendant. Of course, the possibility of bias, in the case of internal expert witnesses, cannot be fully abolished, but it can certainly be minimised, at least partially by the same methods as for the possible biases of the external witnesses. As Renteln herself notes, there should be clear guidelines and codes of ethics to expert witnesses, and I see no reason why these guidelines should apply only to external experts. ${ }^{533}$ Furthermore, whereas it is surely possible for the internal witnesses to distort cultural evidence for the benefit of either the defendant or the victim, this problem is, by no means, restricted to the usage of internal witnesses, but may be equally valid in cases of external experts working as "hired guns" for either the defence or prosecution. ${ }^{534}$ Although I thus agree with Renteln that the avoiding of bias and the ensuring of the credibility of the expert witnesses requires, among other things, clearer guidelines and codes of ethics, I disagree that the best way to ensure fair presentation of minority cultures would be by concentrating on external expert witnesses. On the contrary, in order to ensure fair presentation of the more marginal or suppressed elements of the group, there needs to be a broader basis of expert witnesses, ideally combining both internal as well as external expert witnesses.

Secondly, whereas the expert witnesses (external and internal) may well be used to confirm the existence of a particular practice as

533 It may be objected that external witnesses are professionals (researchers, social workers, regional experts) who give their testimony as professionals (and are thus also bound by their professional codes of conduct) whereas internal witnesses may be private individuals (not bound by the same professional codes of conduct). However, whereas this is at times true, it is, by no means, always the case. To the contrary, the internal expert witnesses may include group leaders, clerics, representatives of women's groups (or other smaller associations), who are thus not giving their testimonies purely as private individuals. Further, there is no reason to think why someone, simply by virtue of being a private individual from a particular group, should be deemed unreliable, as the general codes of conduct surely apply also to the private individuals of minority groups.

${ }^{534}$ Cf. Renteln 2004, 206. 
well as help explain its role and significance within the cultural group (or some of its fraction), the role of the expert witnesses should not be exaggerated. The focus of the expert witnesses is, after all, on cultural interpretations and on the role of particular cultural norms, values or practices in the abstract, not on whether the defendant in particular may have been thus influenced. As discussed in the previous section, identical actions can be performed from a variety of cultural motivations and, even if the action itself could be interpreted as being in line with the norms and values of the defendant's culture, this does not necessarily mean that the actor would have also performed the action for the right reasons - that is, because, due to their cultural background, they genuinely believed their action to be the right thing to do.

\section{Cultural defence test}

Whereas the usage of expert witnesses in cultural defence cases is relatively common, ${ }^{535}$ it is clear that the expert testimonies do not, on their own, suffice to establish the authenticity of the cases at hand. The expert testimonies concentrate primarily on the establishing of the existence of some cultural practice or tradition, and on explaining its meaning and potential significance within a cultural group. They do not, however, say anything, as yet, about how the defendant in question may have been influenced by their culture, or whether the defendant is, thus, eligible to use the cultural evidence for his/her benefit. Acknowledging the potential abuses of cultural defence, Renteln proposes that the courts utilize so-called cultural defence test to help avoid abuse.

The cultural defence test incorporates three basic questions that the courts would need to ask in cases where the defendant's cultural background seems relevant for the assessment of the case at hand:

\footnotetext{
${ }^{535}$ Of course, not all cultural defence cases incorporate or give strong role to expert witnesses as demonstrated by our initial example case of Jacob Zuma's rape trial, where the acknowledged interpretations of Zulu culture were largely based on the defendant's own behaviour and testimonies. See e.g. Robins 2008.
} 
Part II Liberal Multiculturalism and Minority Rights in Practice

1) Is the litigant member of the ethnic group?

2) Does the group have such a tradition?

3) Was the litigant influenced by the tradition when he or she acted? ? $^{536}$

Should one or more of the answers be negative, Renteln argues, the usage of cultural defence should be deemed inappropriate. ${ }^{537}$ Interestingly, the three basic questions of the test each focus on slightly different aspects of culture and of the defendant, and may also require slightly different methods to be answered to.

The second question of the cultural defence test correlates most directly with the common task of the expert witnesses who are brought to the courts to explain the existence, prominence as well as the potential significance of particular cultural practices to the courts. Importantly, as discussed earlier, these expert witnesses should be chosen to give as unbiased picture of the cultural practices as possible, in order to cater also for those interpretations that are not necessarily dominant within the group in question. In order to guarantee fair and equal treatment of all members of minority cultures, the courts should ensure that it is not only the voices of the leaders or the elders of the group that are being represented, but also of those who are not normally given the authority to decide which interpretations of cultural contents are "genuine".

The importance of listening also to the non-dominant cultural interpretations in criminal courts comes from two sources. On the one hand, it is important that the defendant, being influenced by their cultural background, and having acted in ways they thought was right, is not disadvantaged or privileged by the fact that the practices or traditions they were adhering to were only marginal or, on the other hand, prevalent practices of their culture. Should the defendant be seen to have acted in a reasonable good-faith belief in the propriety of their action, it should not make a difference

${ }^{536}$ Renteln 2004, 207; 2010, 62

${ }^{537}$ Renteln 2010, 71. 
whether their actions were in line with the most prominent, main stream interpretations of their culture, or with some slightly more marginal understandings. On the other hand, the bringing forth of the alternative interpretations may also help to identify the actual motivations of the defendant by providing important background information to answering the third question of the cultural defence test, that of whether the litigant was influenced by the tradition when he or she acted. ${ }^{538}$

To see why this is the case, let us recall that identical actions may be performed from a multiplicity of cultural motivations, including those of adherence, conformity, preservation, protection, and change. It does, and it also should, however, make a difference whether one's actions are motivated by one's good-faith belief that one is doing the right thing (adherence), or whether one is simply acting in order to please others, or in order to shed an example to those whose cultural interpretations one happens to disagree with. Whereas it is not always easy to make a distinction between the substantive and the instrumental motivations of the defendant, the bringing forth of alternative interpretations helps to highlight the possibility that the defendant may have also acted for other reasons than for having believed that they were, in accordance with their cultural norms and values, doing the right thing. Whereas the establishing of a particular cultural practice or tradition as an element of the defendant's culture is often used to indicate that the defendant was, indeed, acting in good-faith belief in the propriety of their actions, the bringing forth of alternative interpretations should inform the courts of the complexity of the matter, including the possibility of the defendant to have acted from other, perhaps less acceptable, motivations.

${ }^{538}$ As will become clear in due course, I do not entirely agree with Renteln's formulation of the third question. Given the working definition of cultural defence, it is not enough that the defendant is influenced (in whichever way) by some cultural practice or tradition, but that this influence has also lead the defendant to genuinely believe that his actions, according to the norms and values of his culture, were the right thing to do (or, at least, not wrong). 
Part II Liberal Multiculturalism and Minority Rights in Practice

The answering of the third question - that of whether the litigant was influenced by the tradition when they acted - requires much more than the establishing of the existence of such tradition in the defendant's culture. The establishing of the existence of cultural traditions and the understanding of their potential influence may help the courts to understand why, in the lights of the defendant's culture, it may well have been reasonable for the defendant to act the way they did, but it is not enough to establish whether the defendant did, indeed, act due to these influences. As Anne Phillips has forcefully argued, it would be absurd to think that culture (its norms, values, practices) would influence all of its members identically, giving straight forward explanations of people's actions or behaviour. ${ }^{539}$ People can be influenced as well as motivated by their cultures in a variety of ways, and it would also be absurd to think that any culturally induced action should also be conceived as potentially mitigating the defendant's culpability in criminal courts. On the contrary, as indicated by the working definition of cultural defence, the defendant's actions must have also been made for the right reasons, and the identification of these reasons can only be done at the level of the individual. Instead of asking, whether the defendant's actions were influenced by the defendant's cultural traditions, the courts should rather ask, whether the defendant genuinely believed in the rightness of their actions, based on their cultural background, and were thus culturally motivated. Instead of concentrating on the (apparently) objective elements of the defendant's culture (such as the existence and importance of certain traditions or practices), the courts should rather focus on the subjective elements of the defendant (such as their motivations and intentions), even if the assessment of these motivations needs to be done in the context of the defendant's cultural framework. ${ }^{540}$

\footnotetext{
${ }^{539}$ Phillips 2006; 2007.

${ }^{540}$ A strong case for a more individuated, although culturally sensitive, assessment of the cases at hand have also been developed by Leti Volpp, who cautions against the dangers of linking people's behaviour to their group identity. Volpp also shows how the subjective cultural experts (that
} 
In my view, the use of sufficiently unbiased information about the norms, traditions or practices of the minority culture, and the assessing - on a case to case basis - of the defendant's actual motivations for acting the way they did should already suffice to establish the authenticity of the case at hand. But Renteln's cultural defence test incorporates one more question that is supposed to help prevent the misuse of cultural defence in criminal courts. According to Renteln, the courts should also try to establish whether the litigant was a member of the particular group and base the litigant's eligibility to use cultural defence on this membership. According to Renteln "if a person is not a member of the group, then even if the group has the custom in question, he or she cannot claim to have been influenced by the cultural imperative." ${ }^{, 41}$

Given the relatively general consensus about cultural membership as one of the criteria for allocating differentiated rights ${ }^{542}$ it should not come as a surprise that this criterion is also suggested to cases of cultural defence. The using of the criterion of membership is directed to prevent cases, such as Abankwah v. INS (1999), in which the courts were clearly incompetent in establishing the facts of the case, granting political asylum to a person who was not, in the end, a member of the group they claimed to be, nor in danger of being subject to the group practices in case of being returned to their home country. ${ }^{53}$ The criterion of membership is

is, internal expert witnesses) can be used to provide fuller, more nuanced analyses of the cases at hand, taking also into account the individual variations in culturally motivated actions. (Volpp 1994; see also: Volpp 2000)

${ }_{541}$ Renteln 2010, 71.

542 See also discussions in Ch. $1,4 \& 5$.

${ }^{543}$ The case of Abankwah v. INS involved a Ghanaian woman who, after having entered in the USA sought political asylum on the grounds that, should she have been returned to her tribe (Nkumssa) in central Ghana, she may have been subject to female genital mutilation (FGM). After having been granted political asylum, it became apparent that Abankwah's claim was false in several respects, including that she was not necessarily a member of the Nkumssa tribe, nor would she have been subject FGM, as 
Part II Liberal Multiculturalism and Minority Rights in Practice

supposed to guard against opportunistic usage of cultural defence as, in order to establish the authenticity of their claims, the defence must also show that the defendant is, indeed, a member of the group whose rules and traditions they claim to be following, instead of a mere opportunist trying to portray themselves as acting in accordance with their cultural commitments. ${ }^{544}$

In the light of my earlier analyses on the constitution of politically relevant membership (esp. Ch 4), the use of the criterion of membership for the eligibility of the defendant to cultural defence, becomes suspect. The same considerations also show why, in cases such as Abankwah vs. INS, the establishing of the claimant's membership may have produced right outcomes, but why, as a default, the criterion of membership should be rejected.

In my analysis, one's group membership is primarily based on different forms and types of recognition, including the person's own self-identification, the (other) group members' recognition, as well as the recognition of others (including the state) as a member of any particular cultural group. The recognition-based account of group membership was adopted due to it being better able to incorporate heterogeneities in cultural contents, as well as due to it reflecting the political significance of group membership by way of recognizing how one's own behaviour as well as the behaviour of others could depend on whether one was recognized as a member. At the same time, there is always a possibility of there being discrepancies in different actors' recognition, as not all involved may have identical views on who, and on what grounds, counts as a member of any particular group.

In the light of the recognition-based account of membership, it should be clear that one's membership of a cultural group should

FGM was not practiced in central Ghana where she came from. For further details and discussion, see Renteln 2010, 71-74.

${ }^{544}$ For example, in the case of State v. Bauer (1996), there was suspicion that the defendants may not have been Rastafarians, but simply using Rastafarianism as a protective cloak for their endeavours. See: Renteln 2010, 68-71. 
not operate as a necessary requirement for the defendant to be able to claim to have acted in accordance with their cultural commitments. Firstly, it is far from clear who should be allowed to decide whether the defendant is, indeed, a member of the group in question. In the previous discussions, I emphasized the need to listen to the individuals themselves on matters of membership, although, in most cases, the commonly used criteria do not follow the criterion of self-identification. Secondly, even if such decision could be made, ${ }^{545}$ it is far from clear why one's membership should bear upon the authenticity of one's claims. As noted time and again during the course of this work, it is perfectly possible for one to be considered to be a member of a cultural group without them accepting the common (or not so common) norms, values, traditions or practices of the group, just like it is possible for one to be considered a non-member, or ex-member, and still view some of the norms, values, traditions or practices as central to one's identity, and as appropriate guidelines to one's behaviour. It is thus important that the membership in a cultural group does not operate as a necessary requirement for the establishing of the authenticity of the defendant's claims, as it is highly contested, how one's membership is decided, as well as how this membership resonates with one's beliefs on what it is right for one to do.

To reiterate, I do not claim that the establishing of the defendant's membership could not, at times, direct the courts to make right decisions about the authenticity of the defendant's claims, although I do think that one's membership is neither a necessary nor a sufficient requirement for the establishing of such authenticity. As demonstrated by the Abankwah vs. INS -case, the establishing of the claimant's group membership (or nonmembership), could have helped the courts to establish whether the claimant did require political asylum, although it should be

${ }^{545}$ As already indicated, the politically relevant decisions on membership often follow either the (apparent) consensus of the group itself, or some content-based criteria, such as ancestry, the following of the group rituals etc. 
Part II Liberal Multiculturalism and Minority Rights in Practice

remembered that this case was, not only very specific, but also far less straight forward than would at first seem. Firstly, the case of Abankwah vs. INS does not fit well with the more common cases of cultural defence as it was not about the establishing of Abankwah's motivations to act in ways that would be appropriate in her own culture but criminalized by the state law. In Abankwah's claims for asylum, her group membership (or non-membership) could be seen as relevant, as her claims were based on the ways she would be treated by other group members, should she be returned to her home country. Should the courts have found out that Abankwah was not considered to be a member of the Nkumssa (the tribe that, allegedly, would have subjected her to FGM), the courts could have seen the fault in her claims. However, even in this case, Abankwah's membership is relevant only if, firstly, the established membership coincides with the views of membership of the Nkumssa tribe and, secondly, if the threat of FGM is also tied with the tribe's views of one's membership. ${ }^{546}$ On its own, the establishing of the claimant's membership (or non-membership) tells the courts nothing, as it must first be established how this membership (and whose view of membership) relates to those threats or motives that the court is in the process of assessing.

On a more positive note, I believe that the establishing of the authenticity of the defendant's claims can also be done without such focus on the defendant's membership (or non-membership) and the relations in which one's membership stands to one's cultural motivations. As highlighted by the working definition of cultural defence, what the courts should be primarily interested in is whether the defendant had a reasonable good-faith belief in the propriety of his/her action, based on his/her cultural heritage or tradition. The establishment of the existence of this good-faith belief does not, however, require the establishment of one's

\footnotetext{
${ }^{546}$ It should be noted that, in the case of Abankwah v. INS, this latter aspect should also have been deemed as incorrect, not because the practice of FGM was not dependent on the tribe membership, but because the Nkumssa tribe of central Ghana did not normally practice FGM.
} 
membership, but rather, the establishment of the appropriate influence of one's cultural heritage or tradition to one's beliefs on the right modes of action. Recall that, one does not need to be a formal member of a group to be influenced by its norms, values or traditions, although, no doubt, some connection to these values and traditions must be in place. And, in order to establish this, the two other questions of the cultural defence test seem to suffice. Firstly, whether there exist such traditions that the defendant could have been influenced by, and secondly, whether this influence resulted in the defendant believing that, within the norms and values of their culture, they did the right thing. Establishing these two things may, as already discussed, require far more complex and sophisticated understandings of both the existing cultural norms, values and traditions, as well as of the defendant's cultural motivations, but these understandings need not depend on the establishing of the defendant's membership. Rather, in cases of cultural defence, it is the subjective, individuated elements of the defendant's motivations that should be assessed, on the background of those norms and traditions that the defendant may have been influenced by.

\section{Conclusion on liberal individualism and cultural defence}

In this chapter, I have concentrated on one particular debate within multiculturalism, that of the usage of cultural defence in criminal courts. Being closely connected to legal proceedings and to actual court cases, this debate has helped to highlight some of the more concrete problems associated with the accommodation of people's cultural differences in the light of the more individuated approach developed earlier on in this work (Ch. $4 \& 5$ ). With respect to the usage of culture in criminal courts, the on-going discussion has highlighted the difficulties of responding to group's internal heterogeneities and power structures by showing how the current practices as well as the suggested guidelines for using culture in criminal courts may work for the benefit of upholding of the status quo and fail to treat all members of minority cultures fairly and equally. 
Part II Liberal Multiculturalism and Minority Rights in Practice

It should be emphasized that my intention in this chapter has not been to develop normative guidelines on how and when exactly the defendant's cultural background should operate as a mitigating factor in criminal courts. As discussed in section 2 of this chapter, there are good reasons both for as well as against such mitigation, and the balancing of these reasons need to be done on a case to case basis. In general, this assessment should take into account, not only the severity of the crime and the role of the (possible) victim, but also the actual motivation of the defendant to commit the crime in question.

The main focus, and contribution, of this chapter has been on this latter aspect of discussion, that of the analysis of different kinds of cultural motivations, and the possible difficulties of identifying these motivations in criminal courts. I distinguished between five types of cultural motivation - those of adherence, conformity, preservation, protection, and change - and argued that not all of these motivations could be seen as falling within the basic tenets of cultural defence, and the requirement of the defendant to have had "a reasonable good-faith belief in the propriety of his/her actions, based on his/her cultural heritage or tradition". Having outlined some of the difficulties of differentiating between these motivations, I turned to see how in criminal courts the claims of the defendant's good-faith belief were assessed. I discussed two methods of trying to account for the authenticity of the defendant's claims, that of the using of expert testimonies, and that of the socalled cultural defence test. I suggested that, in order for the courts to treat all members of minority cultures equally, two developments to these methods should be made. Firstly, in establishing the existence and the potential significance of a particular cultural practice or tradition, the courts should utilize a broader basis of expert witnesses, including those who are not normally given the power to decide about the prevalent interpretations of their culture. Secondly, in order to establish the defendant's good-faith belief, more attention should be placed on the subjective elements of the defendant's motivations rather than on the apparently objective elements of group membership or the existence of particular 
cultural practices or traditions. Only by focusing on the individuated motivations of the defendants (assessed within the context of their own cultural framework) could the courts be seen as treating members of minority cultures equally, without prioritizing or suppressing some members on the basis of status quo.

As a whole, this Part II (Ch. 4, $5 \&$ 6) has focused on the questions of allocating differentiated rights or, more generally, on the questions of who, and on what grounds, the liberal state should treat differentially. Contrary to Part I (Ch. 1, 2 \& 3) that concentrated mainly on the questions of how to justify culturally differentiated treatment, this part has started from a presumption that there are strong liberal egalitarian grounds for differentiated treatment, and that, in order for such treatment to do the job it is supposed to do (that is, to alleviate cultural disadvantages), questions of allocation must be attended to. The second presupposition, and the main target of this part, has been the commonly accepted view of culturally differentiated treatment as specifically group-differentiated treatment, including group-based and membership-based allocation.

In order to argue for an individual-centred, albeit culturally sensitive, approach for responding to issues of cultural diversity, I have looked at both, the ways in which people may be affected by their culture, as well as the ways in which differentiated treatment (variously construed) may rectify people's cultural disadvantages. By careful analyses of the constitution of group memberships, cultural identities, as well as culturally motivated actions, I have shown some of the flaws of thinking about culturally differentiated treatment primarily in terms of group-differentiated treatment, and the allocation of such treatment primarily in terms of membershipbased allocation. Although I have not attempted to give any concrete policy advice, or even criteria through which to assess the necessity of culturally differentiated treatment in particular cases, these chapters have, nevertheless, shown something important about the focus of those policies that the liberal state may adopt in 
Part II Liberal Multiculturalism and Minority Rights in Practice

circumstances of cultural diversity. Due to the heterogeneities of cultural contents, memberships as well as their influences on individual human beings (including cultural motivations), I have argued that it is essential that the individual (albeit culturally embedded individual) is brought back to the forefront of the discussions. Rather than asking what should be done in order to guarantee fair and equal treatment of members of minority cultural groups, it may be more fruitful to ask what should be done in order to guarantee fair and equal treatment of all individuals, whose needs, wants and well-being may well have been influenced by a variety of sources, including those cultures they are or have been connected to. 


\section{Conclusion}

\section{Liberal multiculturalism and its limits}

As the debates on the accommodation of people's cultural differences within western liberal societies have become more common, they have also become more detailed and fragmented. The theoretical, empirical as well as political discussions on different kinds of groups (national and linguistic minorities, indigenous peoples, immigrants, religious minorities, etc.) as well as on different kinds of minority rights (self-governance, representation, assistance, exemption, symbolic recognition, etc.) have, to a large extent, been differentiated, taking into account the complexity of normative considerations inherent in each. Many of the discussions have also operated within the political and legal contexts of particular societies, directing the debates away from the more abstract questions on the justifiability of differentiated rights within liberalism, to the more pragmatic questions on the kinds of consequences that different cultural policies may have, not only for the minorities or minority members, but also for society at large. The critical assessments of different political models of multiculturalism have also led to scepticism, both with respect to liberal multicultural theories as well as the applicability of these theories in practice. ${ }^{547}$

Whereas acknowledging of the complexity of multicultural issues, and the variety of ways in which these issues are approached, bear many positive aspects to it, the fragmentation of the field has not been an altogether positive development. The

547 Some go as far as to claim that there has been 'multiculturalism backlash' that rejects the basic tenets of multiculturalism and cultural accommodation for more uniform, nationalistic approaches. Whether, and to what extent, such backlash has happened is debatable, as many (although by no means all) multicultural policies have been established as standard policies of accommodation in many countries. For debate, see Vertovec and Wessendorf 2010; Kymlicka 2007. 
contemporary debates owe a lot to the older, more general debates on multiculturalism and minority rights and should also be assessed in the light of these historical roots. Many of the contemporary discussions still utilize the theoretical frameworks developed at the height of the theoretical debates on multiculturalism (late 90's, early millennium), taking these debates as the general frameworks within which to assess the more specific issues at hand. Consequently, many of the flaws and presuppositions of the socalled grand theories ${ }^{548}$ have been transferred into the contemporary debates, leaving some of the crucial presuppositions of liberal multiculturalism unquestioned. ${ }^{549}$

In the light of these developments, the aims of this work have been twofold. On the one hand, I have tried to return to the roots of liberal multiculturalism in order to see why, in contemporary contexts, the liberal multicultural project is seen both as a failure, as well as a framework within which the more specific debates on cultural accommodation should, nevertheless, be conducted. This question has drawn me to look at the very basic questions of liberal multiculturalism, including the questions relating to the initial framing of the debates, and the difficulties this framing has led to with respect to the applicability of liberal multicultural theories in practice.

\footnotetext{
548 In this work, I have used the term "grand theories" to refer to those approaches that attempt to construct a relatively comprehensive account of a variety of multicultural issues (including different types of differentiated rights) based on a particular liberal value such as individual autonomy, equality or freedom of association. See also: Background and introduction to Part I.

${ }^{549}$ This is not to say that all aspects of the so-called grand theories would have gone unquestioned, nor that there would have been no theoretical developments within liberal multiculturalism since. Quite the contrary, the more contextualized approaches have affected, not only actual multicultural policies, but also the theoretical frameworks themselves (for debate, see.: Bader and Saharso 2004; Carens 2004; Kukathas 2004) and many of the most pressing critiques (including issues of cultural heterogeneity and contestability, plurality of group commitments, etc.) are already acknowledged in most contemporary debates on multiculturalism.
} 
On the other hand, I have also tried to point out some of the presuppositions inherent in the more contemporary debates on multiculturalism, including the group-differentiated nature of cultural policies, and the difficulties this group-differentiation brings to the specifically liberal approaches to cultural diversity. My focus on the issues of group-differentiation has led me to look for ways in which the liberal state, engaging in a variety of accommodative measures, could develop these measures by taking better into account both the basic tenets of liberalism as well as multiculturalism. As a result, suggestions for more individuated, yet culturally sensitive approaches to cultural diversity were put forward, bringing the basic liberal commitment to the primacy of the individual back to the centre of debate.

\section{The grand theories and their constraints: theoretical frameworks vs. policy guidance}

In Part I of this work, I concentrated on the so-called grand theories of multiculturalism, assessing them both for internal coherence as well as for scope of application. The applicability of the autonomy, equality and toleration-based approaches to cultural diversity were discussed, not only in the light of their own theoretical frameworks, but also in the context of the more general framework of multiculturalism and liberal multiculturalism in particular.

Drawing from the initial framing of debates, the discussions on liberal multiculturalism can be seen as incorporating three levels of discussion, addressing slightly different issues and being in slightly different relations to one another. ${ }^{550}$ On the most general level are the questions within liberalism itself, with respect to those basic liberal values and principles that any liberal multicultural theory should be committed to. As shown in this work, many of the differences between the grand theories of multiculturalism can be traced back to the differences at this level of discussion, although it is clear that the autonomy, equality and toleration -based arguments

${ }^{550}$ See also: Figure 2, in Background 3.1. 
are also often used conjointly as well as selectively depending on the issues at hand.

The second level of discussion, perhaps at the very centre of debates on liberal multiculturalism, incorporates questions relating to the application of the liberal principles to the circumstances of cultural diversity. The basic questions about the reasons for the liberal state to take cultural considerations into account, and about the justifiability of different cultural policies (including minority rights) within the liberal framework, lie precisely at this level of discussion. For the most part, it was shown that the grand theories of multiculturalism were operating at this level, trying to show why the liberal state should (or should not) take cultural claims seriously, and why differentiated rights were (or were not) compatible with liberalism.

The third level, and the level towards which many of the contemporary debates on multiculturalism have been turning, incorporates questions about the actual cultural policies and the responses that the liberal state should take in particular cases. Should the wearing of burqas and niqabs be banned in public places? Should traditional or religious laws be recognized in domestic matters? Should minority quotas be used in public offices? These are just some of the more concrete questions that liberal multiculturalists, as well as political decision makers, have been confronted with, each incorporating a slightly different set of normative considerations as well as empirical issues to be dealt with.

The relation of these more concrete questions of policy to the other two levels of discussion (liberalism and liberal multiculturalism) is, as I have tried to show, very complex and not as straight forward as one might think. Utilizing the grand theories of liberal multiculturalism may help one to conceptualize some of the normative issues involved, but may not give any straight forward answers to what the liberal state's responses should be in any given circumstances. As my discussions on autonomy, equality and toleration-based approaches showed, the grand theories of multiculturalism were (sometimes contrary to their proponents) 
successful in showing two things. Firstly, why cultural claims and, especially, culturally induced disadvantages are a proper concern of the liberal state and, secondly, that differentiated treatment or differentiated rights (variously construed) are not necessarily incompatible with liberalism. The establishing of these two things does not, however, say anything yet about how cultural matters, or cultural disadvantages, should be responded to, nor does it thus say anything yet about whether differentiated treatment or the granting of differentiated rights should be the appropriate responses to adopt. Rather than giving concrete policy advice, the grand theories of liberal multiculturalism should be viewed as providing frameworks within which the more concrete questions of cultural accommodation can be discussed, leaving considerable scope of legitimate variation to those policies that the liberal state may eventually adopt.

2. Minority rights in practice: group-differentiated rights vs. individuated allocation

Given the success of the liberal multicultural theories in establishing both, strong reasons for the liberal state to take cultural considerations into account, as well as the justifiability of different types of minority rights within the liberal framework, it becomes important to see how, in practice, people's cultural differences are accommodated and how the adopted policies fit within the liberal multicultural framework. The assessment of such questions can take several routes, none of which may, perhaps, be fully satisfactory.

As the discussions on multiculturalism developed, the debates within the field became separated and somewhat fragmented. The debates concerning the general justifiability of minority rights (as a bulk) turned into discussions on different types of rights separately, and further, into debates about particular issues in particular circumstances. One example of this kind of narrowing the focus approach can be found in discussions on Muslim head scarves that focus on particular (set of) practices within particular (set of) communities, and the approaches of the liberal state(s) to these practices. The debates on Muslim head scarves can further be 
narrowed, for example, by contextualizing the debates into particular social and political circumstances, or by focusing on one specific controversy (for example, the banning of burqas and niqabs in public places) and the relevant normative (as well as empirical) questions surrounding this particular issue. ${ }^{55}$

The benefits of focusing on one particular issue (head scarves, or the usage of particular kinds of head scarves in particular circumstances), affecting one particular group (Muslims, or a particular subgroup of Muslims), in one particular social surroundings (in France, Belgium etc.) should be obvious. The more focused the discussion, the better can this discussion take a variety of considerations into account, including factual matters relating to the role and status of the practice both within the group as well as in the wider liberal society. On the down side, it is clear that an assessment of a particular policy (affecting a particular group in particular circumstances) is not going to produce results that would be generally applicable, even to cases that pay close resemblance to the case at hand. ${ }^{552}$

It should be made clear that I fully acknowledge and respect the need for more contextualized and specified analyses and discussions on particular cases and policies, as the normative

551 Perhaps the most well-known group of debates concerning Muslim head scarves has been conducted within the French context of laïcité, and the banning of ostensive religious symbols in public institutions. For overview, see Laborde 2005; 2008; Bowen 2007; McGoldrick 2006; O'Brien 2005. For some attempts to conceptualize the recent bans on burqas, see: Van der Schyff and Overbeeke 2011; Parvez 2011.

552 For example, the debates on the banning of burqas and niqabs (incorporating, among others, questions relating to public recognizability) may not be easily transferred into debates on other types of head scarves for example in employment or in education (involving, among others, questions of equality of opportunity), and neither of these debates may be easily transferred into debates concerning other cultural or religious garments, such as the Jewish yarmulkes or Sikh turbans (that involve, among others, very different kinds of power relations within the groups in question). 
considerations inherent in each are bound to differ. ${ }^{553}$ The more general theoretical frameworks of liberal multiculturalism can provide good starting points for these analyses, by providing certain constraints as well as focal points of discussion. ${ }^{54}$ Whereas the more specified approaches need not be uncritical of the theoretical frameworks upon which they are built, focusing on the many details of the cases at hand may, nevertheless, render some of the theoretical presuppositions unquestioned. One of these presuppositions, that of the conceiving of differentiated rights as specifically group-differentiated rights, has been the starting point of the Part II of this work, requiring also a slightly different approach to the assessment of different cultural policies and their relation to the theoretical frameworks of liberal multiculturalism.

Instead of taking the common approach of assessing the justifiability of different types of minority rights or the effects of particular policies in particular circumstances, in Part II, I have concentrated on a different question of liberal multiculturalism that of the allocation of differentiated treatment or differentiated rights in accordance with the basic tenets of liberal multiculturalism. My enquiry started from a fairly general observation according to which culturally differentiated rights were often viewed as group-differentiated rights, also in the senses in which these rights were granted, either to particular groups as collectives (group rights proper) or to members of these groups by virtue of one's membership in the group in question (membership rights). The acknowledgement of the group-differentiated nature of minority rights led me to look at various questions relating to the constitution of one's membership, the role of one's cultural identity as well as the ways in which culture (variously construed) could be

\footnotetext{
553 See also discussions on the irreducibility of normative considerations relevant for each type of minority right in Background 2.3.

${ }^{554}$ By constraints and focal points, I refer to those values and principles (including liberal individualism, value of liberty, autonomy and equality) that any, specifically liberal approach to cultural diversity cannot ignore. See also: Background 1.2.
} 
seen as affecting people's behaviour, either as a member or nonmember of any particular cultural group.

Like the more specified, narrowing the focus -approaches mentioned above, my approach, too, has certain shortcomings. Firstly, as the issues of multiculturalism, and the adopted culturally differentiated policies, are varied, it has been impossible to build a systematic account of all those cases in which the group-based or membership-based allocation would deserve further scrutiny. In this work, I have thus utilized only a few, albeit well-known and widely discussed examples in order to illustrate my points, not only for the more individuated approach to allocation, but also for the importance of bringing the questions of allocation to the centre of debates on liberal multiculturalism. No doubt, more work on the questions of allocation remains, although if I have convinced the reader about the need and relevance of such work for liberal multiculturalism, I claim some success.

Secondly, it is clear that focusing on the questions of allocation - that is, on the questions of who, and according to which principles, should come under culturally differentiated treatment leaves some of the questions regarding the need for such differentiated treatment unanswered. Instead of asking, who should, for example, be exempt from certain rules or regulations, the objection goes, we should rather ask whether such exemptions are needed in the first place. However, whereas I acknowledge (and have, during the course of my work, acknowledged) the need to ask these latter questions too, ${ }^{555}$ this does not take away the importance of thinking about those principles according to which differentiated rights are allocated. After all, most western liberal societies have adopted some systems of minority rights and, although the culturally differentiated treatment may not always be the best of policies, it may, nevertheless, be an acceptable policy within the liberal multicultural framework. Any policies, whether good or bad, can, of course, always be made better, and my analyses of the

${ }^{555}$ See esp. Ch. 3. 
questions of allocation should be seen as attempts to serve this purpose.

\section{Towards more individuated approach to cultural diversity}

The main claim of this work, that of the need for a more individuated, yet culturally sensitive approach to cultural diversity, has been built by looking at some of the benefits as well as constraints of the traditional, liberal approaches to cultural diversity. As argued in Part I, there are strong reasons for the liberal state to take cultural considerations into account, and to be concerned about people's cultural disadvantages. The cultural bias of liberal institutions, connected with cultural diversity, bring cultural matters into the realm of liberal politics. The potentially tremendous importance of cultural norms and practices to the identities and self-respect of their followers, also provide reasons for the liberal state to at least aim to rectify those disadvantages that result from the incompatibility of these norms or practices with the general rules and norms of the wider society. It may not, of course, be possible, or even justifiable, to accommodate all cultural norms and practices, although, as I argued in Part I, the liberal state should, as a default, view people's interests in adhering to these norms and practices as legitimate, and the disadvantages induced by such adherence as deserving of being rectified.

Importantly, the rationale for the liberal state to be concerned about people's cultural disadvantages and, as a default, to attempt to rectify these disadvantages, say nothing as yet about the kinds of policies through which this could be done, or about the scope within which the effects of such policies should be extended. As the liberal theories of multiculturalism show, differentiated rights are not necessarily incompatible with liberalism, but the justifiability of such rights in any particular circumstances should be done in context. Whereas no comprehensive method for assessing the justifiability of any particular right in any particular circumstances were developed, in this work, I have, nevertheless, emphasized the need to balance the reasons both for as well as against these rights on a case to case basis. In some cases (for example, where cultural 
practices incorporate gross human rights violations), the balance of reason may work against the accommodation of such practices, whereas in other cases, the balance of reasons may well tip to the other side, legitimating also the possibility, albeit not the requirement, for a liberal state to accommodate people's cultural differences with the help of differentiated rights. Provided that in many cases, differentiated treatment or differentiated rights are, indeed, justifiable (although not required) liberal responses to cultural diversity, the question follows: to whom should these rights be extended.

Starting from the relative consensus among liberal multiculturalists about differentiated rights as specifically groupdifferentiated rights, in Part II, I have provided strong reasons for the liberal multiculturalists to reassess this view and to turn rather to more individuated approaches to accommodating people's cultural differences. As shown by the recognition-based account of group-membership, ${ }^{556}$ it is not only cultural contents that should be viewed as heterogeneous and contested, but also people's group memberships, the acknowledgement of which can be done from several different perspectives. The difficulties brought forth by the contestability of people's group memberships can be seen especially clearly in the context of group-differentiated rights that, despite efforts to the contrary, always support certain cultural contents at the expense of others. ${ }^{557}$ Whereas I did not reject the possibility of group membership (that is, the general conception or, what often comes to same thing, the state's recognition of group membership) as an appropriate criterion for allocating differentiated rights in specific cases, ${ }^{558} \mathrm{I}$ did, nevertheless, point out that in many, perhaps even most, cases, more attention should be paid to the person's own views of their culture as well as of their

\footnotetext{
${ }^{556}$ See esp. Ch. 4 and Ch. 5.

${ }^{557}$ For full argument to this effect, see esp. Ch. 1 and Ch. 4.

${ }^{558}$ For example, in cases where the purpose of differentiated treatment is to rectify those disadvantages that result from structural discrimination or general prejudices against particular group of people.
} 
membership. This, it was argued, was necessary in order for the differentiated rights to do the work they were supposed to do without disadvantaging certain individuals or fractions of groups along the way.

The two final chapters - those concerning the debates on the right of exit and on cultural defence - not only clarified some of the details of my approach, but also operated as examples of the ways in which a more individuated, yet culturally sensitive approach to cultural diversity could work in practice. As argued with respect to the discussions on exit, there are several ways in which people's memberships as well as their identities as members of cultural or religious groups can be conceived of. Consequently, one's exit from a cultural group may not be thought of simply in terms of leaving the contours of one's group, but may also incorporate an identityaspect to it - that of renouncing one's belonging as a member of that group. These ways of understanding exit from one's cultural group do not, however, need to go hand in hand, but a person, despite having left the contours of their group, may still identify as a member and view this identification as an inherent element of who they conceive themselves to be. From the perspective of the liberal state, it was argued, the following of people's selfidentifications was to be the preferred approach to the recognizing of people's memberships, for two reasons. Firstly, this recognition, by the liberal state, would provide certain external affirmation to people's identities as group members and, by way of doing so, also contribute to the making of formal rights of exit (as commonly understood) more realistic. Secondly, and more importantly, it is only by tracking the ways in which people themselves identify as group-members (or non-members) that the liberal state manages to steer clear from defining any substantive requirements for group membership, and leaves it to the group members themselves to decide, what these requirements may be.

The final chapter, and my discussions on cultural defence, further elaborated the importance of focusing on individuals (rather than groups or group members) by emphasizing, not only the importance of recognizing the heterogeneity and contestability of 
group memberships and cultural contents, but also of those reasons that people may have for acting "in accordance with their culture". The debates on cultural defence (that is, on the using of culture as a potentially mitigating factor in criminal courts) incorporate important ideas about the ways in which people's actions can be culturally motivated, and how these motivations (or, as I argued, certain types of motivations) may affect the culpability of the actor in criminal courts. In the course of my discussions I did, however, show that not all culturally motivated actions should be conceived of as diminishing the defendant's culpability, and that the suggested methods for identifying these motivations were often far from sufficient. Rather than attempting to establish the existence of a particular practice or tradition in a particular culture, or the defendant's membership in the group with which this practice or tradition is commonly associated, I argued that the courts should pay more attention to those motivations that any particular individual (that is, the defendant) may have for acting the ways they did, not only as a cultural being, but as a person with complex cultural and social backgrounds as well as a variety of personality traits.

Being in line with the general argument of this work, I suggested that, in order for the liberal state (including the criminal courts) to treat all individuals fairly and equally, the influence of different cultures or cultural practices on individuals could not be ignored. The taking into account of cultural factors should not, however, be too strictly connected to any particular cultural groups or people's memberships in these groups, but take better into account individual variations. As it is clear that cultures can be variously interpreted, it should also be clear that the influence of different cultures, however interpreted, are different for different people, at times also independent of their status or relation to the culture or the cultural group in question. 


\section{Bibliography}

Ackerman, B. (1980) Social Justice and the Liberal State. New Haven: Yale University Press.

Addis, A. (1992) "Individualism, Communitarianism and the Rights of Ethnic Minorities”, Notre Dame Law Review 67(3), 615-676.

Amirthalingam, K. (2010) "Culture, Crime, and Culpability: Perspectives on the Defence of Provocation", in: Foblets, M. and Renteln, A.D. (eds.) Multicultural Jurispudence: Comparative Perspectives on the Cultural Defence. Oxford and Portland Oregon: Hart Publishing.

Anderson, E. (1999) "What is the point of Equality?", Ethics 109, $287-$ 337.

Appiah, K.A. (1994) “Identity, Authenticity, Survival”, in: Gutmann (ed.): Multiculturalism: Examining the Politics of Recognition. Princeton, New Jersey: Princeton University Press.

- (1996) "Race, Culture, Identity: Misunderstood Connections", in Appiah, K.A. and Gutmann, A. (eds.) Colour Conscious - The Political Morality of Race. Princeton, New Jersey: Princeton University Press.

- (2001) "Liberalism, Individuality, and Identity", Critical Inquiry 27, 305-332.

- (2005) The Ethics of Identity. Princeton, New Jersey: Princeton University Press.

Archard, D. (2007) "The Wrong of Rape", The Philosophical Quarterly 57(228), 374-393.

Arneson, R. (1989) "Equality and Equal Opportunity for Welfare," Philosophical Studies 56, 77-93.

- (1990) "Liberalism, Distributive Subjectivism, and Equal Opportunity for Welfare", Philosophy and Public Affairs 19(2), 158-194.

- (2002) "Equality of Opportunity", Stanford Encyclopedia of Philosophy, http://plato.stanford.edu/entries/equal-opportunity/ (seen 24.10. 2012)

- (2008) "Justice is not equality", Ratio (new series) XXI, 371-391.

Bader, V. and Saharso, S. (2004): "Introduction: Contextualized Morality and Ethno-Religious Diversity", Ethical Theory \& Moral Practice $7(2), 107-115$ 
Limits of Liberal Multiculturalism

Bala, N. (2011) "Polygamy in Canada: Justifiably Not Tolerated", JURIST - Forum, Dec. 3, 2011, http://jurist.org/forum/2011/12/nicholas-balacanada-polygamy.php (seen 22.10.2012)

Barclay, L. (2005) "Liberalism and Diversity", in: Jackson, F. and Smith, M. (eds.) The Oxford Handbook of Contemporary Philosophy, 155180.

Barry, B. (2001) Culture and Equality: an Egalitarian Critique of Multiculturalism. Cambridge: Polity Press.

- (2002) "Second Thoughts - and Some First Thoughts Revived", in: Kelly, P. (ed.) Multiculturalism Reconsidered. Cambridge and Malden: Polity Press.

Beitz, C. (1979) Political Theory and International Relations. Princeton: Princeton University Press.

Beitz, C. (2005) "Cosmopolitanism and Global Justice", Journal of Ethics 9, 11-27.

Benhabib, S. (ed.) (1996) Democracy and Difference. Princeton, New Jersey: Princeton University Press.

- (2002) The Claims of Culture: Equality and Diversity in the Global Era. Princeton and Oxford: Princeton University Press.

- (2004) The Rights of Others. Cambridge University Press.

Benson, P. (1994) "Free Agency and Self-Worth", The Journal of Philosophy 91(12), 650-668.

Berlin, I. (1969) "Two Concepts of Liberty”, in: Berlin, I.: Four Essays on Liberty. Oxford: Oxford University Press.

Berman, B., Eyoh, D. and Kymlicka , W. (eds.) (2004) Ethnicity and Democracy in Africa. Ohio University Press.

Borchers, D. (2012) "Calculating on Identity? The Costs and Benefits of the Costs-of-Exit Debate", in: Borchers, D. and Vitikainen, A. (eds.): On Exit: Interdisciplinary perspectives on the right of exit in liberal multicultural societies. Berlin and Boston: De Gruyter.

Borchers, D. and Vitikainen, A. (eds.) (2012) On Exit: Interdisciplinary perspectives on the right of exit in liberal multicultural societies. Berlin and Boston: De Gruyter.

Bowen, J.R. (2007) Why the French Don't Like Headscarves: Islam, the State, and Public Space. Princeton: Princeton University Press.

Boxill, B. and Boxill, J. (2003) "Affirmative Action", in: Frey, R.G. and Wellman, C.H. (eds.) A Companion to Applied Ethics. Blackwell Publishing. 
Bibliography

Brubaker, R. (2004) Ethnicity Without Groups. Cambridge, Mass.: Harvard University Press.

Buchanan, A.E. (1989) "Assessing the Communitarian Critique of Liberalism", Ethics 99(4), 852-882.

Burgess-Jackson, K. (ed.) (1999) A Most Detestable Crime. New York and Oxford: Oxford University Press.

Caney, S. (2002) "Equal Treatment, Exceptions and Cultural Diversity", in: Kelly, P. (ed.) Multiculturalism Reconsidered. Cambridge and Malden: Polity Press.

- (2005) Justice beyond Borders: A Global Political Theory. Oxford: Oxford University Press.

Carens, J.H. (1997) "Liberalism and Culture", Constellations 4(1), 35-47.

- (2000) Culture, Citizenship and Community: A Contextual Exploration of justice as Evenhandedness. Oxford: Oxford University Press.

- (2004) "A Contextual Approach to Political Theory", Ethical Theory \& Moral Practice 7(2), 117-132.

Carstens, P.A. (2010) "The Cultural Defence in Criminal Law: South African Perspectives", in: Foblets, M. \& Renteln, A.D. (eds.) Multicultural Jurispudence: Comparative Perspectives on the Cultural Defence. Oxford and Portland Oregon: Hart Publishing.

Christman, J. (1987) "Autonomy: A Defence of the Split-level Self", Southern Journal of Philosophy 25, 281-293.

- (1991) "Autonomy and Personal History", Canadian Journal of Philosophy 21, 1-24.

- (2001) "Liberalism, Autonomy \& Self-Transformation", Social Theory \& Practice 27(2), 185-206.

- (2005) "Procedural Autonomy and Liberal Legitimacy", in: Taylor, J.S. (ed.): Personal Autonomy: New Essays on Personal Autonomy and Its Role in Contemporary Moral Philosophy. Cambridge University Press.

Cohen, G.A. (1989) "On the Currency of Egalitarian Justice," Ethics 99, 906-944.

- (2008) Rescuing Justice and Equality. Cambridge, Mass.: Harvard University Press.

Colburn, B. (2010) Autonomy and Liberalism. New York and London: Routledge.

Coleman, D.L. (1996) "Individualizing Justice through Multiculturalism: The Liberal's Dilemma”, Columbia Law Review 96(5), 1093-1167.

Connolly, W.E. (1991) Identity|Difference. Ithaca: Cornell University Press. 
Limits of Liberal Multiculturalism

Crowder, G.E. (2007) "Two Concepts of Liberal Pluralism", Political Theory 35(2), 121-146.

- (2009) "Thunder versus Enlightenment: A response to Thunder", Political Theory 37(1), 161-166.

Den Uyl, D.J. and Rasmussen, D. (2006) "The Myth of Atomism”, The Review of Metaphysics 59, 841-868.

Deveaux, M. (2000) Cultural Pluralism and Dilemmas of Justice. Ithaca: Cornell University Press.

Deveney, M.R. (1992) “Courts and Cultural Distinctiveness”, University of Michigan Journal of Law Reform 25(3\&4), 867-877.

Dworkin, G. (1988) The Theory and Practice of Autonomy. Cambridge University Press.

- (2005) "Moral Paternalism", Law and Philosophy 24, 305-319.

Dworkin, R. (1978) "Liberalism," in: Hampshire, Stuart (ed.) Public and Private Morality. Cambridge: Cambridge University Press.

- (1981a) "What is Equality? Part 1: Equality of Welfare", Philosophy and Public Affairs 10(3): 185-246.

— (1981b) "What is Equality? Part 2: Equality of Resources", Philosophy and Public Affairs 10(4): 283-345.

- (1989) "Foundations on Liberal Equality", in: Tanner Lectures on Human Values, Vol. 2. Salt Lake City: University of Utah Press.

- (2002) Sovereign Virtue: The Theory and Practice of Equality. Harvard University Press.

Festenstein, M. (2005) Negotiating Diversity: Culture, Deliberation, Trust. Cambridge: Polity Press.

Fischer, Meik (2012) "Minors and the Exit Option under German Law", in: Borchers, D. and Vitikainen, A. (eds.): On Exit: Interdisciplinary perspectives on the right of exit in liberal multicultural societies. Berlin and Boston: De Gruyter.

Foblets, M. and Renteln, A.D. (eds.) (2010) Multicultural Jurispudence: Comparative Perspectives on the Cultural Defence. Oxford and Portland Oregon: Hart Publishing.

Forst, R. (1997) "Foundations of a Theory of Multicultural Justice", Constellations 4(1), 63-71.

Frankfurt, H. (1971) "Freedom of the Will and the Concept of a Person", Journal of Philosophy 68, 5-20.

Fraser, N. and Honneth, A. (2003) Redistribution or Recognition: A Political-Philosophical Exchange. London, New York: Verso. 
Freeman, S. (2002) "Liberalism and the Accommodation of Group Claims", in: Kelly, P. (ed.) Multiculturalism Reconsidered. Cambridge and Malden: Polity Press.

Friedman, M. (1986) "Autonomy and the Split-level Self", Southern Journal of Philosophy 24, 19-35.

- (2003) Autonomy, Gender and Politics. Oxford University Press.

Galeotti, A.E. (2002) Toleration as Recognition. Cambridge: Cambridge University Press.

Galston, W. (1995) “Two Concepts of Liberalism”, Ethics 105, 516-534.

- (2002) Liberal Pluralism: The Implications of Value Pluralism for Political Theory and Practice. Cambridge: Cambridge University Press.

- (2005) The Practice of Liberal Pluralism. Cambridge: Cambridge University Press.

Gaus, G. (2003) "Liberal Neutrality: A Compelling and Radical Principle", in: Wall, S. and Klosko, G. (eds.) Perfectionism and Neutrality: Essays in Liberal Theory. New York and Oxford: Rowman and Littlefield.

Geertz, C. (1973) The Interpretation of Cultures. New York: Basic Books.

Glazer, N. (1997) We Are All Multiculturalists Now. Cambridge, Mass. Harvard University Press.

Goldstein, T.F. (1994) "Cultural Conflicts in Court: Should the American Criminal Justice System Formally Recognize A "Cultural Defence”?", Dickinson Law Review 99, 141-168.

Golding, M. P. (2002) "The Cultural Defence", Ratio Juris 15(2), 146158.

Goodin, R.E. (2006) "Liberal Multiculturalism: Protective and Polyglot", Political Theory 34(3), 289-303.

Gould, C. (2001) "Group Rights and Social Ontology", in: Sistare, C., May, L. and Francis, L. (eds.): Groups and Group Rights. University Press of Kansas.

Gracia, J. (2006) "Individuality, Life Plans, and Identity: Foundational Concepts in Appiah's The Ethics of Identity", Journal of Social Philosophy 37(2), 283-291.

Gray, J. (1986) Liberalism. Milton Keynes: Open University Press.

- (2000) Two Faces of Liberalism. New York: The New Press.

Griffin, J. (1986) Well-Being: Its Meaning, Measurement, and Moral Importance. Oxford: Oxford University Press. 
Limits of Liberal Multiculturalism

Gutmann, A. (1986) “Communitarian Critics of Liberalism”, Philosophy \& Public Affairs 14(3), 308-322.

- (2003): Identity in Democracy. Princeton and Oxford: Princeton University Press.

Hacking, I. (1992a) "Making Up People", in Stein, E. (ed), Forms of Desire: Sexual Orientation and the Social Constructionist Controversy. New York and London: Routledge.

- (1992b) "World-Making by Kind-Making: Child Abuse for Example", in: Douglas, M. and Hull, D. (eds.) How Classification Works: Nelson Goodman among the Social Sciences. Edinburgh University Press.

Hansson, S.O. (2004) "What are opportunities and why should they be equal?", Social Choice and Welfare 22: 305-316.

Hartney, M. (1991) "Some Confusions Concerning Collective Rights", Canadian Journal of Law and Jurisprudence 4(2), 293-314.

Hassim, S. (2009) “Democracy's Shadows: Sexual Rights and Gender Politics in the Rape Trial of Jacob Zuma", African Studies 68(1), 5777.

Hirschmann, N.J. (2003) The Subject of Liberty: Toward a Feminist Theory of Freedom. Princeton and Oxford: Princeton University Press.

Holtug, N. and Lippert-Rasmussen, K. (2007) Egalitarianism: New Essays on the Nature and Value of Equality. Oxford, New York: Oxford University Press.

Holtzleithner, E. (2012) "Interrogating Exit in Multiculturalist Theorizing: Conditions and Limitations", in: Borchers, D. and Vitikainen, A. (eds.) On Exit: Interdisciplinary perspectives on the right of exit in liberal multicultural societies. Berlin and Boston: De Gruyter.

Honneth, A. (1997) "Recognition and Moral Obligation", Social Research 64(1), 16-35.

- (2001) "Recognition or Redistribution? Changing perspectives on the Moral Order of Society", Theory, Culture \& Society 18(2-3), 43-55.

IslamToday (2011) "BC Supreme Court's Polygamy Ruling Sets Limits on Canada's Religious Freedom" (4 ${ }^{\text {th }}$ Dec. 2011) http://en.islamtoday.net/artshow-230-4268.htm (seen 22.10.2012)

Johnson, J. (2000) "Why Respect Culture?", American Journal of Political Science 44(3), 405-418.

Johnston, D. (1989) "Native Rights as Collective Rights", Canadian Journal of Law and Jurisprudence 2(1), 19-34.

Jones, P. (1999) "Human Rights, Group Rights, and People's Rights", Human Rights Quarterly 21(1), 80-107. 
- (2006) "Toleration, Recognition and Identity", The Journal of Political Philosophy 14(2), 123-143.

Kelly, P. (2002) "Introduction: Between Culture and Equality", in: Kelly, P. (ed.) Multiculturalism Reconsidered. Cambridge and Malden: Polity Press.

Kenny, M. (2004) The Politics of Identity: Liberal Political Theory and the Dilemmas of Difference. Cambridge and Malden: Polity.

Killmister, S. (2011) "Group-Differentiated Rights and the Problem of Membership", Social Theory and Practice 37(2), 227-255

Kim, N.S. (2006) "Blameworthiness, intent, and Cultural Dissonance: The Unequal Treatment of Cultural Defence Defendants", University of Florida Journal of Law and Public Policy 17/2, 199-229.

Kraybill, D. (ed.) (2003): The Amish and the State (2 ${ }^{\text {nd }}$ edition). Baltimore, Maryland: The Johns Hopkins University Press.

Kukathas, C. (1992a) “Are There Any Cultural Rights?”, Political Theory 20(1), 105-139.

- (1992b) "Cultural Rights Again: A Rejoinder to Kymlicka", Political Theory 20(4), 674-680.

- (1997a) "Multiculturalism as Fairness: Will Kymlicka's Multicultural Citizenship", The Journal of Political Philosophy 5(4), 406-427.

- (1997b) "Cultural Toleration", in: Shapiro and Kymlicka (eds.): Ethnicity and Group Rights, NOMOS XXXIX. New York and London: New York University Press.

- (1998) "Liberalism and Multiculturalism: The Politics of Indifference", Political Theory 26(5), 686-699.

- (2001) "Can a Liberal Society Tolerate Illiberal Elements", Policy 17(2), 39-45.

- (2003) The Liberal Archipelago: A Theory of Diversity and Freedom. Oxford Political Theory.

- (2004) "Contextualism Reconsidered: Some Skeptical Reflections", Ethical Theory \& Moral Practice 7(2), 215-225.

- (2012) "Exit, Freedom, and Gender", in: Borchers, D. and Vitikainen, A. (eds.) On Exit: Interdisciplinary perspectives on the right of exit in liberal multicultural societies. Berlin and Boston: De Gruyter.

Kymlicka, W. (1989) Liberalism, Community and Culture. Oxford: Clarendon Press.

- (1992) "The Rights of Minority Cultures: Reply to Kukathas", Political Theory 20(1), 140-146. 
Limits of Liberal Multiculturalism

- (1995) Multicultural Citizenship: A Liberal Theory of Minority Rights. Oxford: Clarendon Press.

- (1997) "Do we need a liberal theory of minority rights? Reply Carens, Young, Parekh and Forst", Constellations 4(1), 72- 87.

- (2001) Politics in the Vernacular: Nationalism, Multiculturalism, and Citizenship. Oxford: Oxford University Press.

- (2002) Contemporary Political Philosophy, $2^{\text {nd }}$ edition. Oxford University Press.

- (2007a) Multicultural Odysseys: Navigating the New International Politics of Identity. Oxford: Oxford University Press.

- (2007b) "The new debate on minority rights (and postscript)", in: Laden, S. and Owen, D. (eds.): Multiculturalism and Political Theory. Cambridge and New York: Cambridge University Press.

Kymlicka, W. and Banting, K. (eds.) (2006) Multiculturalism and the Welfare State: Recognition and Redistribution in Contemporary Democracies. Oxford: Oxford University Press.

Kymlicka, W. and Opalski, M. (eds.) (2001) Can Liberal Pluralism Be Exported?: Western Political Theory and Ethnic Relations in Eastern Europe. New York: Oxford University Press.

Laborde, C. (2005) : "Secular Philosophy and Muslim Headscarves in Schools", The Journal of Political Philosophy 13(3), 305-329.

- (2008) Critical Republicanism: The Hijab Controversy and Political Philosophy. Oxford and New York: Oxford University Press.

Levy, J.T. (1997) "Classifying Cultural Rights", in: Shapiro, I. and Kymlicka, W. (eds.) Ethnicity and Group Rights. New York: New York University Press.

— (2004) "Liberal Jacobinism", Ethics 114, 318-336.

- (2009) "Multicultural Manners", available at SSRN: http://ssrn.com/ abstract=1403687 or http://dx.doi.org/10.2139/ssrn.1403687

Lippert-Rasmussen, K. (2006) "The Badness of Discrimination”, Ethical Theory and Moral Practice 9, 167-185.

- (2007) "Nothing Personal: On Statistical Discrimination", The Journal of Political Philosophy 15(4), 385-403.

Loobuyck, P. (2005) "Liberal multiculturalism: A Defence of liberal multicultural measures without minority rights", Ethnicities 5(1), 108135.

Lukes, S. (2003) Liberals \& Cannibals. London and New York: Verso.

Lyman, J.C. (1986) "Cultural Defence: Viable Doctrine or Wishful Thinking”, Criminal Law Journal 9, 87-117. 
Lyon, D. \& Spini, D. (2004) "Unveiling the Headscarf Debate", Feminist Legal Studies 12, 333-345.

Ma, V. (1995) "Cultural Defence: Limited Admissibility for New Immigrants", San Diego Justice Journal 3, 461-484.

MacIntyre, A. (1981) After Virtue. London: Duckworth.

Mackenzie, C. \& Stoljar, N. (eds.) (2000) Relational Autonomy: Feminist Perspectives on Autonomy, Agency and the Social Self. Oxford University Press.

Magnarella, P.J. (1991) "Justice in a Culturally Pluralistic Society: The Cultural Defence on Trial", Journal of Ethnic Studies 19, 65-84.

Margalit, A. and Halbertal, M. (1994) "Liberalism and the Right to Culture", Social Research 61(3), 491-510.

Martin, R. and Reidy, D.A. (eds.) (2006) Rawls's Law of Peoples: A Realistic Utopia? Blackwell Publishing.

Mason, A. (2000) Community, Solidarity and Belonging. Cambridge: Cambridge University Press.

- (2006) Levelling the Playing Field: The Idea of Equal Opportunity and its Place in Egalitarian Though . Oxford: Oxford University Press.

- (2007) "Multiculturalism and the critique of essentialism", in: Laden, S. and Owen, D. (eds.): Multiculturalism and Political Theory. Cambridge and New York: Cambridge University Press.

May, L. Sistare, C. and Schonshecke, J. (eds.) (1997) Liberty, Equality and Plurality. Lawrence: University Press of Kansas.

May, S., Modood, T. and Squires, J. (2004) "Ethnicity, nationalism, and minority rights: charting the disciplinary debates", in: May, S., Modood, T. and Squires, J. (eds.): Ethnicity, Nationalism and Minority Rights. Cambridge University Press.

McDonald, M. (1991) "Should Communities Have Rights?", Canadian Journal of Law and Jurispudence 4(2), 217-237.

McGoldrick, D. (2006) Human Rights and Religion: The Islamic Head Scarf Debate in Europe. Oxford and Portland, Oregon: Hart Publishing.

Mendus, S. (1989) Toleration and the Limits of Liberalism. Basingstoke: Macmillan.

- (2002) "Choice, Chance and Multiculturalism", in: Kelly, P. (ed.) Multiculturalism Reconsidered. Cambridge and Malden: Polity Press.

Meyers, D.T. (1989) Self, Society, and Personal Choice. New York: Columbia University Press. 
Limits of Liberal Multiculturalism

Mill, J.S. (1986) [1859] On Liberty. New York: Prometheus Books.

Miller, D. (1995) On Nationality. Oxford: Clarendon Press.

- (2000) Citizenship and National Identity. Cambridge: Polity Press.

- (2002a) "Group Rights, Human Rights and Citizenship", European Journal of Philosophy 10(2), 178-195.

- (2002b) "Liberalism, Equal Opportunities and Cultural Commitments" in: Kelly, P. (ed.) Multiculturalism Reconsidered. Cambridge and Malden: Polity Press.

- (2005) "Against Global Egalitarianism”, The Journal of Ethics 9, 5579

Moellendorf, D. (2002) Cosmopolitan Justice. Boulder: Westview Press.

Moore, A. and Crisp, R. (1996) "Welfarism in Moral Theory", Australasian Journal of Philosophy 74(4), 598-613.

Moody-Adams, M. (2006) "Reflections on Appiah's The Ethics of Identity", Journal of Social Philosophy 37(2), 292-300.

Mulhall, S. and Swift, A. (1992) Liberals \& Communitarians, $2^{\text {nd }}$ edition. Oxford and Malden, Mass.: Blackwell Publishers.

Narveson, J. (1991) "Collective Rights?", Canadian Journal of Law and Jurisprudence 4(2), 329-245.

Narveson, J. and Sterba, J.P. (2010) Are Liberty and Equality Compatible? Cambridge and New York: Cambridge University Press.

Note (1986) "The Cultural Defence in the Criminal Law", Harward Law Review 99, 1293-1311.

Nussbaum, M. (1988) "Nature, Function, and Capability: Aristotle on political distribution", Oxford Studies in Ancient Philosophy 6, Supplementary Volume, 145-84.

O'Brien, R. (2005) The Stasi Report:The Report of the Committee of Reflection on the Application of the Principle of Secularity in the Republic. Buffalo, New York: William S. Hein \& Co., Inc.

Okin, S. M. (1999) "Is Multiculturalism Bad for Women", in: Cohen, J., Nussbaum, M., Howard, M. (eds.) Is Multiculturalism Bad for Women?, Princeton: Princeton University Press.

- (2002) “'Mistresses of Their Own Destiny': Group Rights, Gender and Realistic Rights of Exit", Ethics 112, 205-30.

- (2005) "Multiculturalism and feminism: no simple question, no simple answers", in: Eisenberg, A. and Spinner-Halev, J. (eds.): Minorities within Minorities. Equality, Rights and Diversity. Cambridge University Press 
Parekh, B. (1997) "Equality in a Multiracial Society”, in: Franklin, J. (ed.) Equality, London: Institute for Public Policy Research.

- (2000) Rethinking Multiculturalism: Cultural Diversity and Political Theory. Basingstone, Hampshire: Palgrave.

- (2008) A New Politics of Identity: Political Principles for an Interdependent World. Basingstone, Hampshire: Palgrave.

Parvez, Z. (2011): "Debating the Burqa in France: the Antipolitics of Islamic Revival", Qualitative Sociology 34(2), 287-312.

Pettit, P. (1997) Republicanism: A Theory of Freedom and Government. Oxford: Oxford University Press.

- (2001) A Theory of Freedom. Cambridge: Polity Press.

Phillips, A. (1995) The Politics of Presence. Oxford: Clarendon Press.

- (2003), "When Culture Means Gender: Issues of Cultural Defence in the English Courts", The Modern Law Review 66(4), 510- 531.

- (2006) "Really' Equal: Opportunities and Autonomy", The Journal of

Political Philosophy 14(1), 18-32.

- (2007) Multiculturalism without Culture. Princeton and Oxford: Princeton University Press.

- (2010) Gender \& Culture. Cambridge and Malden: Polity.

Pierik, R. (2004) "Conceptualizing Cultural Groups and Cultural Difference: The social mechanism approach", Ethnicities 4(4), 523544.

Pogge, T. (1989) Realizing Rawls. Ithaca: Cornell University Press.

- (1994) "An Egalitarian Law of Peoples", Philosophy and Public Affairs 23(3), 195-224.

- (2002) World Poverty and Human Rights: Cosmopolitan Responsibilities and Reforms. Cambridge and Malden: Polity Press.

Quong, J. (2006) "Cultural Exemptions, Expensive Tastes, and Equal Opportunities", Journal of Applied Philosophy 23(1), 53-71.

Radcliffe Richards, J. (1997) "Equality of Opportunity", Ratio (new series) X, 253-279.

Rawls, J. (1971) A Theory of Justice. Cambridge, Mass.: Harvard University Press.

- (1986) "Justice as Fairness: Political not Metaphysical", Philosophy and Public Affairs 14 (3), 223-251.

- (1996) Political Liberalism. New York: Columbia University Press.

- (1999) Law of the Peoples. Cambridge, Mass.: Harvard University Press. 
Limits of Liberal Multiculturalism

- (2001) Justice as Fairness. Cambridge, Mass.: Harvard University Press.

Raz, J. (1986) The Morality of Freedom. Oxford: Clarendon Press.

- (1994) "Multiculturalism: A Liberal Perspective", in Raz, J. Ethics in the Public Domain: Essays in the Morality of Law and Politics. Oxford: Clarendon Press.

— (1998) "Multiculturalism", Ratio Juris 11, 193-205.

- (2001) Value, Respect, and Attachment. Cambridge: Cambridge University Press.

Raz J. and Margalit, A. (1994) [1990] "National Self-Determination", in Raz, Joseph (1994) Ethics in the Public Domain: Essays in the Morality of Law and Politics. Oxford: Clarendon Press.

Reaume, D. (2000) "Official Language Rights: Intrinsic Value and the Protection of Difference", in: Kymlicka, W. and Norman, W. (eds) Citizenship in Diverse Societies. Oxford: Oxford University Press.

Reitman, O. (2005): "On Exit", in: Eisenberg, A. and Spinner-Halev, J. (eds.): Minorities within Minorities. Equality, Rights and Diversity. Cambridge University Press.

Renteln, A. D. (2004) The Cultural Defence, New York: Oxford University Press.

- (2010) "The Use and Abuse of the Cultural Defence", in: Foblets, M. and Renteln, A.D. (eds.) Multicultural Jurispudence: Comparative Perspectives on the Cultural Defence. Oxford and Portland Oregon: Hart Publishing.

Resnik, J. (1989) "Dependent Sovereigns: Indian Tribes, States, and the Federal Courts", University of Chicago Law Review 56, 671-759.

Robins, S. (2008) "Sexual Politics and the Zuma Rape Trial", Journal of Southern African Studies 34(2), 411-427.

Roemer, J.E. (1998) Equality of Opportunity. Cambridge, Mass.: Harvard University Press.

Sandel, Michael (1982) Liberalism and the Limits of Justice. Cambridge: Cambridge University Press.

Saunders, Ben (2010) "Fairness Between Competing Claims", Res Publica $16,41-55$.

Scott, D. (2003) “Culture in Political Theory”, Political Theory 31(1), 92115.

Scott, J.W. (2007) The Politics of the Veil. Princeton: Princeton University Press. 
Bibliography

Scheffler , S. (2003) "What is Egalitarianism?", Philosophy \& Public Affairs 31(1), 5-39.

- (2007) "Immigration and the Significance of Culture", Philosophy \& Public Affairs 35(2), 93-125.

Sen, A. (1980) "Equality of What", in: McMurrin, S.M. (ed.) The Tanner Lectures on Human Values Vol I. Salt Lake City: University of Utah Press.

- (1997) On Economic Inequality (expanded edition with a substantial annexe by James Foster and Amartya Sen). Oxford and New York: OxfordUniversity Press.

Shachar, A. (1998) "Group Identity and Women's Rights in Family Law: The Perils of Multicultural Accommodation", Journal of Political Philosophy 6(3), 285-305.

- (2000) "On Citizenship and Multicultural Vulnerability", Political Theory 28(1), 64-89.

- (2001) Multicultural Jurisdictions: Cultural Differences and Women's Rights. Cambridge: Cambridge University Press.

Siesling, M.and Ten Voorde, J. (2010) "The Paradox of Cultural Differences in Dutch Criminal Law", in: Foblets, M. \& Renteln, A.D. (eds.) Multicultural Jurispudence: Comparative Perspectives on the Cultural Defence. Oxford and Portland Oregon: Hart Publishing.

Sistare, C., May, L. and Francis, L. (eds.) (2001) Groups and Group Rights. University Press of Kansas.

Skeen, E. (2007) The Rape of a Trial: Jacob Zuma, AIDS, Conspiracy, and Tribalism in Neo-liberal Post-Apartheid South Africa. BA Thesis, Department of Anthropology, Princeton University.

Skinner, Q. (2002) "A Third Concept of Liberty", Proceedings of the British Academy 117, 237-68.

Smith, N.H. (2002) Charles Taylor: Meaning, Morals and Modernity. Malden: Polity.

Sona, F. (2005) "Polygamy in Britain", Osservatorio Delle Liberta Ed Instituzioni Religiose, http://www.olir.it/areetematiche/104/documents/Sona_Polygamy_in Britain.pdf (seen 22.10.2012)

Song, S. (2007) Justice, Gender and the Politics of Multiculturalism. Cambridge: Cambridge University Press.

Spinner-Halev, J. (1994) The Boundaries of Citizenship: Race, Ethnicity and Nationality in the Liberal State. Baltimore: Johns Hopkins University Press. 
Limits of Liberal Multiculturalism

- (2000) Surviving Diversity: Religion and Democratic Citizenship. Baltimore: Johns Hopkins University Press.

- (2005) "Autonomy, association and pluralism", in: Eisenberg, A. and Spinner-Halev, J. (eds.) Minorities within Minorities. Equality, Rights and Diversity. Cambridge University Press.

Stone, P. (2007) "Why Lotteries Are Just", The Journal of Political Philosophy 15(3), 276-295.

Sunder, M. (2001) "Cultural Dissent”, Stanford Law Review 54, 495-567.

Tamir, Y. (1994) Liberal Nationalism. Princeton: Princeton University Press.

Tan, K. (2004) Justice without Borders: Cosmopolitanism, Nationalism and Patriotism. Cambridge: Cambridge University Press.

Taylor, C. (1985) Philosophy and the Human Sciences: Philosophical Papers, vol. 2 Cambridge: Cambridge University Press.

- (1989) Sources of the Self. Cambridge: Cambridge University Press.

- (1994) "The Politics of Recognition", in: Gutmann, A (ed.) Multiculturalism: Examining the Politics of Recognition. Princeton: Princeton University Press.

- (1995) "Irreducibly Social Goods", in: Taylor, C. Philosophical Arguments. Cambridge, Massachusetts: Harvard University Press.

Temkin, L. (1993) Inequality. Oxford and New York: Oxford University Press.

Thunder, D. (2009) "Why Value Pluralism Does Not Support the State's Enforcement of Liberal Autonomy: A Response to Crowder", Political Theory 37(1), 154-160.

Tomasi, J. (1995) "Kymlicka, Liberalism, and Respect for Cultural Minorities", Ethics 105, 580-603.

Tully, J. (1995) Strange Multiplicity: Constitutionalism in an age of diversity. Cambridge University Press.

Tylor, Sir. E. B. (1973) [1871] Primitive Culture: Researches into the Development of Mythology, Philosophy, Religion, Language, Art and Custom, New York: Gordon Press.

Valadez, J.M. (2007) "The continuing significance of ethnocultural diversity", in: Benhabib, S., Shapiro, I., Petranovic, D. (eds.) Identities, Affiliations and Allegiances. Cambridge University Press.

Van Broeck, J. (2001) "Cultural Defence and Culturally motivated Crimes (Cultural Offences)", European Journal of Crime, Criminal Law and Criminal Justice 9(1), 1-31. 
Van der Schyff, G. and Overbeeke, A. (2011): "Exercising Religious Freedom in the Public Space: A Comparative and European Convention Analysis of General Burqa Bans", European Constitutional Law Review 7(3), 424-452.

Van Dyke, V. (1975) "Justice as Fairness: For Groups?", American Political Science Review 69, 607-614.

(1977) "The Individual, the State, and Ethnic Communities in Political Theory", World Politics 29(3), 343-369.

Vertovec, S. \& Wessendorf, S. (eds.) (2010) The Multiculturalism Backlash. London and new York: Routledge.

Vitikainen, A. (2009) "Liberal Multiculturalism, Group Membership, and Distribution of Cultural Policies", Ethnicities 9(1), 53-74.

- (2012) "Exit, Identity, and Membership", in: Borchers, D. and Vitikainen, A. (eds.) On Exit: Interdisciplinary perspectives on the right of exit in liberal multicultural societies. Berlin and Boston: De Gruyter.

Volpp, L. (1994) “(Mis)identifying Culture: Asian Women and the "Cultural Defence"”, Harvard Women's Law Journal 17, 57-101.

- (2000) "Blaming Culture For Bad Behavior", Yale Journal of Law \& the Humanities 12, 89-116.

Waetjen, T. and Maré, G. (2009) "Tradition's Desire: The Politics of Culture in the Rape Trial of Jacob Zuma", Theoria, March 2009, 63-81

Waldron, J. (1992) "Minority Cultures and the Cosmopolitan Alternative", University of Michigan Journal of Law Reform 25, 751-793.

Wall, S. and Klosko, G. (eds.) (2003) Perfectionism and Neutrality: Essays in Liberal Theory. New York and Oxford: Rowman and Littlefield.

Wallerstein, I. (1990) "Culture as the Ideological Battleground of the Modern World-System”, Theory, Culture \& Society 7, 31-55.

Walzer, M. (1983) Spheres of Justice. New York: Basic Books.

Weinstock, D. (2005) "Beyond Exit Rights", in: Eisenberg, A. and Spinner-Halev, J.: Minorities within Minorities. Equality, Rights and Diversity. Cambridge University Press.

Williams, B. (1973) "The Idea of Equality”, in: Williams, B.: Problems of the Self Cambridge: Cambridge University Press.

Williams, M.S. (1996) "Memory, History and Membership: The Moral Claims of Marginalized Groups in Political Representation", in: Räikkä, J. (ed.) Do We Need Minority Rights? Kluwer Law International. 
Limits of Liberal Multiculturalism

Williams, M.S. and Waldron, J. (eds.) (2008) Toleration and its limits, NOMOS XLVIII, New York and London: New York University Press.

Wolff, J. (1998)"Fairness, Respect, and the Egalitarian Ethos", Philosophy \& Public Affairs 27, 97-122.

Woodman, G.R. (2010) "The Culture Defence in English Common Law: the Potential for Development”, in: Foblets, M. \& Renteln, A.D. (eds.) Multicultural Jurispudence: Comparative Perspectives on the Cultural Defence. Oxford and Portland Oregon: Hart Publishing.

Young, I.M. (1990) Justice and the politics of Difference. Princeton University Press.

- (1997) "A Multicultural Continuum: A Critique of Will Kymlicka's Ethic-Nation Dichotomy", Constellations 4(1), 48-53.

- (2000) Inclusion and Democracy. New York: Oxford University Press. 